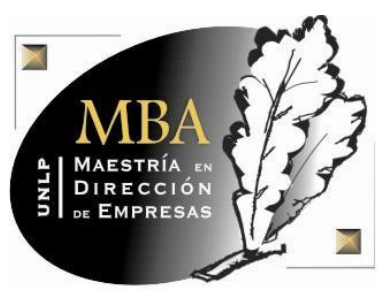

Universidad Nacional de La Plata

Facultad de Ciencias Económicas

MBA - Maestría en Dirección de Empresas

\title{
Calidad Educativa del Nivel Secundario de Ensenada
}

Autora: Bolognini, Diana Sofía

\author{
Director: Dr. Daniel Alberto Lauría
}

\section{La Plata}

Diciembre de 2013 


\section{Contenido}

1. Planteo del Problema

2. Objetivos de la investigación

3. Evaluación del problema 6

4. Alcances de la investigación 9

5. Marco teórico 10

5.1 Antecedentes de la Investigación 10

5.1.1 Programa para la Evaluación Internacional de Alumnos PISA (OECD) 10

5.1.2 Laboratorio Latinoamericano de Evaluación de la Calidad de la Educación LLECE (UNESCO)

5.1.3 Estudio Internacional de Alfabetización Computacional y Manejo de Información ICILS (IEA) 24

5.1.4 Estudio Internacional de Tendencias en Matemática y Ciencias TIMSS (IEA) 27

5.1.5 Sistema Nacional de Evacuación de Resultados de aprendizaje del Ministerio de Educación de Chile SIMCE 29

5.2. Bases Teóricas 33

5.2.1 Calidad Total 33

5.2.2 Calidad en Educación 37

5.3. Definición de términos Básicos 42

5.3.1 Educación 42

5.3.2 Educación Secundaria 45

5.4. Sistema de variables 50

6. Metodología de la investigación 52

6.1. Población y muestra 52

6.2. Tipo de investigación 53

6.3. Técnica de recolección de datos 53

6.4. Técnicas de análisis 57

7. Resultados de la Investigación 60 
7.1 Datos de Fuente Secundaria 60

7.2 Datos de Fuente Primaria 65

7.2.1 Docentes 65

7.2.2 Empresarios 73

7.2.3 Total Global 80

7.2.4 Comparación respuestas de Docentes y Empresarios 81

7.2.5 Comparación Total respuesta Docentes y Empresarios 86

7.2.6 Comparación regional respuestas de docentes 87

7.2.7 Comparación regional respuestas de empresarios 96

7.2.8 Total regional 104

7.2.9 Comparación internacional 106

8. Conclusiones 113

9. Recomendaciones 115

10. Bibliografía 118

11. Referencias y Anexos 120

11.1 Encuestas sobre Calidad Educativa del Nivel Secundario 120

11.2 Tablas de resultados de encuestas 125

11.2.1 Docentes 125

11.2.2 Empresarios 127

11.2.3 Total Global 128

11.2.4 Comparación Docentes y Empresarios 129

11.2.5 Resultado Regional - Docentes 130

11.2.6 Resultado regional - Empresarios 132

11.2.7 Resultado total regional 133

11.3 Datos de Fuente Secundaria 134

11.4 Artículos periodísticos 136 


\section{Planteo del Problema}

La educación en la República Argentina empezó a tener peso a partir del presidente Domingo Faustino Sarmiento, quien fomentó la inmigración y trajo educadores estadounidenses y europeos. A su vez, la educación tuvo un papel central en la constitución de la nación, considerada una condición esencial para hacer del país una república. En ese marco, Julio A. Roca sancionó en 1884 la Ley $n^{\circ} 1420$ de Educación Común, estableciendo su carácter obligatorio, estatal, laico y gratuito.

Actualmente, en una sociedad democrática y participativa, los ciudadanos tienen derecho a conocer el funcionamiento de un servicio público como es el de la educación. Sin embargo, el problema principal en Argentina radica en la falta de información acerca del nivel de calidad de la educación, tanto a escala provincial como nacional.

En la región de La Plata, Berisso y Ensenada no existen datos de acceso público que permitan conocer con certeza el estado o nivel de situación real de la educación en el nivel secundario.

En el ámbito regional, uno de los puntos más resonantes de los últimos años tiene que ver con el ingreso a primer año en las carreras de la Universidad Nacional de La Plata, si bien concurren estudiantes del interior del país sirve como una gran muestra del nivel que posee el alumno al concluir la escuela secundaria. En muchos casos no llegan a responder sobre cuestionarios preparados para alumnos de séptimo grado de la primaria, estas preguntas son sobre matemática, química y física, y solo aprueban el examen de ingreso entre el $10 \%$ y el $30 \%$ de los alumnos (véase Anexo Artículos Periodísticos).

Además, se observa que la transición de la escuela al trabajo para los jóvenes de hoy es más difícil que para sus pares de hace apenas unas décadas. Las habilidades adquiridas en la secundaria son menos valoradas por los empleadores.

En el caso de los países con mayor desarrollo en educación, comunican los resultados de las evaluaciones inmediatamente a las escuelas, estos datos están a disposición de la comunidad de un modo transparente. En Argentina, los 
resultados de las evaluaciones no son devueltos a las escuelas en tiempo y forma, son comunicados en forma discontinua, de modo poco claro y todo eso deteriora su credibilidad.

«A la educación le falta tener normas claras y un clima apropiado para la enseñanza. Algunos de los problemas que presenta están relacionados con el respeto por los horarios y la inasistencia tanto de profesores como de los alumnos, no hay hábitos de orden y de trabajo, hay mucha interferencia y desorden en las aulas, se pierden días de clases por problemas gremiales, existe una deficiente capacitación para los docentes, los edificios no están en las condiciones apropiadas de limpieza y orden, y los padres por lo general no apoyan a los docentes, ni participan en forma positiva en la educación de sus hijos» ${ }^{1}$.

Por otra parte, cada vez más jóvenes pueden acceder al sistema educativo, pero al mismo tiempo disminuye la cantidad de los que logran permanecer hasta el final del ciclo. A su vez, las habilidades adquiridas en la escuela secundaria son menos valoradas por los empleadores.

La escuela siempre estuvo sometida a la tensión entre la necesidad de integración social y la adecuación de los requerimientos del desarrollo personal. En la actualidad el sistema educativo está fuertemente cuestionado porque el perfil del egresado no condice con la imagen del ciudadano que la sociedad pretende que la escuela forme. Los alumnos no adquieren los conocimientos necesarios para satisfacer demandas sociales y personales.

La expansión en las décadas anteriores aseguró el acceso de la mayoría de los niños a la escuela, pero no a la educación. Esta crisis comienza a denotar desequilibrios entre la oferta ofrecida por el sistema educativo y los requerimientos del mercado laboral.

"A pesar de la preocupación por aumentar la calidad de la educación y un efectivo incremento de la matrícula, comienzan a aparecer altos índices de repetición y deserción. Esta situación puso sobre el tablero el problema de la calidad del sistema educativo. Comenzaron los interrogantes acerca de la real

${ }^{1}$ Georgina Binstock y Marcela Cerrutti (2005) - "Carreras Truncadas - El abandono escolar en el nivel medio en la Argentina" - Unicef / Buenos Aires 
capacidad para retener a los alumnos que accedían al mismo. Con esto, la masificación del sistema educativo significó pérdida en su calidad."

"El retraso escolar y el abandono constituyen graves problemas que afectan básicamente a los sectores populares, notándose una distribución desigual en las diferentes regiones del país. El análisis de la calidad de la educación constituye cada vez más un objetivo y una necesidad impostergables. Percibimos un sistema educativo en el cual la calidad está sumamente deteriorada y cuestionada,3.

Tenti Fanfani expresa: "Resulta lamentable tener que afirmar que el deterioro de los insumos del proceso educativo (caída del gasto, deterioro del salario docente, disminución del tiempo de aprendizaje, etc.) no puede menos que producir un empobrecimiento de los procesos de producción del aprendizaje y por lo tanto, una pérdida de calidad de los productos educativos".

"Las críticas acerca de la educación, provienen no sólo de los especialistas en educación; sino que además expresan su insatisfacción los alumnos, sus padres, los docentes, los directivos, en fin, la opinión pública en general. Se percibe un descontento; un desajuste entre lo que la escuela ofrece y los que los protagonistas esperan de ella:

- Los contenidos son poco significativos para los alumnos;

- Hay escasa relación de los planes y programas con las necesidades socioeconómicas y culturales del mundo actual;

- Existe un déficit en la formación y capacitación docente;

- Los modos de gestión están burocratizados lo cual impiden la resolución eficaz de los problemas;

- Fracasan grandes sectores de la población que no logran financiar con éxito un ciclo o nivel;

- Están desvinculados el mundo de la escuela y el mundo del trabajo;

\footnotetext{
2 Paviglianiti, Norma y otros. "El sistema educativo en Argentina: Características y problemas"

3 Tenti Fanfani, Emilio. (1993) "La escuela vacía: Deberes del estado y responsabilidades de la sociedad." UNICEF I Losada - Buenos Aires
} 
- Los sesgos de autoritarismo impiden el desarrollo de una educación verdaderamente democrática;

- La especulación y el automatismo se privilegian frente a producción y la reflexión;

- La tarea docente se encuentra desvalorizada y desprestigiada"A

Un estudio del BID ${ }^{5}$, (Banco Interamericano de Desarrollo), con datos de Argentina, analizó las habilidades sociales de las nuevas camadas de empleados. Según el $80 \%$ de las empresas, escasean cualidades importantes, como son el compromiso y la educación, y esto no está incluido en los programas de la escuela secundaria.

El estudio del Banco Interamericano de Desarrollo señala que la formación académica no alcanza, y que las empresas necesitan gente que asuma responsabilidades. La impuntualidad y la falta de compromiso es habitual en su accionar. No se incomodan cuando no pueden dar una respuesta adecuada. A los jóvenes, el mundo del trabajo se les presenta lejano y extraño, la calidad y la cantidad de educación recibida influyen en su accionar, pero el mejor promedio no los convertirá necesariamente en un buen trabajador.

El BID indagó sobre las condiciones en que los jóvenes argentinos ingresan al mercado laboral y concluyó lo siguiente: "Se requieren políticas educativas urgentes no sólo para abordar el problema de la calidad de la educación, sino de la pertinencia de la misma cuando se trata de facilitar las transiciones de los jóvenes al mundo del trabajo".

Los conocimientos académicos no son suficientes para el desarrollo de los jóvenes en su vida adulta. La escuela tiene que cambiar y desarrollar metodologías que les permitan poder desempeñarse en el mundo del trabajo. No están preparados, no saben cumplir un horario, no saben identificar un problema ni comunicarlo a sus jefes y no saben trabajar en equipo.

${ }^{4}$ La transformación del sistema educativo Nueva Escuela El sistema en crisis

${ }^{5}$ Desconectados - Habilidades, educación y empleo en América Latina 
Por su parte, Nancy Montes, investigadora del Área de Educación de la FLACSO (Facultad Latinoamericana de Ciencias Sociales), señala que si bien en los últimos años aumentó la presencia de los jóvenes en las escuelas y disminuyó el porcentaje de los que teniendo edad para ir al colegio se encuentran trabajando, todavía subsiste una diferencia entre lo que los jóvenes esperan de la escuela, lo que los docentes esperan de ellos, y lo que efectivamente puede promover la escuela con su conformación actual.

Un estudio reciente de la CEPAL $^{6}$ (Comisión Económica para América Latina y el Caribe) señala que existen fuertes distorsiones en la distribución interna de la inversión educativa en perjuicio de los escalones primarios del sistema. Esta forma de distribución afecta, en primer lugar, a los grupos de menores ingresos, que dependen del sistema público para su educación básica. En segundo lugar perjudica a los escalones superiores del sistema, que reciben aspirantes con formación inadecuada. Este déficit obliga a las universidades a establecer sistemas de selección o de nivelación. Si estos sistemas son estrictos impiden el ingreso de muchos aspirantes, pero si no lo son obligan a las universidades a costear la permanencia de un enorme grupo de estudiantes que abandonarán las aulas. Además de aumentar los recursos destinados a la educación, es necesario prestar atención a otros aspectos clave como la forma más adecuada de distribuir los fondos, la mejora en la calidad y la búsqueda de una mejor articulación entre sus diferentes niveles. De este modo se logrará una mejor utilización de los recursos sociales.

${ }^{6}$ CEPAL (2001) - "Perspectivas Económicas de América Latina 2012: Transformación del Estado para el Desarrollo" 


\section{Objetivos de la investigación}

Los objetivos planteados en esta investigación son:

- Identificar parámetros de eficiencia del nivel secundario de la educación de Ensenada

- Comparar los parámetros de educación de Ensenada con la región.

- Generar información acerca de la calidad educativa en el nivel secundario de la educación de Ensenada

\section{Evaluación del problema}

La educación se ha convertido en uno de los principales caminos para el desarrollo económico de un País. De allí que los países avanzados hagan fuertes inversiones para aumentar el volumen y la calidad de la educación. En el mundo industrializado, la adecuación de los estándares educativos a lo que cada país o grupo de interés considera estratégico es motivo de análisis y discusión permanente.

En educación básica, la escuela secundaria es considerada como etapa propedéutica para el alumno, ya que al término de tres ciclos escolares debe decidir hacia qué área productiva enfocarse. La educación secundaria es entonces concebida como fundamental para el desarrollo sano e integral del adolescente. Sin embargo, es sabido que la escuela secundaria sufre una marcada crisis porque las adecuaciones que debieran formularse en este nivel para lograr la calidad requerida al egresar el alumno, no se han puesto en marcha, por lo tanto, no se logra hacer tangible en esta etapa, su calidad y pertinencia.

Los jóvenes de hoy, desde su propia perspectiva, ven una escasez de expectativas en su futuro inmediato, tanto en su formación y estudios como en su calidad de vida y futuro profesional aun cuando éste no sea tan inmediato. Por 
eso, todos los esfuerzos que el conjunto de la sociedad pueda realizar en educación, y en particular en este nivel de la escuela pública, pueden parecer insuficientes para atender una demanda creciente que hoy por hoy, no ha logrado el nivel de cobertura y calidad que se requieren para dar certidumbre a los futuros alumnos de educación secundaria, que el país demanda.

Defender, reformar y fortalecer a la secundaria pública es importante para el desarrollo nacional no sólo por su característica de accesibilidad para todos, sino porque representa el espacio más importante de influencia para la estructuración del perfil de la juventud.

La segmentación y la exclusión aparecen como fenómenos sociales importantes pero se observa que desde la relación con el mercado laboral acompañan la expansión de la economía en conocimiento. Recrudecen así problemas como el desempleo, la pobreza y distintas formas de manifiesto de la situación que afecta directamente a los trabajadores: la reducción de puestos de trabajo estables y la utilización total de las personas que ocupan dichos puestos, así las empresas sólo garantizan puestos estables a una reducida parte del personal, dando lugar a la precarización de los demás trabajadores.

El secundario parece haber quedado muy atrás para ofrecer las herramientas necesarias para dar el primer paso en el mundo adulto, un mundo cada vez más competitivo pero también que ofrece empleos cada vez más precarizados.

La valorización de la educación en el desarrollo económico o la creación de empleos cumple un papel determinante en los demás factores de la producción y de la economía de un país. La buena formación de la población contribuye a mejorar el ambiente económico, pero no alcanza para generar empleos. En Argentina existen situaciones en las que los conocimientos no son utilizados o aprovechados debidamente, e incluso existe una fuga de talentos que no encuentra puestos de trabajo en el país.

El nivel educativo de la sociedad siempre fue importante para el desempeño de las instituciones públicas o privadas, pero esa importancia aumenta con la complejidad de los procesos administrativos o productivos. También, con la velocidad con la que cambia la información educativa y la 
necesidad de actualizarla. Las exigencias de la actualidad, de la globalización y las demandas del mercado, son las nuevas reglas de juego para emprender nuevos desafíos.

Cabe destacar, que la escuela secundaria es el último contacto con el sistema educativo y la plataforma desde la cual los adolescentes ingresan al mercado laboral. Es por ello que el sistema educativo de la región tiene el enorme desafío de retener a los jóvenes hasta culminar su formación y de proporcionarles las destrezas que el trabajo y la sociedad les exigirán después. 


\section{Alcances de la investigación}

Los resultados que se presentan son el producto de un proyecto de investigación del MBA cuyo título es "La competitividad empresarial y su impacto regional", acreditado en el marco del Programa de Incentivos de la Secretaría de Ciencia y Técnica de la UNLP, con un tronco común que posteriormente se subdivide de acuerdo con la región evaluada, siendo su alcance geográfico, La Plata, Berisso y Ensenada.

Existen limitaciones de información debido a la falta de datos estadísticos sobre los alumnos que no terminan el secundario, y los alumnos que finalizan pero luego no realizan carrera terciaria o universitaria alguna, ni se insertan al mundo laboral; es por ello que no es factible tener el seguimiento correspondiente de estos casos.

Para el cálculo de los indicadores se utilizó información del año 2011, proveniente del Ministerio de Educación de la Provincia de Buenos Aires. 


\section{Marco teórico}

\subsection{Antecedentes de la Investigación}

\section{Evaluaciones Internacionales}

\subsubsection{Programa para la Evaluación Internacional de Alumnos PISA (OECD)}

El nombre PISA corresponde con las siglas del programa según se enuncia en inglés: Programme for International Student Assessment, es decir, Programa para la Evaluación Internacional de Alumnos. Se trata de un proyecto de la OCDE (Organización para la Cooperación y el Desarrollo Económicos), cuyo objetivo es evaluar la formación de los alumnos cuando

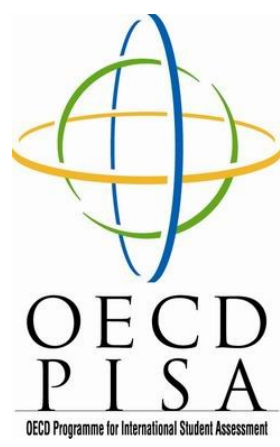
llegan al final de la etapa de enseñanza obligatoria, hacia los 15 años.

Se trata de una población que se encuentra a punto de iniciar la educación post-secundaria o que está a punto de integrarse a la vida laboral. Es muy importante destacar que el Programa ha sido concebido como un recurso para ofrecer información abundante y detallada que permita a los países miembros adoptar las decisiones y políticas públicas necesarias para mejorar los niveles educativos.

La evaluación cubre las áreas de lengua, matemáticas y competencia científica. El énfasis de la evaluación está puesto en el dominio de los procesos, el entendimiento de los conceptos y la habilidad de actuar o funcionar en varias situaciones dentro de cada dominio.

\section{Los exámenes}

Los exámenes utilizados en el proceso de evaluación no requieren otra cosa que papel y lápiz y cada estudiante cuenta con dos horas para responderlo. Cada examen es una combinación de preguntas directas con una única respuesta correcta (preguntas que sólo admiten algunas palabras o algunas frases breves por respuesta, o que ofrecen múltiples opciones para que el alumno marque 
alguna o algunas), y preguntas que requieren que los estudiantes elaboren sus propias respuestas. Las preguntas del primer tipo sólo pueden ser correctas o incorrectas, y las del segundo tipo son de evaluación más compleja y admiten respuestas parcialmente correctas. Es importante destacar que si bien PISA utiliza la herramienta de las preguntas de opción múltiple, una porción importante de los reactivos, particularmente los más complejos, requieren del alumno la redacción de textos e incluso la elaboración de diagramas.

No todos los alumnos tienen el mismo examen sobre la mesa el día de la prueba; a diferentes alumnos les tocan cuadernillos distintos. Tal como se aplicó la prueba en 2006, había 13 cuadernillos de examen diferentes, cada uno de ellos con cuatro capítulos o grupos de actividades de evaluación.

Además del examen propiamente dicho, los estudiantes deben responder un cuestionario en el que se les hacen preguntas sobre sí mismos y sobre sus hogares. Este cuestionario de contexto es una herramienta muy importante para el aprovechamiento de la prueba de PISA, y se hará una referencia a este más adelante.

\section{La muestra}

Para la realización de PISA se utilizan muestras representativas de entre 4.500 y 10.000 estudiantes por país. Este tamaño de muestra permite realizar inferencias del país en su totalidad pero no permite inferencias por regiones o estados. Algunos países solicitan sobre muestras para utilizar la prueba también en la exploración de las diferencias regionales. Tal fue el caso de México, que en el ciclo de evaluación de 2003 condujo una evaluación con 29,983 estudiantes y en el ciclo 2006 con 30,971 estudiantes.

\section{Los resultados}

Los resultados PISA ofrecen un perfil de las capacidades de los estudiantes de 15 años de todos los países donde se aplica el examen. Además, provee información sobre el contexto personal, familiar y escolar de los participantes en la muestra. 
El carácter cíclico (trienal) de la evaluación permite tener indicadores sobre las tendencias en cada país y en el conjunto de los países involucrados en el proyecto. En última instancia, la calidad y riqueza de los datos arrojados en el proceso de evaluación pretende constituirse en la base para la investigación y análisis destinados a mejores políticas en el campo de la educación.

\section{¿Qué evalúa PISA?}

A diferencia de otros exámenes que se han utilizado en el pasado, PISA está diseñado para conocer las competencias, o, dicho en otros términos, las habilidades, la pericia y las aptitudes de los estudiantes para analizar y resolver problemas, para manejar información y para enfrentar situaciones que se les presentarán en la vida adulta y que requerirán de tales habilidades.

PISA se concentra en la evaluación de tres áreas: competencia lectora, competencia matemática y competencia científica. Si bien la adquisición de conocimientos específicos es importante en el aprendizaje escolar, la aplicación de esos conocimientos en la vida adulta depende rigurosamente de la adquisición de conceptos y habilidades más amplios. En ciencia, tener conocimientos específicos, como los nombres de las plantas y los animales, tiene menor valor que comprender temas más amplios, como el consumo de energía, la biodiversidad y la salud humana, cuando se trata de pensar en los grandes problemas en debate dentro de la comunidad adulta.

\section{Evaluación cíclica}

La evaluación a través del PISA se realiza cada tres años, con el objeto de permitir a los países supervisar adecuadamente su desempeño y valorar el alcance de las metas educativas propuestas. Cada año de su realización el proyecto se ha concentrado en alguna de las tres áreas evaluadas: en la evaluación del año 2000 se dio especial atención a la competencia en lectura, en el 2003 a la competencia en matemáticas y en 2006 a la competencia en el área de ciencias. 
Esto quiere decir que la parte más extensa del examen se refiere al área de concentración correspondiente a ese año (Los porcentajes son aproximadamente $66 \%$ para el área de concentración y $17 \%$ para cada una de las otras áreas).

\section{Contexto}

La universalidad que le da a PISA el hecho de no estar ligado a currículos y planes de estudio específicos no implica una indiferencia frente al contexto.

Un cuestionario dirigido al responsable de cada escuela permite recabar información sobre el contexto del estudiante: las condiciones de su entorno, su familia, sus hábitos de estudio, las condiciones de su escuela.

\section{Lo que evalúa PISA}

PISA no está diseñado para evaluar el aprendizaje de los contenidos específicos fijados en los programas de las escuelas o de los distritos o regiones correspondientes. Tampoco está pensado para evaluar el desempeño de los docentes ni los programas vigentes. PISA se centra en el reconocimiento y valoración de las destrezas y conocimientos adquiridos por los alumnos al llegar a sus quince años. La adquisición de tales destrezas y conocimientos es fruto de numerosas circunstancias familiares, sociales, culturales y escolares. PISA trata de recoger información sobre esas circunstancias para que las políticas que pudieran desprenderse del análisis de los resultados de la prueba atiendan a los diferentes factores involucrados.

Los resultados de la prueba describen el grado en el que se presentan las competencias estudiadas y permiten observar la ubicación de los resultados de cada país en el contexto internacional.

\section{Evaluar las competencias}

La evaluación de competencias no se dirige a la verificación de contenidos; no pone la atención en el hecho de que ciertos datos o conocimientos hayan sido adquiridos. Se trata de una evaluación que busca identificar la existencia de ciertas capacidades, habilidades y aptitudes que, en conjunto, permiten a la persona resolver problemas y situaciones de la vida. No interesa, pues, en el 
enfoque de la evaluación de competencias, sólo si una persona lee y cuánto lee, por ejemplo, sino más bien qué competencia tiene en la lectura: qué capacidad para identificar ideas y argumentos en el texto, qué destreza para reconocer problemas y planteamientos distintos.

Hay competencias muy generales, que preceden a la formación escolar, como la competencia comunicativa, o las competencias de colaboración o de creatividad. Algunas competencias básicas ligadas a la enseñanza escolar son, por ejemplo, la lectura, la escritura y el cálculo. La exploración del proyecto PISA se refiere a competencias específicas (lectura, matemáticas, ciencia), detalladas y divididas en sub-competencias, dentro de cada área.

La definición de competencia utilizada en México por el Instituto Nacional para la Evaluación de la Educación es la siguiente: "un sistema de acción complejo que abarca las habilidades intelectuales, las actitudes y otros elementos no cognitivos, como motivación, valores y emociones, que son adquiridos y desarrollados por los individuos a lo largo de su vida y son indispensables para participar eficazmente en diferentes contextos sociales". La clave del concepto de competencia, tal como se utiliza para el PISA y lo ha explicado el INEE, está en valorar la capacidad del estudiante para poner en práctica sus habilidades y conocimientos en diferentes circunstancias de la vida.

Al examinar los conocimientos y habilidades cerca del final de la enseñanza básica, PISA examina el grado de preparación de los jóvenes para la vida adulta y, hasta cierto punto, la efectividad de los sistemas educativos. Su ambición es evaluar el éxito con relación a los objetivos subyacentes (definidos por la sociedad) del sistema educativo, y no con relación a la enseñanza de un cuerpo de conocimientos determinado.

\section{Escalas de puntaje en PISA}

Los puntajes obtenidos en PISA van de 0 a los 800 puntos y se distribuyen en 6 niveles, donde el sexto nivel es el de mejor desempeño

En ellos se describen habilidades típicas que pueden desarrollar los estudiantes que se ubican en cada uno, de acuerdo con el puntaje en las escalas. 
Los estudiantes que al menos alcanzan el nivel 2, tienen las competencias mínimas para desenvolverse en el mundo e integrarse productivamente a la sociedad.

\begin{tabular}{|r|c|c|c|}
\hline Nivel & Matemáticas & Lengua & Ciencias \\
\hline 1 & 358 a 419 & 262 a $406\left(^{*}\right)$ & 335 a 409 \\
\hline 2 & 420 a 481 & 407 a 480 & 410 a 483 \\
\hline 3 & 482 a 544 & 481 a 552 & 484 a 557 \\
\hline 4 & 545 a 606 & 553 a 625 & 558 a 632 \\
\hline 5 & 607 a 669 & 626 a 698 & 633 a 707 \\
\hline 6 & 670 a 800 & 699 a 800 & 708 a 800 \\
\hline
\end{tabular}

(*) Cabe destacar que para el área "Lengua", PISA desglosa el Nivel 1 en $1 \mathrm{~b}$ (262 a 334$)$ y 1 a (335 a 406$)$.

Para el área de Matemática en PISA se distinguen seis niveles de desempeño, cada uno de los cuales aporta información respecto del tipo de tareas que son capaces de desarrollar los estudiantes que se ubican en ellos, y respecto de la dificultad de las mismas.

\section{Descripción de Niveles de desempeño en la escala de Matemática}

\begin{tabular}{|c|c|}
\hline $\begin{array}{c}\text { Nivel } 6 \\
(670 \text { y } \\
\text { más } \\
\text { puntos) }\end{array}$ & $\begin{array}{l}\text { Los estudiantes ubicados en este nivel, son capaces de conceptualizar, } \\
\text { generalizar y usar información basada en sus investigaciones y en el } \\
\text { modelamiento de situaciones problemáticas complejas. Pueden relacionar } \\
\text { diferentes fuentes de información y representaciones y hacer } \\
\text { traducciones entre ellas de manera flexible. Poseen un razonamiento y } \\
\text { pensamiento matemático avanzado, y pueden aplicarlo, junto con el } \\
\text { dominio de las operaciones y relaciones matemáticas simbólicas y } \\
\text { formales, en el desarrollo de nuevas aproximaciones y estrategias para }\end{array}$ \\
\hline
\end{tabular}




\begin{tabular}{|c|c|}
\hline & $\begin{array}{l}\text { enfrentar situaciones novedosas. Asimismo, son capaces de formular y } \\
\text { comunicar con precisión las acciones y reflexiones que les surgen de sus } \\
\text { descubrimientos, interpretaciones y argumentos, y de adecuarlas a } \\
\text { situaciones distintas de las originales. }\end{array}$ \\
\hline $\begin{array}{r}\mathrm{Ni} \\
(\mathrm{de} \\
\mathrm{a} \\
\text { pur }\end{array}$ & $\begin{array}{l}\text { Los estudiantes ubicados en et Nivel } 5 \text {, son capaces de abordar } \\
\text { situaciones complejas, desarrollando y utilizando modelos, identificando } \\
\text { sus limitaciones y especificando sus supuestos. Adicionalmente, son } \\
\text { capaces de seleccionar, comparar y evaluar estrategias de resolución de } \\
\text { problemas, para abordar situaciones problemáticas complejas referidas a } \\
\text { estos modelos. Estos estudiantes también son capaces de trabajar de } \\
\text { manera estratégica estas situaciones, usando habilidades de } \\
\text { pensamiento y razonamiento amplias y correctamente desarrolladas; } \\
\text { representaciones adecuadamente vinculadas, y caracterizaciones } \\
\text { simbólicas y formales. Finalmente, también son capaces de reflexionar } \\
\text { sobre sus acciones, y de formular y comunicar sus interpretaciones y } \\
\text { razonamientos. }\end{array}$ \\
\hline $\begin{array}{c}\text { Nivel } 4 \\
\text { (de } 545 \\
\text { a } 606 \\
\text { puntos) }\end{array}$ & $\begin{array}{l}\text { Los estudiantes ubicados en el Nivel 4, son capaces de trabajar de } \\
\text { manera eficiente con modelos explícitos de situaciones complejas } \\
\text { concretas, que involucran condicionantes o la necesidad de reconocer } \\
\text { supuestos. Pueden seleccionar e integrar diferentes representaciones } \\
\text { (incluyendo las simbólicas), relacionándolas directamente con situaciones } \\
\text { del mundo real. Asimismo, poseen la habilidad de razonar } \\
\text { flexiblemente y de lograr cierta profundización de los contextos, y } \\
\text { pueden elaborar y comunicar sus explicaciones y razonamientos, sobre la } \\
\text { base de sus propias interpretaciones, argumentos y acciones. }\end{array}$ \\
\hline $\begin{array}{c}\text { Nivel } 3 \\
\text { (de } 482 \\
\text { a } 544 \\
\text { puntos) }\end{array}$ & $\begin{array}{l}\text { Los estudiantes ubicados en el Nivel } 3 \text { de la escala, son capaces de } \\
\text { ejecutar procedimientos claramente descritos (incluyendo tos que } \\
\text { requieren decisiones secuenciales); de seleccionar y aplicar estrategias } \\
\text { simples de resolución de problemas; de interpretar, y de usar } \\
\text { representaciones basadas en diferentes fuentes de información y razonar } \\
\text { directamente a partir de ellas. Asimismo, son capaces de elaborar }\end{array}$ \\
\hline
\end{tabular}




\begin{tabular}{|c|c|}
\hline & $\begin{array}{l}\text { comunicaciones breves para reportar sus interpretaciones, resultados y } \\
\text { razonamientos. }\end{array}$ \\
\hline $\begin{array}{c}\text { Nivel } 2 \\
\text { (de } 420 \\
\text { a } 481 \\
\text { puntos) }\end{array}$ & $\begin{array}{l}\text { Los estudiantes que se ubican en este Nivel, son capaces de interpretar y } \\
\text { reconocer situaciones en contextos que requieren solo inferencia directa, } \\
\text { extraer información relevante de solo una fuente de información a la vez } \\
\text { y hacer uso de una sola forma de representación. Pueden utilizar } \\
\text { algoritmos, fórmulas, procedimientos o convenciones básicas, son } \\
\text { capaces de razonar directamente y de hacer interpretaciones literales } \\
\text { de los resultados. }\end{array}$ \\
\hline $\begin{array}{c}\text { Nivel } 1 \\
\text { (de } 358 \\
\text { a } 419 \\
\text { puntos) }\end{array}$ & $\begin{array}{l}\text { Los estudiantes que se ubican en este Nivel, pueden responder preguntas } \\
\text { claramente definidas, que involucren contextos familiares, en los cuales } \\
\text { toda la información relevante está presente. También son capaces de } \\
\text { identificar información y de llevar a cabo procedimientos rutinarios, } \\
\text { siguiendo instrucciones directas, en situaciones explícitas. Finalmente, } \\
\text { estos estudiantes pueden realizar acciones obvias o aquellas que se } \\
\text { desprenden directamente de los estímulos presentados. }\end{array}$ \\
\hline
\end{tabular}

Para el área de Lengua, en la evaluación PISA se distinguen siete niveles de desempeño, cada uno de los cuales aporta información respecto del tipo de tareas que son capaces de desarrollar los estudiantes que se ubican en ellos, de la dificultad de las mismas, y de las características que poseen los materiales de lectura que logran abordar los estudiantes que se ubican en ellos.

\section{Descripción de Niveles de desempeño en la escala de Lengua}

\begin{tabular}{|c|l|}
\hline $\begin{array}{c}\text { Nivel } 6 \\
(699 \text { y }\end{array}$ & Los estudiantes ubicados en el Nivel 6 son lectores experimentados; \\
más & que leen, y de tener una comprensión detallada de la información \\
\hline
\end{tabular}




\begin{abstract}
puntos) $\quad$ explícita e implícita; y por otra, de reflexionar sobre lo que leen y evaluar el contenido de los textos a nivel general. En términos del material de lectura, estos estudiantes comprenden prácticamente todos los tipos de textos y pueden manejar la información de varios textos a la vez. Otra particularidad de esta clase de lectores es su capacidad para superar prejuicios al enfrentarse a información nueva, incluso cuando dicha información se opone a sus expectativas.
\end{abstract}

Los estudiantes ubicados en el Nivel 5 son capaces de comprender Nivel 5 textos que tienen formas y contenidos que les resultan familiares y (de 626 también no familiares. Pueden encontrar información detallada y realizar a 698 inferencias, así como también evaluar críticamente los textos, formular puntos) hipótesis sobre los mismos (basándose en conocimiento especializado) y manejar conceptos que pueden ser contrarios a sus expectativas.

Los estudiantes ubicados en el Nivel 4 son capaces de realizar tareas de lectura que requieren acceder a información explícita e implícita (por ejemplo, localizar y organizar múltiples fragmentos con información Nivel 4 implícita), captar el significado de expresiones que usan giros no (de 553 familiares o matices del idioma, (basándose en información del texto y/o a 625 aplicando categorías en contextos desconocidos o novedosos), formular puntos) hipótesis y evaluar textos de una manera crítica (utilizando conocimiento especializado y/o público). En cuanto at material de lectura, los estudiantes de este nivel comprenden de manera exacta textos extensos y complejos, cuyos contenidos o formas pueden no resultarles familiares.

Los estudiantes ubicados en el Nivel 3 son capaces de localizar fragmentos múltiples de información; establecer relaciones entre las Nivel 3 distintas partes de un texto; relacionar el contenido del texto con (de 481 conocimientos previos, asociados a tareas de la vida cotidiana, e integrar a 552 las partes del texto para identificar la idea principal, para comprender puntos) una relación y/o para construir el significado de palabras y oraciones. En este nivel, los estudiantes pueden comparar, contrastar o clasificar información en diversas categorías y en función de distintos criterios. En 


\begin{tabular}{|c|c|}
\hline & $\begin{array}{l}\text { términos del material de lectura, los textos de este nivel suelen contener } \\
\text { mucha información implícita, o bien, explícita de difícil localización; pueden } \\
\text { contener ideas que son contrarias a las expectativas o ideas expresadas } \\
\text { en forma negativa. }\end{array}$ \\
\hline $\begin{array}{l}\text { Nivel } 2 \\
\text { (de } 407 \\
\text { a } 480 \\
\text { puntos) }\end{array}$ & $\begin{array}{l}\text { Los estudiantes ubicados en el Nivel } 2 \text { son capaces de localizar } \\
\text { información que satisfaga varios criterios, contrastar información en } \\
\text { relación con una característica, comprender el significado de un fragmento } \\
\text { específico del texto, identificar información explícita de distintos niveles de } \\
\text { dificultad (destacada, próxima a otras, etc.) y relacionar el contenido de } \\
\text { los textos con su experiencia personal. }\end{array}$ \\
\hline $\begin{array}{l}\text { Nivel 1a } \\
\text { (de } 335 \\
\text { a } 406 \\
\text { puntos) }\end{array}$ & $\begin{array}{l}\text { Los estudiantes ubicados en el Nivel 1a, son capaces de localizar } \\
\text { información explícitamente declarada, de fácil localización; también } \\
\text { pueden reconocer la idea principal de un texto y establecer conexiones } \\
\text { entre la información de un texto y su experiencia cotidiana. En cuanto al } \\
\text { material de lectura, estos estudiantes solo son capaces de abordar textos } \\
\text { de contenidos familiares. }\end{array}$ \\
\hline $\begin{array}{l}\text { Nivel 1b } \\
\text { (de } 262 \\
\text { a } 334 \\
\text { puntos) }\end{array}$ & $\begin{array}{l}\text { Los estudiantes ubicados en el Nivel } 1 \mathrm{~b} \text {, identifican información } \\
\text { explícitamente declarada y realizan inferencias de bajo nivel, como } \\
\text { reconocer una relación causal entre dos oraciones, aun cuando esta } \\
\text { relación no haya sido declarada. En términos del material de lectura, en } \\
\text { este nivel el alumno es capaz de comprender textos cortos, simples, y } \\
\text { con estilo y contenido familiares. En los textos de este nivel, } \\
\text { generalmente se apoya al lector con información repetida, imágenes o } \\
\text { símbolos que son familiares, etc. }\end{array}$ \\
\hline
\end{tabular}

La escala de Ciencias Naturales tiene seis niveles de desempeño, cada uno de los cuales informa acerca del tipo de tareas que son capaces de desarrollar los estudiantes que se ubican en ellos, y su nivel de dificultad. 


\section{Descripción de Niveles de desempeño en la escala de Ciencias Naturales}

\begin{tabular}{|c|c|}
\hline $\begin{array}{c}\text { Nivel } 6 \\
\text { (708 y } \\
\text { más } \\
\text { puntos) }\end{array}$ & $\begin{array}{l}\text { Los estudiantes ubicados en el Nivel 6, consistentemente son capaces } \\
\text { de identificar, explicar y aplicar conocimientos científicos y conocimientos } \\
\text { sobre la ciencia, en una variedad de situaciones complejas. Asimismo, son } \\
\text { capaces de justificar sus decisiones, utilizando evidencia proveniente de } \\
\text { diversas fuentes de información. Estos estudiantes tienen la capacidad } \\
\text { de demostrar, de manera clara y consistente, pensamientos y } \\
\text { razonamientos científicos avanzados, y de usar su comprensión para } \\
\text { respaldar la búsqueda de soluciones a situaciones científicas y } \\
\text { tecnológicas poco habituales. Finalmente, pueden usar conocimiento } \\
\text { científico en las argumentaciones orientadas a respaldar } \\
\text { recomendaciones y decisiones sobre situaciones locales (personales o } \\
\text { sociales) y globales. }\end{array}$ \\
\hline $\begin{array}{c}\text { Nivel } 5 \\
\text { (de } 633 \\
\text { a } 707 \\
\text { puntos) }\end{array}$ & $\begin{array}{l}\text { Los estudiantes ubicados en el Nivel } 5 \text { pueden identificar los componentes } \\
\text { científicos de muchas situaciones complejas y responder a situaciones } \\
\text { cotidianas, aplicando conceptos científicos y conocimiento sobre la } \\
\text { ciencia, para comparar, seleccionar y evaluar evidencia. Además, poseen } \\
\text { habilidades de indagación bien desarrolladas, son capaces de establecer } \\
\text { adecuadamente relaciones entre conocimientos y poseen una } \\
\text { comprensión lúcida y relevante de diversas situaciones. Finalmente, son } \\
\text { capaces de elaborar explicaciones fundadas en evidencia y de desarrollar } \\
\text { argumentos basados en un análisis crítico. }\end{array}$ \\
\hline $\begin{array}{c}\text { Nivel } 4 \\
\text { (de } 558 \\
\text { a } 632 \\
\text { puntos) }\end{array}$ & $\begin{array}{l}\text { Los estudiantes que se sitúan en el Nivel 4, son capaces de enfrentar con } \\
\text { éxito, diversas situaciones y problemas que involucran además de } \\
\text { fenómenos explícitos, la necesidad de realizar inferencias acerca del rol } \\
\text { de la ciencia o la tecnología. Pueden seleccionar e integrar explicaciones } \\
\text { de diferentes disciplinas científicas o tecnológicas y relacionarlas } \\
\text { directamente con aspectos de la vida cotidiana. Asimismo, reflexionan } \\
\text { sobre sus acciones y pueden comunicar sus decisiones, usando } \\
\text { conocimiento y evidencia científica. }\end{array}$ \\
\hline
\end{tabular}




\begin{tabular}{|c|c|}
\hline $\begin{array}{r}\text { (de } \\
\text { a }\end{array}$ & $\begin{array}{l}\text { Los estudiantes ubicados en el Nivel } 3 \text { de la escala, son capaces de } \\
\text { ejecutar procedimientos claramente descritos (incluyendo los que } \\
\text { requieren decisiones secuenciales), de seleccionar y aplicar estrategias } \\
\text { simples de resolución de problemas, de interpretar, y de usar } \\
\text { representaciones basadas en diferentes fuentes de información y de } \\
\text { razonar directamente a partir de ellas. Asimismo, son capaces de } \\
\text { elaborar comunicaciones breves para reportar sus interpretaciones, } \\
\text { resultados y razonamientos. }\end{array}$ \\
\hline $\begin{array}{c}\text { Nivel } 2 \\
\text { (de } 410 \\
\text { a } 483 \\
\text { puntos) }\end{array}$ & $\begin{array}{l}\text { Los estudiantes de Nivel 2, poseen el conocimiento científico suficiente } \\
\text { para dar explicaciones posibles en contextos habituales o para establecer } \\
\text { conclusiones basadas en investigaciones simples. Estos estudiantes son } \\
\text { además, capaces de realizar razonamiento directo y de hacer } \\
\text { interpretaciones literales de los resultados de una investigación científica } \\
\text { o de la resolución de un problema tecnológico. }\end{array}$ \\
\hline $\begin{array}{c}\text { Nivel } 1 \\
\text { (de } 335 \\
\text { a } 409 \\
\text { puntos) }\end{array}$ & $\begin{array}{l}\text { Los estudiantes de Nivel 1, tienen un conocimiento científico limitado } \\
\text { que sólo pueden aplicar a escasas situaciones de la vida cotidiana, en la } \\
\text { medida en que les resulten habituales. Además son capaces de } \\
\text { presentar explicaciones científicas muy elementales, mientras estas se } \\
\text { desprendan explícitamente de la evidencia. }\end{array}$ \\
\hline
\end{tabular}




\subsubsection{Laboratorio Latinoamericano de Evaluación de la Calidad de la Educación LLECE (UNESCO)}

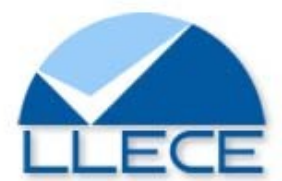

Es una red de sistemas de evaluación de la calidad de la educación de los países de América Latina y el Caribe. Lo coordina la Oficina Regional de Educación de la UNESCO para América Latina y el Caribe.

Constituye un ámbito de discusión técnico-político sobre el aprendizaje, variables relativas al desarrollo personal de los estudiantes y de los factores asociados a estas.

Creado en Ciudad de México en noviembre de 1994, el LLECE marcó un Hito en el desarrollo de nuevas formas de cooperación entre los países. Su objetivo principal es generar conocimientos que contribuyan a que los Ministerios de Educación de la región tomen decisiones informadas en materia de políticas educativas a partir del análisis de los resultados de las investigaciones evaluativas que el LLECE realiza.

En el Laboratorio participa Argentina, Brasil, Chile, Colombia, Costa Rica, Ecuador, Guatemala, Honduras, México, Nicaragua, Panamá, Paraguay, Perú, República Dominicana y Uruguay, junto al estado mexicano de Nuevo León. El LLECE realiza permanentes gestiones para que se integre a sus actividades el resto de los países de la región.

Las prioridades del LLECE son:

- Diseñar, implementar y asegurar el financiamiento del Tercer Estudio Regional Comparativo y Explicativo (TERCE).

- Diseñar y ejecutar un estudio cualitativo de escuelas con resultados destacables en el Segundo Estudio Regional Comparativo y Explicativo (SERCE).

- Realizar y fomentar la realización de estudios sobre factores asociados, a partir del SERCE. 
- Fortalecer el apoyo técnico a los sistemas de evaluación de los países miembros del LLECE y el trabajo en red.

- Generar información sobre evaluación docente.

- Favorecer la generación de conocimientos sobre modelos de evaluación de la calidad educativa que tengan un enfoque holístico.

- Favorecer el debate y la reflexión sobre nuevos modelos de evaluación: sistemas integrales, donde se considere el desarrollo global del estudiante, sus diferencias, etc. en coherencia con el concepto de calidad de la educación de la OREALC/UNESCO Santiago.

- Apoyar las diversas acciones de la UNESCO en materia de evaluación. 


\subsubsection{Estudio Internacional de Alfabetización Computacional}

y Manejo de Información ICILS (IEA)

Hoy por hoy no hay quien niegue el papel transformador (TIC), prácticamente en todos los campos de la actividad humana. Precisamente, esos cambios acelerados y revolucionarios de las TIC en la sociedad, están demandando de las personas competencia en su uso para poder insertarse efectivamente tanto en el mundo académico como laboral. Estas demandas, las deben atender los sistemas escolares contemporáneos.

A pesar de la urgencia manifiesta, la competencia en TIC y el manejo de información, históricamente han estado desatendidos por los sistemas educativos latinoamericanos. Si a esta situación se le agrega la falta de estándares educativos en TIC, la baja penetración de infraestructura TIC en las Instituciones Educativas y el muy desigual desarrollo de competencias en TIC que demuestran los estudiantes Latinoamericanos cuando terminan su último grado escolar, el panorama no resulta alentador.

Sin embargo, dado que tanto el desarrollo de competencia en TIC, como el enriquecimiento de ambientes de aprendizaje con estas, son un proceso gradual, un factor importante de la ecuación es medir el nivel actual en el que se encuentran los estudiantes de la región en su uso efectivo. Medición esta que debe hacerse con total seriedad y de manera periódica, para determinar así, avances o retrocesos.

El ICILS evaluará los resultados que obtengan los estudiantes, de diferentes países. El alfabetismo en el uso del computador y en información (CIL por su sigla en inglés), hace referencia a la habilidad individual de las personas en el uso de computadores para investigar, crear y comunicarse de manera que puedan participar efectivamente en el hogar, la Institución Educativa, el sitio de trabajo y la comunidad.

La evaluación de ICILS es hecha directamente en la computadora. Incluye preguntas de respuesta múltiple y temas en los que se deben construir las 
respuestas en base a material de estímulo realista; esto es, simulaciones de software de aplicaciones genéricas en los que se pide al estudiante completar una acción como respuesta a una instrucción dada; además de realizar tareas auténticas que requieren del estudiante modificar y generar productos de información usando aplicaciones de software de computador en "vivo".

El cuestionario que se aplique a los estudiantes recopilará información sobre el uso de computadores dentro y fuera de la Institución Educativa, las actitudes hacia las Tecnologías de la Información y la Comunicación (TIC), autoevaluación de la competencia en el uso de computadores y características del contexto particular de los estudiantes. Los cuestionarios a docentes e Instituciones, preguntarán sobre el uso de computadores, los recursos de cómputo y las políticas y prácticas relevantes. Un número de temas enlazarán a SITES 2006.

La encuesta, en el contexto nacional, recopilará datos sistémicos de políticas y prácticas educativas para el desarrollo del alfabetismo en el uso del computador y en información, idoneidad de los docentes y recursos de las tecnologías digitales (TIC) existentes en las instituciones.

\section{$\underline{\text { Instrumentos }}$}

- Pruebas realizadas en CIL, directamente en el computador, que ofrecerán un rango amplio de módulos de evaluación auténticos en un ambiente coherente.

- Cuestionario para el estudiante

- Cuestionario para el docente (incluyendo enlaces a IEA SITES 2006)

- Cuestionario para la Institución Educativa (incluyendo enlaces a IEA SITES 2006)

- Encuesta nacional de contexto

\section{Programación}

ICILS se inició en el encuentro Nacional de Coordinadores de Investigación, en junio 21 de 2010, en Ámsterdam. El proyecto pretendía elaborar 
la evaluación marco en el 2010 y terminarla en el 2011, desarrollar y hacer pilotos de esos instrumentos durante el 2011, hacer una prueba de campo en la primera mitad del 2012 y recolectar los datos a principios del 2013 en el Hemisferio Norte y a fines del mismo año en el Hemisferio Sur, para entregar resultados en Noviembre de 2014.

\section{Participantes}

Los sistemas educativos que están considerando participar en ICILS-2013 son: Canadá, Chile, Croacia, Chipre, República Checa, Dinamarca, Alemania, Hong Kong-China, Israel, Holanda, Noruega, Polonia, la Federación Rusa, Arabia Saudita, Eslovaquia, Eslovenia, España (Cataluña), Tailandia y los Estados Unidos.

\section{Población objetivo}

El foco de la población a la que se aplicará la encuesta, incluirá a todos los estudiantes matriculados en el grado correspondiente a ocho (8) años de escolarización, contados a partir del primer año de ISCED Nivel 1; siempre y cuando, el promedio de edad en el momento de tomar la prueba sea por lo menos de 13,5 años. Para muchos países correspondería al grado $8^{\circ}$. Además, esta evaluación se ofrecerá como una opción, con un conjunto de temas modificados, para el grado $4^{\circ}$. 


\subsubsection{Estudio Internacional de Tendencias en Matemática y Ciencias TIMSS} (IEA)

Es un proyecto de la Asociación Internacional para la Evaluación Educativa (IEA). La IEA es una institución independiente que coopera con las instituciones nacionales de investigación en la realización estudios de evaluación desde 1959.

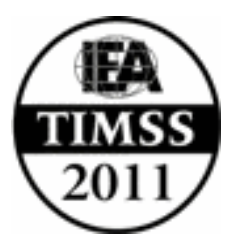

El estudio TIMSS se realiza cada cuatro años y proporciona a los países una oportunidad única para medir el progreso en la enseñanza de Matemáticas y Ciencias.

TIMSS por medio de cuestionarios pregunta a estudiantes, profesorado y miembros de los equipos directivos acerca de los contextos para aprender Matemáticas y Ciencias. Los datos de estos cuestionarios proporcionan un retrato dinámico de los cambios en las prácticas educativas y son una ayuda para mejorar dichas prácticas e implementar normas.

El modelo curricular de TIMSS tiene tres aspectos:

- El currículo diseñado.

- El currículo aplicado.

- El currículo logrado.

Estos representan, por una parte, lo que la sociedad piensa que los estudiantes tienen que aprender de las Matemáticas y las Ciencias, y por otra parte, cómo el sistema educativo se ha de organizar para facilitar dicho aprendizaje.

- Las pruebas de TIMSS se elaboran mediante un consenso internacional contando con expertos en Didáctica, en Matemáticas, en Ciencias y en Estadística.

- Los diseñadores de la prueba e investigadores, así como la comunidad educativa pueden esperar que los resultados en Matemáticas y en Ciencias. 
- Informen sobre comparaciones de los resultados obtenidos por cada país y entre países y, en unión con otros datos de TIMSS, sugieran las razones para establecer diferencias entre ellos.

- Mejoren la evaluación de la eficacia de la enseñanza y el aprendizaje en Matemáticas y en Ciencias dentro de cada país.

- Descubran los aspectos más relevantes del progreso en el conocimiento y habilidades matemáticas y científicas en $2^{\circ}$ curso de la E.S.O.

- Proporcionen datos complementarios acerca de los resultados en distintos sistemas educativos y centros escolares, así como en la mejora de la práctica docente. 


\subsubsection{Sistema Nacional de Evacuación de Resultados de aprendizaje del Ministerio de Educación de Chile SIMCE}

EI SIMCE es el Sistema Nacional de Evaluación de resultados de aprendizaje del Ministerio de Educación de Chile. Su propósito principal es contribuir al mejoramiento de la calidad y equidad de la educación, informando sobre el desempeño de los estudiantes en diferentes áreas de aprendizaje del Currículum Nacional, y relacionando estos desempeños con el contexto escolar y social en que aprenden.

Las pruebas SIMCE evalúan el logro de los Objetivos Fundamentales y Contenidos Mínimos Obligatorios (OF-CMO) del Marco Curricular vigente en diferentes sectores de aprendizaje, a través de una medición que se aplica a nivel nacional, una vez al año, a los estudiantes que cursan un determinado nivel educacional. Hasta el año 2005, la aplicación de las pruebas se alternó entre $4^{\circ}$ Básico, $8^{\circ}$ Básico y $2^{\circ}$ Medio. A partir del año 2006, se evalúa todos los años a $4^{\circ}$ Básico y se alternan $8^{\circ}$ Básico y $2^{\circ}$ Medio. Desde el año 2010 se aplica cada dos años la evaluación del sector Inglés en $3^{\circ}$ Medio, y todos los años una evaluación del sector de Educación Física en $8^{\circ}$ Básico, con el objetivo de diagnosticar la condición física de los estudiantes.

Además de las pruebas asociadas al currículum, el SIMCE también recoge información sobre docentes, estudiantes y padres y apoderados a través de cuestionarios de contexto. Esta información se utiliza para contextualizar y analizar los resultados de los estudiantes en las pruebas SIMCE.

\section{Propósito}

El propósito principal de SIMCE es contribuir al mejoramiento de la calidad y equidad de la educación, informando sobre el desempeño de los estudiantes en distintas áreas de aprendizaje y del Currículum Nacional y relacionando estos desempeños con el contexto escolar y social en que aprenden. Para cumplir con 
este propósito, SIMCE fomenta el uso de la información de las pruebas nacionales e internacionales por parte de distintos usuarios.

1. - A los profesores, directivos y sostenedores la información entregada por el SIMCE les sirve para:

- Conocer cómo le fue a sus estudiantes en comparación con aquellos del mismo curso evaluado en años anteriores. Los profesores pueden saber, por ejemplo, si al $4^{\circ}$ Básico de este año le fue mejor, peor o similar que al $4^{\circ}$ Básico del año pasado. Esto es importante para saber si las nuevas generaciones de estudiantes alcanzan mejores desempeños en comparación con las generaciones más antiguas.

- Conocer si sus estudiantes obtienen un puntaje promedio mejor, peor o similar que otros alumnos del país, de su comuna, o de establecimientos que atienden a estudiantes con similares características socioeconómicas. Cuando dos establecimientos con similares características socioeconómicas obtienen puntajes promedios significativamente distintos, es más probable que estas diferencias se deban a que una escuela ofrece una educación de mejor calidad que la otra.

- Evaluar si las iniciativas implementadas en la escuela tuvieron un efecto positivo en el nivel de desempeño de los alumnos. Por ejemplo, en una escuela los resultados SIMCE podrían haber subido como consecuencia de un cambio planificado en los énfasis de contenidos que los profesores tratan en clases.

- Conocer qué porcentaje de los estudiantes de $4^{\circ}$ y $8^{\circ}$ Básico del establecimiento se encuentra en el nivel avanzado, intermedio e inicial de los Niveles de Logro. Estos resultados deben ayudar a que los profesores tomen conciencia de la diversidad de rendimientos que presentan sus alumnos.

- Conocer el tipo de problemas que se espera que los alumnos puedan resolver. Al analizar los Niveles de Logro y las preguntas publicadas del SIMCE, los profesores pueden revisar en qué medida los estudiantes han tenido oportunidades de aprender los contenidos y habilidades evaluados. 
Es importante que esta pregunta se la hagan todos los profesores del ciclo de enseñanza, y no solo los profesores del curso evaluado. También pueden revisar si el nivel de exigencia de sus evaluaciones de aula se adecua al nivel de exigencia señalado en el currículo oficial y en las pruebas SIMCE.

- Pensar cómo ofrecer clases más estimulantes y provechosas para estudiantes con distintos Niveles de Logro. Por ejemplo, en clases los profesores podrían armar grupos de alumnos del nivel avanzado, intermedio e inicial; y dar a cada grupo actividades acordes con sus necesidades de aprendizaje.

- Ponerse metas. Por ejemplo, sostenedores, directivos y docentes podrían proponerse disminuir en 10 puntos porcentuales la proporción de estudiantes en el nivel inicial de los Niveles de Logro, junto con aumentar significativamente el puntaje promedio del establecimiento.

- A través de las evaluaciones internacionales, conocer las competencias que manejan los estudiantes chilenos en comparación con los estudiantes de otros países. Los estudiantes en cada país merecen aprender y desarrollarse tanto como los estudiantes de cualquier otro país. El que lo hagan es importante para su desarrollo personal y para el desarrollo económico y social del país.

2. - A los padres y apoderados, la información entregada por el SIMCE les sirve para:

- Conocer cómo le fue a su escuela en comparación con otras escuelas de la misma comuna o dependencia. Los padres pueden preguntarle al director del establecimiento por qué la escuela obtuvo estos resultados, y qué pueden hacer para que mejore.

- Conocer qué porcentaje de los estudiantes de $4^{\circ}$ y $8^{\circ}$ Básico del establecimiento se encuentra en el nivel avanzado, intermedio e inicial de los Niveles de Logro. Conocer qué se espera que sean capaces de hacer los alumnos en el curso evaluado. Los padres pueden consultar al profesor 
si su hijo maneja las competencias de cada Nivel de Logro, y qué pueden hacer para ayudarlo a alcanzarlas.

- Complementar la información sobre las notas. Con las notas, los padres pueden saber cómo es el rendimiento de su hijo en comparación con el de sus compañeros de curso. Con el SIMCE pueden saber cómo es el rendimiento de su escuela en comparación con otras escuelas del país.

3. - Al Ministerio de Educación, la información entregada por el SIMCE le sirve para:

- Realizar el seguimiento de la calidad y equidad de la educación desde la perspectiva de los logros de aprendizaje que alcanzan los estudiantes en distintas áreas curriculares. El Ministerio de Educación puede saber en qué medida los estudiantes están logrando los objetivos curriculares y si ha habido progreso en el logro de estos objetivos a través de los años. También puede monitorear en qué medida distintos grupos de estudiantes (ej. estudiantes de distinto nivel socioeconómico) están alcanzando estos objetivos.

- Identificar establecimientos que presentan sistemáticamente bajos resultados en el SIMCE y que necesitan apoyo externo para mejorar el desempeño de sus estudiantes.

- Evaluar la efectividad de programas de intervención cuyo objetivo es mejorar el desempeño de los estudiantes en distintas áreas curriculares.

- Asignar incentivos a las escuelas que logran mantener altos puntajes en el SIMCE o que los suben sistemáticamente.

- Aprender de la experiencia de países que alcanzan altos estándares de calidad y equidad en educación, a partir de los resultados de las evaluaciones internacionales.

- Conocer las principales características del entorno escolar y familiar en el que estudian los alumnos chilenos y de otros países del mundo. Esta información de contexto puede ser muy valiosa para comprender mejor los resultados. 


\subsection{Bases Teóricas}

\subsubsection{Calidad Total}

La Gestión de Calidad Total (abreviada TQM, del inglés Total Quality Management) es una estrategia de gestión creada por W. E. Deming orientada a crear conciencia de calidad en todos los procesos organizacionales. La TQM ha sido ampliamente utilizada en manufactura, educación, gobierno e industrias de servicio. Se le denomina «total» porque en ella queda concernida la organización de la empresa globalmente considerada y las personas que trabajan en ella.

\section{Composición de la gestión de calidad total}

La gestión de calidad total está compuesta por tres paradigmas:

- Gestión: el sistema de gestión con pasos tales como planificar, organizar, controlar, liderar, etc.

- Total: organización amplia.

- Calidad: con sus definiciones usuales y todas sus complejidades.

\section{Concepto de calidad total}

En el concepto de calidad se incluye la satisfacción del cliente y se aplica tanto al producto como a la organización. La Calidad Total pretende, teniendo como idea final la satisfacción del cliente, obtener beneficios para todos los miembros de la empresa. Por tanto, no sólo se pretende fabricar un producto con el objetivo de venderlo, sino que abarca otros aspectos tales como mejoras en las condiciones de trabajo y en la formación del personal.

El concepto de la calidad total es una alusión a la mejora continua, con el objetivo de lograr la calidad óptima en la totalidad de las áreas.

Kaoru Ishikawa, un autor reconocido de la gestión de la calidad, proporcionó la siguiente definición respecto a la Calidad Total: "Filosofía, cultura, estrategia o estilo de gerencia de una empresa según la cual todas las personas en la misma, estudian, practican, participan y fomentan la mejora continua de la calidad". 
La calidad total puede entenderse como la satisfacción global aplicada a la actividad empresarial.

\section{Clientes internos y externos}

El concepto de calidad total distingue a dos tipos de clientes, los cuales son identificados como internos y externos.

- Se consideran clientes internos a los departamentos de la empresa que solicitan un producto o servicio a otro departamento de la misma empresa.

- El cliente externo es quien compra los productos o servicios a la empresa, sin necesariamente tener relación con esta.

Por lo mismo la calidad total es un proceso al cual se suman esfuerzos para alcanzar una meta establecida y superarla de forma relevante y mejorar el producto o servicio a oferta.

La calidad total puede ser definida en dos palabras: "Mejora continua".

\section{Dirección de la calidad}

La responsabilidad que recae en la dirección de la calidad juega un papel importante en todo el proceso, puesto que mientras mejor estén organizados y compenetrados todos los miembros, mejor será el trabajo que realicen y mejores resultados se obtienen en su conjunto.

\section{Concepto de percepción de la calidad}

El concepto de calidad total está relacionado con otro concepto: el de la "percepción de la calidad", que es la percepción que se tiene de la calidad de un producto o de cómo ve la gente a una empresa o una marca (su forma de vender, el trato hacía los clientes, su implicación en proyectos sociales o con el medio ambiente). 


\section{Satisfacción global}

La satisfacción global, como su nombre indica, no solo atañe a los clientes de cada empresa, sino a todo el "universo" de la empresa, es decir: a los propios empleados y a otras empresas que le venden sus productos/servicios (lo que se denomina clientes internos).

\section{Resultados de un sistema de calidad}

La experiencia ha demostrado que tras implantar un sistema de calidad se consiguen resultados tales como:

- Aumento en la satisfacción del cliente.

- Trabajo interno de la empresa más eficaz.

- Incremento de la productividad.

- Mayores beneficios.

- Menores costos.

- Mayor calidad en los productos elaborados.

La calidad de un producto es, por tanto, una consecuencia de cómo una empresa está organizada.

\section{Herramientas para la medición de la calidad}

Existen diversos métodos de medición de la calidad, ya sea mediante herramientas propias o bien herramientas de ayuda de implantación (estadísticas, indicadores de calidad preestablecidos, estándares de producción, peso, tamaño, color). La medición es a la vez el último y el primer paso a la hora de mejorar la calidad de servicio y conseguir ofrecer un servicio excelente. Es muy difícil conseguir mejorar un servicio si no se tiene en cuenta los resultados que se están obteniendo con un sistema que permita cuantificarlos. 


\section{Valores de una cultura de Administración de Calidad Total}

La transculturalización necesaria para poder sobrevivir y crecer en un contexto turbulento, requiere que las organizaciones adopten como valores permanentes los conceptos de calidad y productividad.

Valores de una cultura organizacional de Calidad Total:

- El éxito viene del compromiso de las personas con el destino de la organización y su creencia en una verdadera y confiable asociación de administradores y trabajadores;

- El objetivo convocante es lograr calidad, es decir, la satisfacción del cliente, interno o externo.

- La generación de valor agregado a largo plazo, para una organización, dependerá del mejoramiento de la productividad;

- El mejoramiento de la calidad reduce los costos y genera un incremento de la participación en el mercado;

- Siendo el valor agregado un producto contabilizado en los índices de productividad, el mejoramiento de la calidad y de la productividad se convierten en sinónimos.

- La diferencia competitiva de una organización está en el potencial de su gente, por ello ha de brindarse entrenamiento y capacitación de manera sistemática.

\section{Calidad total en la educación}

En el sector educativo la cultura de la Calidad Total pareciera ser de dificultosa implementación toda vez que se trata de estructuras burocráticas y no resulta sencillo definir quién es el cliente final y la detección de sus requerimientos.

Esto implica asumir que la Calidad Total solamente está destinada a satisfacer las necesidades del cliente, sin embargo, Calidad Total es mucho más que eso: es reducir costos, es incrementar la productividad y es lograr una mejor calidad de vida. 
Son estas últimas consideraciones las que permiten afirmar que en el ámbito educativo también es aplicable la Calidad Total.

El proceso de implantación de un sistema de calidad en un centro docente considera las siguientes fases:

- Toma de conciencia de la situación actual del centro, de los problemas, de la necesidad de cambio

- Decisión de empezar que se concreta en dos momentos: ¿qué se va a hacer? (se formará a la dirección y parte del personal sobre el tema de la calidad y los instrumentos que se utilizan en los sistemas de calidad), ¿dónde se está posicionado? (se hará un diagnóstico de la situación actual del centro).

- Declaración de un plan para la mejora del centro y aceptación por todo el colectivo.

- Actuación de todo el personal según los acuerdos

- Seguimiento y control del proceso, con el fin de comprobar el logro de los objetivos, analizar las desviaciones y sus posibles causas; y establecer mecanismos de corrección.

- Establecimiento de un sistema de mejora continua de la calidad. Comprenderá: una estructura organizativa y el empleo de herramientas adecuadas.

\subsubsection{Calidad en Educación}

La OCDE (Organización para la Cooperación y Desarrollo Económico) define la educación de calidad como aquella que "asegura a todos los jóvenes la adquisición de los conocimientos, capacidades destrezas y actitudes necesarias para equipararles para la vida adulta".

Otra definición: "La escuela de calidad es la que promueve el progreso de sus estudiantes en una amplia gama de logros intelectuales, sociales, morales y emocionales, teniendo en cuenta su nivel socioeconómico, su medio familiar y su 
aprendizaje previo. Un sistema escolar eficaz es el que maximiza la capacidad de las escuelas para alcanzar esos resultados". (J. Mortimore)

La eficacia no estará en conseguir un buen producto a partir de unas buenas condiciones de entrada, sino en hacer progresar a todos los alumnos a partir de sus circunstancias personales. En este sentido conviene enfatizar en la calidad de los procesos escolares, y evitar dar un valor absoluto a los productos obtenidos.

\section{La calidad desde la esfera de los valores}

Un sistema educativo de calidad se caracteriza por su capacidad para:

- Ser accesible a todos.

- Facilitar los recursos personales, organizativos y materiales, ajustados a las necesidades de cada alumno para que todos puedan tener las oportunidades que promoverán lo más posible su progreso académico y personal.

- Promover cambio e innovación en la institución escolar y en las aulas (lo que se conseguirá, entre otros medios, posibilitando la reflexión compartida sobre la propia práctica docente y el trabajo colaborativo del profesorado)

- Promover la participación activa del alumnado, tanto en el aprendizaje como en la vida de la institución, en un marco de valores donde TODOS se sientan respetados y valorados como personas.

- Lograr la participación de las familias e insertarse en la comunidad

- Estimular y facilitar el desarrollo y el bienestar del profesorado y de los demás profesionales del centro.

Características de los centros docentes eficaces:

- Compromiso con normas y metas compartidas y claras. Los fines generales de la educación deben considerar las tres categorías básicas:

1. Competencia académica y personal,

2. Socialización de los estudiantes

3. Formación integral.

- Búsqueda y reconocimiento de unos valores propios. 
- Liderazgo profesional de la dirección. La actividad directiva se centra en el desarrollo de actividades de información, organización, gestión, coordinación y control. Supone una continua toma de decisiones en aspectos: administrativos y burocráticos, jefatura del personal, disciplina de los alumnos, relaciones externas, asignación de recursos y resolución de problemas. Debe conocer bien lo que pasa en el centro, mediar en la negociación de los conflictos y ver de tomar decisiones compartidas.

- Estabilidad laboral y estrategias para el desarrollo del personal, acorde con las necesidades pedagógicas de cada centro. Procurar el aprendizaje continuo del profesorado y la actualización de los contenidos, recursos y métodos.

- Currículum bien planeado y estructurado, con sistemas de coordinación y actualización periódica.

- Clima de aprendizaje. La enseñanza y el aprendizaje deben constituir el centro de la organización y la actividad escolar. Se debe cuidar el ambiente de aprendizaje buscando el aprovechamiento del estudiante y el empleo eficiente de los tiempos de aprendizaje. La motivación y los logros de cada estudiante están muy influidos por la cultura o clima de cada escuela.

- Profesionalidad de la docencia: organización eficiente del profesorado, conocimiento claro de los propósitos por los alumnos, actividades docentes estructuradas, tratamiento de la diversidad, seguimiento de los avances de los estudiantes, uso de refuerzos positivos, claras normas de disciplina, en fin, eficacia docente

- Expectativas elevadas sobre los alumnos y sus posibilidades, comunicación de estas expectativas, proponer desafíos intelectuales a los estudiantes.

- Atención a los derechos y responsabilidades de los estudiantes, darles una cierta responsabilidad en actividades del centro, control de su trabajo, atender a su autoestima.

- Elevado nivel de implicación y apoyo de los padres. Participación de la comunidad educativa

- Apoyo activo y sustancial de la administración educativa 
Con todo hay que tener en cuenta que según la perspectiva sobre la noción de calidad que se adopte variará lo que se considere una escuela eficaz; sólo se puede hablar de eficacia en función del logro de unos fines específicos.

\section{Principios de la calidad total en educación}

A lo largo del tiempo ha ido variando la consideración de lo que resulta fundamental en la calidad. Primero fue el "producto", más tarde el "proceso", luego los "trabajadores". Actualmente la calidad total se fundamenta en la idea de la satisfacción del cliente (en el ámbito educativo esto puede considerarse la superación de los principios de las "escuelas eficaces")

- Lo más importante es la satisfacción del cliente, con el costo más bajo posible. La empresa de éxito será la que identifique y satisfaga las expectativas de sus clientes.

- El proceso de calidad total se inicia con la detección de problemas y deficiencias y la propuesta de determinadas soluciones.

- La gestión de la calidad se fundamenta en el desarrollo continuo de planes integrales, no en la ejecución de simples acciones aisladas o puntuales.

- La toma de decisiones se debe realizar como consecuencia de datos y evidencias, no a partir de suposiciones y opiniones. Por lo tanto es preciso evaluar.

- La calidad depende básicamente de las personas, por ello resulta fundamental atender a aspectos como:

- La participación

- El compromiso

- La implicación voluntaria

- La colaboración

- El trabajo en equipo

- La formación de las personas

- Propiciar el desarrollo/crecimiento personal de cada individuo como clave del crecimiento y enriquecimiento de la organización

- La calidad total implica a toda la organización 
Una educación de calidad es aquella que promueve:

- La construcción de conocimientos psicológica, social y científicamente significativos.

- El desarrollo de procesos de pensamiento y estrategias cognitivas que le permitan al sujeto "aprender a aprender".

- La apropiación de instrumentos para participar en la vida económica, política y social, contribuyendo a la construcción de un modelo social democrático.

- El desarrollo de habilidades básicas que posibiliten al educando, la inserción en condiciones adecuadas en el nivel siguiente del sistema educativo o la incorporación a la vida activa.

- La aplicación del conocimiento para operar sobre la realidad.

- La posibilidad de la duda y la discusión.

- La consideración de las características propias del sujeto de aprendizaje, en sus aspectos cognitivos, socio-afectivos y psicomotrices.

- El crecimiento profesional del docente. 


\subsection{Definición de términos Básicos}

\subsubsection{Educación}

La educación, (del latín educere "sacar, extraer" o educare "formar, instruir") puede definirse como:

- El proceso multidireccional mediante el cual se transmiten conocimientos, valores, costumbres y formas de actuar. La educación no sólo se produce a través de la palabra, pues está presente en todas las acciones, sentimientos y actitudes.

- El proceso de vinculación y concienciación cultural, moral y conductual. Así, a través de la educación, las nuevas generaciones asimilan y aprenden los conocimientos, normas de conducta, modos de ser y formas de ver el mundo de generaciones anteriores, creando además otros nuevos.

- Proceso de socialización formal de los individuos de una sociedad.

- La educación se comparte entre las personas por medio de las ideas, cultura, conocimientos, etc. respetando siempre a los demás. Ésta no siempre se da en el aula.

Existen tres tipos de educación: la formal, la no formal y la informal. La educación formal hace referencia a los ámbitos de las escuelas, institutos, universidades, módulos, mientras que la no formal se refiere a los cursos, academias, e instituciones, que no se rigen por un particular currículo de estudios, y la educación informal es aquella que fundamentalmente se recibe en los ámbitos sociales, pues es la educación que se adquiere progresivamente a lo largo de toda la vida.

\section{Educación básica}

Preescolar, educación primaria y secundaria es la etapa de formación de los individuos en la que se desarrollan las habilidades del pensamiento y las competencias básicas para favorecer el aprendizaje sistemático y continuo, así 
como las disposiciones y actitudes que regirán sus respectivas vidas (educación en valores). Lograr que todos los niños, las niñas, y los adolescentes del país tengan las mismas o similares oportunidades de cursar y concluir con éxito la educación básica, para así lograr los aprendizajes que se establecen para cada grado y nivel, son factores fundamentales para sostener el desarrollo de la nación.

En una educación básica de buena calidad el desarrollo de las competencias básicas y el logro de los aprendizajes de los alumnos son los propósitos centrales, son las metas a las cuales los profesores, la escuela y el sistema dirigen sus esfuerzos.

Permiten valorar los procesos personales de construcción individual de conocimiento por lo que, en esta perspectiva, son poco importantes los aprendizajes basados en el procesamiento superficial de la información y aquellos orientados a la recuperación de información en el corto plazo.

Una de las definiciones más interesantes la propone uno de los más grandes pensadores, Aristóteles: "La educación consiste en dirigir los sentimientos de placer y dolor hacia el orden ético."

También se denomina educación al resultado de este proceso, que se materializa en la serie de habilidades, conocimientos, actitudes y valores adquiridos, produciendo cambios de carácter social, intelectual, emocional, etc. en la persona que, dependiendo del grado de concienciación, será para toda su vida o por un periodo determinado, pasando a formar parte del recuerdo en el último de los casos.

\section{Objetivos}

- Incentivar el proceso de estructuración del pensamiento, de la imaginación creadora, las formas de expresión personal y de comunicación verbal y gráfica.

- Favorecer el proceso de maduración de los niños en lo sensorio-motor, la manifestación lúdica y estética, la iniciación deportiva y artística, el crecimiento socio afectivo, y los valores éticos.

- Estimular hábitos de integración social, de convivencia grupal, de solidaridad y cooperación y de conservación del medio ambiente. 
- Desarrollar la creatividad del individuo.

- Fortalecer la vinculación entre la institución educativa y la familia.

- Prevenir y atender las desigualdades físicas, psíquicas y sociales originadas en diferencias de orden biológico, nutricional, familiar y ambiental mediante programas especiales y acciones articuladas con otras instituciones comunitarias.

\section{Concepto de Educación}

La educación es un proceso de socialización y endoculturación de las personas a través del cual se desarrollan capacidades físicas e intelectuales, habilidades, destrezas, técnicas de estudio y formas de comportamiento ordenadas con un fin social (valores, moderación del diálogo-debate, jerarquía, trabajo en equipo, regulación fisiológica, cuidado de la imagen, etc.).

En muchos países occidentales la educación escolar o reglada es gratuita para todos los estudiantes. Sin embargo, debido a la escasez de escuelas públicas, también existen muchas escuelas privadas y parroquiales.

La función de la educación es ayudar y orientar al educando para conservar y utilizar los valores de la cultura que se le imparte, fortaleciendo la identidad nacional. La educación abarca muchos ámbitos; como la educación formal e informal.

Pero el término educación se refiere sobre todo a la influencia ordenada ejercida sobre una persona para formarla y desarrollarla a varios niveles complementarios; en la mayoría de las culturas es la acción ejercida por la generación adulta sobre la joven para transmitir y conservar su existencia colectiva. Es un ingrediente fundamental en la vida del ser humano y la sociedad. Se remonta a los orígenes mismos del ser humano. La educación es lo que transmite la cultura, permitiendo su evolución. 


\subsubsection{Educación Secundaria}

La educación secundaria es la que tiene como objetivo capacitar al alumno para proseguir estudios superiores o bien para incorporarse al mundo laboral. Al terminar la misma se pretende que el alumno desarrolle las suficientes habilidades, valores y actitudes para lograr un buen desenvolvimiento en la sociedad. En particular, la enseñanza secundaria debe brindar formación básica para responder al fenómeno de la universalización de la matrícula; preparar para la universidad pensando en quienes aspiran y pueden continuar sus estudios; preparar para el mundo del trabajo a los que no siguen estudiando y desean o necesitan incorporarse a la vida laboral; $y$ formar la personalidad integral de los jóvenes, con especial atención en los aspectos relacionados con el desempeño ciudadano.

Puede ser una educación secundaria común para todos los alumnos o diversificada en vías formativas según las salidas posteriores. Las modalidades, a la vez, pueden tener diversas especializaciones y orientaciones que permiten formarse en temas específicos. Por ejemplo, en la educación técnico profesional se prepara mayoritariamente para el trabajo después de terminar la escuela secundaria, en esta modalidad se entrena al alumno para que aprenda una carrera técnica o industrial.

En muchos países no es obligatoria y las edades varían mucho de una nación a otra, si bien por lo común cubre la etapa de la adolescencia, en general se comienza con 12 o 13 años y se termina con 17 o 18.

\section{Argentina}

En Argentina, la Educación Secundaria es obligatoria y constituye una unidad pedagógica y organizativa destinada a los/as adolescentes y jóvenes que hayan cumplido con el nivel de Educación Primaria.

La Educación Secundaria se divide en dos ciclos: un Ciclo Básico, de carácter común a todas las orientaciones y un Ciclo Orientado, de carácter diversificado según distintas áreas del conocimiento, del mundo social y del trabajo. Sus objetivos son: 
a) Brindar una formación ética que permita a los/as estudiantes desempeñarse como sujetos conscientes de sus derechos y obligaciones que practican el pluralismo, la cooperación y la solidaridad, que respetan los derechos humanos, rechazan todo tipo de discriminación, se preparan para el ejercicio de la ciudadanía democrática y preservan el patrimonio natural y cultural.

b) Formar sujetos responsables, que sean capaces de utilizar el conocimiento como herramienta para comprender y transformar constructivamente su entorno social, económico, ambiental y cultural, y de situarse como participantes activos/as en un mundo en permanente cambio.

c) Desarrollar y consolidar en cada estudiante las capacidades de estudio, aprendizaje e investigación, de trabajo individual y en equipo, de esfuerzo, iniciativa y responsabilidad, como condiciones necesarias para el acceso al mundo laboral, los estudios superiores y la educación a lo largo de toda la vida.

d) Desarrollar las competencias lingüísticas, orales y escritas de la lengua española y comprender y expresarse en una lengua extranjera.

e) Promover el acceso al conocimiento como saber integrado, a través de las distintas áreas y disciplinas que lo constituyen y a sus principales problemas, contenidos y métodos.

f) Desarrollar las capacidades necesarias para la comprensión y utilización inteligente y crítica de los nuevos lenguajes producidos en el campo de las tecnologías de la información y la comunicación.

g) Vincular a los/as estudiantes con el mundo del trabajo, la producción, la ciencia y la tecnología.

h) Desarrollar procesos de orientación vocacional a fin de permitir una adecuada elección profesional y ocupacional de los/as estudiantes. 
i) Estimular la creación artística, la libre expresión, el placer estético y la comprensión de las distintas manifestaciones de la cultura.

j) Promover la formación corporal y motriz a través de una educación física acorde con los requerimientos del proceso de desarrollo integral de los adolescentes.

A través del tiempo, el sistema de educación secundaria en Argentina ha sido modificado varias veces.

La educación en instituciones del estado es gratuita, en los niveles primario, secundario y terciario así como en las carreras de grado de nivel universitario (no así para los posgrados).

La Ley 26.206 define la estructura del Sistema Educativo Nacional, la cual está comprendida por cuatro niveles y ocho modalidades.

"Constituyen modalidades del Sistema Educativo Nacional aquellas opciones organizativas y/o curriculares de la educación común, dentro de uno o más niveles educativos, que procuran dar respuesta a requerimientos específicos de formación y atender particularidades de carácter permanente o temporal, personales y/o contextuales, con el propósito de garantizar la igualdad en el derecho a la educación y cumplir con las exigencias legales, técnicas y pedagógicas de los diferentes niveles educativos. Son modalidades: la Educación Técnico Profesional, la Educación Artística, la Educación Especial, la Educación Permanente de Jóvenes y Adultos, la Educación Rural, la Educación Intercultural Bilingüe, la Educación en Contextos de Privación de Libertad y la Educación Domiciliaria y Hospitalaria"”

\footnotetext{
${ }^{7}$ Ley 26.206 Art 17
} 
En la actualidad la estructura educativa de la República Argentina, no es universal para todas las provincias, sino que éstas están encargadas de la educación bajo su jurisdicción. En las provincias encabezadas por la provincia de Buenos Aires, el sistema educativo comprende los siguientes años de educación:

- básica (nivel inicial - edad 5 años)

- nivel primario (de 6 a 12 años)

- nivel secundario ( de 12 a 18 años)

\section{$\underline{\text { Nivel Secundario }}$}

1. Primer Año

12-13 años

2. Segundo Año 13-14 años

3. Tercer Año 14-15 años

4. Cuarto Año 15-16 años

5. Quinto Año 16-17 años

6. Sexto Año 17-18 años

En cuarto año los alumnos deben elegir una orientación, cada una tiene sus materias especificas y diferencias en los horarios:

- Ciencias Sociales: Psicología, Sociología, Filosofía, Economía, Cultura, Historia, Geografía (en las otras hasta 5to)

- Ciencias Naturales: Genética, Biología, Astronomía, Física, Química (en las otras Física y Biología 4to, Química en 5to)

- Economía y Administración: Contabilidad, Derecho, Informática, Teoría del desarrollo, Elementos de la Microeconomía y Macroeconomía, Gestión Organizacional, Filosofía, Cultura, Política y Ciudadanía.

- Artes Visuales y Escénicas: Arte, Música, Danza, Teatro, Expresión Corporal, Historia del arte

- Arte y Diseño: Arte, Producción De Imágenes, Informática

- Salud y Deporte: Salud y Adolescencia, Deportes, Gimnasia, Biología, higiene, nutrición

- Lenguas Extranjeras: Inglés, Italiano, Francés, Alemán, Latín, Portugués 
Para la Educación Secundaria Técnica se definen las siguientes tecnicaturas:

- Técnico en Electromecánica

- Técnico en Administración de las Organizaciones

- Técnico Químico

- Técnico en Tecnología de los Alimentos

- Técnico en Electrónica

- Técnico en Informática Personal y Profesional

- Maestro Mayor de Obras

- Técnico en Aeronáutica

- Técnico en Automotores

- Técnico en Servicios Turísticos

- Técnico en Multimedios

- Técnico Constructor Naval 


\subsection{Sistema de variables}

En esta investigación se evaluaron la tasa de Matriculación Bruta Combinada, Sobre edad escolar, Alfabetismo y Analfabetismo, con el fin de tener un panorama acerca de la situación educativa de Ensenada.

La tasa de Matriculación muestra el nivel general de participación en un nivel educativo determinado. Es un indicador que refleja la importancia que un país asigna o puede asignar a la formación de capital humano mediante el sistema educativo, al considerarse este recurso como vital para el desarrollo futuro.

Con respecto a la tasa de Sobre edad escolar, es aquella que mide los patrones y la incidencia de la repetición de grados, como parte de la eficiencia interna del sistema educativo.

Y por último, la tasa de alfabetismo (o tasas de analfabetismo) Representa una medición resumida de la efectividad del sistema educativo. Es decir, evalúa la presencia de un sistema eficaz de educación o de programas de alfabetización que permitan entregar a una gran parte de la población la habilidad de utilizar la palabra escrita (y realizar operaciones simples de aritmética) en su vida diaria, y seguir aprendiendo.

A continuación se presentan las fórmulas correspondientes a cada tasa evaluada:

\section{Matriculación Bruta Combinada}

$$
\frac{\text { Cantidad de alumnos matriculados }}{\text { Total población en edad correspondiente }} \cdot 100
$$

Se calcula esta tasa para cada curso, luego para cada nivel Educativo y luego se hace un Promedio simple de la Tasa Bruta de Matriculación por Niveles. Esta tasa, particularmente en los primeros cursos de la educación formal puede ser superior al $100 \%$ ya que calcula la proporción entre los matriculados y la población con la edad correspondiente para cada año de la educación formal. En 
países o regiones en los cuales la sobre-edad es un fenómeno de relevancia, esto se ve con frecuencia.

Sobre edad escolar

Cantidad de alumnos mayores a edad correspondiente

Cantidad de matriculados en el año

Esta tasa hace referencia a la cantidad de alumnos que se encuentran cursando el secundario y tienen una edad mayor a la correspondiente, de acuerdo con el nivel que debería cursar.

\section{$\underline{\text { Tasa de Alfabetización }}$}

$$
\frac{\text { Cantidad de alumnos que reportan leer y escribir }^{(1)}}{\text { Total de alumnos }^{(2)}} \cdot 100
$$

(1) Alumnos de Nivel secundario mayores de 11 (12) años y menores de 17 (18) años.

(2) Población general de la región mayores de 11 (12) años y menores de 17 (18) años.

Mediante esta fórmula se evalúa el nivel de alfabetización, esto es la habilidad que tiene la persona de utilizar texto para comunicarse a través del espacio y el tiempo. Esto se reduce a la habilidad de leer y escribir.

\section{Tasa de Analfabetismo}

Cantidad de alumnos que reportar no leer ni escribir

$$
\text { Total de alumnos }
$$

Es justamente lo contrario a la tasa anterior. El analfabetismo es la incapacidad de leer y escribir, lo cual se debe generalmente a la falta de aprendizaje. 


\section{Metodología de la investigación}

\subsection{Población y muestra}

La técnica de investigación utilizada fue la de "Panel de Expertos" 8 (o especialistas) el cual, como su nombre lo indica, está formado por un grupo de personas expertas en educación secundaria, con un gran bagaje profesional en el tema en cuestión y potenciales clientes del producto a evaluar -"siguientes en la etapa del proceso", acorde con el concepto de evaluación de calidad.

Es decir, que la población está compuesta por los docentes de nivel terciario y empresarios de la región de Ensenada, y la muestra seleccionada para la formación del panel de expertos fue de 10 docentes y 7 empresarios de dicha localidad.

Se tuvieron en cuenta algunas características esenciales al seleccionar la muestra bajo estudio. Entre éstas se pueden contar las siguientes:

- Homogeneidad: todos los consultados debían contar con similares conocimientos acerca del nivel de educación presentado por los egresados del secundario.

- Tiempo: para el cálculo de los indicadores se utilizó información del año 2011, la cual fue proporcionada por el Ministerio de Educación.

- Espacio: el estudio se basa en especialistas de la región de La Plata, Berisso y Ensenada; provincia de Buenos Aires.

- Cantidad: El tamaño de la población de los especialistas a consultar se limitó a dos grupos de paneles de expertos que brindaron respuestas, luego de comprender la metodología y consigna propuesta. Uno de los paneles está compuesto por profesores de universidades y escuelas terciarias, debido a que son quienes reciben a los egresados del secundario, y son capaces de evaluar el nivel de educación que estos presentan. El otro panel está conformado por empresarios, ya que saben acerca de las capacidades, habilidades y conocimiento que poseen los egresados, y su respectivo desempeño en el mercado laboral.

\footnotetext{
${ }^{8}$ Personas especialistas independientes y reputadas que conocen en profundidad la temática del campo al que concierne el objeto que se pretende evaluar, a quienes se recurre para que emitan un juicio sobre dicho objeto.
} 


\subsection{Tipo de investigación}

La investigación que se llevó a cabo es de tipo exploratoria y descriptiva. Es exploratoria debido a que la investigación se efectúa sobre un tema u objeto desconocido o poco estudiado, por lo que sus resultados constituyen una visión aproximada de dicho objeto, es decir, un nivel superficial de conocimiento.

El objetivo de la investigación descriptiva consiste en llegar a conocer las situaciones, costumbres y actitudes predominantes a través de la descripción exacta de las actividades, objetos, procesos y personas. Su meta no se limita a la recolección de datos, sino a la predicción e identificación de las relaciones que existen entre dos o más variables. Consiste, fundamentalmente, en caracterizar un fenómeno o situación concreta indicando sus rasgos más peculiares o diferenciadores.

\subsection{Técnica de recolección de datos}

La investigación se basó en la recolección de datos primarios y secundarios. Los datos secundarios fueron recabados del Ministerio de Educación de la Provincia de Buenos Aires y los datos primarios se obtuvieron mediante la realización de encuestas a un panel de expertos.

Los paneles se consideran una técnica de investigación socialmente responsable, ya que reducen la necesidad de realizar encuestas "masivas" a la sociedad en general cada vez que se necesita obtener información cuantitativa de un determinado grupo selecto de personas.

Las principales ventajas de recurrir a un Panel de Especialistas sobre los métodos de investigación de mercados tradicionales son:

- Ahorro de costos

- Superación de barreras geográficas, pudiendo reunir en una sesión a personas de diferentes ciudades

- Lograr una mayor desinhibición de los participantes, lo que provoca que las opiniones vertidas sean más sinceras y arriesgadas

- Posibilidad de recopilación inmediata de las opiniones 
- Mayor individualidad en las respuestas frente a técnicas alternativas como el Focus Group, en el que la presión del grupo puede llevar a ciertos participantes a cambiar de opinión y por ende "contaminar" los resultados.

La realización de la encuesta, se basó en la metodología de PISA (Programa para la Evaluación Internacional de Alumnos), debido a que es un programa de evaluación internacional ya utilizado en varios países, que permite la comparación de los resultados obtenidos. Este se trata de un programa de evaluación continuada que a largo plazo, conduce al desarrollo de una información que sirve para llevar un control de las tendencias que marca la evolución de los conocimientos y las habilidades de los alumnos de varios países, así como de diversos subgrupos poblacionales dentro de cada país.

Se analizaron los conocimientos, las habilidades, capacidades y otros atributos pertenecientes a los individuos que influyen de forma significativa en el bienestar personal, social y económico. Esta forma de enfocar el rendimiento educativo se hace necesaria si se desea fomentar que los centros de enseñanza y los sistemas educativos se centren en los desafíos que plantea la sociedad contemporánea.

La investigación se dividió en cuatro áreas:

- Competencia matemática: La capacidad que tiene un individuo de identificar y comprender el papel que desempeñan las matemáticas en el mundo, emitir juicios bien fundados y utilizar e implicarse en las matemáticas de una manera que satisfaga sus necesidades vitales como un ciudadano constructivo, comprometido y reflexivo.

- Competencia lectora: La capacidad que tiene un individuo de comprender, utilizar y analizar textos escritos con objeto de alcanzar sus propias metas, desarrollar sus conocimientos y posibilidades de participar en la sociedad. 
- Competencia científica: Hace referencia a los conocimientos científicos de un individuo y al uso de ese conocimiento para identificar problemas, adquirir nuevos conocimientos, explicar fenómenos científicos y extraer conclusiones basadas en pruebas sobre cuestiones relacionadas con la ciencia. Asimismo, comporta la comprensión de los rasgos característicos de la ciencia, entendida como un método del conocimiento y la investigación humanas, la percepción del modo en que la ciencia y la tecnología conforman el entorno material, intelectual y cultural, y la disposición a implicarse en asuntos relacionados con la ciencia y con las ideas de la ciencia como un ciudadano reflexivo.

- $\quad$ Aptitudes personales: capacidad que tiene el individuo para poder realizar satisfactoriamente una tarea. Hay que destacar que la aptitud está estrechamente relacionada con la inteligencia y con las habilidades tanto innatas como adquiridas fruto de un proceso de aprendizaje.

Las encuestas se realizaron a dos grupos de paneles de expertos, un grupo conformado por profesores de instituciones de enseñanza superior, ya sea universidades o escuelas terciarias; y otro compuesto por empresarios con gran conocimiento acerca de la inserción de los egresados al mundo laboral y el nivel educativo que presentan. La encuesta a este último panel de expertos es más reducida, debido a que se pregunta acerca de los conocimientos generales, no tan específicos como lo es en el caso de los profesores.

Para ello, se le entregó a cada uno de los especialistas una encuesta donde debían contestar los interrogantes acerca del nivel educativo. Los expertos debían marcar la respuesta que consideraba que representa su opinión al respecto. 
Las distintas opciones de respuestas presentes en la encuesta son las siguientes:

\begin{tabular}{|c|c|c|c|c|c|}
\hline Mal & Regular & Bien & Muy Bien & Excelente & NS/NC \\
\hline $\mathbf{1}$ & $\mathbf{2}$ & $\mathbf{3}$ & $\mathbf{4}$ & $\mathbf{5}$ & $\mathbf{6}$ \\
\hline $\begin{array}{c}\text { (calificación } \\
\text { 0 a 2) }\end{array}$ & $\begin{array}{c}\text { (calificación } \\
\text { más de 2 } \\
\text { hasta 4) }\end{array}$ & $\begin{array}{c}\text { (calificación } \\
\text { más de 4 } \\
\text { hasta 6) }\end{array}$ & $\begin{array}{c}\text { (calificación } \\
\text { más de 6 } \\
\text { hasta 8) }\end{array}$ & $\begin{array}{c}\text { (calificación } \\
\text { más de 8 } \\
\text { hasta 10) }\end{array}$ & $\begin{array}{c}\text { (No sabe } \\
\text { / No } \\
\text { contesta) }\end{array}$ \\
\hline
\end{tabular}

La encuesta, además de estar dividida en cuatro áreas, y en dos grupos de paneles de expertos (docentes y empresarios), se realizó en la región de La Plata, Berisso y Ensenada, lo cual permitió la comparación de los resultados de ambos paneles, y a su vez con los resultados de la región.

Las instituciones de Ensenada donde se realizaron las encuestas a los expertos fueron las siguientes:

- Centro de Formación Profesional nº 401

Dirección: Calle Ferella esq. H. Irigoyen 401 - Ensenada

Teléfono: 0221- 4695447

- Centro de Formación Profesional no 402

Dirección: Calle 32 e/ 126 y 127 s/n - Ensenada

Teléfono: 221- 4237290

- Instituto Superior de Formación Técnica nº 193 - Astillero Santiago

Dirección: Hipólito Irigoyen y Don Bosco - Ensenada

Teléfono: 221- 5217700

- Instituto Superior de Formación Docente y Técnica nº 136

Dirección: Calle San Martín y Chile - Ensenada

Teléfono: 0221- 4691351 
- Cámara de Comercio e Industria Ensenada

Dirección: Calle La Merced n 473 - Ensenada

Teléfono: 221-4691126

www.cceda.com.ar

\subsection{Técnicas de análisis}

Con los datos obtenidos del Ministerio de Educación de la provincia de Buenos Aires se generaron coeficientes indicativos del grado de desempeño de los alumnos del nivel secundario. Tales indicadores son la Matrícula bruta combinada, Sobre-edad escolar, Alfabetización y Analfabetismo.

Por otra parte, a las encuestas al panel de expertos se les aplicó un análisis estadístico univariado. Una vez obtenidos los indicadores pertinentes, los resultados fueron volcados en tablas y gráficos.

Los resultados de la encuesta fueron contabilizados y volcados en una tabla con el siguiente formato:

\begin{tabular}{|l|c|c|c|c|c|c|c|c|}
\hline \multicolumn{9}{|c|}{ Área } \\
\hline & Mal & Regular & Bien & Muy Bien & Excelente & NS/NC & \\
\hline & 1 & 2 & 3 & 4 & 5 & 6 & Total & $\begin{array}{c}\text { Saldo de } \\
\text { Respuesta }\end{array}$ \\
\hline ¿El alumno...? & & & & & & & & \\
\hline & & & & & & & & \\
\hline Total & & & & & & & & \\
\hline Porcentaje & & & & & & & & \\
\hline
\end{tabular}


Luego se calculó el "Saldo de respuesta"9 de cada pregunta realizada, en función de la fórmula siguiente:

$$
\text { Saldo de Respuesta }=\frac{\sum_{i=1}^{n} F_{i} \cdot i}{\sum_{i=1}^{n} F_{i}}
$$

Donde:

$F_{i}=$ Es la cantidad de respuestas (frecuencias) de cada ítem para cada valor de las opciones de respuesta

$\mathrm{i}=$ Es el valor de cada uno de las opciones de respuesta

El cálculo consiste en multiplicar los componentes de las cantidades de respuestas (frecuencias) por el tipo de respuesta dado y luego sumar esos productos. Posteriormente a ese número se lo divide por la sumatoria de la cantidad de respuestas.

Tanto en el cálculo del saldo de respuesta y del porcentaje, no se tuvo en cuenta la cantidad de respuestas obtenidas del tipo "No sabe/No contesta" ya que se busca evaluar el conocimiento que presenta el alumno, con el mínimo error o desvío posible.

A efectos de realizar la comparación con los datos de la última publicación disponible de PISA, fue necesario realizar un re-escalamiento de variables, toda vez que PISA utiliza una escala que va de 0 a 800 puntos y en la encuesta se usó un rango de 1 a 5 .

\footnotetext{
${ }^{9}$ El cálculo de ese promedio sigue idéntica metodología que la del Global Competitiveness Index del World Economic Forum para el procesamiento de la Executive Opinion Survey en que se pregunta sobre una serie de cuestiones y se solicita que se califique en un rango que va de 1 a 7 en que 1 es lo peor y 7 lo mejor y que luego se sintetiza a través de un promedio. Xavier Sala-iMartin (Cabrera de Mar, Barcelona, España, 1963), es un economista de origen español y de nacionalidad estadounidense, articulista, catedrático de economía en la Universidad de Columbia y Asesor Jefe ("Chief Advisor") del World Economic Forum donde, además, es coautor del Global Competitiveness Report y el padre intelectual del Global Competitiveness Index que ordena a más de 140 países del mundo según su competitividad.
} 
Fue necesario establecer la ecuación de la recta de transformación en función de los ejes cartesianos de los extremos.

\begin{tabular}{|l|r|r|}
\hline & Encuesta & \multicolumn{1}{|c|}{ PISA } \\
\hline Mínimo & 1 & 0 \\
\hline Máximo & 5 & 800 \\
\hline
\end{tabular}

Los extremos conforman los pares siguientes:

$$
\begin{aligned}
& \left(x_{0} ; y_{0}\right)=(1 ; 0) \\
& \left(x_{1} ; y_{1}\right)=(5 ; 800)
\end{aligned}
$$

De tal modo, la pendiente de la recta de transformación "m" es:

$$
m=\frac{\left(y_{1}-y_{0}\right)}{\left(x_{1}-x_{0}\right)}=\frac{(800-0)}{(5-1)}=200
$$

Y la ordenada al origen "b" es:

$$
b=-m \cdot x_{0}+y_{0}=-200 \cdot 1+0=-200
$$

Y la ecuación de la recta de transformación es:

$$
y=m \cdot x+b=200 \cdot x-200=200 \cdot(x-1)
$$




\section{Resultados de la Investigación}

\subsection{Datos de Fuente Secundaria}

\section{Ensenada}

Tasa de Matricula Bruta Combinada $=\frac{4183}{6517} \times 100=64,19 \%$

Tasa de Sobre edad escolar $=\frac{1028}{2629} \times 100=39,10 \%$

Tasa de Alfabetización $n=\frac{6435}{6517} \times 100=98,74 \%$

Tasa de Analfabetismo $=\frac{82}{6217} \times 100=1,26 \%$ 


\section{Comparación con la región}

\begin{tabular}{|l|r|r|r|r|}
\hline \multicolumn{4}{|c|}{ Tasa de Matriculación Bruta Combinada } \\
\hline \multirow{2}{*}{} & \multicolumn{2}{|c|}{$\mathbf{2 0 1 0}$} & \multicolumn{2}{c|}{$\mathbf{2 0 1 1}$} \\
\cline { 2 - 5 } & \multicolumn{1}{|c|}{ Región } & Ensenada & \multicolumn{1}{c|}{ Región } & Ensenada \\
\hline Cant. de alumnos matriculados & 65.154 & 5.020 & 71.867 & 4.183 \\
\hline Total de población en la edad correspondiente & 84.886 & 6.590 & 82.922 & 6.517 \\
\hline Tasa de Matriculación Bruta Combinada & $\mathbf{7 6 , 7 5 \%}$ & $\mathbf{7 6 , 1 8 \%}$ & $\mathbf{8 6 , 6 7 \%}$ & $\mathbf{6 4 , 1 9 \%}$ \\
\hline
\end{tabular}

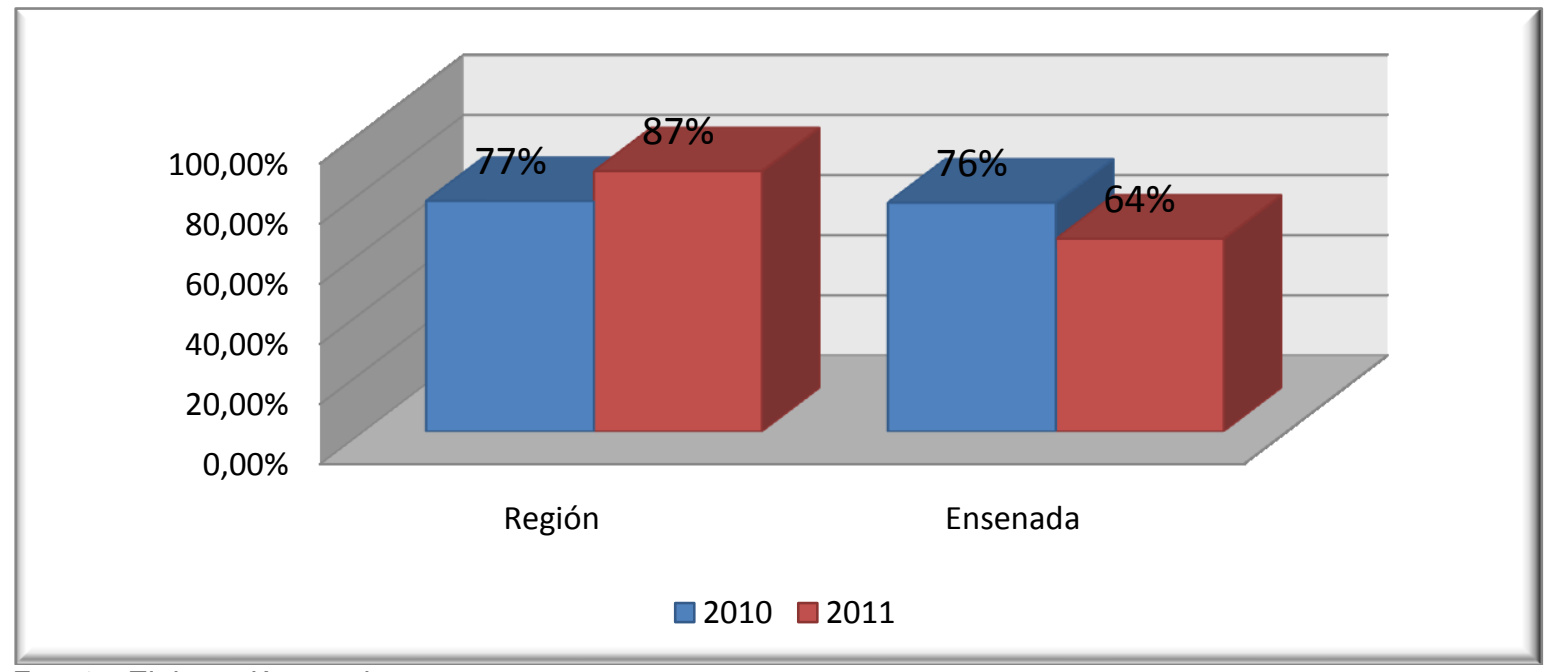

Fuente: Elaboración propia

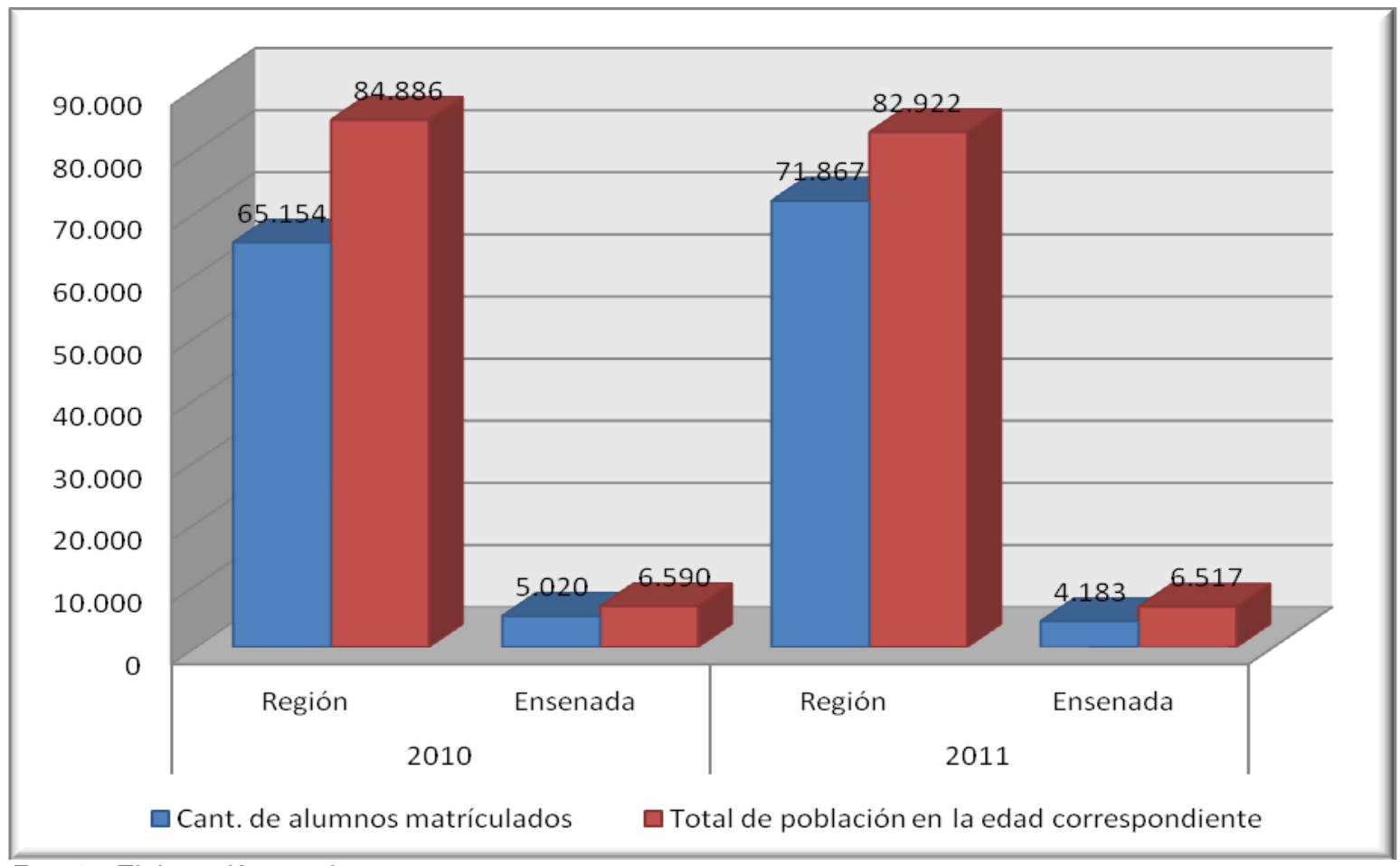

Fuente: Elaboración propia 


\begin{tabular}{|l|r|r|r|r|}
\hline \multicolumn{4}{|c|}{ Tasa de Sobre-edad escolar } \\
\hline & \multicolumn{2}{|c|}{$\mathbf{2 0 1 0}$} & \multicolumn{2}{c|}{2011} \\
\cline { 2 - 5 } & Región & Ensenada & Región & Ensenada \\
\hline $\begin{array}{l}\text { Cant. de alumnos mayores a la edad } \\
\text { correspondiente }\end{array}$ & 18.314 & 1.358 & 13.870 & 1.028 \\
\hline Cant. de matriculados en el curso & 45.876 & 3.638 & 52.934 & 2.629 \\
\hline Tasa de Sobre-edad Escolar & $39,92 \%$ & $\mathbf{3 7 , 3 3 \%}$ & $\mathbf{2 6 , 2 0 \%}$ & $\mathbf{3 9 , 1 0 \%}$ \\
\hline
\end{tabular}

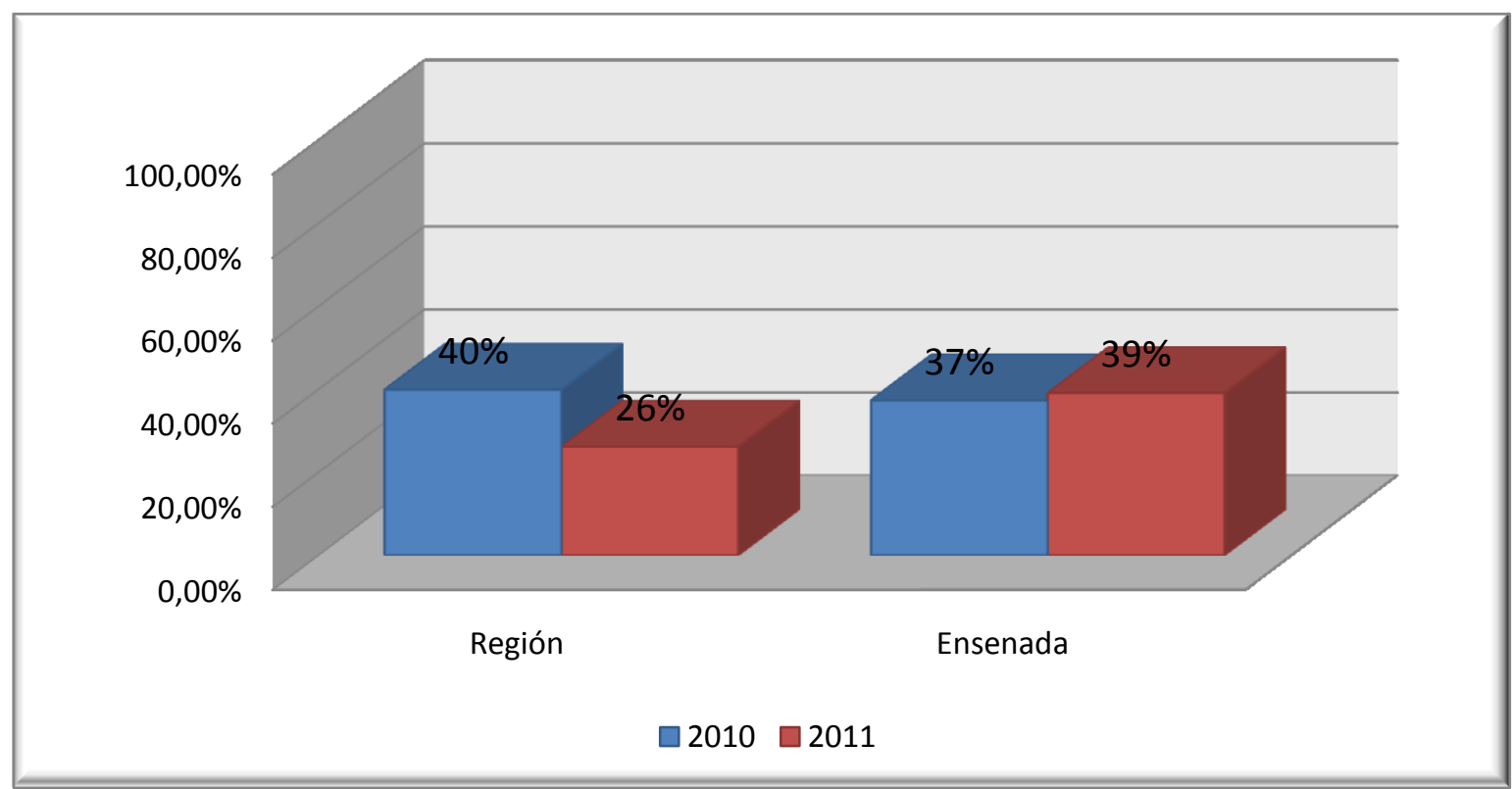

Fuente: Elaboración propia

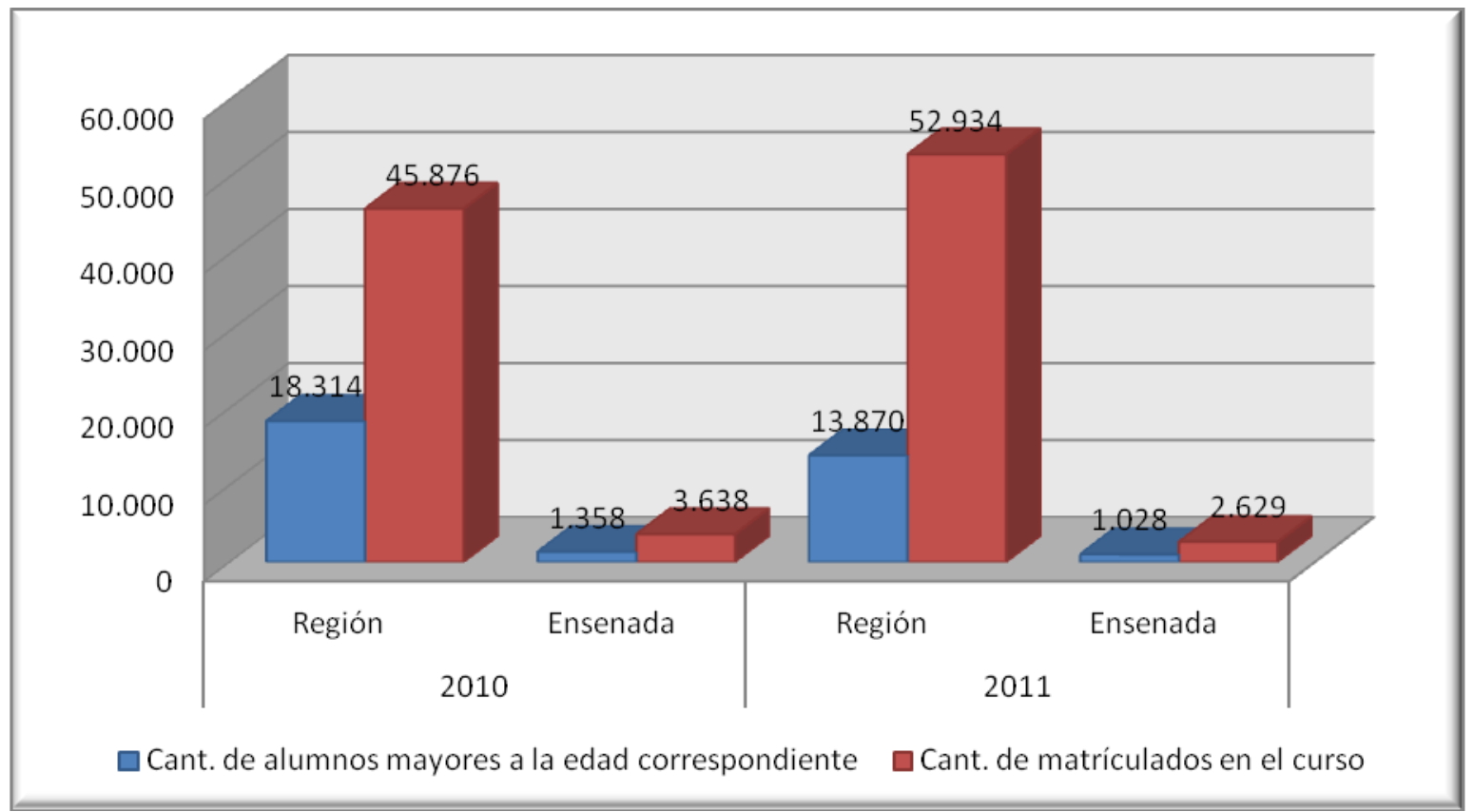

Fuente: Elaboración propia 
Calidad Educativa del Nivel Secundario de Ensenada

\begin{tabular}{|l|r|r|r|r|}
\hline \multicolumn{4}{|c|}{ Tasa de Alfabetización } \\
\hline & \multicolumn{2}{|c|}{$\mathbf{2 0 1 0}$} & \multicolumn{2}{c|}{$\mathbf{2 0 1 1}$} \\
\cline { 2 - 5 } & Región & Ensenada & Región & Ensenada \\
\hline $\begin{array}{l}\text { Cantidad de personas que reportan leer y } \\
\text { escribir }\end{array}$ & 83.856 & 6.505 & 81.923 & 6.435 \\
\hline Total de población en la edad correspondiente & 84.886 & 6.590 & 82.922 & 6.517 \\
\hline Tasa de Alfabetización & $\mathbf{9 8 , 7 9 \%}$ & $\mathbf{9 8 , 7 1 \%}$ & $\mathbf{9 8 , 8 0 \%}$ & $\mathbf{9 8 , 7 4 \%}$ \\
\hline
\end{tabular}

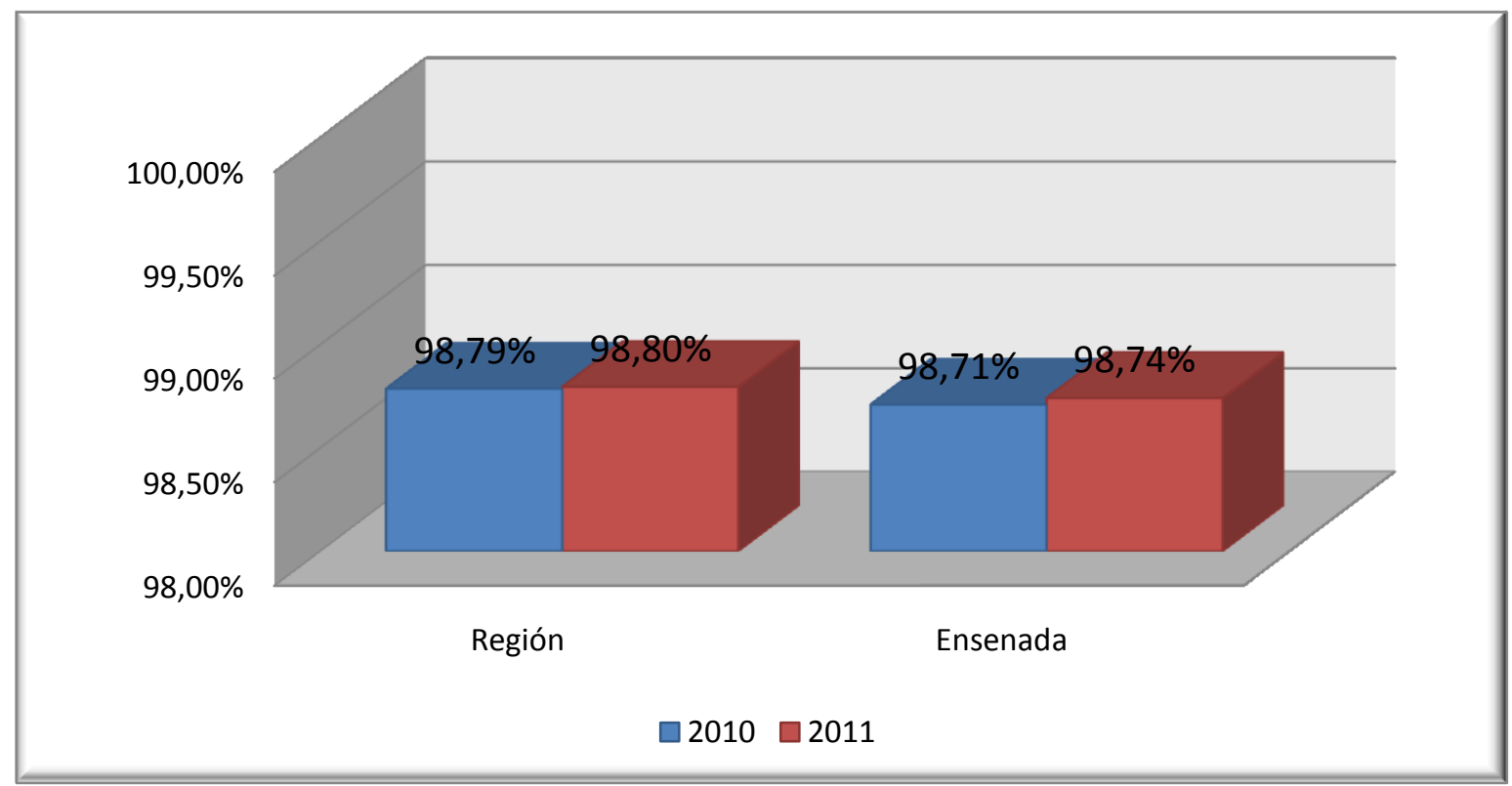

Fuente: Elaboración propia

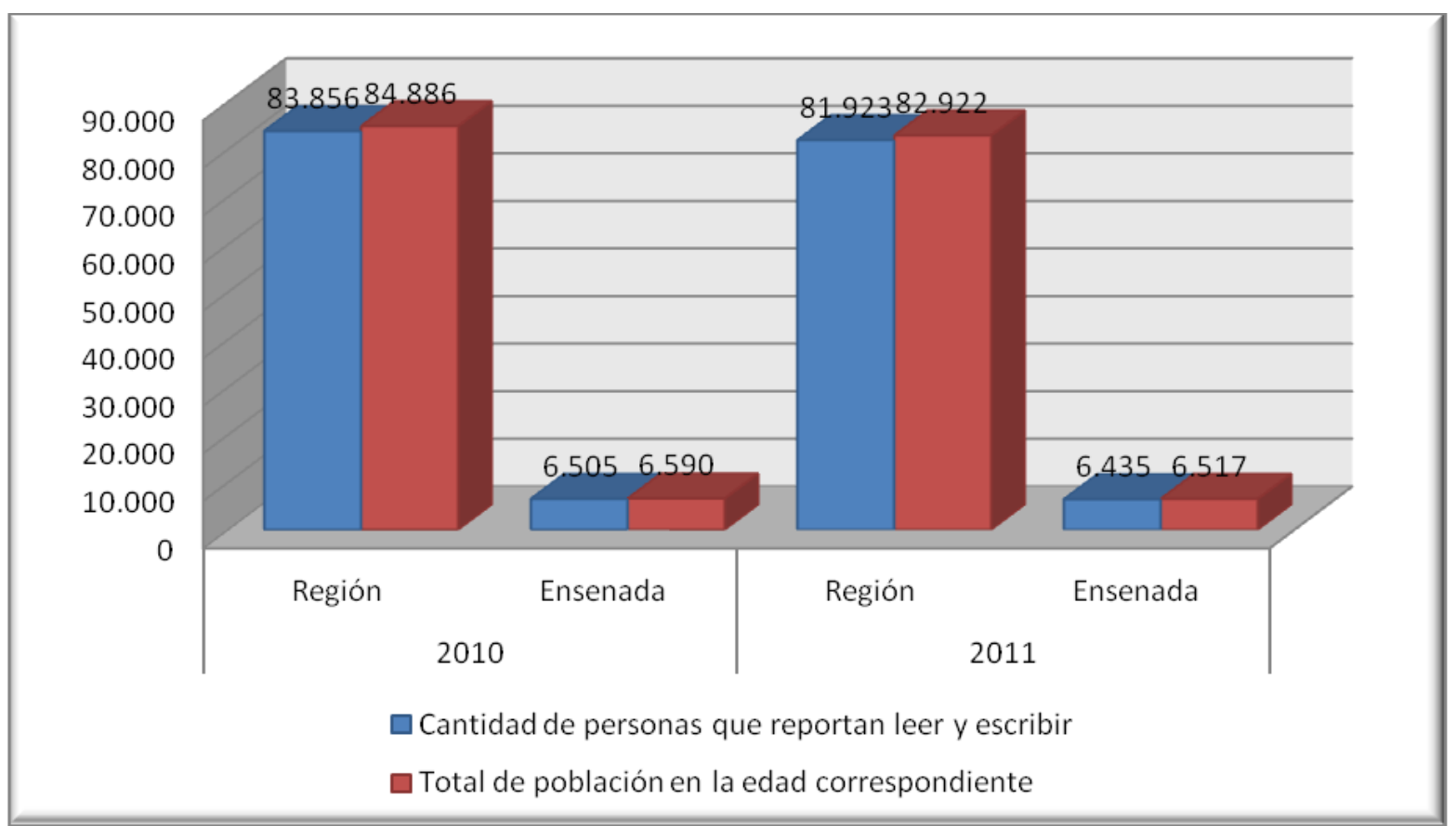

Fuente: Elaboración propia 
Calidad Educativa del Nivel Secundario de Ensenada

\begin{tabular}{|l|r|r|r|r|}
\hline \multicolumn{4}{|c|}{ Tasa de Analfabetismo } \\
\hline & \multicolumn{2}{|c|}{$\mathbf{2 0 1 0}$} & \multicolumn{2}{c|}{$\mathbf{2 0 1 1}$} \\
\cline { 2 - 5 } & Región & Ensenada & Región & Ensenada \\
\hline $\begin{array}{l}\text { Cantidad de personas que reportan no leer, ni } \\
\text { escribir }\end{array}$ & 1.030 & 85 & 999 & 82 \\
\hline Total de población en la edad correspondiente & 84.886 & 6.590 & 82.922 & 6.517 \\
\hline Tasa de Analfabetismo & $\mathbf{1 , 2 1} \%$ & $\mathbf{1 , 2 9} \%$ & $\mathbf{1 , 2 0} \%$ & $\mathbf{1 , 2 6 \%}$ \\
\hline
\end{tabular}

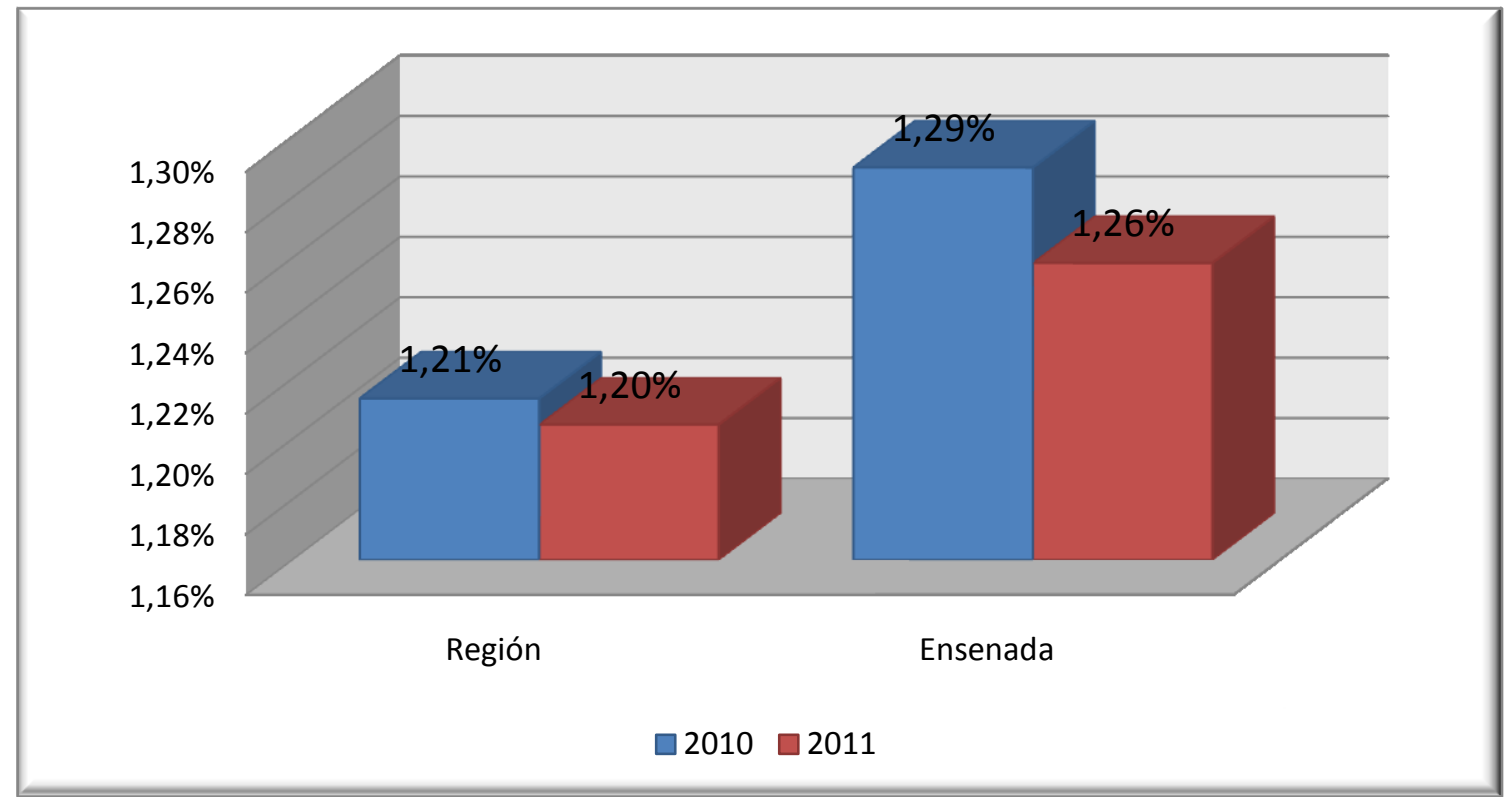

Fuente: Elaboración propia

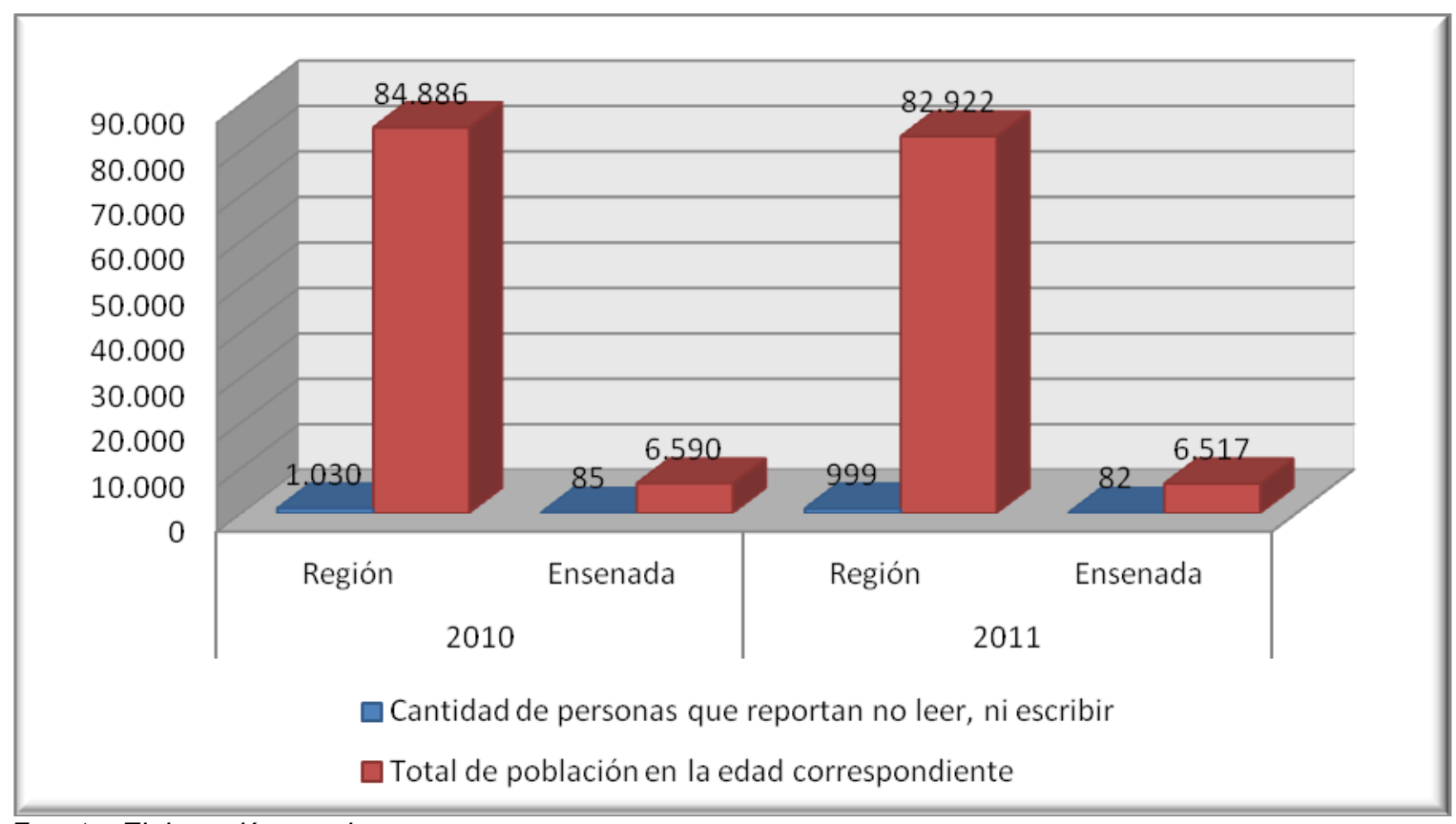

Fuente: Elaboración propia 


\subsection{Datos de Fuente Primaria}

\subsubsection{Docentes}

\section{Área Matemáticas}

En los gráficos se puede observar que, según el panel de expertos compuesto por docentes, en el Área de Matemáticas, la mayoría de los egresados presentan un nivel Bueno (41\%) y Regular (35\%). Solamente el $15 \%$ es Muy bueno, y Excelente 8\%, quedando $\mathrm{Mal}$ con $1 \%$.

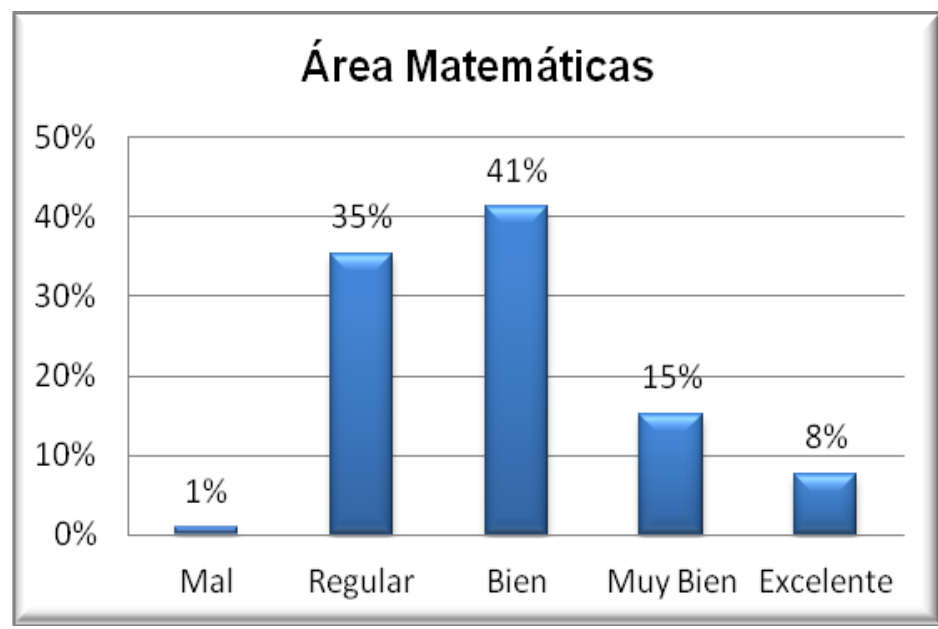

Fuente: Elaboración propia

Los puntos donde obtuvieron mayor puntuación son en: conocimiento acerca de los sistemas monetarios de Argentina, distinguir los distintos tipos de figuras geométricas, y realizar un cálculo de porcentajes simples. En cambio, los puntos más bajos se dan en la capacidad para calcular el volumen de un cuerpo, y en realizar operaciones básicas con fracciones. 


\section{Saldo de respuesta Docentes Área Matemáticas}

1.1.- Cuentas básicas sin uso de tecnología...

1.2.- Cálculos de porcentajes simples...

1.3.- Conversiones con unidades de medidas...

1.4.- Conoce los tipos de triángulos existentes...

1.5.- Distingue los distintos tipos de figuras geométricas...

1.6.- Realiza las operaciones básicas con fracciones...

1.7.- Calcula la superficie de un objeto ...

1.8.- Calcula el volumen de un cuerpo...

1.9.- Conoce los sistemas monetarios utilizados en Argentina ...

1.10.- Noción sobre patrones de medida...

1.11.- Conoce y comprende los distintos tipos de gráficos...

1.12.- Comprende datos estadísticos...

1.13.- Realiza un cálculo financiero elemental...

$\begin{array}{lllllllllll}0 & 0,5 & 1 & 1,5 & 2 & 2,5 & 3 & 3,5 & 4 & 4,5 & 5\end{array}$

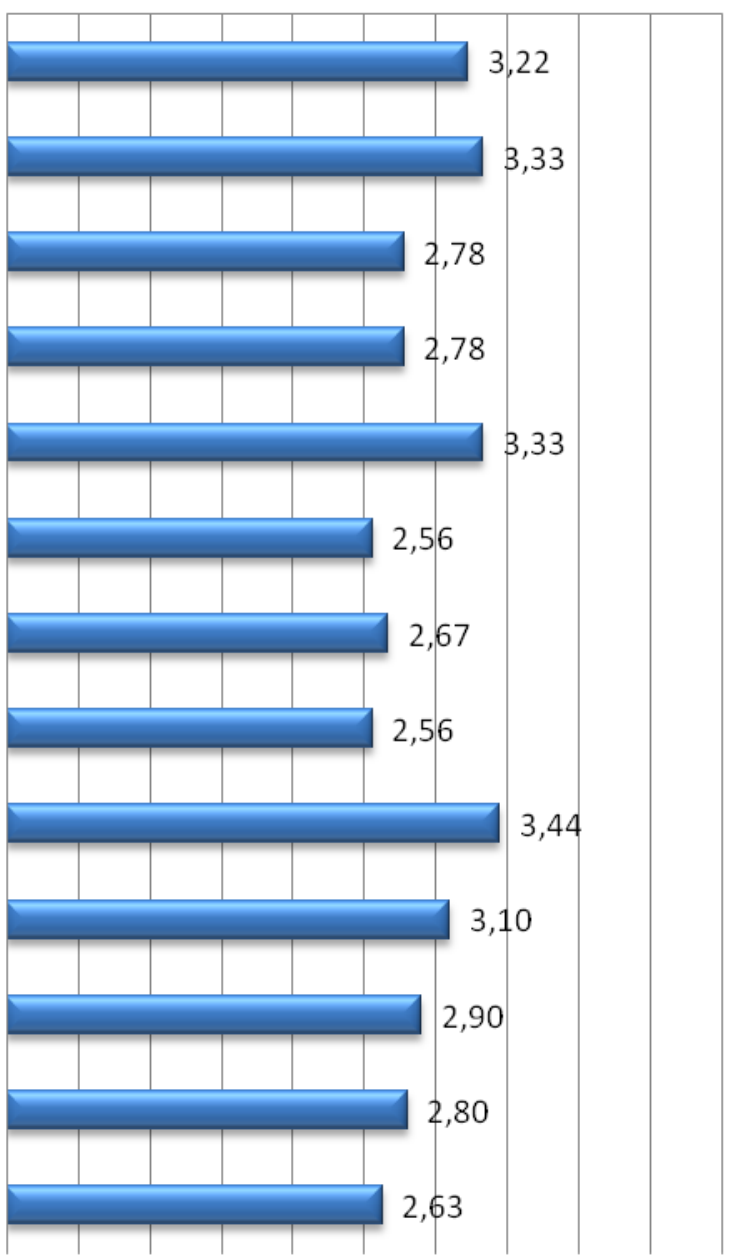

Fuente: Elaboración propia 
Área Lengua

En el Área Lengua, los resultados son similares a Matemáticas, debido a que la mayor cantidad de respuestas se encuentran en Bien (45\%) y Regular (43\%). Muy bien esta representado por el $8 \%$, mal $2 \%$ y Excelente $1 \%$.

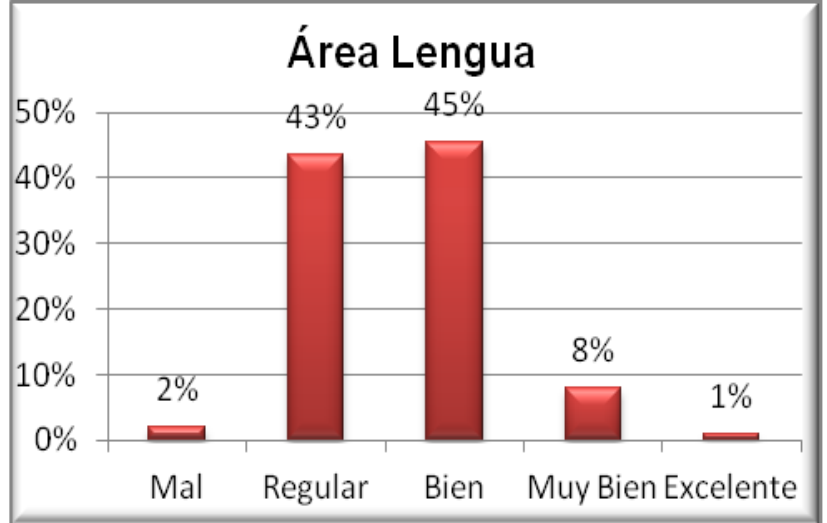

Fuente: Elaboración propia

Según los docentes, el punto donde más se destacan los egresados, es en la comprensión de los textos, con un saldo de respuesta de 3,30 (equivalente a un "Bien +"), seguido de la capacidad de resumir un texto y exponer una idea de forma oral, con un 2,90 ("Bien -“) . El punto con respuesta más baja, por gran diferencia con los demás, fue la ortografía que presentan, con 1,90 ("Regular -").

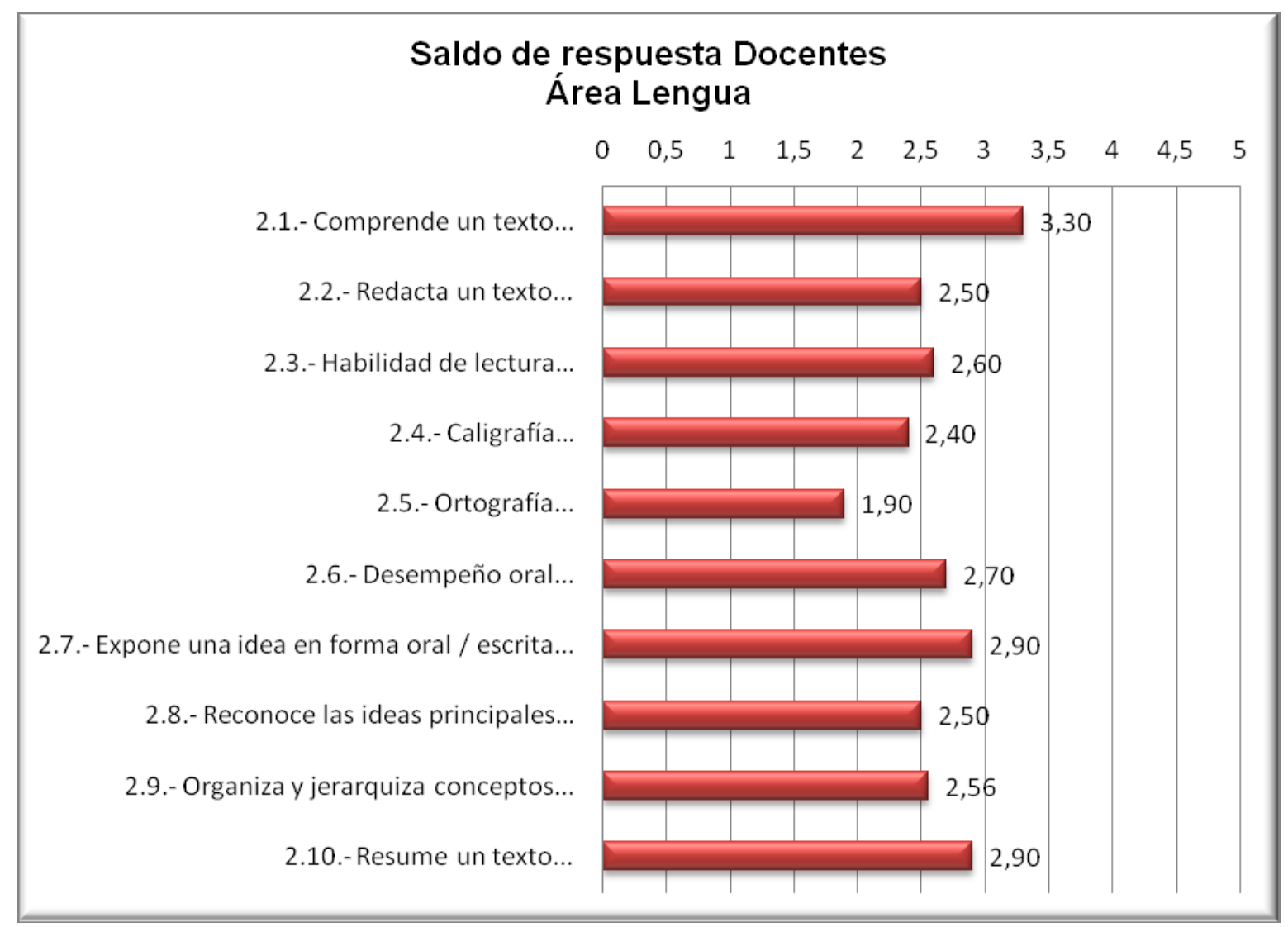

Fuente: Elaboración propia 


\section{Área Ciencias}

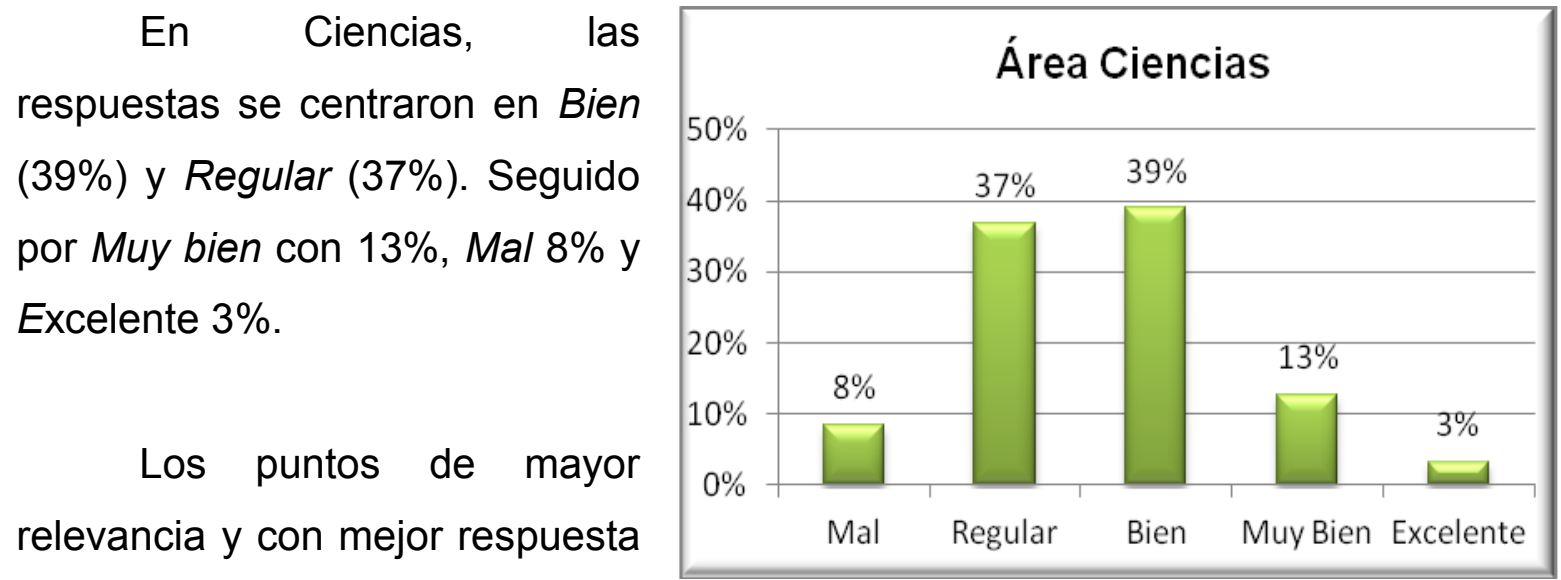

son los relacionados con la Fuente: Elaboración propia

informática, el uso de Internet para la realización de búsqueda de información y el uso de los programas básicos de computación. A diferencia de esto, los temas de menor conocimiento son acerca de los primeros auxilios y la tasa de mortalidad de Argentina.

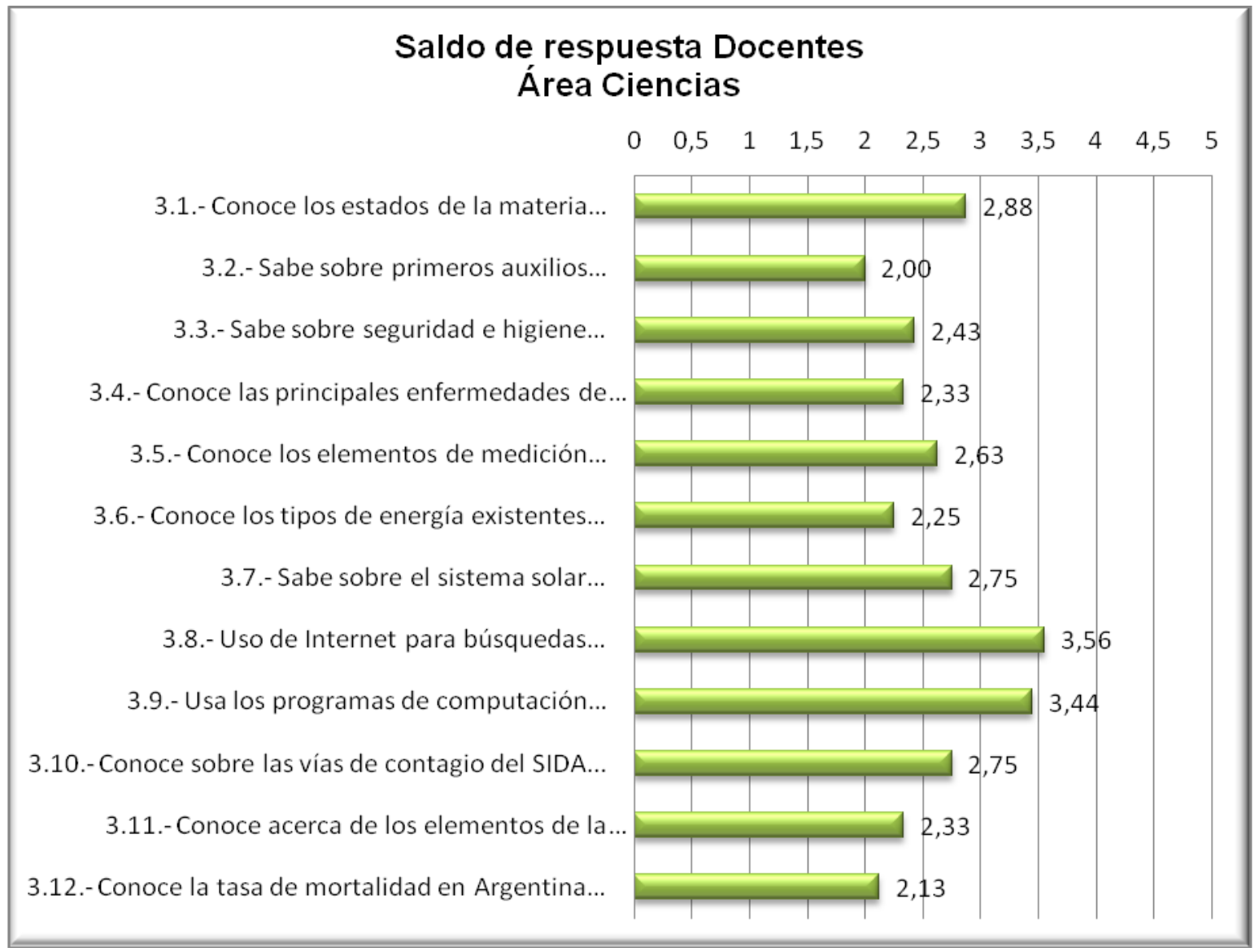

Fuente: Elaboración propia 


\section{Aptitudes Personales}

En la evaluación de las aptitudes que presentan los egresados, se puede observar que un gran porcentaje de las respuestas son Buenas (49\%). Luego, las respuestas son Muy buenas (25\%), Regular (14\%), Excelente (8\%), y por último Mal (2\%).

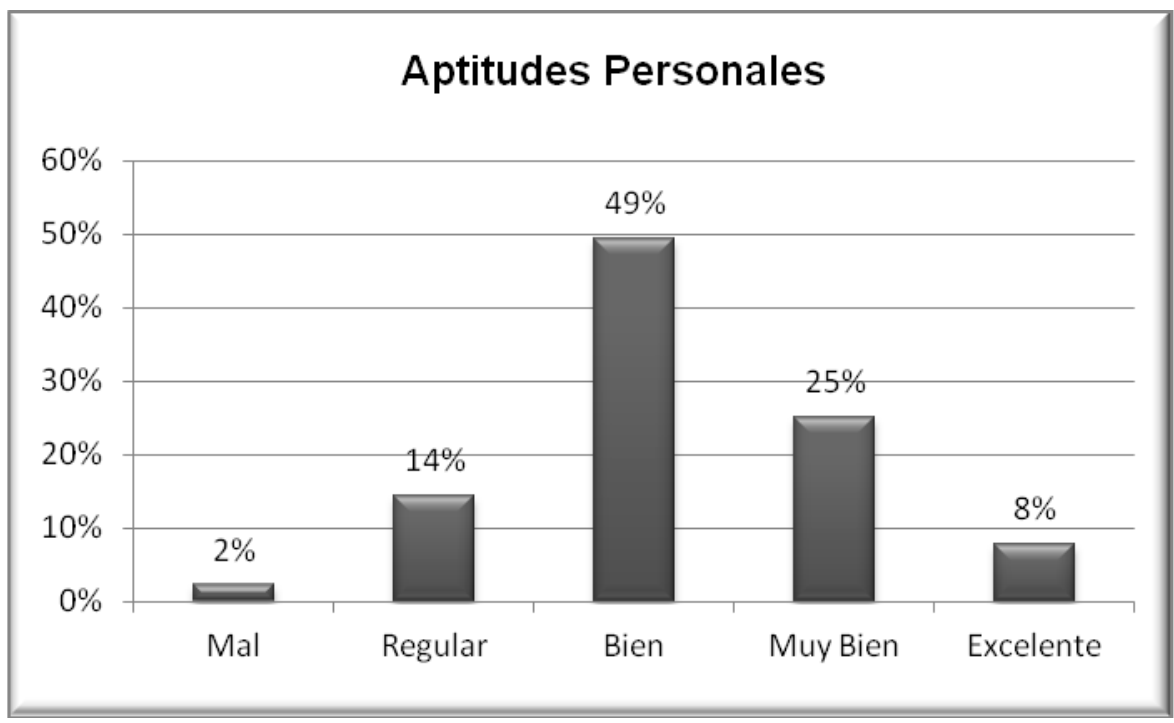

Fuente: Elaboración propia

Las mejores puntuaciones se dan en varios puntos, como son el interés para trabajar en equipo, el compañerismo y el respeto. El punto más bajo es la puntualidad de los egresados. 


\section{Saldo de respuesta Docentes Aptitudes Personales}

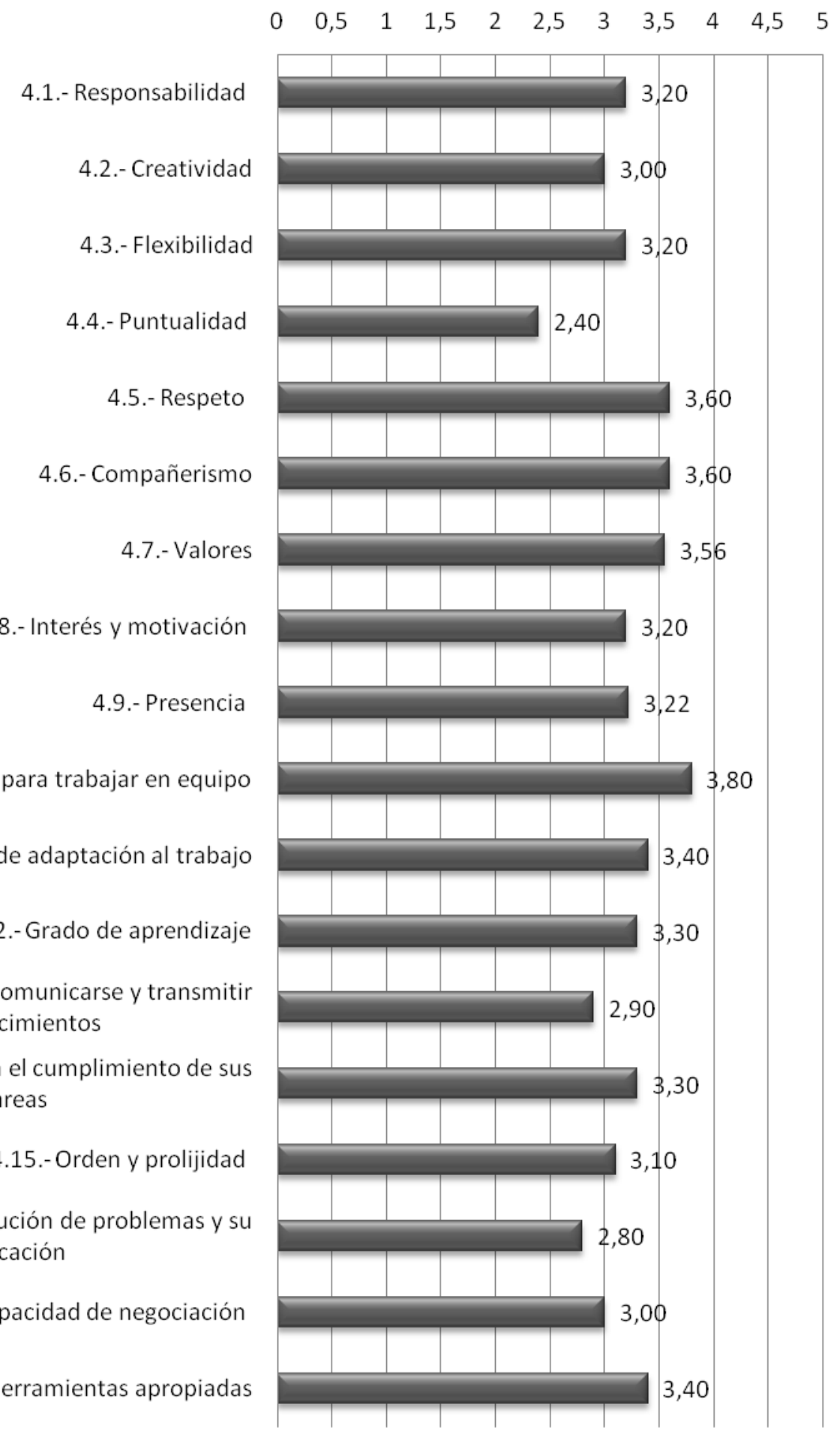

Fuente: Elaboración propia 


\section{Calificación Global de Docentes}

En la calificación global del panel de expertos compuesto por docentes, es posible apreciar los resultados totales, es decir la sumatoria de todas las áreas evaluadas.

En los gráficos se aprecia que la respuesta con mayor porcentaje es Bien (45\%), seguido por Regular (30\%), Muy bien (17\%), Excelente (5\%) y Mal (3\%)

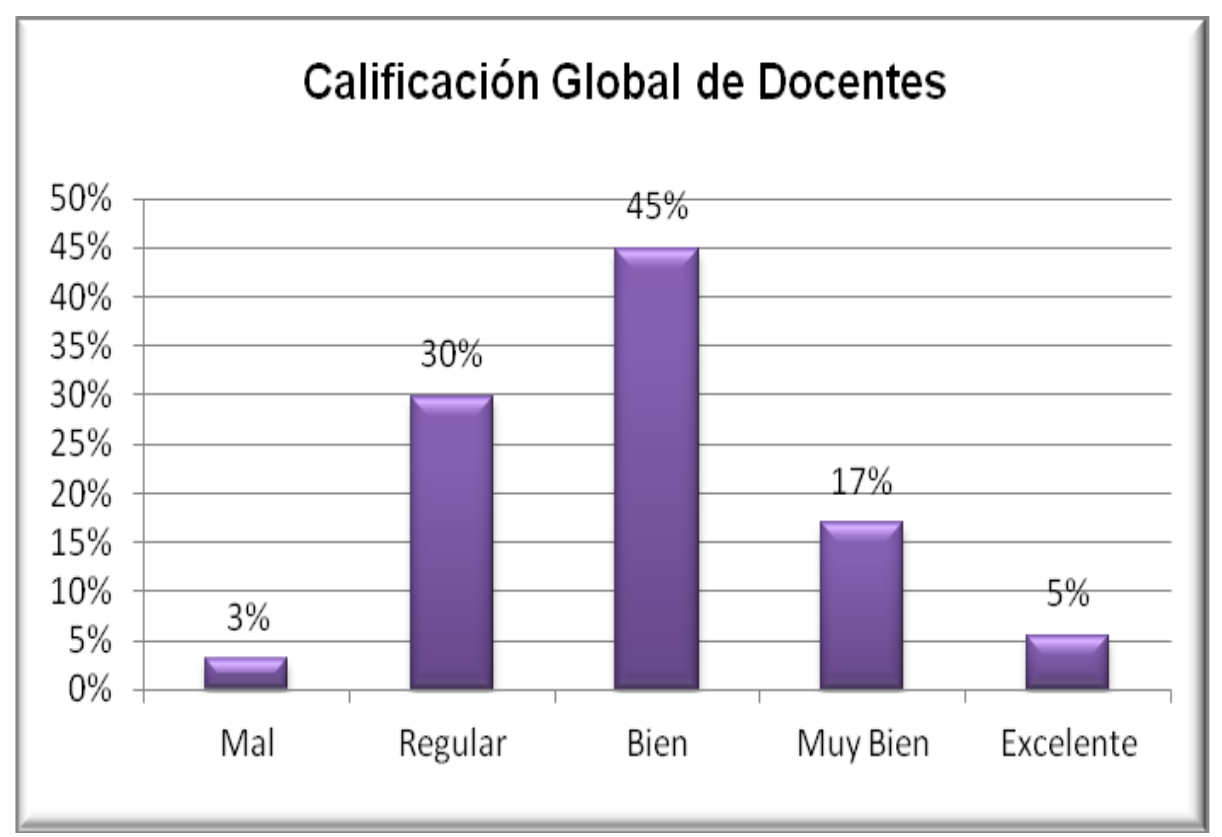

Fuente: Elaboración propia

En el área que los egresados presentaron mejores resultados fue en las aptitudes personales, con un saldo de respuesta de 3,22 ("Bien +"), seguido por Matemáticas, con 2,93 (“Bien -"), y por último Ciencias 2,65 (“Bien -”) y Lengua 2,63 ("Bien -"), sin haber mucha diferencia entre estas dos últimas. 


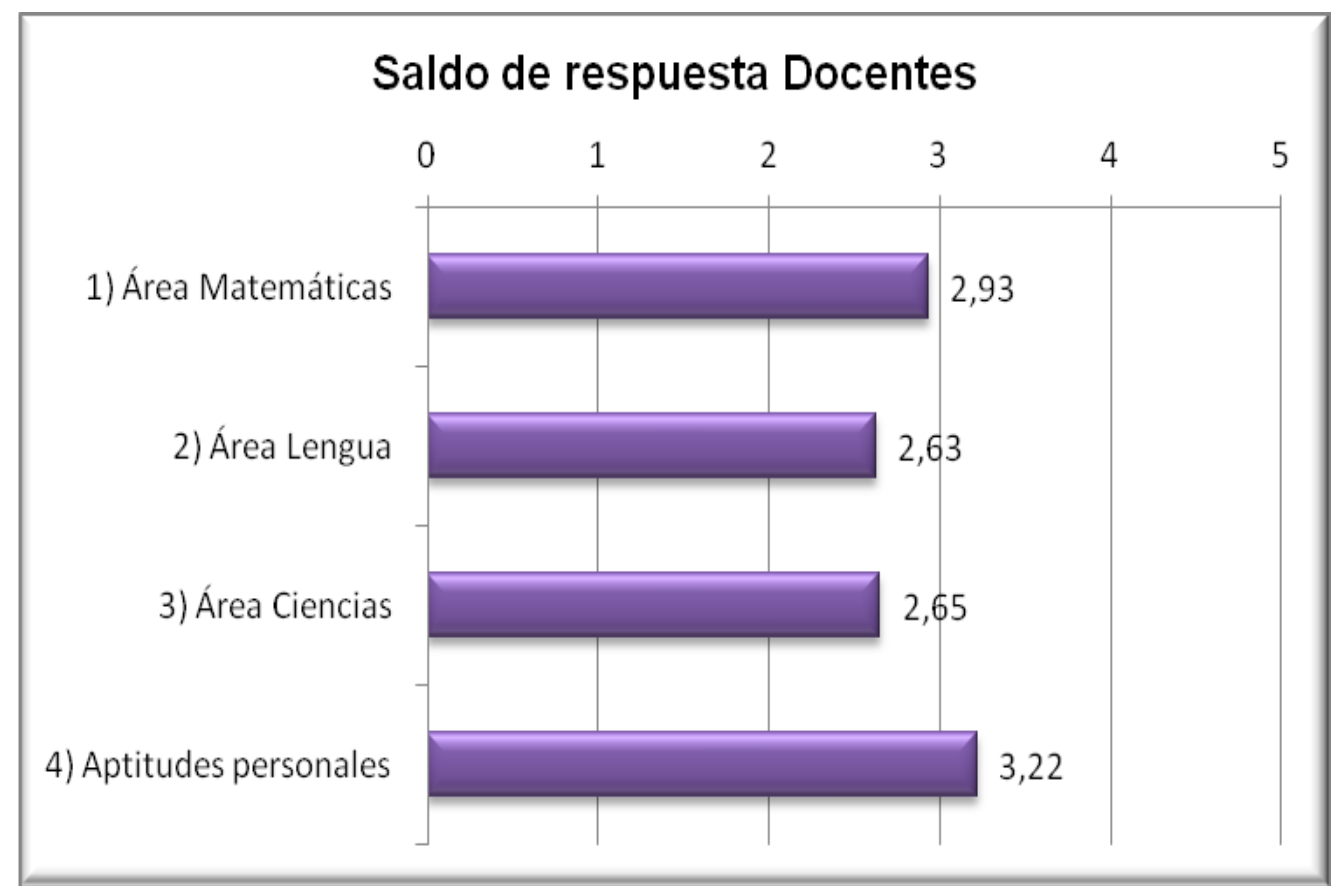

Fuente: Elaboración propia 


\subsubsection{Empresarios}

\section{Área Matemáticas}

El panel de expertos
compuesto por empresarios,
opinó que en el área de
Matemáticas los egresados,
en su mayoría, presentan un
nivel Regular (41\%). Luego,
en menor porcentaje, los
conocimientos son Buenos
(36\%), Malos (18\%), Muy
buenos (5\%).

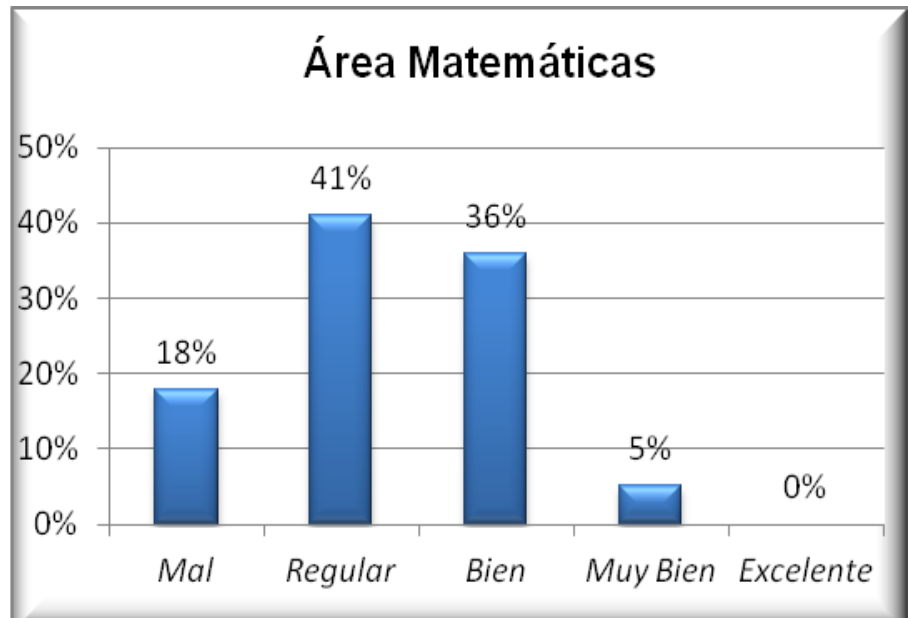

Los puntos más sobresalientes en esta área, son acerca del conocimiento que presentan acerca de los sistemas monetarios de Argentina, y la comprensión de los distintos tipos de gráficos. En cambio, la respuesta con menor puntaje es la realización de cálculos de porcentajes.

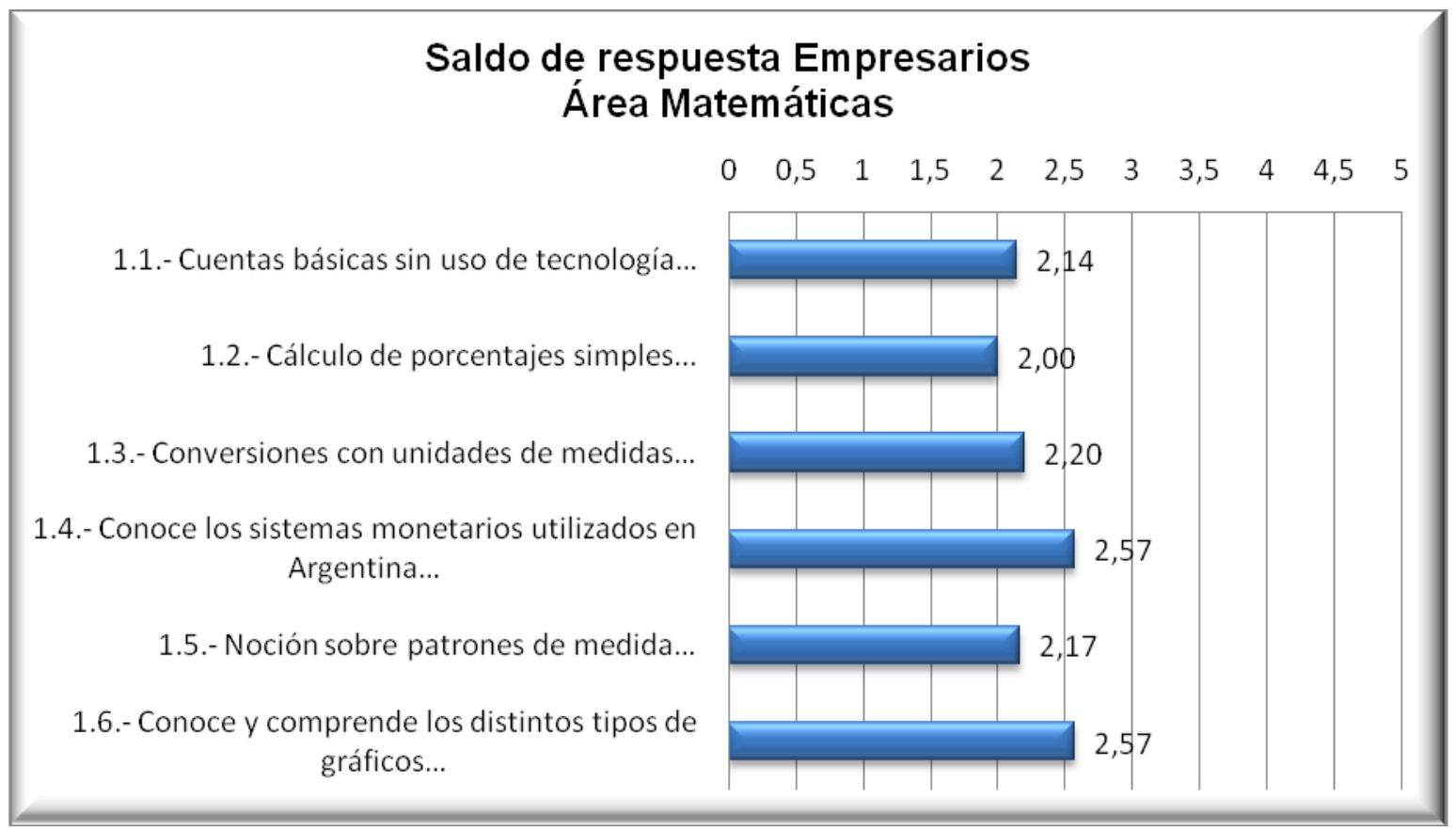

Fuente: Elaboración propia 
Área Lengua

En esta área, al igual que la anterior, la mayor parte de las respuestas fueron Regular (39\%), y Bien (35\%). Seguido por un nivel Mal (19\%), Muy bien (7\%) y por último Excelente (0\%).

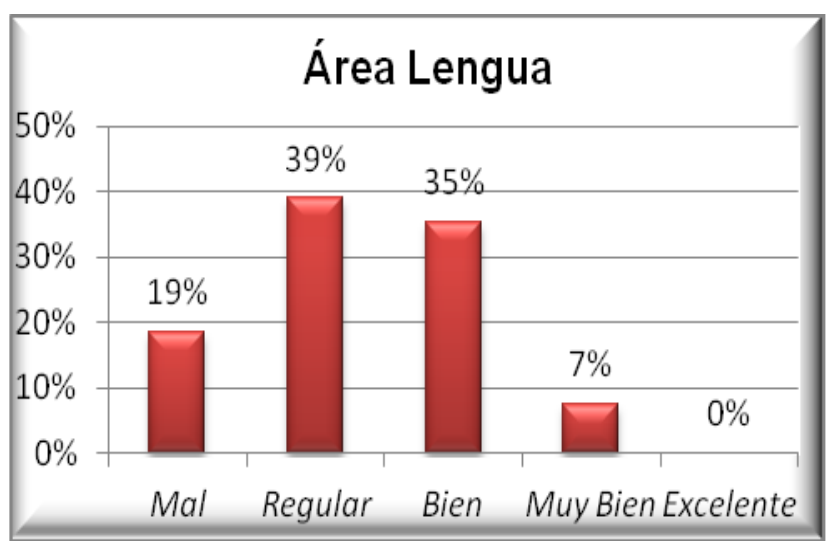

Fuente: Elaboración propia

Según los empresarios, en el área de Lengua, los egresados se desempeñan mejor en la comprensión de textos, y la expresión oral. Por otro lado, en cambio, el punto donde presentan más problemas es en la ortografía.

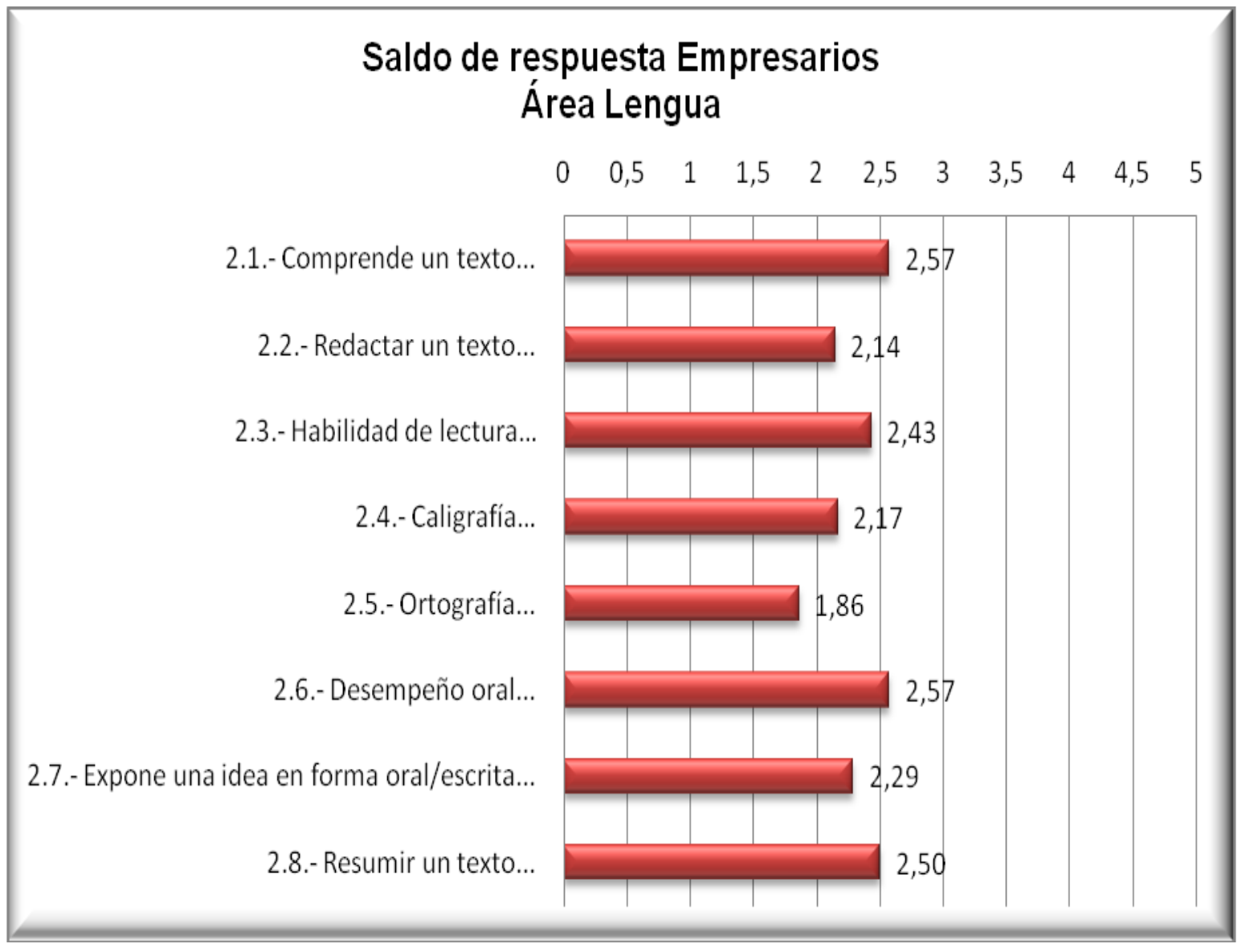

Fuente: Elaboración propia 


\section{Área Ciencias}

En este caso, las
respuestas indican que los egresados presentan un nivel Regular (37\%) y Bien (29\%), en gran medida. Con un porcentaje menor, pero no con mucha diferencia, los resultados fueron Malos (21\%). Por último, se encuentra la respuesta Muy bien $(13 \%)$.

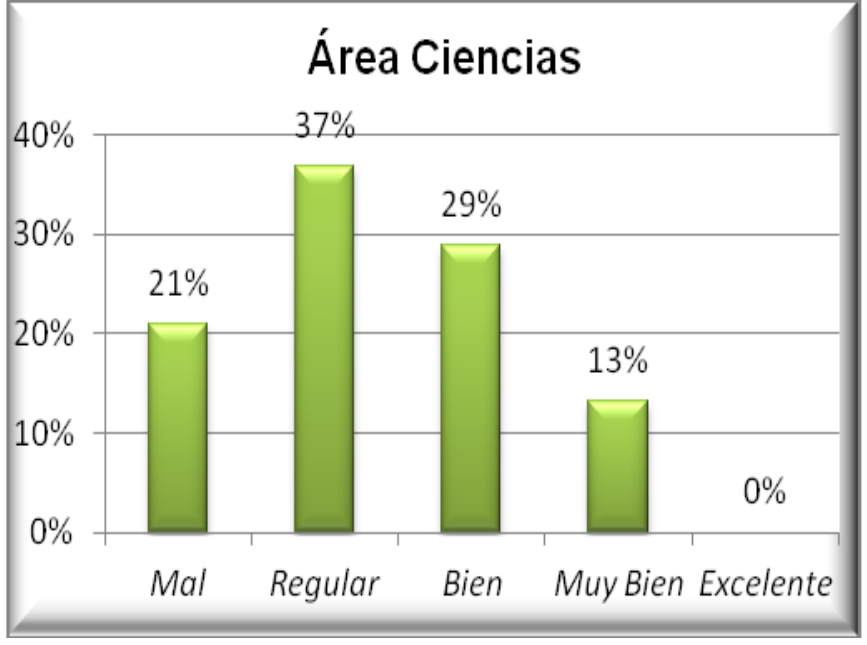

Fuente: Elaboración propia

En el gráfico de abajo, se puede observar que los egresados se desempeñan bien en informática, debido a que los puntos con mayor puntaje fueron el uso de Internet para búsqueda de información relevante $(2,86)$ y el uso de los principales programas de computación $(2,71)$. En cambio, la respuesta con menos puntaje fue acerca del conocimiento que presentan sobre primeros auxilios.

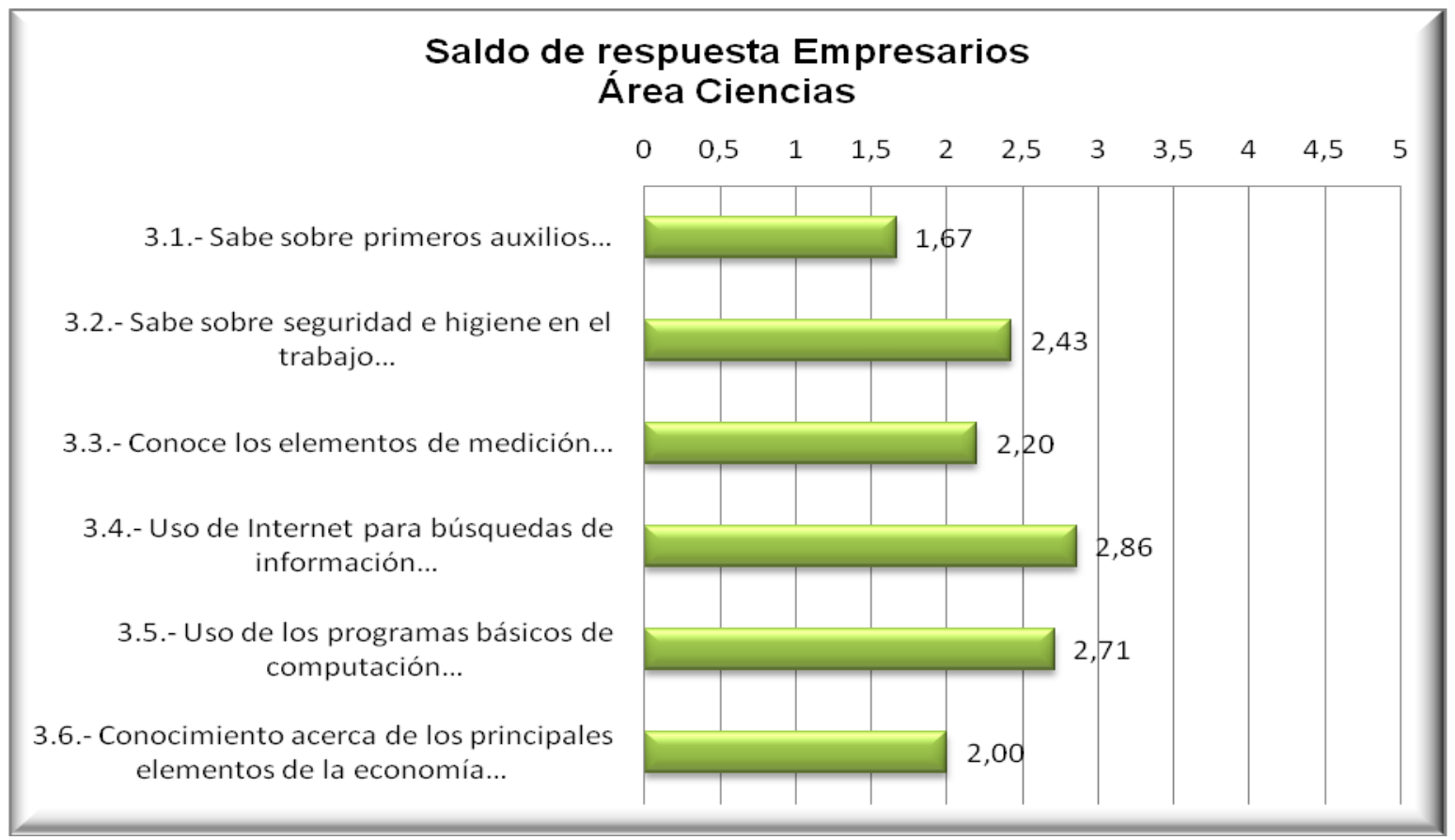

Fuente: Elaboración propia 


\section{Aptitudes Personales}

En las aptitudes presentadas por los egresados, se observa que según los empresarios, éstas son Buenas (37\%). En menor porcentaje, la opinión es Regular (27\%), Muy bien (19\%), Mal (12\%) y por último Excelente (4\%).

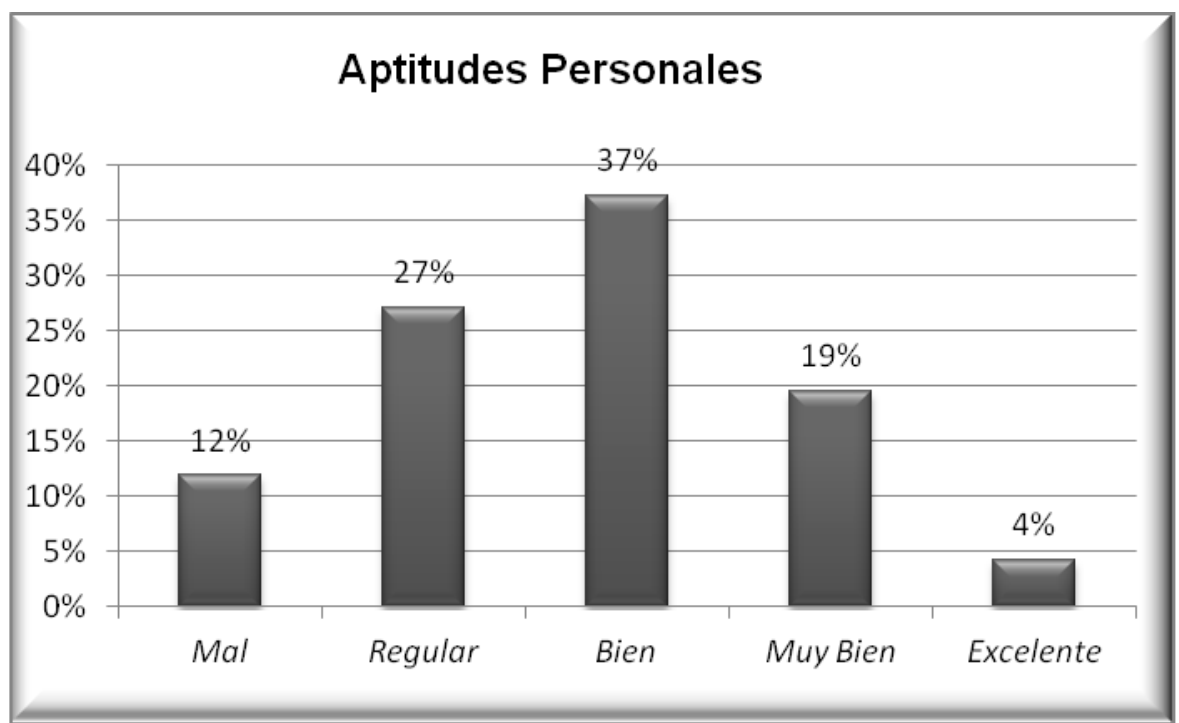

Fuente: Elaboración propia

En el gráfico del saldo de respuesta se observa que el punto más destacado es la Creatividad presentada por los egresados 3,50 ("Bien +"), seguido por el Compañerismo 3,17 (“Bien”) y Valores 3,14 (“Bien”). Y los puntos con menor puntaje son Puntualidad y Respeto 2,29 ("Regular"). 


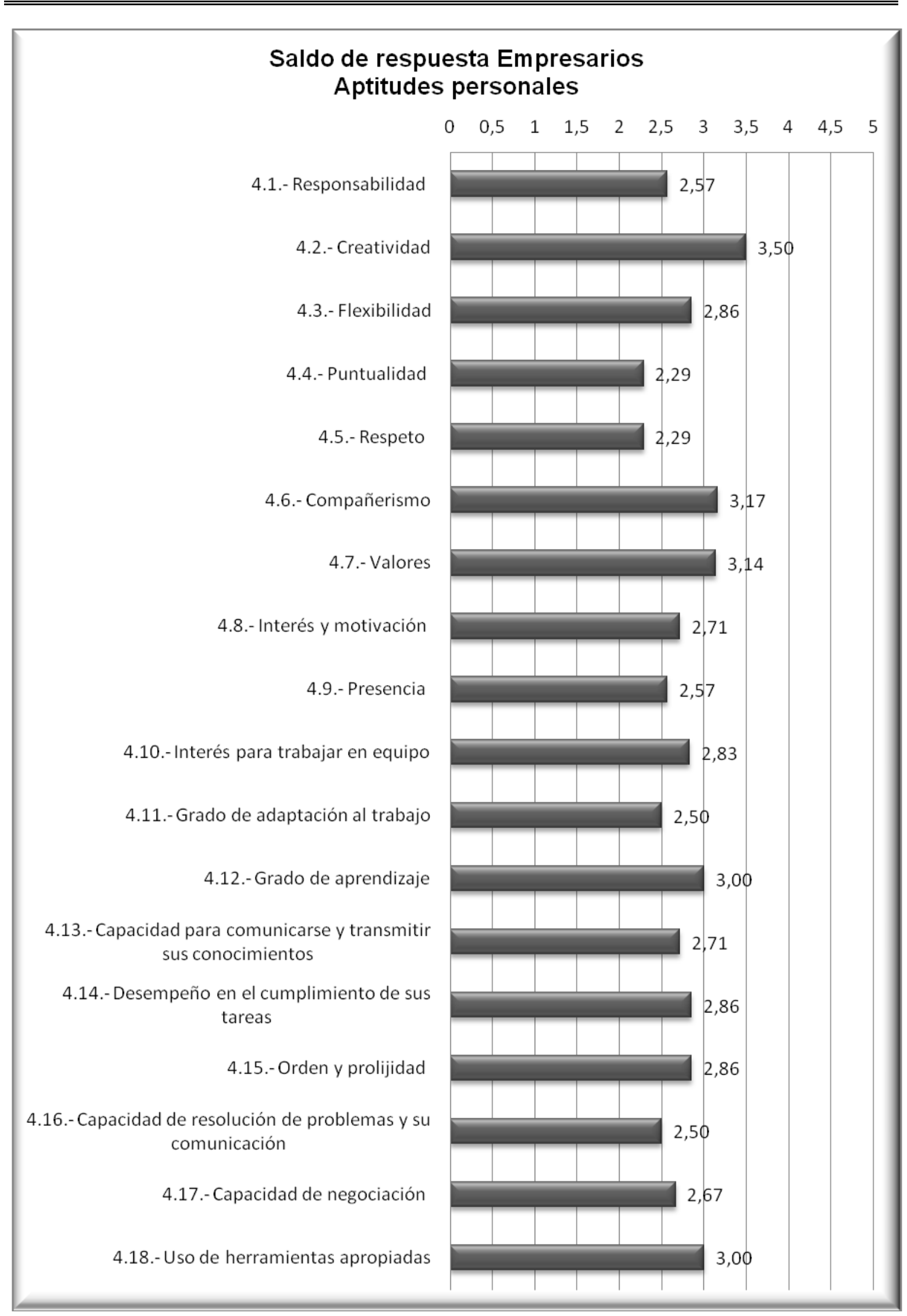

Fuente: Elaboración propia 


\section{Calificación Global de Empresarios}

En el gráfico que representa la calificación global del panel de expertos de empresarios, es decir, aquel que reune los resultados de todas las áreas, se puede observar que el nivel que presentan los egresados en Bueno (35\%) o Regular (33\%). Luego, según el porcentaje, continúa Mal (16\%), Muy bien (14\%) y por último, con muy poco porcentaje, se encuentra Excelente (2\%).

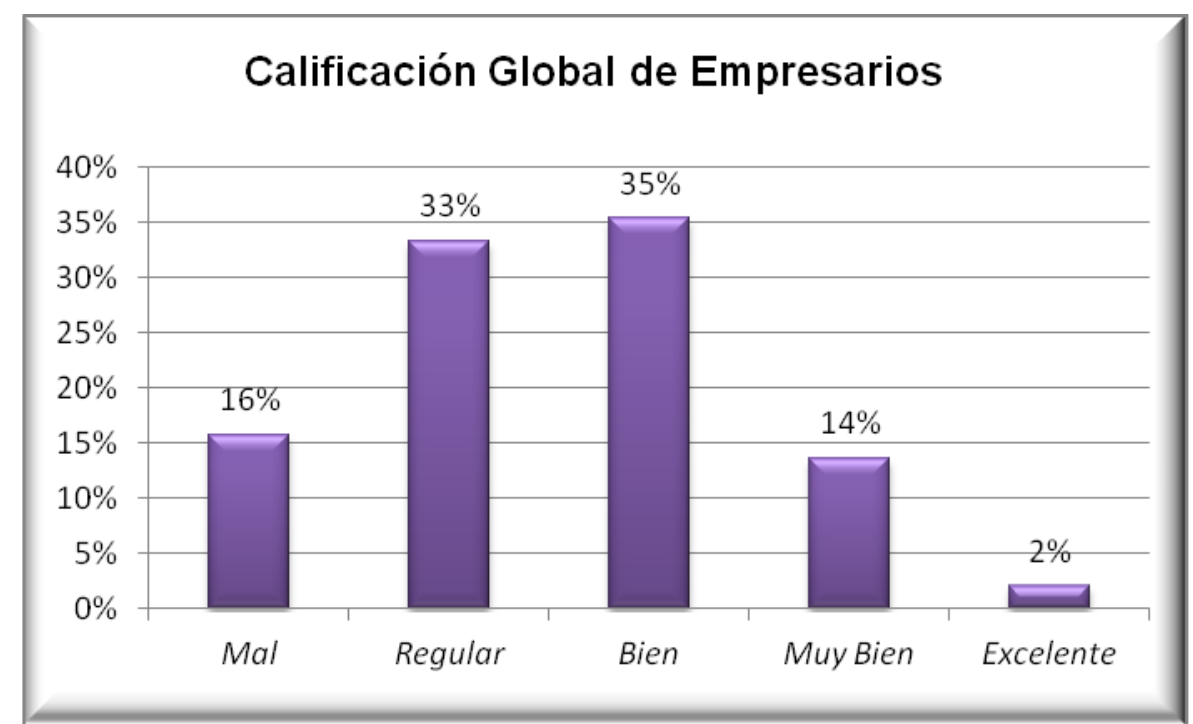

Fuente: Elaboración propia

Por otro lado, se puede observar en el gráfico de Saldo de respuesta, que el área donde los egresados obtuvieron una mejor puntuación es en Aptitudes Personales 2,77 ("Bien -"), quedando por debajo las demás áreas, y con similar saldo de respuesta. Área Ciencias 2,34 ("Regular +"), Área Lengua 2,31 (“Regular +") y por último Área Matemáticas 2,28 ("Regular +"). 
Calidad Educativa del Nivel Secundario de Ensenada

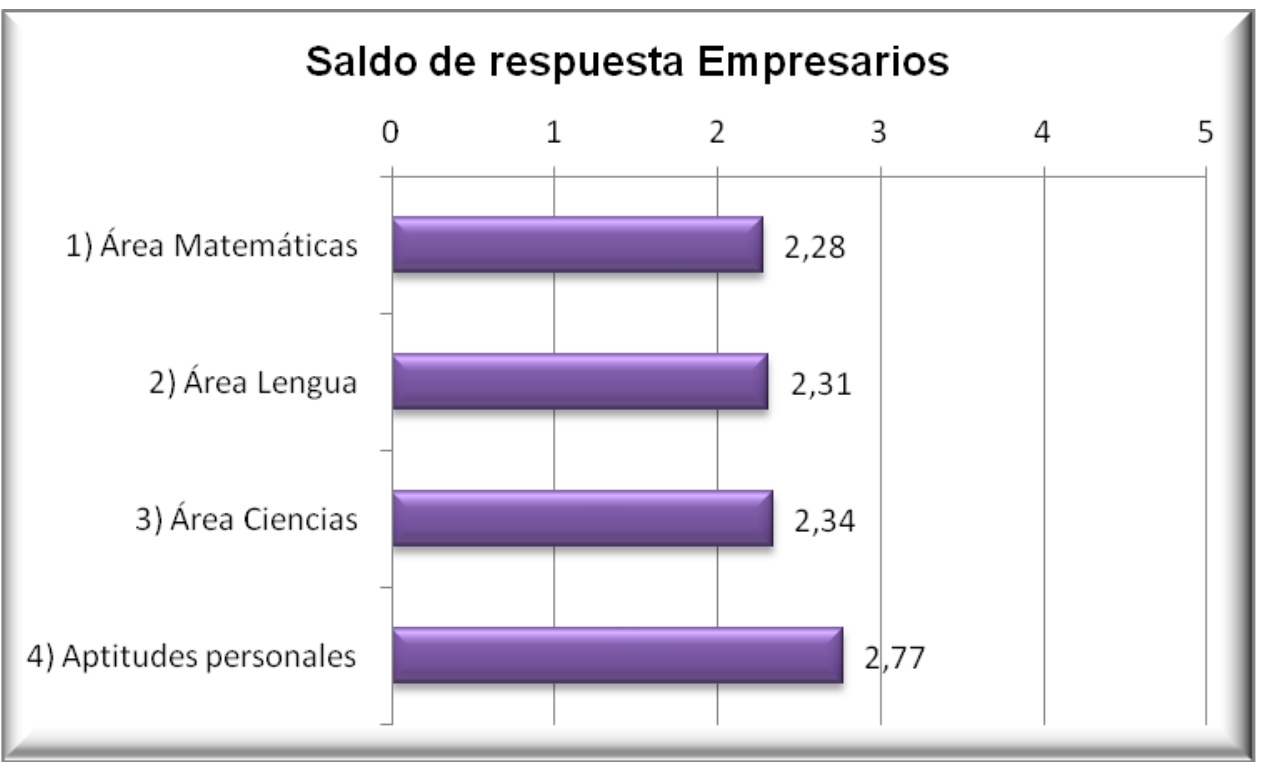

Fuente: Elaboración propia 


\subsubsection{Total Global}

El Total Global hace referencia a la sumatoria de los resultados de ambos paneles de expertos, docentes y empresarios. En este punto, se aprecia que en líneas generales el nivel de educación de los egresados del secundario es Bueno (42\%), con inclinación a Regular (31\%). Con menor porcentaje se encuentran

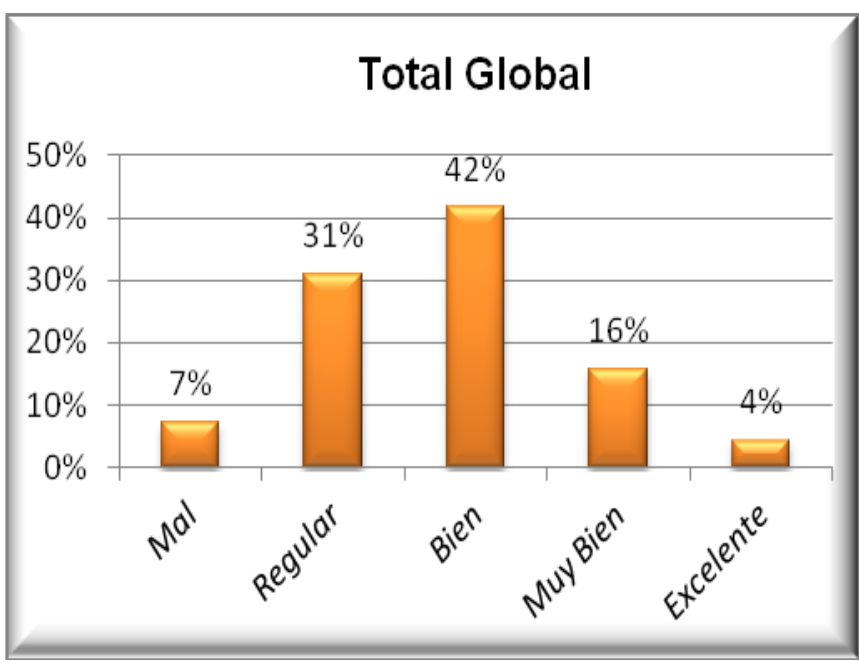

Fuente: Elaboración propia las otras opciones, como son muy Bien (16\%), Mal (7\%), y Excelente (4\%).

Ambos paneles de expertos presentan resultados similares acerca de la educación, ya que tanto los docentes como los empresarios opinan que el nivel de educación es Buena, con inclinación a Regular. El saldo de respuesta de los empresarios de 2,53 es menor al de los docentes de 2,92.

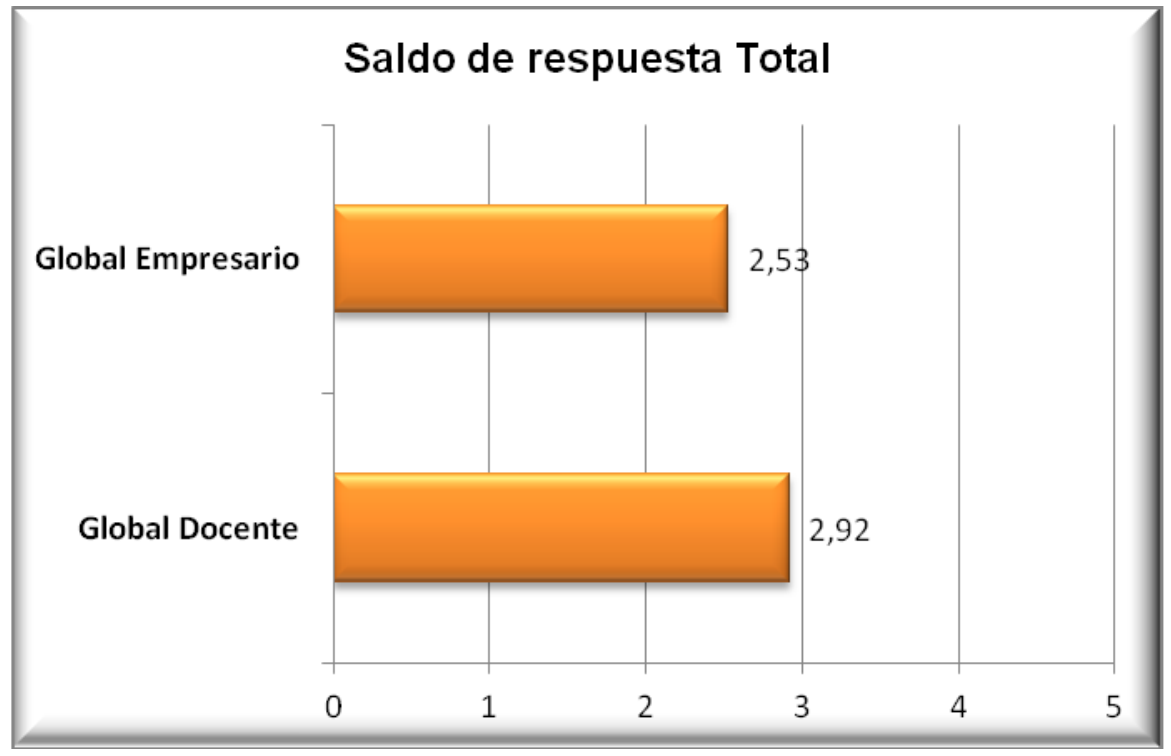

Fuente: Elaboración propia 


\subsubsection{Comparación respuestas de Docentes y Empresarios}

En esta comparación, se puede ver a simple vista que en todas las áreas, el panel de expertos compuesto por docentes tiene una opinión más positiva acerca de los conocimientos de los egresados del secundario.

\section{Área Matemáticas}

En el área de Matemáticas el punto que presenta mayor diferencia entre las respuesta de ambos paneles es en la realización de cálculos de porcentaje simple, y el punto donde están más parejas las respuestas es en la pregunta acerca del conocimiento y comprensión de los distintos tipos de gráficos.

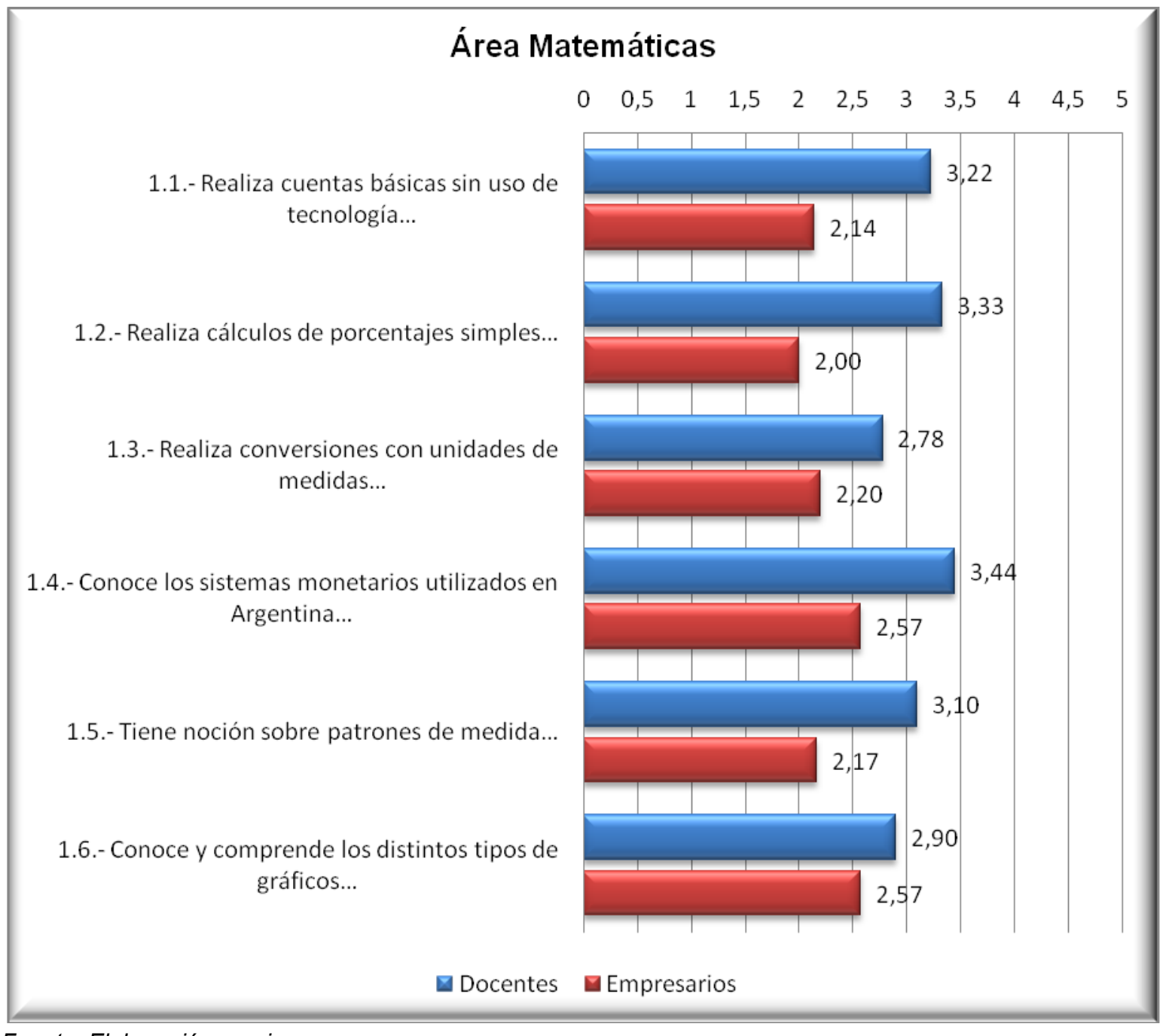

Fuente: Elaboración propia 
Área Lengua

En Lengua también se da que todos los resultados de los docentes son mejores que los de los empresarios. El punto que presenta una mayor diferencia es el de la capacidad para comprender un texto. $Y$ el punto donde presentan opiniones similares es acerca de la mala ortografía que tienen los egresados.

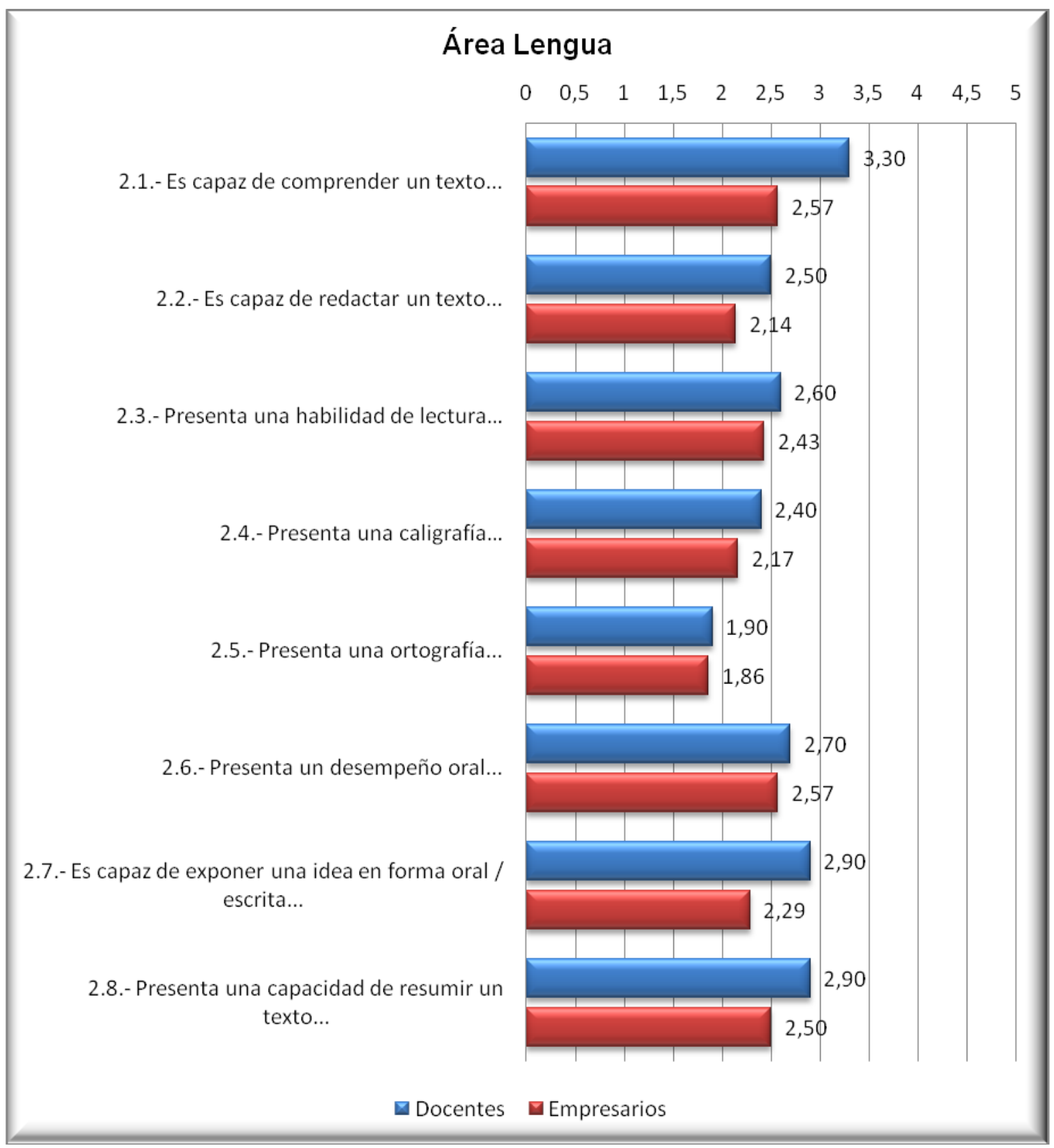

Fuente: Elaboración propia 


\section{$\underline{\text { Área Ciencias }}$}

En ésta área, si bien todas las respuestas los docentes presentan un saldo de respuesta mayor que los empresarios, hay un caso en el que se da el mismo resultado, es en el punto acerca de los conocimientos sobre seguridad e higiene en el trabajo.

Los puntos donde hay mayor diferencia son en los relacionados con informática, ya que hay discrepancia acerca del conocimiento que presentan los egresados sobre el uso de Internet para la búsqueda de información, y el uso de los programas básicos de computación. A su vez, tanto para el panel de expertos de docentes como para el de empresarios, son justamente estos puntos los que presentan mayor puntaje.

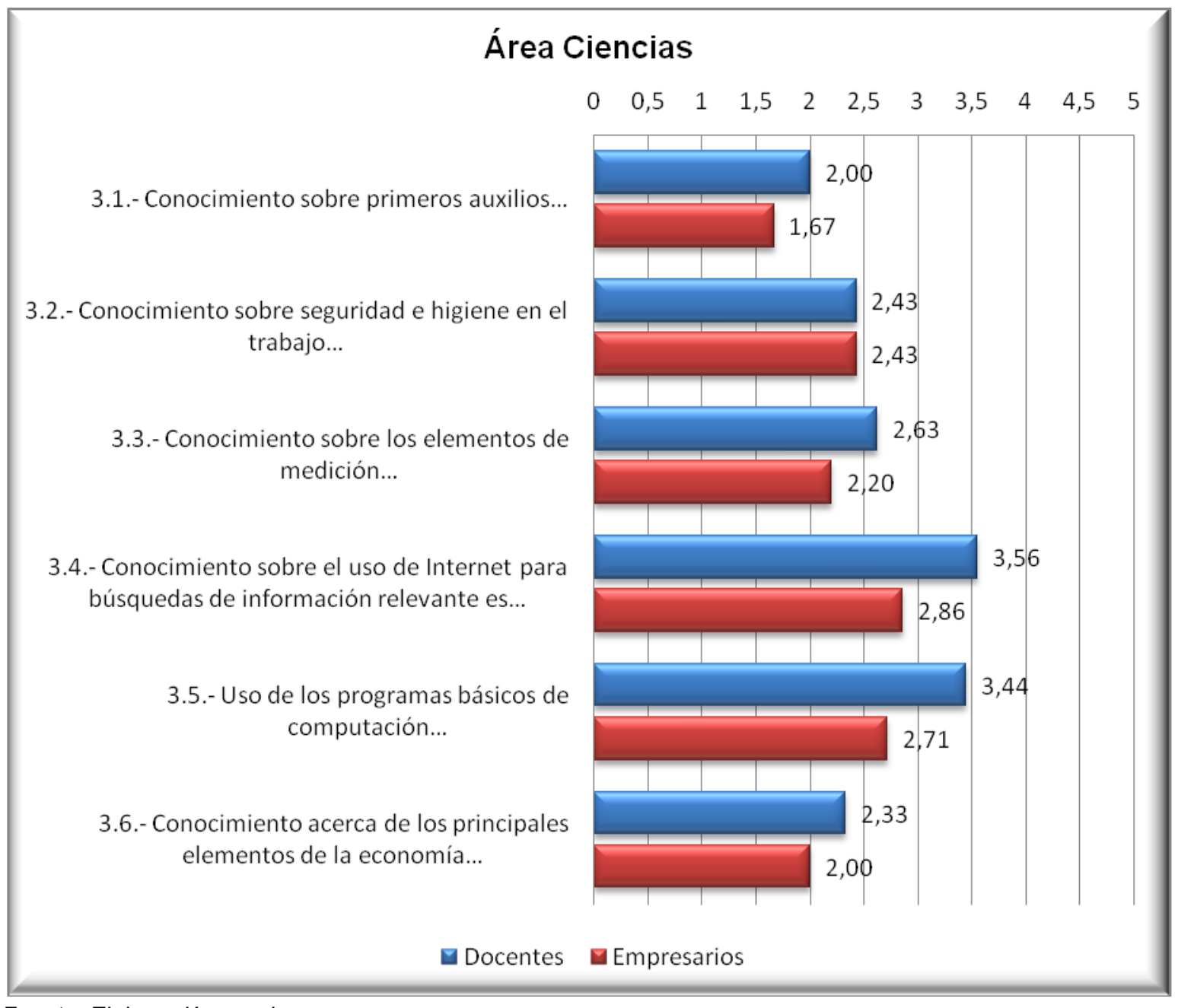

Fuente: Elaboración propia 


\section{Aptitudes Personales}

A diferencia de las áreas anteriores, donde todas las respuestas eran mejores las del panel de docentes, en éste caso se da lo contrario en uno de los puntos. Es en el caso de la creatividad, donde los empresarios le otorgan mayor puntaje que los docentes.

En los demás puntos, es mejor la respuesta de los docentes, teniendo una marcada diferencia los resultados acerca del respeto que presentan los egresados. Luego, las demás aptitudes evaluadas presentan similar diferencia en ambos paneles. Los puntos donde más se asemejan las respuestas son en la puntualidad y en la capacidad que presentan para comunicarse y transmitir ideas y conocimiento. 


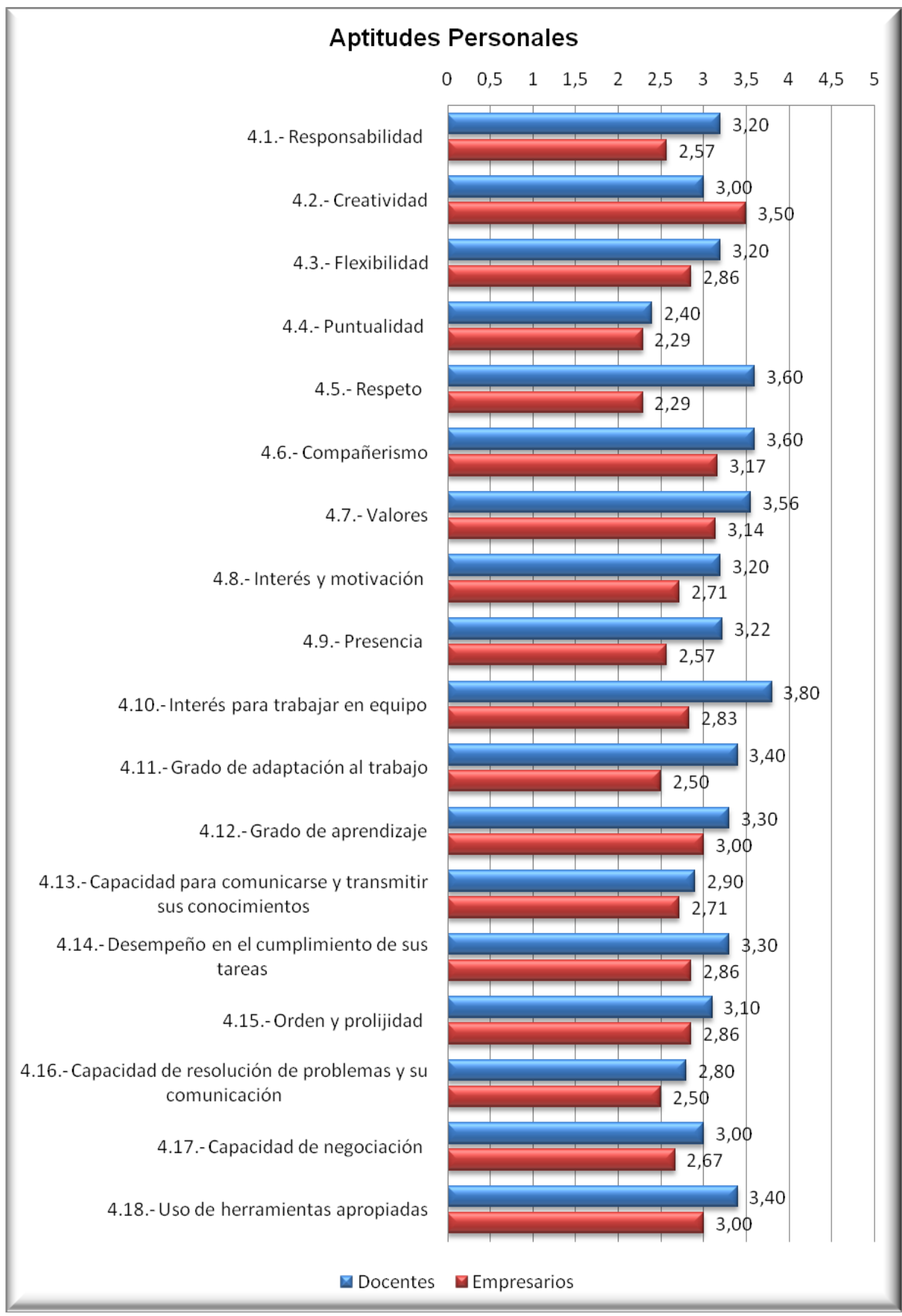

Fuente: Elaboración propia 


\subsubsection{Comparación Total respuesta Docentes y Empresarios}

En el gráfico de barras verticales se pueden observar todos los resultados de la encuesta discriminados por el tipo de respuesta, y por el panel de expertos. Es decir, que se aprecian los resultados totales. En esta gráfico se distingue la opinión crítica que presenta el panel compuesto por

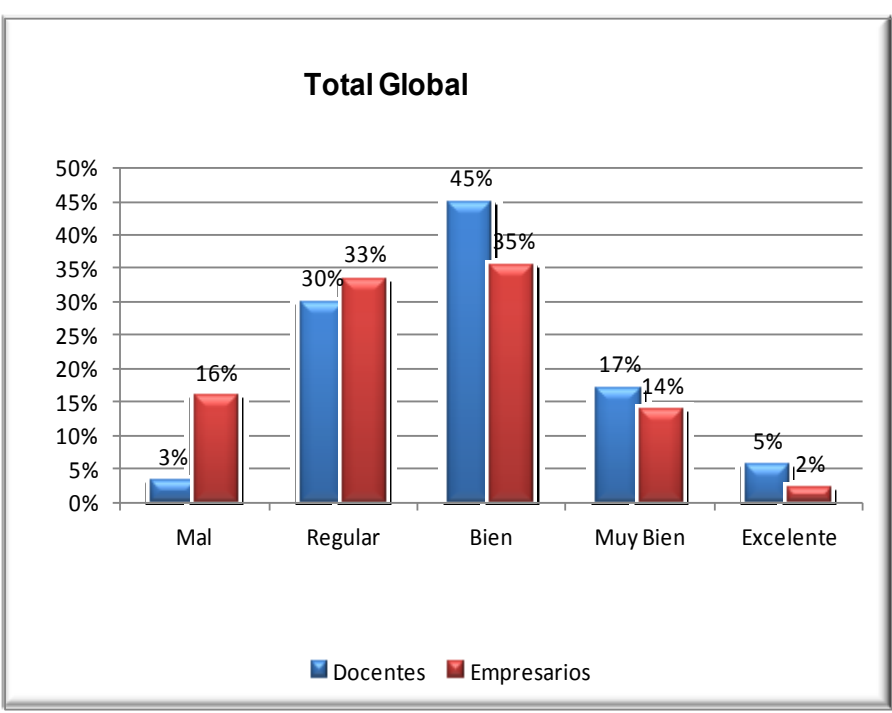

Empresarios, debido a que en Fuente: Elaboración propia comparación con los docentes, tienen una visión de menor calidad en la educación secundaria. Hay diferencia en todos los casos. En las respuestas mal y regular los empresarios presentan un mayor porcentaje, y en las demás opciones el porcentaje es menor.

En el otro gráfico se ve reflejado el Saldo Respuesta Total, donde se observa por área el valor de saldo respuesta de cada panel de expertos. En este caso, los resultados de los empresarios son menores que los del panel de docentes.

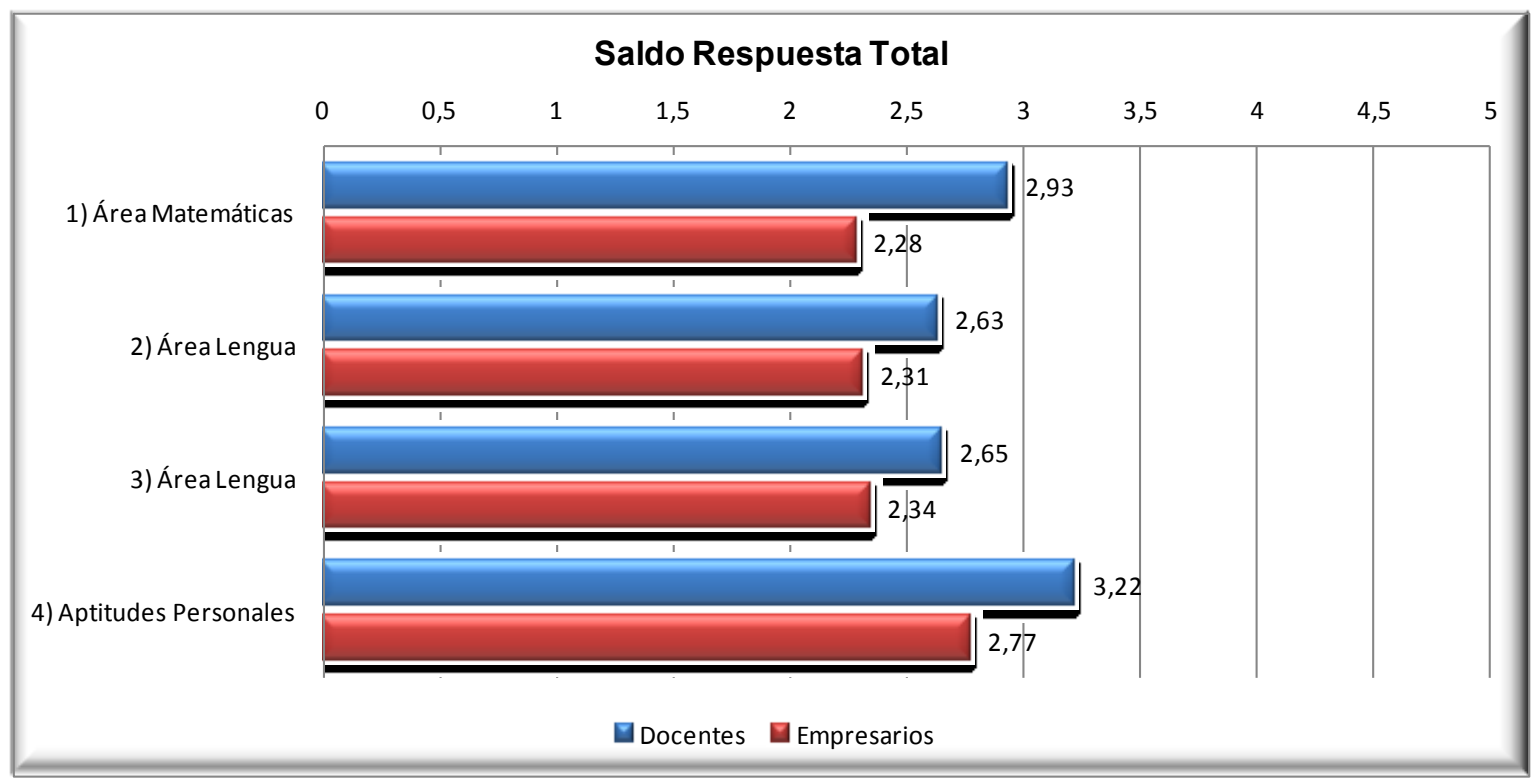

Fuente: Elaboración propia 


\subsubsection{Comparación regional respuestas de docentes}

En esta comparación, se tiene en cuenta el nivel de la calidad educativa del secundario, según el panel de expertos de docentes, de la región compuesta por los partidos de La Plata, Berisso y Ensenada. A su vez, en los gráficos, se puede apreciar las diferencias que presentan estos resultados, en relación con el partido de Ensenada.

\section{$\underline{\text { Área Matemáticas }}$}

En esta área, se da en Ensenada un mayor porcentaje en las respuestas Regular, Bueno, disminuyendo en el caso de Muy bueno, Mal y Excelente.

En el gráfico del saldo de respuesta, se observa que hay un par de puntos donde el nivel del Ensenada está por debajo de la región, como es en la realización de cuentas básicas sin usar tecnología, distinguir los distintos tipos de figuras geométricas, comprendes los datos estadísticos y los distintos tipos de gráfico. A su vez, hay determinados puntos donde se obtuvo mayor puntaje que la región, en el cálculo de porcentajes, en el conocimiento de los sistemas monetarios y noción sobre patrones de medidas, entre otros.

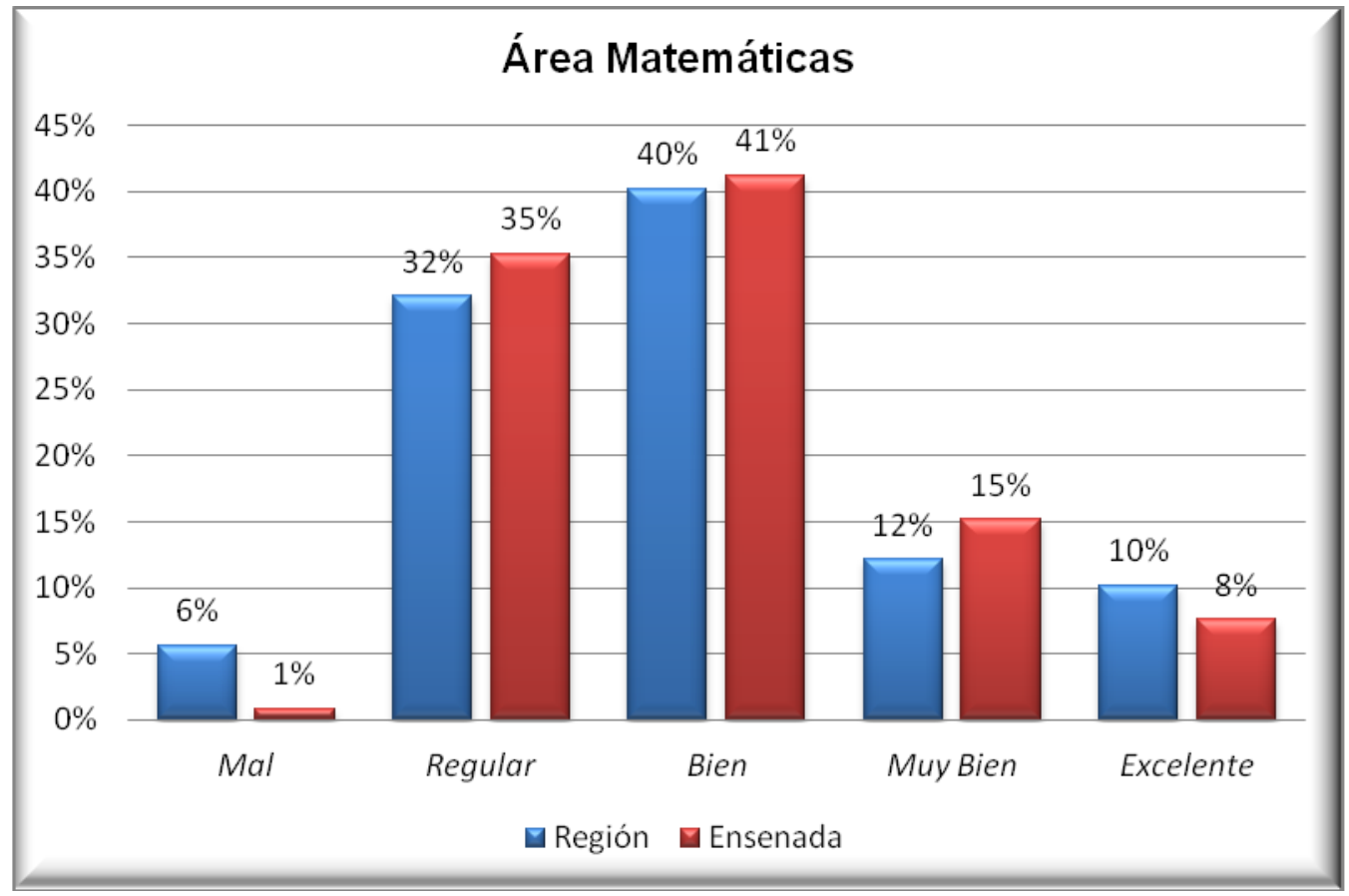

Fuente: Elaboración propia 


\section{Área Matemáticas}

1.1.- Cuentas básicas sin uso de tecnología...

1.2.- Cálculo de porcentajes simples, responde...

1.3.- Conversiones con unidades de medidas...

1.4.- Conoce los tipos de triángulos existentes...

1.5.- Distingue los distintos tipos de figuras geométricas...

1.6.- Realiza las operaciones básicas con fracciones...

1.7.- Calcula la superficie de un objeto ...

1.8.- Calcular el volumen de un cuerpo...

1.9.- Conoce los sistemas monetarios utilizados en Argentina...

1.10.- Tiene noción sobre patrones de medida...

1.11.- Conoce y comprende los distintos tipos de gráficos...

1.12.- Comprende datos estadísticos...

1.13.- Realiza un cálculo financiero elemental...

$\begin{array}{lllllllllll}0 & 0,5 & 1 & 1,5 & 2 & 2,5 & 3 & 3,5 & 4 & 4,5 & 5\end{array}$

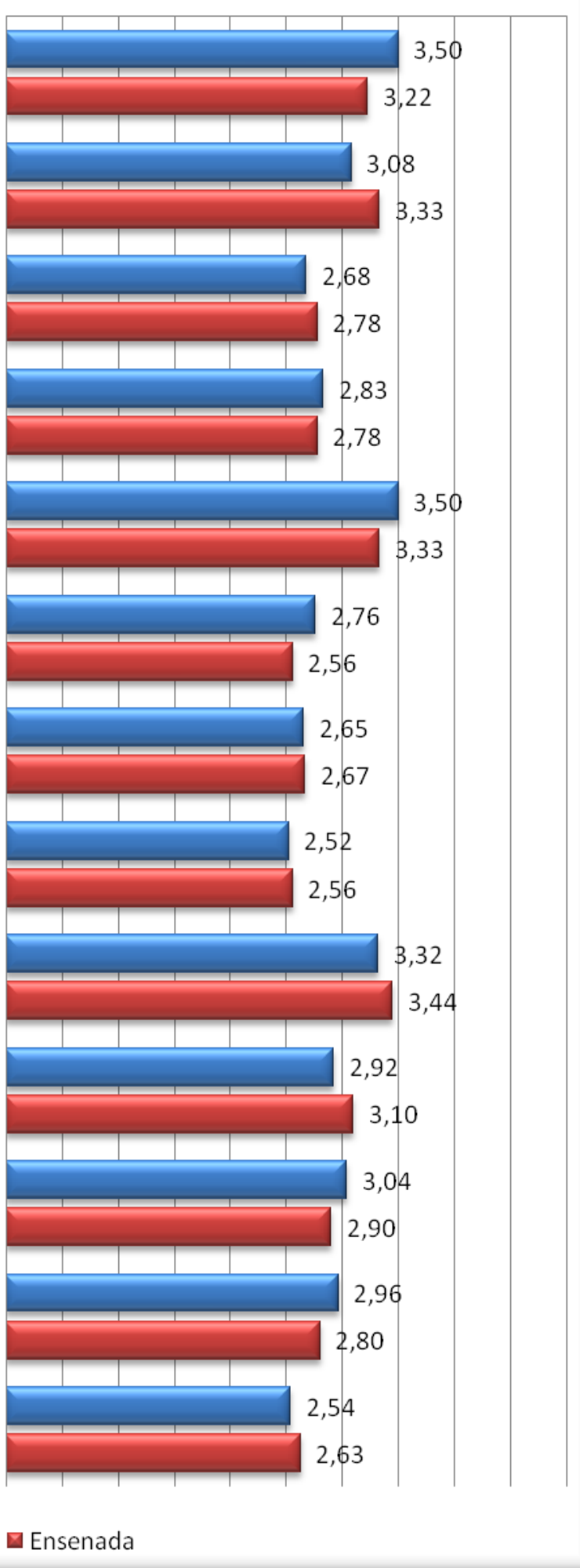

Fuente: Elaboración propia 
Área Lengua

En el área Lengua, a diferencia de Matemáticas, hay mayores diferencias en los porcentajes que presentan los resultados de Ensenada en relación a la región. En punto que más diferencia presenta es Regular, Ensenada tiene 14\% más. Luego está Muy bien, con 7\% por encima de la región.

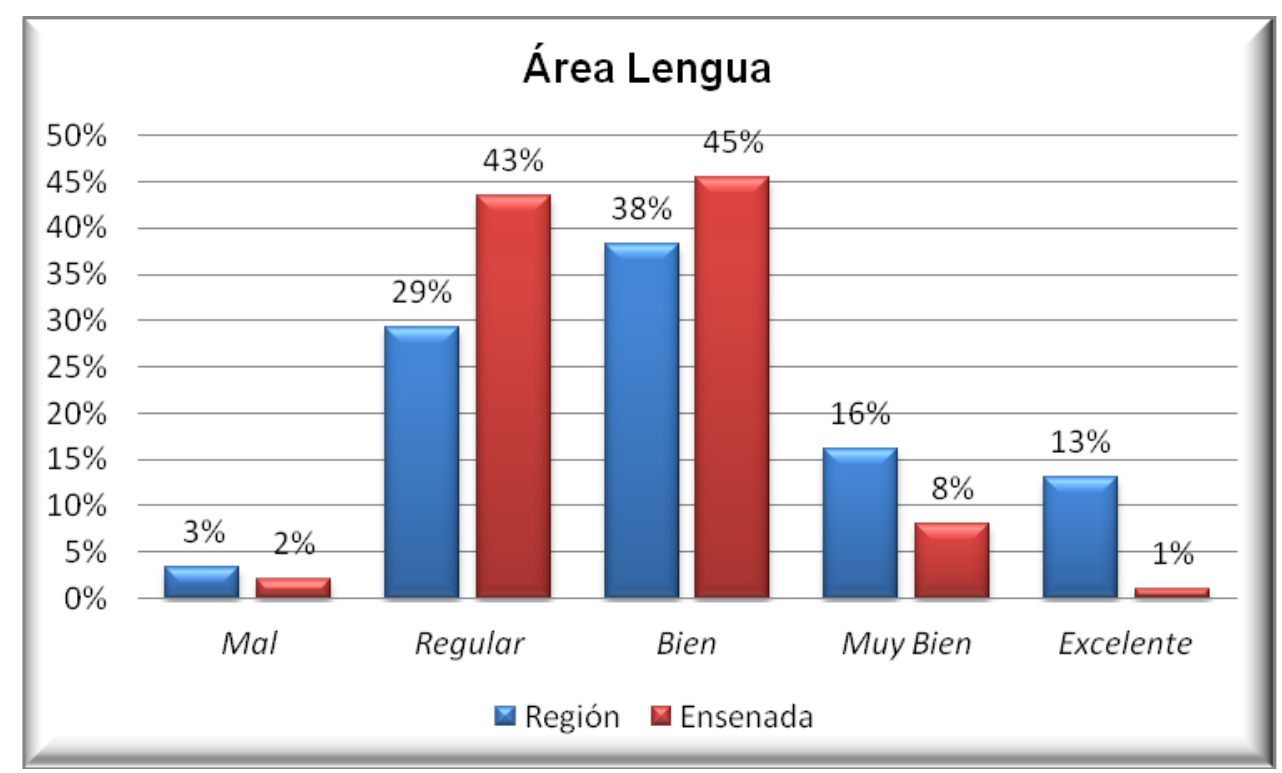

Fuente: Elaboración propia

Los demás puntos se encuentras por debajo de la región. Excelente en Ensenada representa el 1\%, en cambio en la región un $13 \%$, es decir que hay una gran diferencia en este punto. Muy bien tiene 8\% de diferencia, y Mal solo $1 \%$.

En el gráfico que detalla los puntos evaluados en la encuesta, se observa que las respuestas de Ensenada presentan resultados con menor nivel, ya que en comparación a los resultados obtenidos en la región, todos los puntos tienen un saldo de respuesta más bajo.

En conclusión, el partido de Ensenada presenta un menor nivel de calidad educativa, en lo que respecta al área de Lengua. 


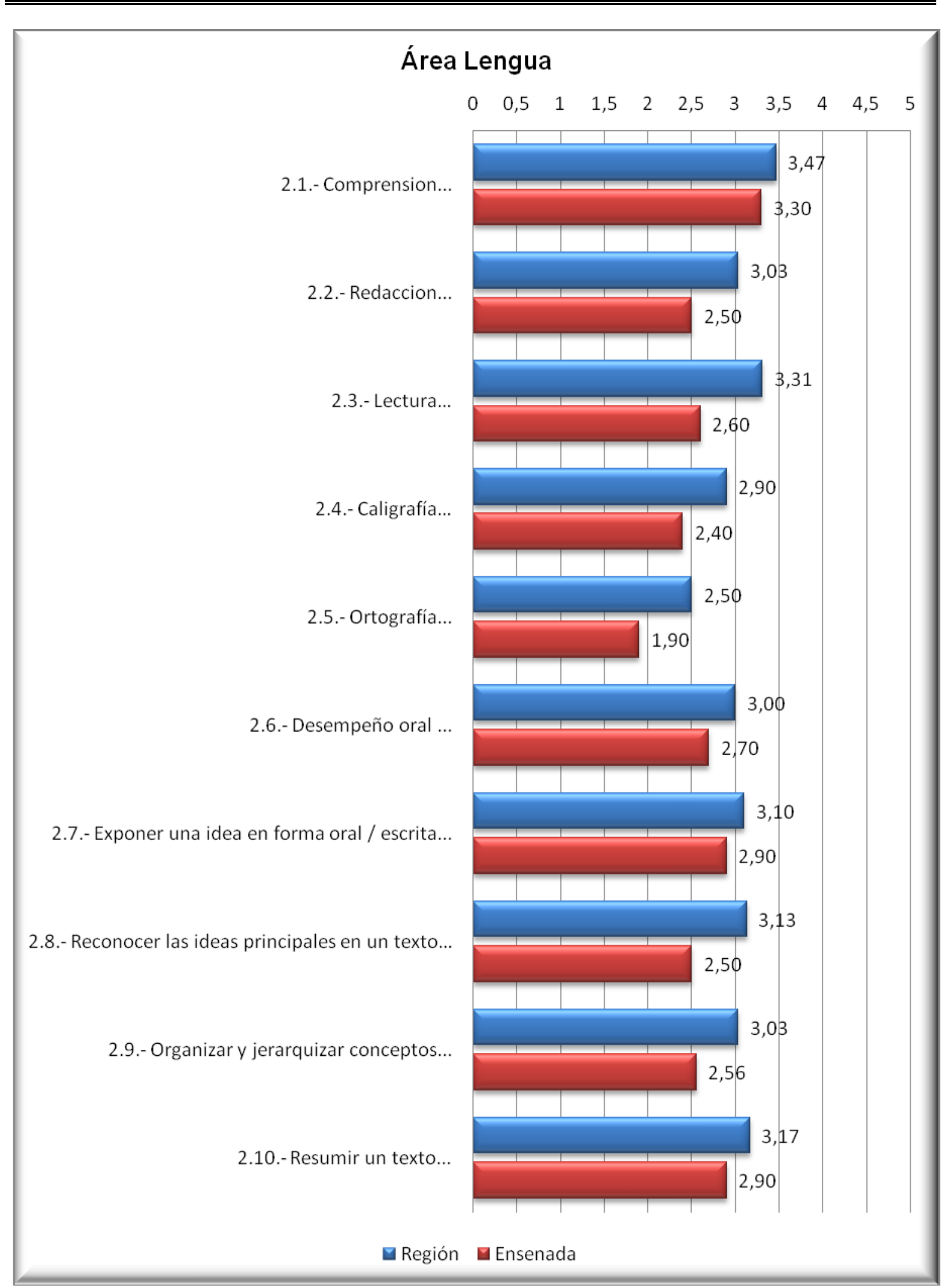

Fuente: Elaboración propia 


\section{Área Ciencias}

Al igual en los casos anteriores, las respuestas que presentan mayor porcentaje en comparación a la región es Regular, con $8 \%$ de diferencia, y Bien con $6 \%$. En esta área $\mathrm{Mal}$ representa el mismo porcentaje en ambos casos,y en cambio, en los casos de Muy bien y Excelente, Ensenada se encuentra por debajo.

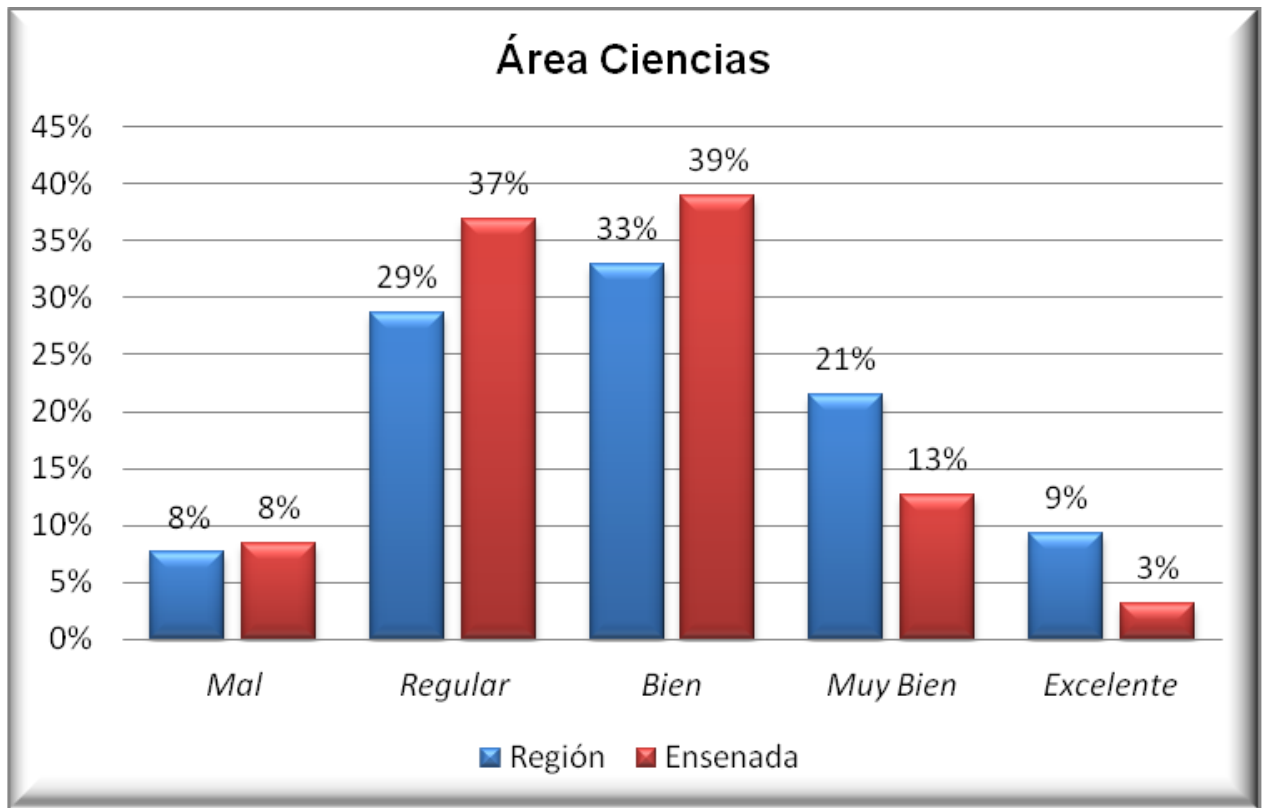

Fuente: Elaboración propia

Al evaluar los saldo de respuesta de las preguntas realizadas, solo hay un punto en el cual el resultado de Ensenada en mayor que el de la región, es en el caso del conocimiento que presentan los egresados acerca del sistema solar. Todos los demás puntos son menores que la región, algunas con mayor diferencia de porcentaje que otras, pero todas con un nivel menor. 


\section{Área Ciencias}

3.1.- Conoce acerca de los estados de la materia...

3.2.- Sabe sobre primeros auxilios...

3.3.- Sabe sobre seguridad e higiene...

3.4.- Conoce las principales enfermedades de Argentina...

3.5.- Conoce los elementos de medición...

3.6.- Conocimiento los tipos de energía existentes...

3.7.- Sabe sobre el sistema solar...

3.8.- Uso de Internet para búsquedas de información relevante es...

3.9.- Uso de los programas básicos de computación...

3.10.- Conoce las principales vías de contagio del SIDA...

3.11.- Sabe acerca de los principales elementos de la economía ...

3.12.- Conoce la tasa de mortalidad en Argentina...
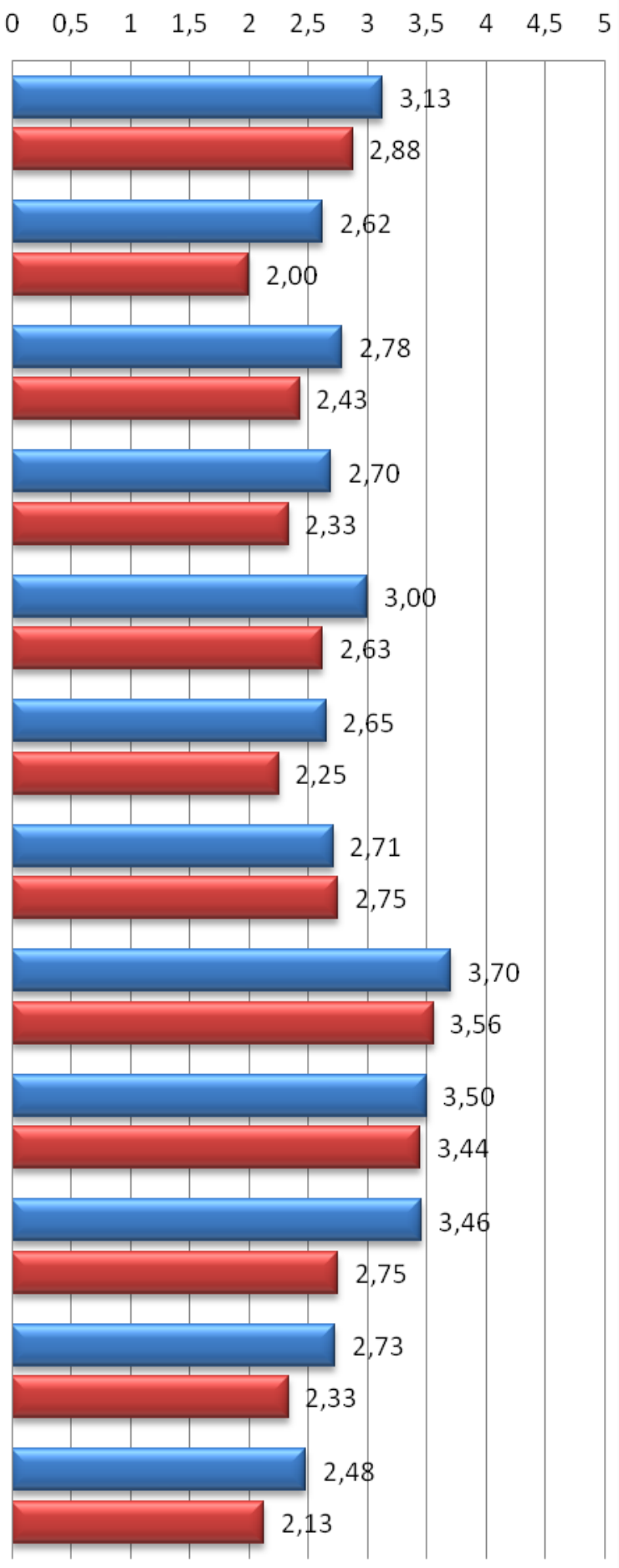

Q Región Ensenada

Fuente: Elaboración propia 


\section{Aptitudes Personales}

En la evaluación de las aptitudes personales de los egresados del secundario, se visualiza que el punto con mayor diferencia positiva es Bien, con $11 \%$. Muy bien solo tiene $1 \%$ por encima de la región, Mal presenta el mismo porcentaje y en los puntos restantes, Ensenada presentó menor porcentaje, como en el caso de Excelente, con $11 \%$ de diferencia y Regular, con $3 \%$.

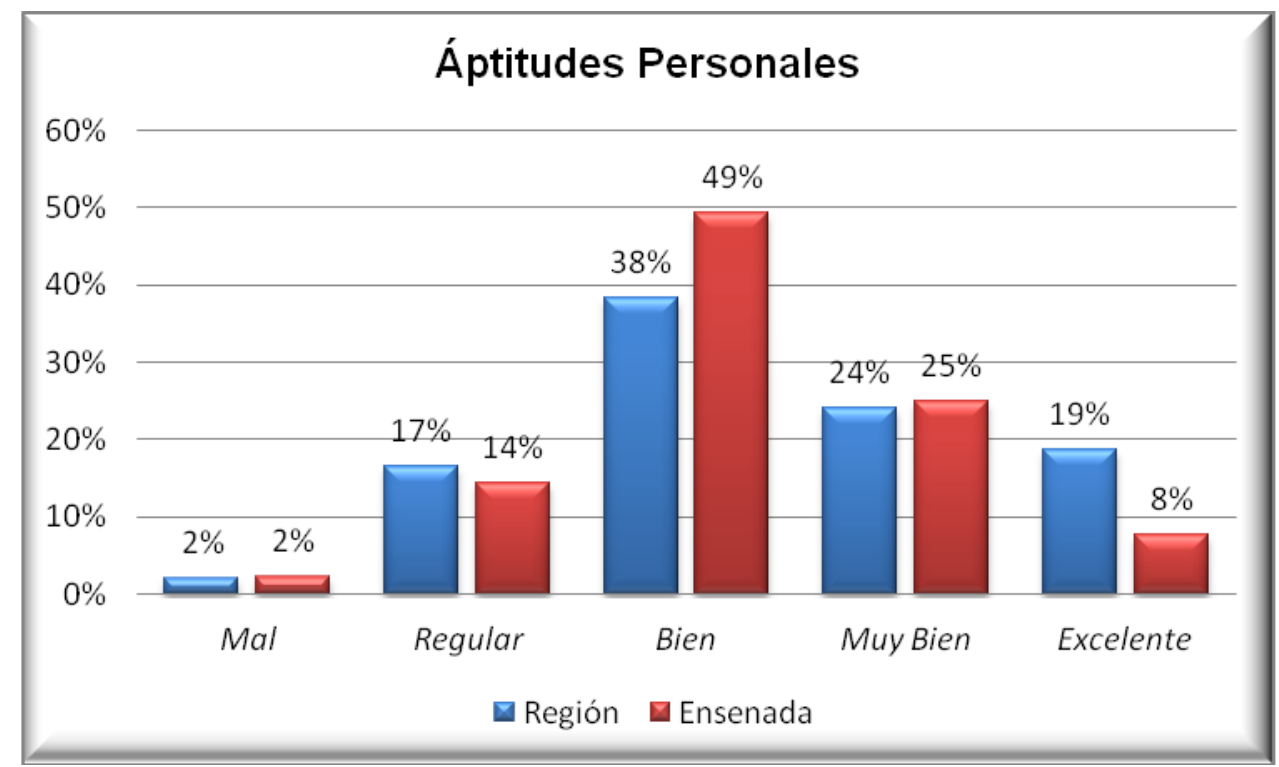

Fuente: Elaboración propia

En el gráfico de los saldo de respuesta, solo en un punto se da que Ensenada supera a la región, y es en el caso del interés que presentan los egresados para trabajar en equipo. En las aptitudes evaluadas, la región presenta mejores resultados. 


\section{Aptitudes Personales}

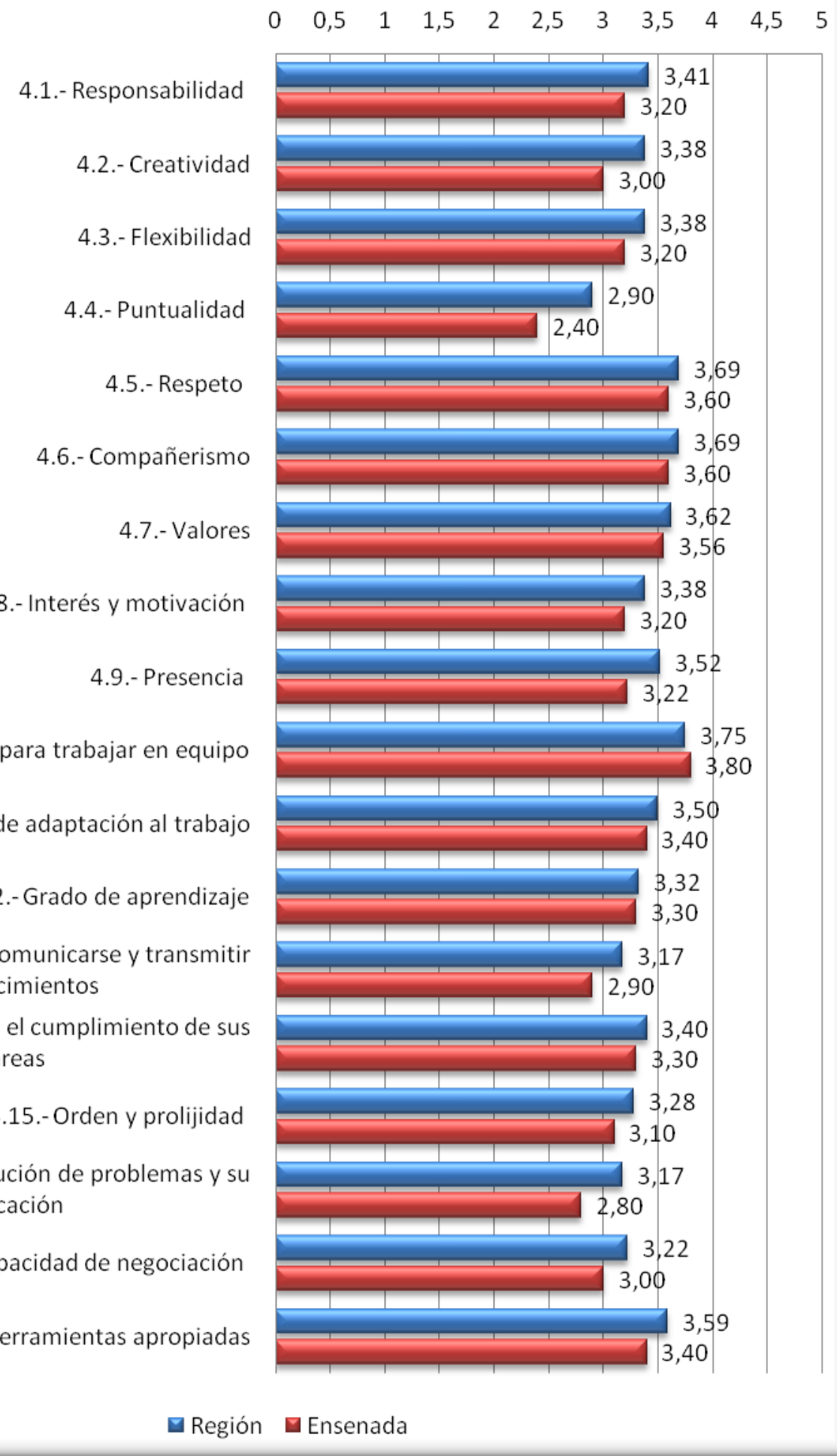

Fuente: Elaboración propia 


\section{Comparación Regional respuestas de Docentes Global}

En este punto se puede observar los resultados globales docentes, y la diferencia que presenta la sumatoria de los resultados de Ensenada con el de la región.

Los puntos de Ensenada, con diferencia positiva, son Regular, con $5 \%$ más, y Bien, $7 \%$

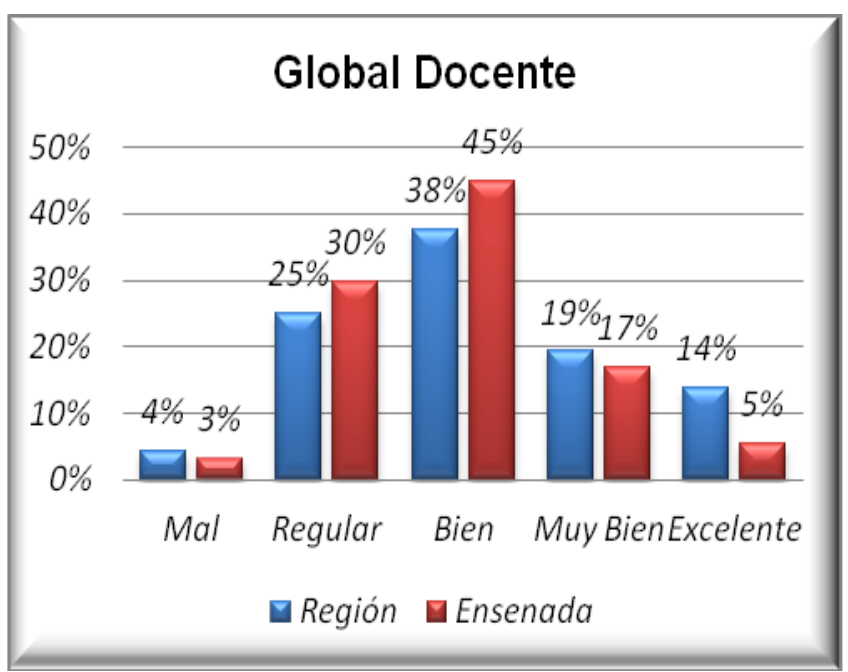
por encima de la región. En los Fuente: Elaboración propia otros casos, los resultados de Ensenada son menores.

Con respecto a la comparación según las áreas evaluadas, se puede ser que sólo en Matemáticas, Ensenada presenta un saldo de respuesta mayor que la región.

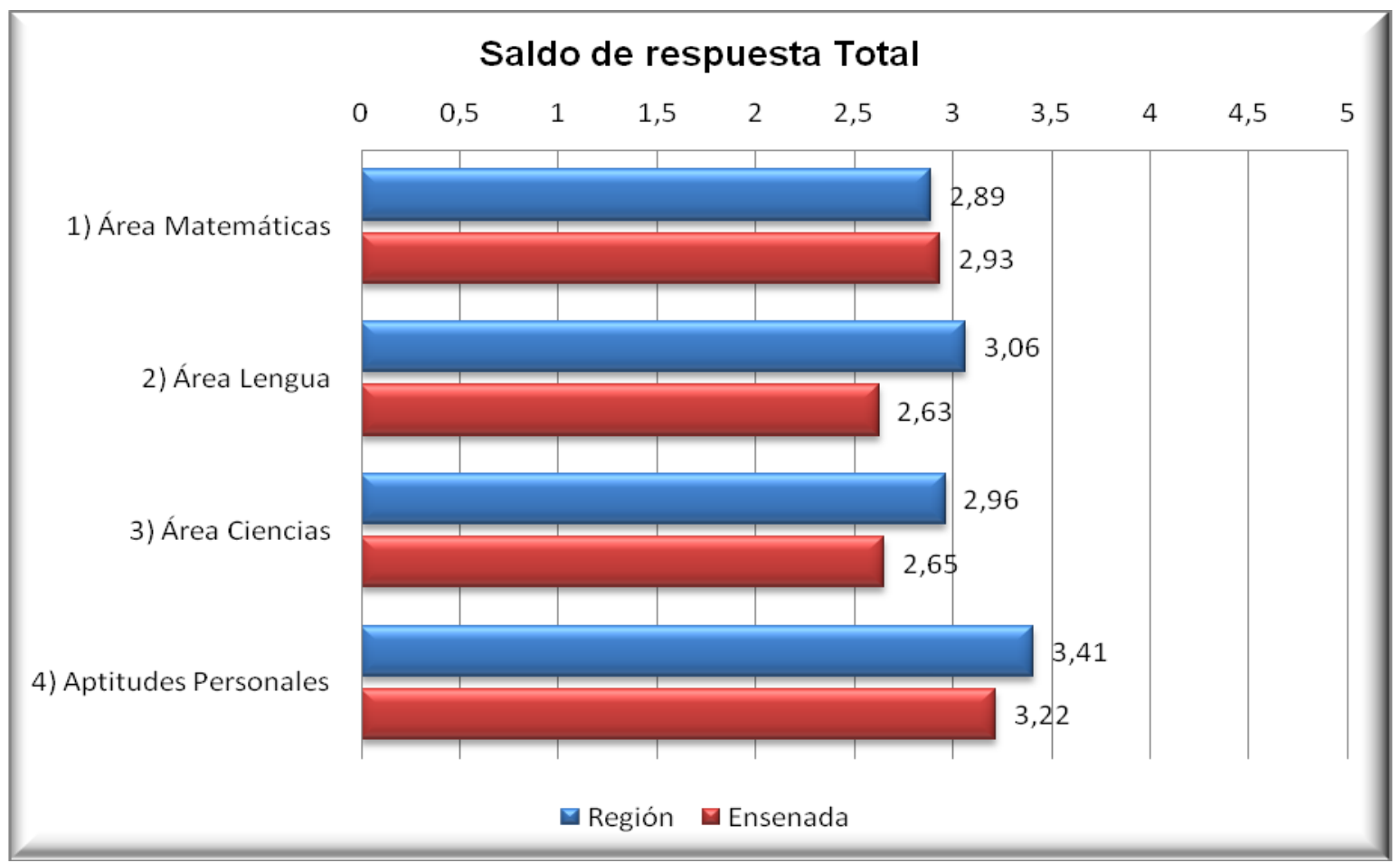

Fuente: Elaboración propia 


\subsubsection{Comparación regional respuestas de empresarios}

En este punto, se presenta la comparación entre los resultados de Ensenada y los de la región, compuesta por los partidos de La Plata, Berisso y Ensenada. Estos son los resultados del nivel de calidad del secundario, según el panel de expertos compuesto por empresarios.

\section{Área Matemáticas}

En esta área, se puede apreciar que los puntos donde Ensenada obtuvo mayor porcentaje en las respuestas Regular, con 12\% de diferencia, Bien con 3\% y Mal con $6 \%$. En cambio en el caso de Muy Bien el porcentaje fue menor, $14 \%$ de diferencia. Por último, Excelente representa el $0 \%$ en Ensenada y un $7 \%$ en la región.

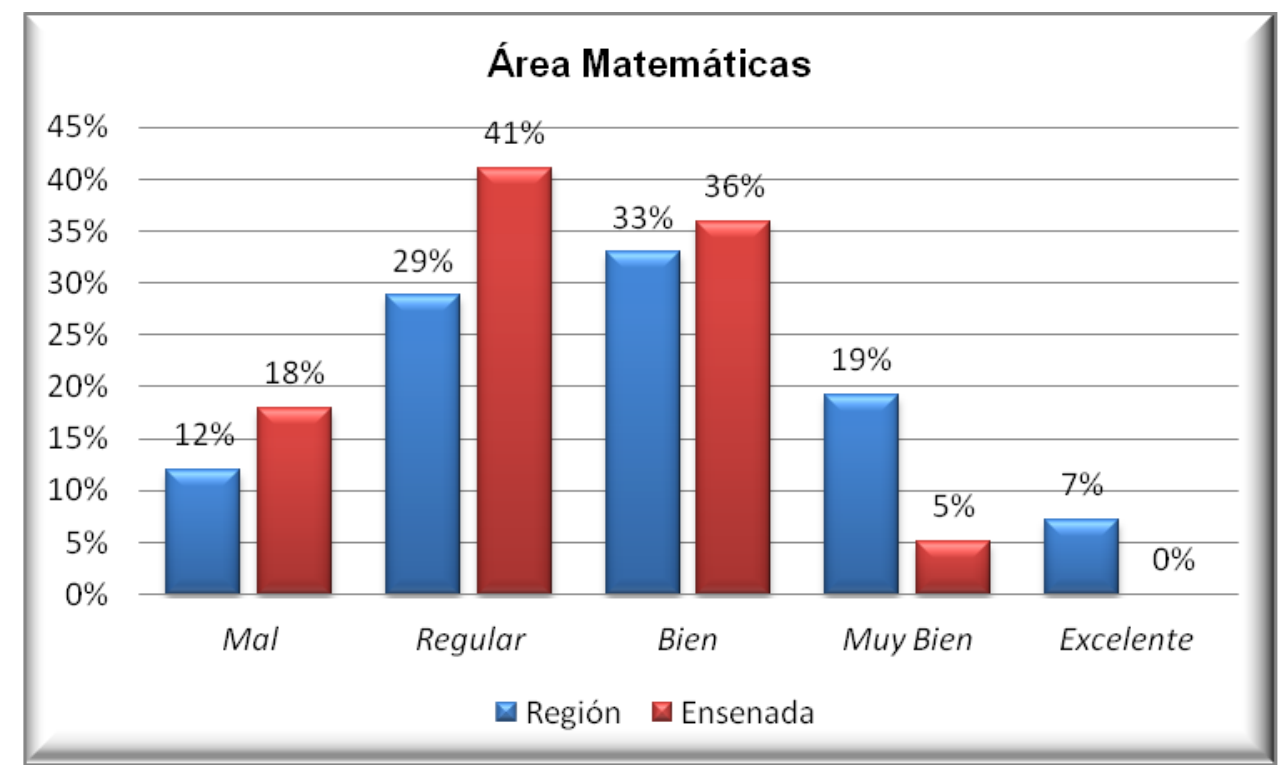

Fuente: Elaboración propia

Esto se refleja en el gráfico donde está el saldo de respuesta de cada pregunta evaluada. Allí se aprecia que en todos los casos, según los resultados de los empresarios, el nivel educativo de Ensenada es menor en comparación con la región. 


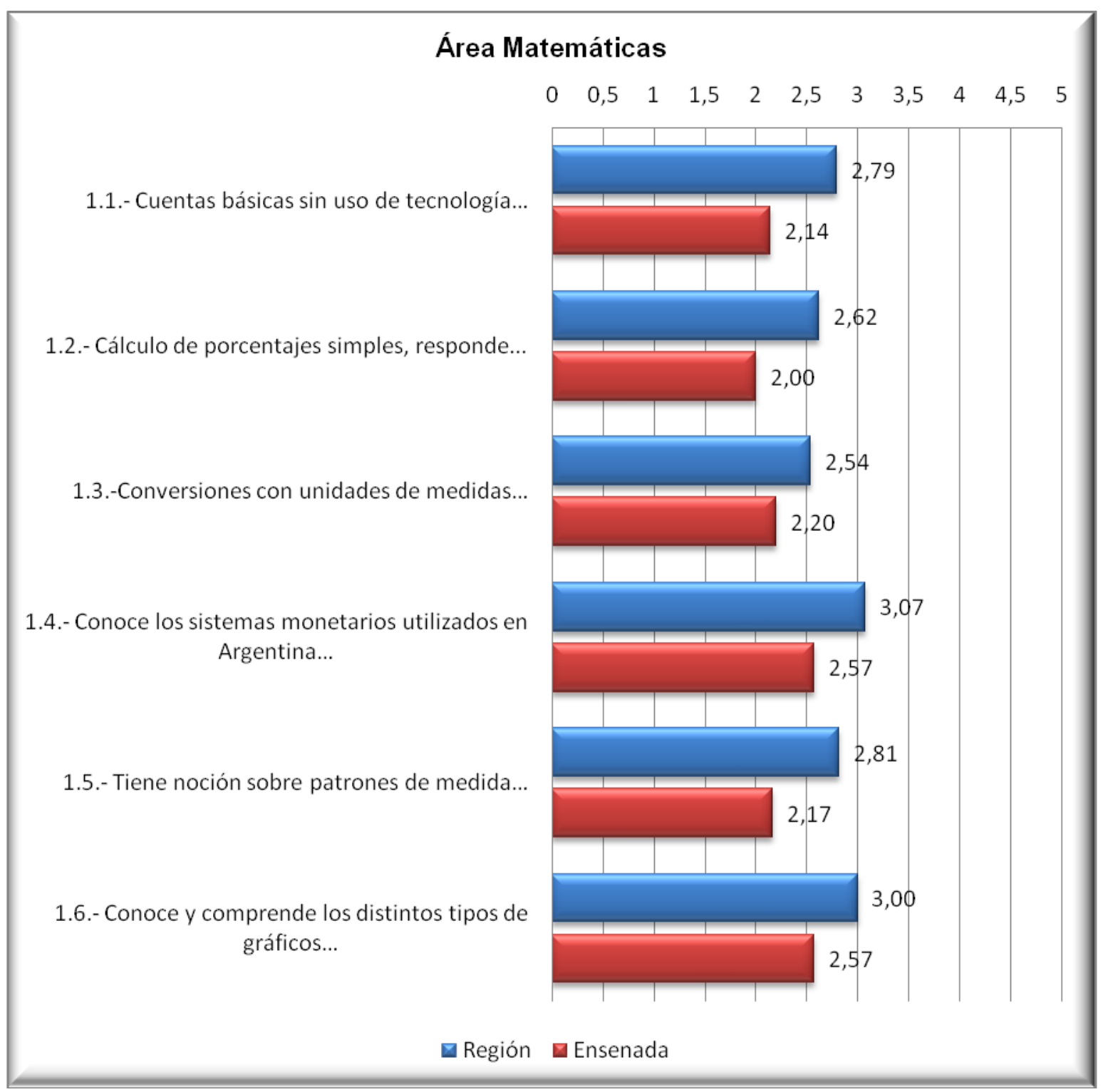

Fuente: Elaboración propia 


\section{Área Lengua}

Aquí se observa que, en ésta área, los puntos de Ensenada con mayor porcentaje con Mal, con $13 \%$ de diferencia y regular con $6 \%$. En cambio, las respuestas Bien y Muy bien, presentan menor porcentaje, y en Ensenada no hubo ninguna respuesta del área de Lengua que sea Excelente.

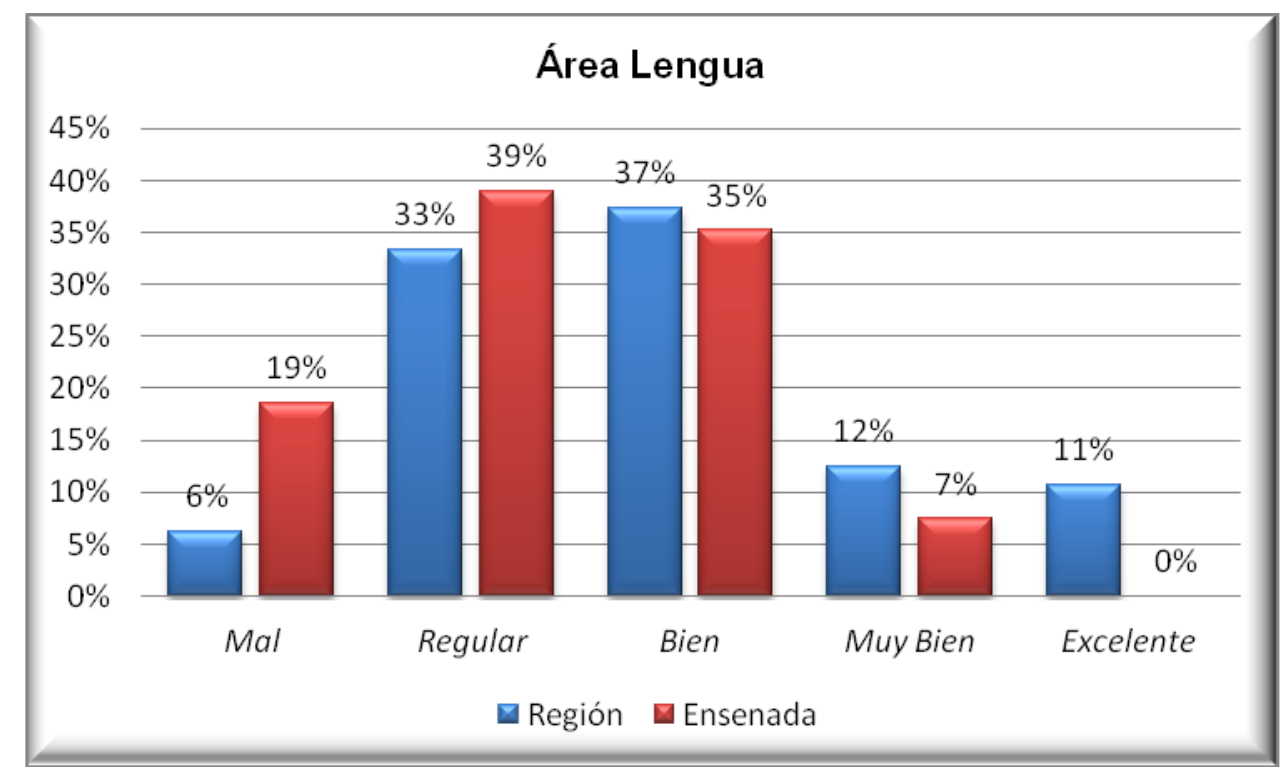

Fuente: Elaboración propia

Por ende, en el gráfico del saldo de respuesta se observa que en todas las preguntas, los resultados de Ensenada son menores que los de la región. 


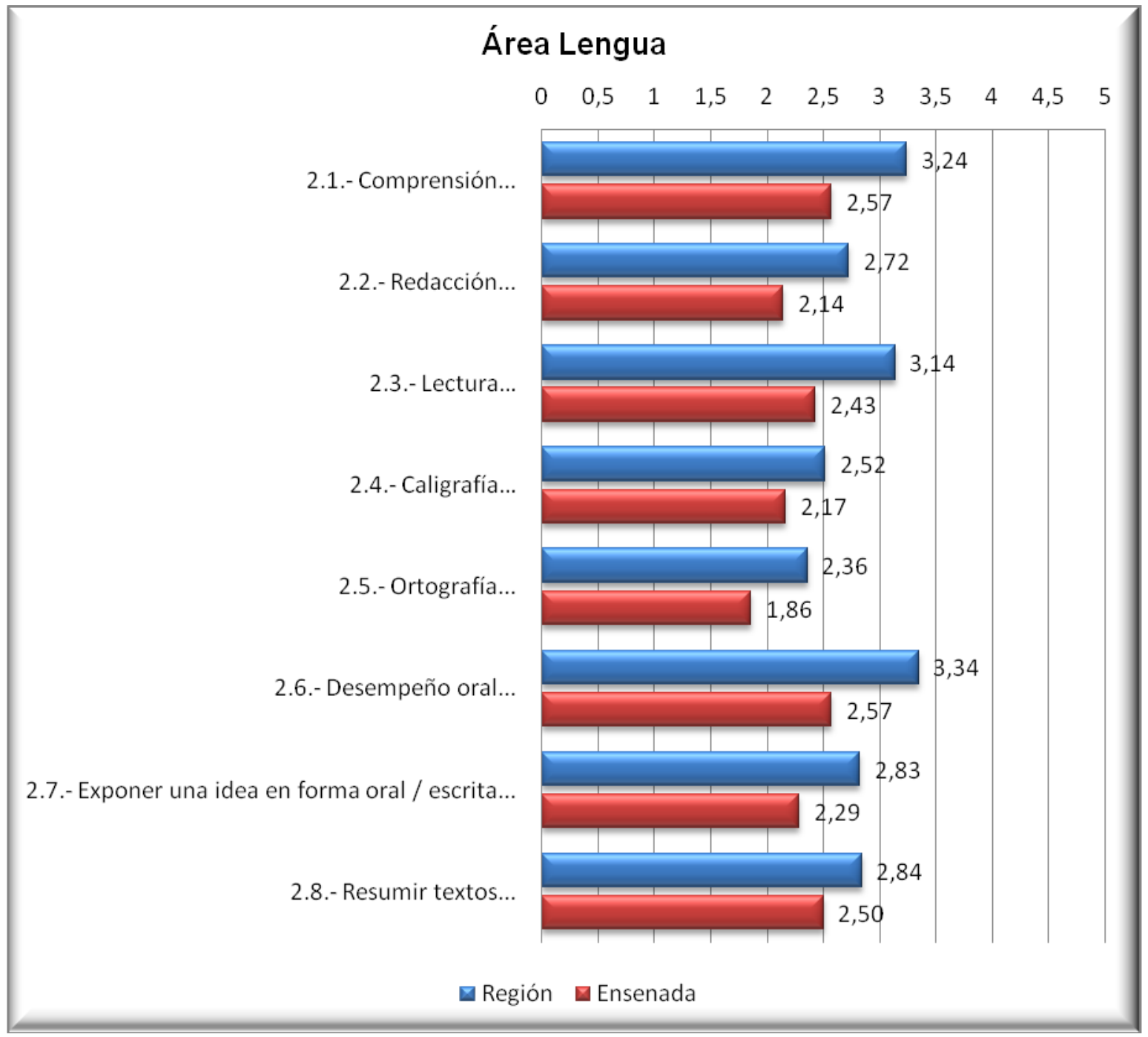

Fuente: Elaboración propia 


\section{Área Ciencias}

En ciencias, según las respuestas de los empresarios del partido de Ensenada, las respuestas que tienen un porcentaje por encima de la región son Regular, $8 \%$ más, Bien, con una diferencia de $3 \%$ y Mal, con $4 \%$. Los puntos

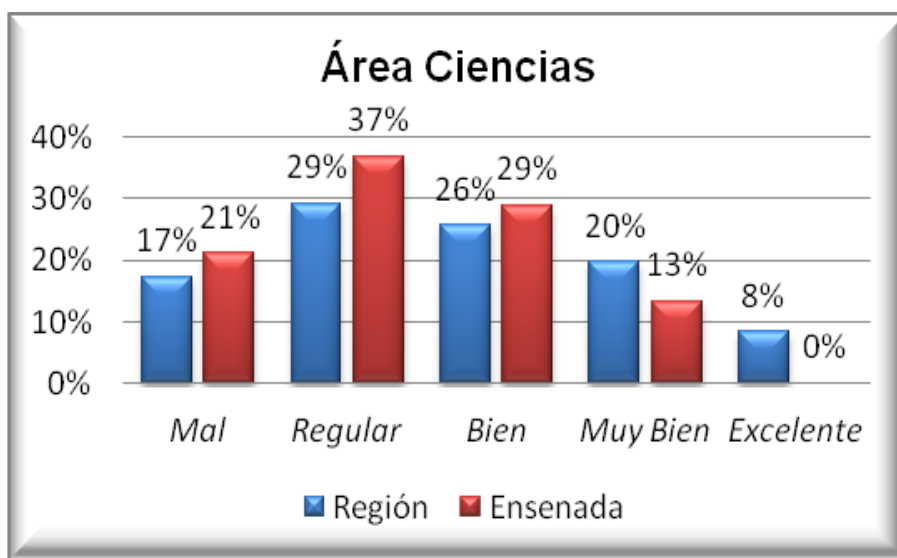
restantes están por debajo de la Fuente: Elaboración propia región, estos son Muy bien, con $7 \%$ menos, y Excelente que representa el $0 \%$ en el caso de Ensenada.

En el gráfico que se halla debajo, se puede observar que todas las respuestas de Ensenada se encuentran abajo del nivel presentado por la región.

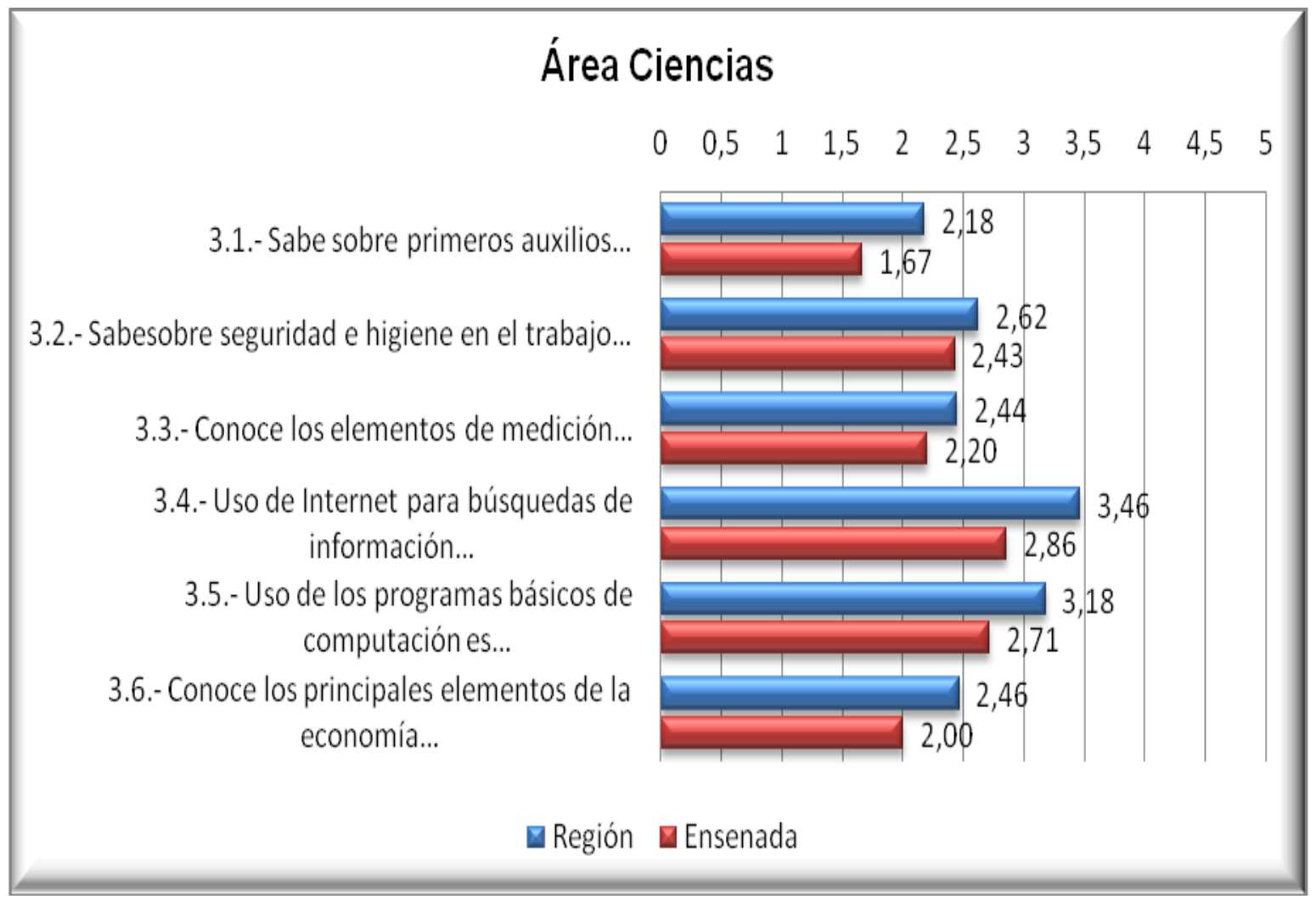

Fuente: Elaboración propia 


\section{Aptitudes personales}

Por último, en el área de las aptitudes personales, se puede observar que las respuestas del partido de Ensenada con mayor porcentaje, en relación con la región, son Bien, con 9\% arriba, Regular, 6\%, y Mal también con 6\%. En cambio, Muy bien se ubica debajo por solo $1 \%$ y excelente presenta una gran diferencia, ya que presenta un $20 \%$ menos en Ensenada.

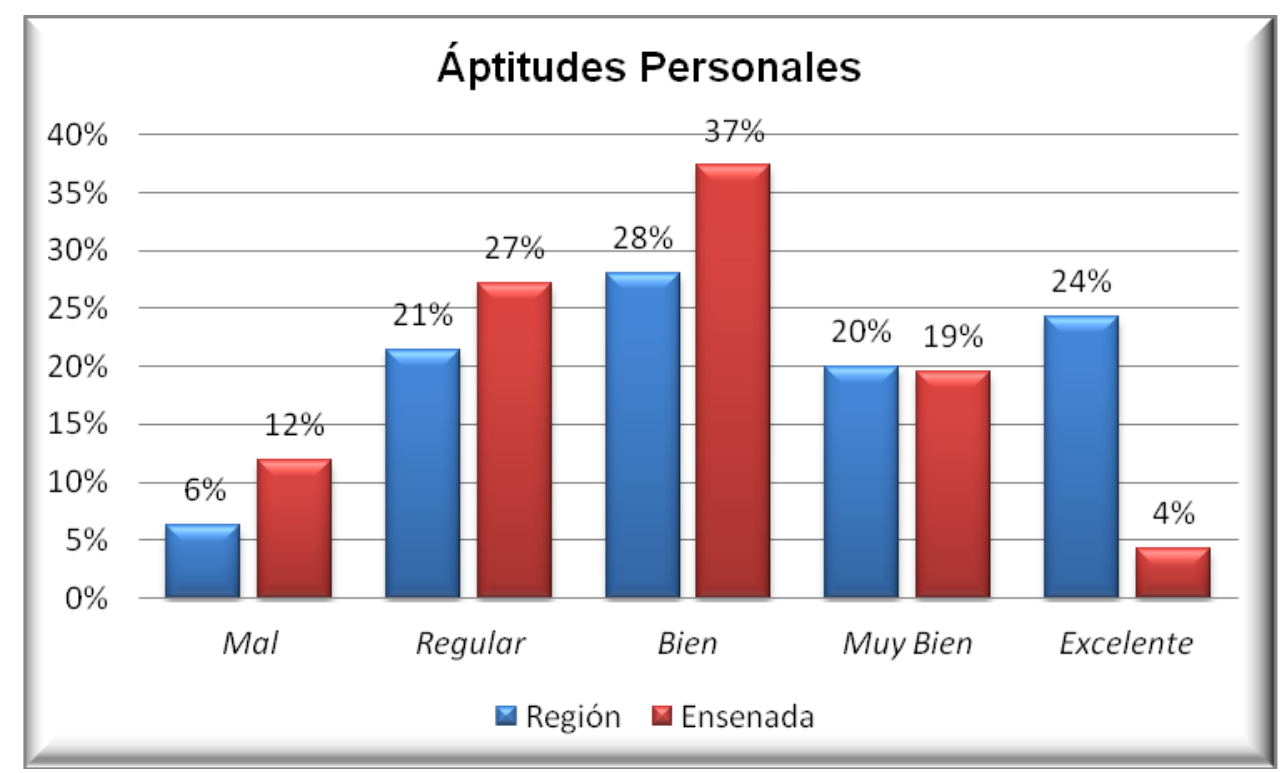

Fuente: Elaboración propia

En el gráfico siguiente se muestran los saldos de respuesta de cada pregunta del área Aptitudes. Se aprecia que el único punto donde los resultados que presentan los egresados de Ensenada son superiores a los de la región, es en la Creatividad, en que es mayor por 0,39.

En todas las demás preguntas, se da lo mismo, ya que el nivel de las respuestas de la región está por encima de las de Ensenada. En algunos puntos en particular, la diferencia que hay entre Ensenada y la región es mayor a las demás, como sucede en el caso del "respeto" y "la adaptación al trabajo". En el resto, la diferencia existente es similar. 


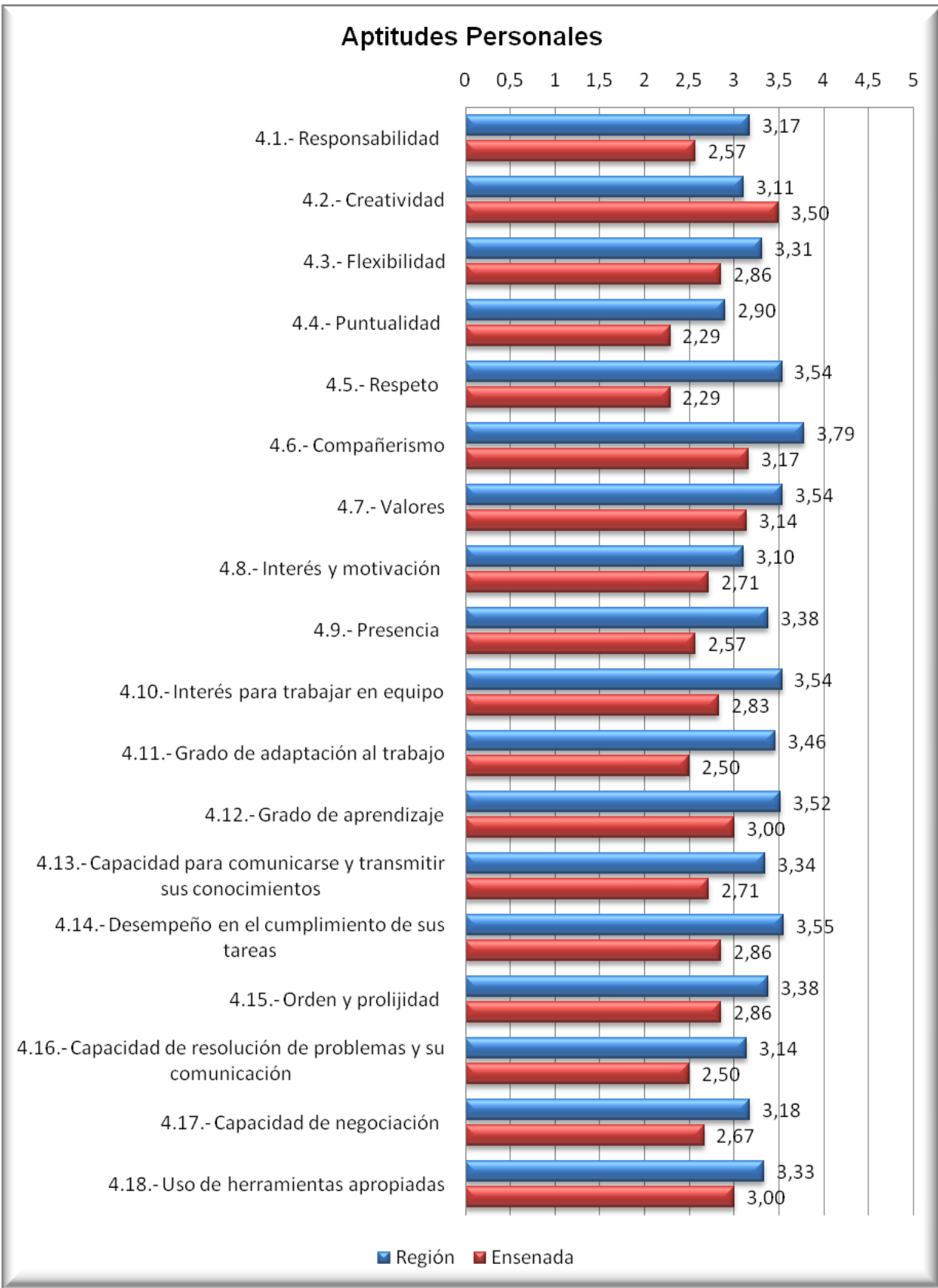

Fuente: Elaboración propia 


\section{Comparación Regional respuestas de Empresarios Global}

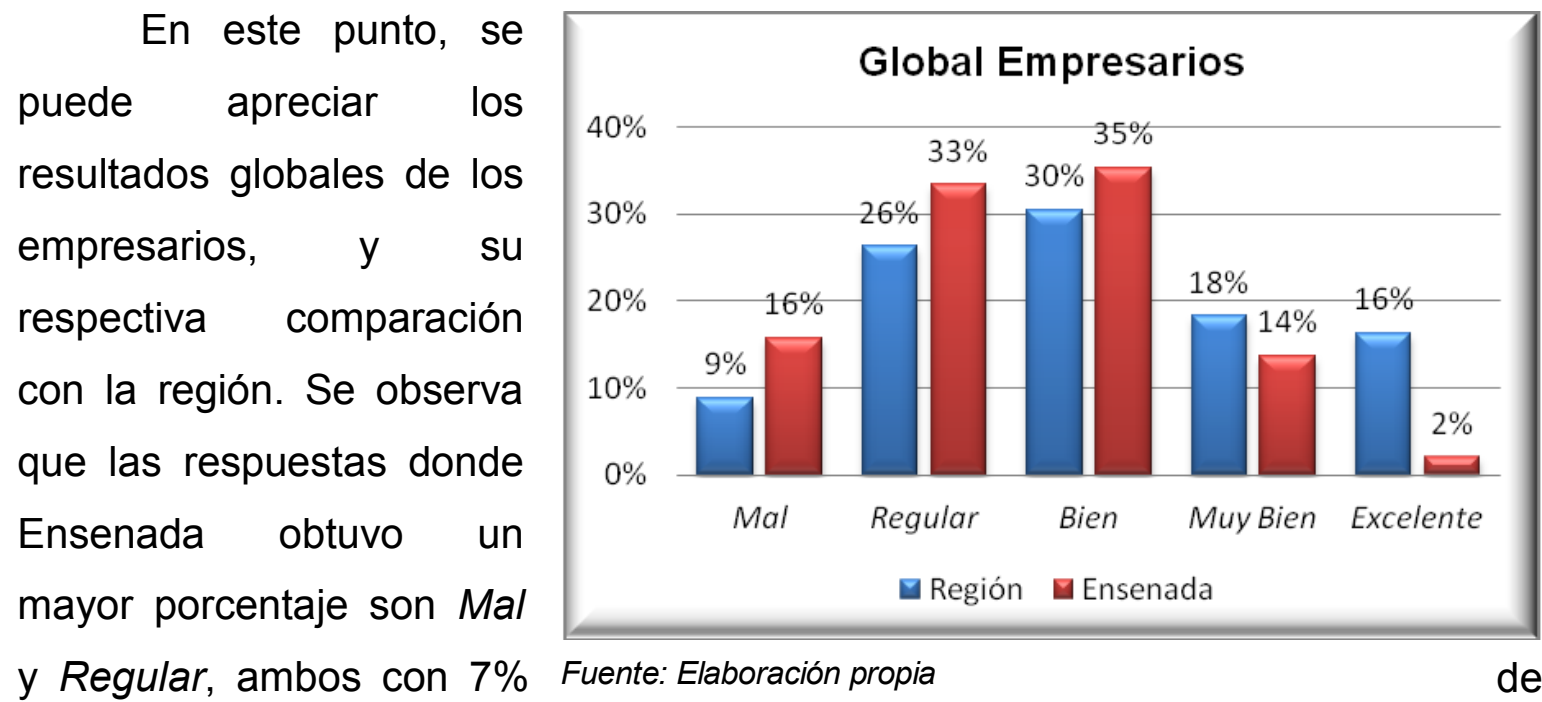

diferencia, y Bien, con 5\%. En cambio, tanto Muy bien, como Excelente, tienen porcentajes menores en el caso de Ensenada, con $4 \%$ y $14 \%$ de diferencia.

En el gráfico del saldo de respuesta está detallada cada área evaluada, y se ve que en todas el resultado según los empresarios de Ensenada es menor que el de la región. Las diferencias que presentan las áreas respectivamente son similares.

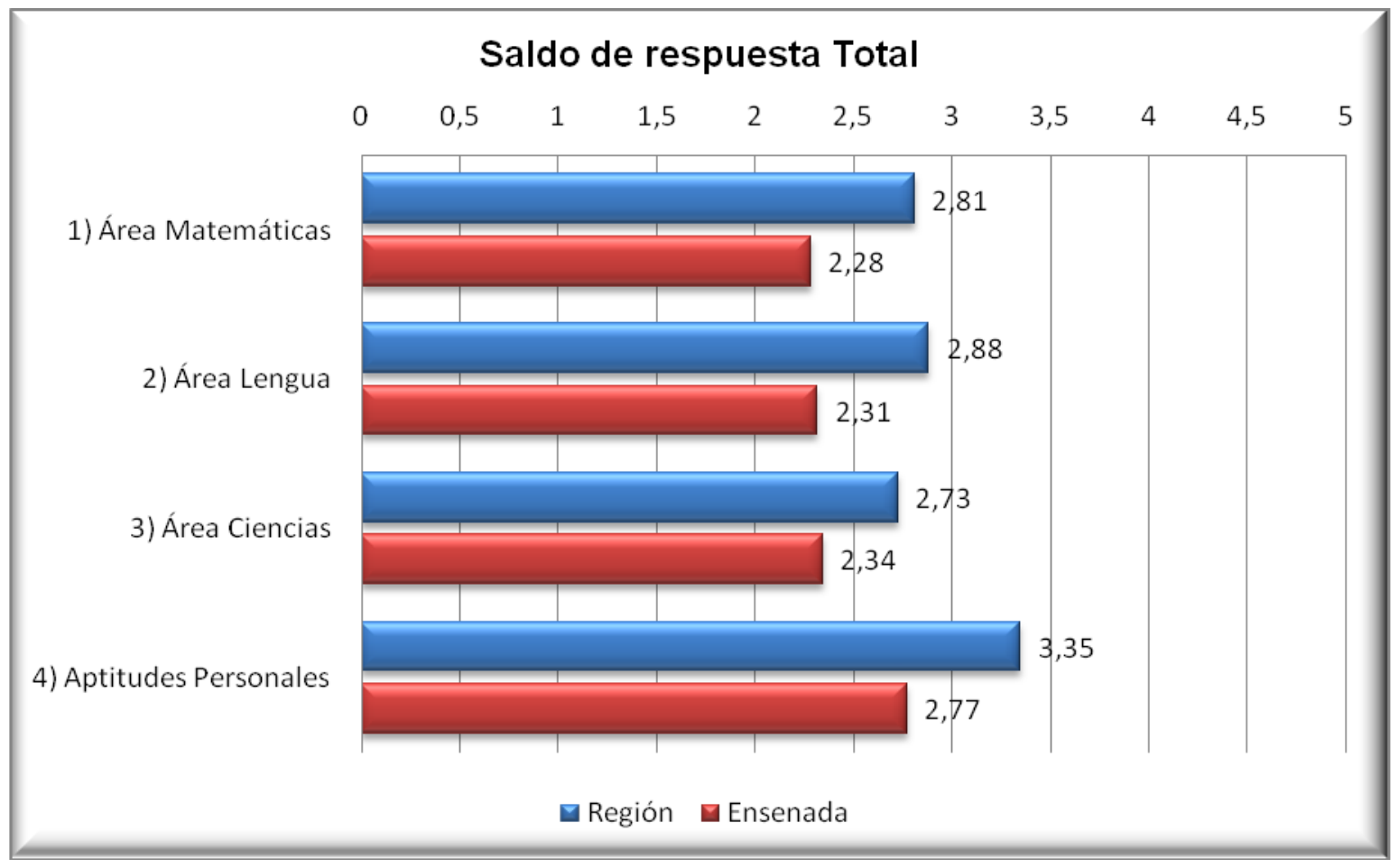

Fuente: Elaboración propia 


\subsubsection{Total regional}

El total regional hace referencia a la sumatoria de todos los resultados obtenidos en la encuesta, es decir los del panel de expertos de docentes, y el de los empresarios. A su vez, se puede observar en los siguientes gráficos la diferencia que hay entre estos resultados y los de la región, la cual está compuesta por los partidos de La Plata, Berisso y Ensenada.

En el gráfico donde se muestran las distintas opciones de respuestas de la encuesta, se puede ver que los resultados del partido de Ensenada tienen mayor porcentaje en las respuestas Bien, con $8 \%$ más, Regular, con $5 \%$, y Mal, con solo $1 \%$ de diferencia. En cambio, Muy bien, presenta 3\% menos, y Excelente un $11 \%$ por debajo de la región.

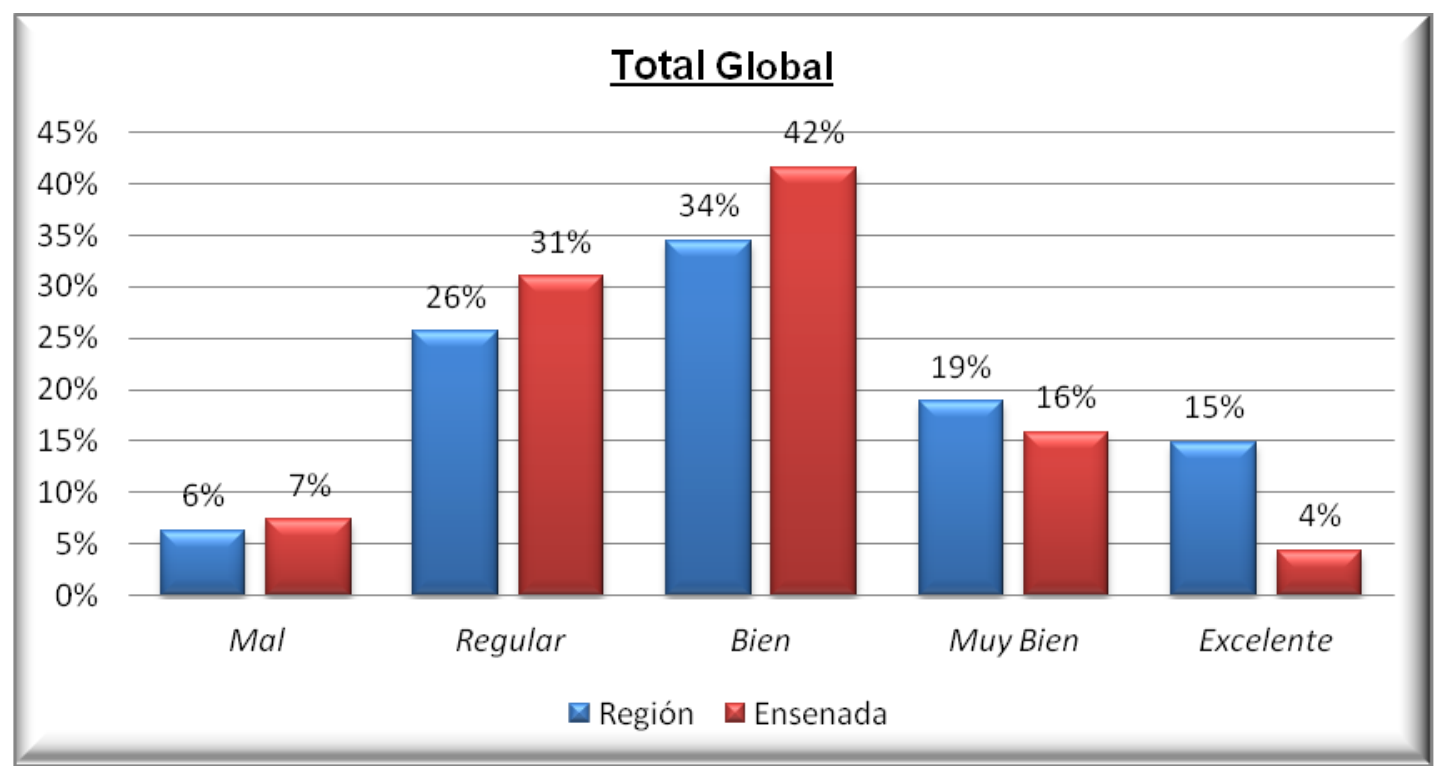

Fuente: Elaboración propia

En el caso del gráfico global, el cual representa los saldos respuestas totales de los docentes y los empresarios, comparados con la región, se puede ver que en ambos casos, los resultados obtenidos en Ensenada están por debajo de la región, con una diferencia más marcada en el caso de los empresarios. 


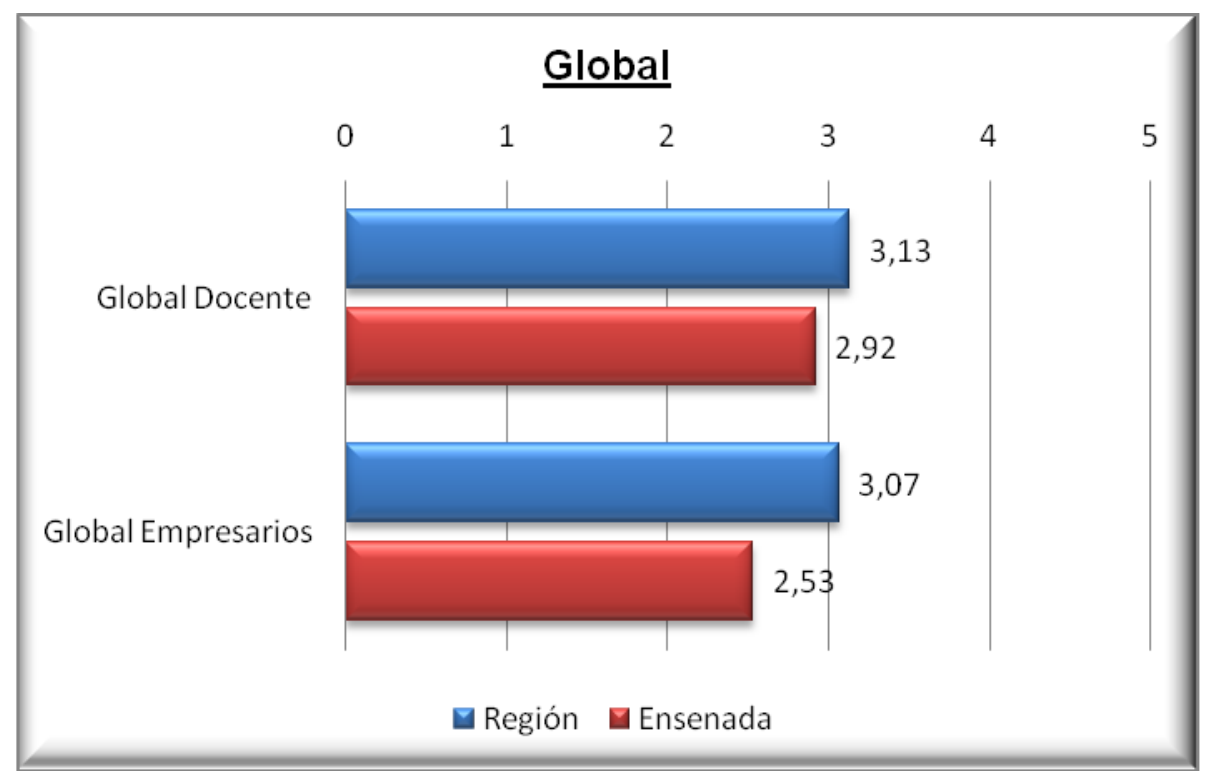

Fuente: Elaboración propia

Por último, el saldo de respuesta total, que hace referencia a todas las respuestas de las áreas evaluadas, tanto de empresarios como docentes. En este caso se observa que, como resumen de los gráficos anteriores, el partido de Ensenada tiene un menor nivel educativo, en comparación con la región, con una diferencia de 0,31.

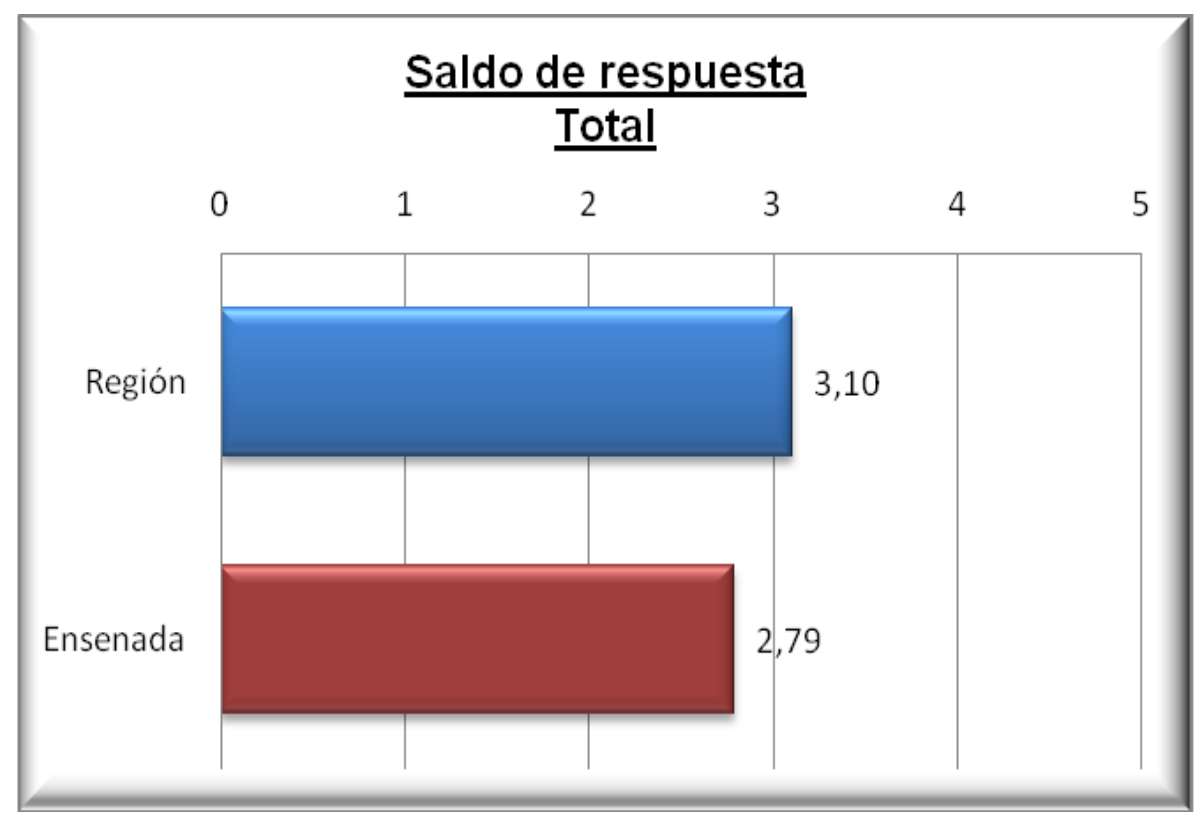

Fuente: Elaboración propia 


\subsubsection{Comparación internacional}

El resumen de las calificaciones para Ensenada por áreas es:

\begin{tabular}{|lrrr|} 
& Matemáticas & Lengua & Ciencias \\
\hline Ensenada (Docentes) & 2,93 & 2,63 & 2,65 \\
\hline Ensenada (Empresarios) & 2,28 & 2,31 & 2,34 \\
\hline Total Ensenada $\left(^{*}\right)$ & 2,66 & 2,50 & 2,52 \\
\hline
\end{tabular}

(*) Promedio ponderado de las calificaciones de Docentes y Empresarios

Su transformación a la escala de PISA, acorde con la ecuación de transformación determinada en el punto 7.4 es:

\begin{tabular}{|rrrr|} 
& Matemáticas & Lengua & Ciencias \\
\hline Ensenada & 332 & 300 & 304 \\
\hline
\end{tabular}

El último informe disponible de PISA corresponde al 2009.

A continuación se muestran las tablas jerárquicas del informe PISA 2009 a las que se les añadió la ubicación en ellas de Ensenada. 
Media en competencia matemática en los países y comunidades autónomas participantes en PISA 2009

\begin{tabular}{|c|c|c|c|}
\hline Nivel & Jerarquía & Países & Media \\
\hline \multirow{4}{*}{4} & 1 & Shanghái - China & 600 \\
\hline & 2 & Singapur & 562 \\
\hline & 3 & Hong Kong - China & 555 \\
\hline & 4 & Corea del Sur & 546 \\
\hline \multirow{32}{*}{3} & 5 & Taipéi - China & 543 \\
\hline & 6 & Finlandia & 541 \\
\hline & 7 & Liechtenstein & 536 \\
\hline & 8 & Suiza & 534 \\
\hline & 9 & Japón & 529 \\
\hline & 10 & Canadá & 527 \\
\hline & 11 & Países Bajos & 526 \\
\hline & 12 & Macao - China & 525 \\
\hline & 13 & Nueva Zelanda & 519 \\
\hline & 14 & Bélgica & 515 \\
\hline & 15 & Australia & 514 \\
\hline & 16 & Alemania & 513 \\
\hline & 17 & Estonia & 512 \\
\hline & 18 & Islandia & 507 \\
\hline & 19 & Dinamarca & 503 \\
\hline & 20 & Eslovenia & 501 \\
\hline & 21 & Noruega & 498 \\
\hline & 22 & Francia & 497 \\
\hline & 23 & República Eslovaca & 497 \\
\hline & 24 & Austria & 496 \\
\hline & 25 & Polonia & 495 \\
\hline & 26 & Suecia & 494 \\
\hline & 27 & República Checa & 493 \\
\hline & 28 & Reino Unido & 492 \\
\hline & 29 & Hungría & 490 \\
\hline & 30 & Luxemburgo & 489 \\
\hline & 31 & Estados Unidos & 487 \\
\hline & 32 & Irlanda & 487 \\
\hline & 33 & Portugal & 487 \\
\hline & 34 & España & 483 \\
\hline & 35 & Italia & 483 \\
\hline & 36 & Letonia & 482 \\
\hline \multirow{8}{*}{2} & 37 & Lituania & 477 \\
\hline & 38 & Federación Rusa & 468 \\
\hline & 39 & Grecia & 466 \\
\hline & 40 & Croacia & 460 \\
\hline & 41 & Dubái (EAU) & 453 \\
\hline & 42 & Israel & 447 \\
\hline & 43 & Turquía & 445 \\
\hline & 44 & Serbia & 442 \\
\hline
\end{tabular}


Calidad Educativa del Nivel Secundario de Ensenada

\begin{tabular}{|c|c|c|c|}
\hline & 45 & Azerbaiyán & 431 \\
\hline & 46 & Bulgaria & 428 \\
\hline & 47 & Rumania & 427 \\
\hline & 48 & Uruguay & 427 \\
\hline & 49 & Chile & 421 \\
\hline \multirow{15}{*}{1} & 50 & Tailandia & 419 \\
\hline & 51 & México & 419 \\
\hline & 52 & Trinidad y Tobago & 414 \\
\hline & 53 & Kazajistán & 405 \\
\hline & 54 & Montenegro & 403 \\
\hline & 55 & Argentina & 388 \\
\hline & 56 & Jordania & 387 \\
\hline & 57 & Brasil & 386 \\
\hline & 58 & Colombia & 381 \\
\hline & 59 & Albania & 377 \\
\hline & 60 & Túnez & 371 \\
\hline & 61 & Indonesia & 371 \\
\hline & 62 & Qatar & 368 \\
\hline & 63 & Perú & 365 \\
\hline & 64 & Panamá & 360 \\
\hline \multirow{3}{*}{$\begin{array}{c}\text { Fuera } \\
\text { de } \\
\text { rango }\end{array}$} & & Ensenada & 332 \\
\hline & 65 & Kirguistán & 331 \\
\hline & & Promedio OCDE & 496 \\
\hline
\end{tabular}

Fuente: PISA 2009 
Media en comprensión lectora en los países y comunidades autónomas participantes en PISA 2009

\begin{tabular}{|c|c|c|c|}
\hline Nivel & Jerarquía & Países & Media \\
\hline 4 & 1 & Shanghái - China & 556 \\
\hline \multirow{32}{*}{3} & 2 & Corea del Sur & 539 \\
\hline & 3 & Finlandia & 536 \\
\hline & 4 & Hong Kong - China & 533 \\
\hline & 5 & Singapur & 526 \\
\hline & 6 & Canadá & 524 \\
\hline & 7 & Nueva Zelanda & 521 \\
\hline & 8 & Japón & 520 \\
\hline & 9 & Australia & 515 \\
\hline & 10 & Países Bajos & 508 \\
\hline & 11 & Bélgica & 506 \\
\hline & 12 & Noruega & 503 \\
\hline & 13 & Estonia & 501 \\
\hline & 14 & Suiza & 501 \\
\hline & 15 & Polonia & 500 \\
\hline & 16 & Islandia & 500 \\
\hline & 17 & Estados Unidos & 500 \\
\hline & 18 & Liechtenstein & 499 \\
\hline & 19 & Suecia & 497 \\
\hline & 20 & Alemania & 497 \\
\hline & 21 & Irlanda & 496 \\
\hline & 22 & Francia & 496 \\
\hline & 23 & Taipéi - China & 495 \\
\hline & 24 & Dinamarca & 495 \\
\hline & 25 & Reino Unido & 494 \\
\hline & 26 & Hungría & 494 \\
\hline & 27 & Portugal & 489 \\
\hline & 28 & Macao - China & 487 \\
\hline & 29 & Italia & 486 \\
\hline & 30 & Letonia & 484 \\
\hline & 31 & Eslovenia & 483 \\
\hline & 32 & Grecia & 483 \\
\hline & 33 & España & 481 \\
\hline \multirow{11}{*}{2} & 34 & República Checa & 478 \\
\hline & 35 & República Eslovaca & 477 \\
\hline & 36 & Croacia & 476 \\
\hline & 37 & Israel & 474 \\
\hline & 38 & Luxemburgo & 472 \\
\hline & 39 & Austria & 470 \\
\hline & 40 & Lituania & 468 \\
\hline & 41 & Turquía & 464 \\
\hline & 42 & Dubái (EAU) & 459 \\
\hline & 43 & Federación Rusa & 459 \\
\hline & 44 & Chile & 449 \\
\hline
\end{tabular}


Calidad Educativa del Nivel Secundario de Ensenada

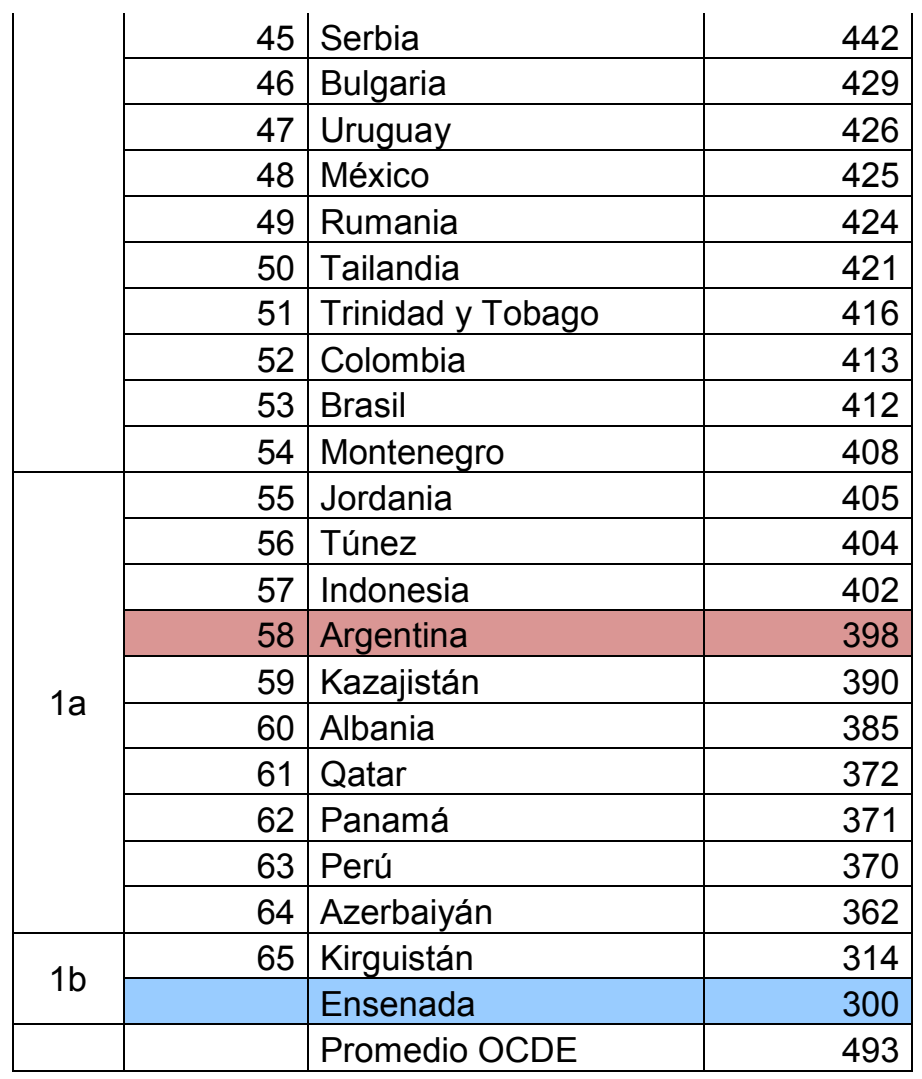

Fuente: PISA 2009 
Media en competencia científica en los países y comunidades autónomas participantes en PISA 2009

\begin{tabular}{|c|c|c|c|}
\hline Nivel & Jerarquía & Países & Media \\
\hline 4 & 1 & Shanghai - China & 575 \\
\hline \multirow{37}{*}{3} & 2 & Finlandia & 554 \\
\hline & 3 & Hong Kong - China & 549 \\
\hline & 4 & Singapur & 542 \\
\hline & 5 & Japón & 539 \\
\hline & 6 & Corea del Sur & 538 \\
\hline & 7 & Nueva Zelanda & 532 \\
\hline & 8 & Canadá & 529 \\
\hline & 9 & Estonia & 528 \\
\hline & 10 & Australia & 527 \\
\hline & 11 & Países Bajos & 522 \\
\hline & 12 & Taipéi - China & 520 \\
\hline & 13 & Alemania & 520 \\
\hline & 14 & Liechtenstein & 520 \\
\hline & 15 & Suiza & 517 \\
\hline & 16 & Reino Unido & 514 \\
\hline & 17 & Eslovenia & 512 \\
\hline & 18 & Macao - China & 511 \\
\hline & 19 & Polonia & 508 \\
\hline & 20 & Irlanda & 508 \\
\hline & 21 & Bélgica & 507 \\
\hline & 22 & Hungría & 503 \\
\hline & 23 & Estados Unidos & 502 \\
\hline & 24 & República Checa & 500 \\
\hline & 25 & Noruega & 500 \\
\hline & 26 & Dinamarca & 499 \\
\hline & 27 & Francia & 498 \\
\hline & 28 & Islandia & 496 \\
\hline & 29 & Suecia & 495 \\
\hline & 30 & Austria & 494 \\
\hline & 31 & Letonia & 494 \\
\hline & 32 & Portugal & 493 \\
\hline & 33 & Lituania & 491 \\
\hline & 34 & República Eslovaca & 490 \\
\hline & 35 & Italia & 489 \\
\hline & 36 & España & 488 \\
\hline & 37 & Croacia & 486 \\
\hline & 38 & Luxemburgo & 484 \\
\hline \multirow{6}{*}{2} & 39 & Federación Rusa & 478 \\
\hline & 40 & Grecia & 470 \\
\hline & 41 & Dubái (EAU) & 466 \\
\hline & 42 & Israel & 455 \\
\hline & 43 & Turquía & 454 \\
\hline & 44 & Chile & 447 \\
\hline
\end{tabular}


Calidad Educativa del Nivel Secundario de Ensenada

\begin{tabular}{|c|c|c|c|}
\hline & 45 & Serbia & 443 \\
\hline & 46 & Bulgaria & 439 \\
\hline & 47 & Rumania & 428 \\
\hline & 48 & Uruguay & 427 \\
\hline & 49 & Tailandia & 425 \\
\hline & 50 & México & 416 \\
\hline & 51 & Jordania & 415 \\
\hline & 52 & Trinidad y Tobago & 410 \\
\hline & 53 & Brasil & 405 \\
\hline & 54 & Colombia & 402 \\
\hline & 55 & Montenegro & 401 \\
\hline & 56 & Argentina & 401 \\
\hline & 57 & Túnez & 401 \\
\hline 1 & 58 & Kazajistán & 400 \\
\hline 1 & 59 & Albania & 391 \\
\hline & 60 & Indonesia & 383 \\
\hline & 61 & Qatar & 379 \\
\hline & 62 & Panamá & 376 \\
\hline & 63 & Azerbaiyán & 373 \\
\hline & 64 & Perú & 369 \\
\hline Fuera & 65 & Kirguistán & 330 \\
\hline rango & & Ensenada & 304 \\
\hline & & Promedio OCDE & 496 \\
\hline
\end{tabular}

Fuente: PISA 2009 


\section{Conclusiones}

Del análisis de los datos obtenidos es factible afirmar lo siguiente:

- Se observa que en todos los casos evaluados, los egresados presentan un desempeño que fluctúa entre bueno a regular.

- El panel de expertos compuesto por empresarios tiene una mirada más crítica acerca de los conocimientos y aptitudes de los egresados, debido a que en las encuestas se puede observar que su valoración al respecto es menor que la de los docentes.

- Según los profesores, las áreas donde los egresados tienen menor calificación son en Lengua y Ciencias, en cambio en el panel de expertos compuesto por los empresarios, los saldos respuesta de las distintas áreas están parejos, es decir no presentan grandes diferencias, excepto en las aptitudes personales.

- Ambos paneles de expertos coincidieron en que el área con mayor saldo de respuesta es el referido a las aptitudes personales.

- El partido de Ensenada, en comparación con la región, muestra menor nivel en la calidad educativa del secundario, ya que en ambos paneles de expertos el saldo de respuesta total fue menor.

- En la comparación regional docente, Ensenada supera a la región solamente en el área de Matemáticas, ya que en las áreas restantes, presenta un saldo de respuesta menor. En cambio, en la comparación de empresarios, Ensenada tiene un saldo de respuesta por debajo a la región en todas las áreas. 
- Con respecto a los datos secundarios, Ensenada en comparación con la región, presenta:

$\checkmark$ menor tasa de matriculación, la cual disminuye en el año 2011.

$\checkmark$ la tasa de sobre-edad es mayor a la de la región en el 2011.

$\checkmark$ el alfabetismo es menor, y por ende mayor el analfabetismo.

En lo relativo a la comparación internacional, se ha observado que Ensenada ha quedado en puestos más bajos que Argentina y excepto en Matemática, se ha ubicado al final de la tabla.

Cabe tener presente que para PISA «Los estudiantes que al menos alcanzan el nivel 2, tienen las competencias mínimas para desenvolverse en el mundo e integrarse productivamente a la sociedad» y, en las tres áreas Ensenada se ha ubicado por debajo de este nivel. 


\section{Recomendaciones}

Debe destacarse la necesidad de enfrentar los problemas vinculados a los precarios niveles de logro académico que logran los estudiantes que transitan por el sistema educativo. Más allá de la certificación formal de estudios, la educación que se brinda a los niños y jóvenes de la región está lejos de ser satisfactoria frente a los desafíos del mundo contemporáneo.

Lograr aprendizajes relevantes para el mundo de hoy es la tarea central de los sistemas educativos. Su orientación, formas de gestión, dinámicas escolares y acción de los sujetos implicados en los procesos educativos deben tender en esta dirección, y este es un desafío de suma urgencia, ya que con el paso del tiempo la brecha del conocimiento se hace cada vez mayor. La dinámica del mundo de hoy exige no sólo dar pasos significativos de progreso, sino avanzar a marcha acelerada para recuperar lo perdido y, además, tratar de alcanzar un mundo que se mueve a toda prisa.

Es necesario que los sistemas educativos sean evaluados y es ésta una fuerte obligación del Estado, pero estas evaluaciones deberían ayudar a entender los problemas, a facilitar la construcción de herramientas que permitan generar políticas educativas que propicien los cambios que se necesitan y que no induzcan a tener una mirada distorsionada de lo que en realidad ocurre dentro de las escuelas.

Para revertir esta situación, se considera que sería interesante llevar a la práctica las siguientes líneas de acción:

- Concientizar a la sociedad acerca de la magnitud del problema educativo. Si las familias no perciben su propia situación como insatisfactoria y se conforman con que el adolescente apruebe y pase de grado, no hay transformación de la educación. Cuando llegue el momento de pretender el ingreso a la Universidad o al empleo, será demasiado tarde. En ese sentido es preciso realizar campañas de sensibilización.

- Promover un pacto educativo nacional para la formulación de políticas de Estado. Algunos temas inevitables son: aumentar la inversión y determinar 
su orientación, monitoreo y evaluación; redefinir los criterios de asignación de recursos tomando en cuenta el principio de eficiencia y equidad; negociar nuevas condiciones de acreditación que prioricen la calificación para determinar el ingreso y ascenso a la carrera docente; mejorar los salarios en función de la calificación alcanzada.

- Abrir la escuela a la comunidad y convertirla en una institución capaz de rendir cuentas a los ciudadanos y a sus organizaciones representativas.

- No perderse con los contenidos y focalizar los objetivos de aprendizaje en campos prioritarios, tales como el desarrollo del lenguaje en sentido amplio; el cálculo; la relación el medio ambiente; con uno mismo y con los demás.

- Construir una institución educativa más fuerte y democrática, garantizando la autonomía y creatividad de las instituciones públicas, y las condiciones mínimas que generen sentido de identidad y permanencia.

- Debe dejar de ser un tema exclusivo de ministros de Educación, sindicatos docentes y expertos, y convertirse en un asunto de todos los argentinos, interesados en construir una sociedad más libre, más justa y más rica.

- El docente debe cumplir con determinadas exigencias para una mejor enseñanza, entre otras:

- Se requiere por parte del profesor una reflexión crítica sobre la práctica, para realizar una secuencia del mejoramiento

- Exige buen juicio, sobre todo en la evaluación de la práctica de lo que se dice, lo que se piensa y de lo que se hace.

- Humildad, tolerancia y lucha en defensa de los derechos

- Exige curiosidad, que moviliza e inserta al sujeto en la búsqueda, la construcción del conocimiento.

- Compromiso por parte del docente

- Seguridad, competencia profesional y generosidad.

En fin, los desafíos involucrados en el logro de una educación de calidad para todos son muy grandes y requieren de un compromiso amplio y sostenido de Argentina a fin de poner un mayor énfasis en el accionar autónomo de las 
personas, en su desarrollo integral, en prestar mayor atención a la diversidad y al compromiso educativo de toda la sociedad. Para ello se puede y debe contar tanto con la orientación de focos estratégicos, como con el accionar de padres de familia, educadores y estudiantes, que son los verdaderos actores del cambio educativo.

Existen suficientes evidencias para enfrentar los desafíos con optimismo. Las limitaciones estructurales no condicionan férreamente el desempeño de los sistemas educativos y es posible constatar que políticas, formas de trabajo y desempeños adecuados pueden llevar a experiencias escolares exitosas que garanticen el derecho de todos los niños a una educación de calidad, incluso en las situaciones adversas 


\section{Bibliografía}

- Braslavsky, Cecilia. (1999) "Re-haciendo escuelas: Hacia un nuevo paradigma en la educación latinoamericana." Editorial Santillana - Buenos Aires

- Braslavsky, C. y Tiramonti, G. (1990). "Conducción educativa y calidad de la enseñanza media." FLACSO - Buenos Aires

- Coll, Cesar y otros (1992) "Los contenidos en la reforma. Enseñanza y aprendizaje de conceptos, procedimientos y actitudes." Editorial Santillana Madrid

- Delors, Jacques (1996) "La educación encierra un tesoro." Informe de la UNESCO

- Dewey, John (1995) “Democracia y educación." Editorial Morata - Madrid

- Edwards Risopatrón, Verónica (1991) "El concepto de calidad de la educación". UNESCO/OREALC - Chile

- Hallak, Jackes (1991) "Invertir en el futuro. Definir las prioridades educacionales en el mundo en desarrollo". Editorial Tecnos - Madrid

- Morín, Edgar (1999) "Los siete saberes necesarios para la educación del futuro." UNESCO - Francia

- Navarrete, Hernando Mariño (1992) "Gerencia de la calidad total." Tercer mundo editores.

- Puiggros, Adriana (2004) "La otra reforma. Desde la educación menemista al fin de siglo." Editorial Galerna - Buenos Aires

- Sander, Benno (1996) "Gestión educativa en América Latina. Construcción y reconstrucción del conocimiento." Editorial Troquel - Buenos Aires

- Tenti Fanfani, Emilio (1993) "La escuela vacía: Deberes del estado y responsabilidades de la sociedad." Editorial Losada - Buenos Aires

- Tedesco, Juan Carlos (1995) "El nuevo pacto educativo. Educación, competitividad y ciudadanía en la sociedad moderna". Editorial Alauda Anaya Madrid

- "Respuesta a la crisis educativa. Primer año del colegio secundario". Artículo de Daniel Filmus 
- "El sistema educativo argentino. Características y problemas". Artículo de Silva Jauregui, María L. Lemos y Norma Paviglianiti.

\section{Páginas consultadas}

- http://www.unesco.org/new/es

- http://es.wikipedia.org/wiki/Wikipedia:Portada

- http://www.educar.org/articulos/calidadeneducacion.asp

- http://www.uis.unesco.org/Library/Documents/eiguide09-es.pdf

- http://www.eduteka.org/pdfdir/Pisa2009.pdf

- http://www.unesco.org/new/es/santiago/press-room/newsletters/newsletter-laboratoryfor-assessment-of-the-quality-of-education-llece/

- http://www.agenciaeducacion.cl/estudios-e-investigaciones/estudiosinternacionales/icils-estudio-internacional-de-alfabetizacion-computacional-y-manejode-informacion/

- $\quad$ http://www.agenciaeducacion.cl/estudios-e-investigaciones/estudiosinternacionales/timss-estudio-internacional-de-tendencias-en-matematica-y-ciencias/

- http://www.agenciaeducacion.cl/simce/que-es-el-simce/ 


\section{Referencias y Anexos}

\subsection{Encuestas sobre Calidad Educativa del Nivel Secundario}

\subsubsection{Docentes}

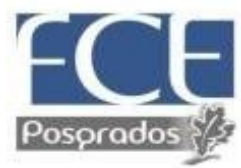

\section{Facultad de}

Ciencias Económicas

UNIVERSIDAD NACIONAL DE LA PLATA

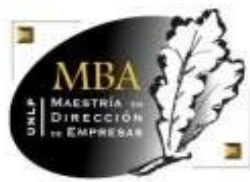

MAESTRIA EN

DIRECCIÓN DE EMPRESAS

Cuestionario para opiniones calificadas (docentes)

\section{Atributos existentes del graduado de escuela media de (Ensenada)}

Las siguientes afirmaciones están destinadas a intentar identificar los atributos existentes del graduado objeto de esta encuesta. Por favor marque con una cruz el número de la respuesta que usted crea que representa sus creencias acerca de la afirmación.

\begin{tabular}{|c|c|c|c|c|c|}
\hline $\begin{array}{c}1 \text { = Mal } \\
\text { (calificación } 0 \\
\text { a 2) }\end{array}$ & $\begin{array}{c}2 \text { = Regular } \\
\text { (calificación } \\
\text { más de } 2 \\
\text { hasta 4) }\end{array}$ & $\begin{array}{c}3=\text { Bien } \\
\text { (calificación } \\
\text { más de } 4 \\
\text { hasta 6) }\end{array}$ & $\begin{array}{c}4 \text { = Muy Bien } \\
\text { (calificación } \\
\text { más de } 6 \\
\text { hasta 8) }\end{array}$ & $\begin{array}{c}5= \\
\text { Excelente } \\
\text { (calificación } \\
\text { más de } 8 \\
\text { hasta 10) }\end{array}$ & $\begin{array}{c}\mathbf{6}=\mathbf{N S} / \mathbf{N C} \\
\text { (No sabe/ } \\
\text { No contesta) }\end{array}$ \\
\hline
\end{tabular}

\section{1.- Área Matemáticas}

\begin{tabular}{|c|c|c|c|c|c|c|}
\hline El individuo... & 1 & 2 & 3 & 4 & 5 & 6 \\
\hline 1.1.- Realiza las cuentas básicas sin uso de tecnología... & & & & & & \\
\hline 1.2.- Al realizarle una consulta sobre porcentajes simples, responde... & & & & & & \\
\hline 1.3.- Realiza conversiones con unidades de medidas... & & & & & & \\
\hline 1.4.- Conoce los tipos de triángulos existentes... & & & & & & \\
\hline 1.5.- Sabe diferenciar los distintos tipos de figuras geométricas... & & & & & & \\
\hline $\begin{array}{l}\text { 1.6.- En caso de fracciones sabe realizar las operaciones básicas } \\
\text { (suma, resta, multiplicación y división)... }\end{array}$ & & & & & & \\
\hline $\begin{array}{l}\text { 1.7.- Sabe realizar el cálculo de la superficie de un objeto (cuadrado, } \\
\text { rectángulo, entre otros)... }\end{array}$ & & & & & & \\
\hline $\begin{array}{l}\text { 1.8.- Sabe realizar el cálculo del volumen de un cuerpo (cilindro, cubo, } \\
\text { entre otros)... }\end{array}$ & & & & & & \\
\hline $\begin{array}{l}\text { 1.9.- Conoce los sistemas monetarios utilizados en Argentina (tipos de } \\
\text { cambio más utilizados y conversión)... }\end{array}$ & & & & & & \\
\hline 1.10.- Tiene noción sobre patrones de medida... & & & & & & \\
\hline 1.11.- Conoce y comprende los distintos tipos de gráficos... & & & & & & \\
\hline 1.12.- Comprende acerca de datos estadísticos... & & & & & & \\
\hline 1.13.- Capacidad para realizar un cálculo financiero elemental & & & & & & \\
\hline
\end{tabular}




\section{2.- Área Lengua}

\begin{tabular}{|c|c|c|c|c|c|c|}
\hline El individuo... & 1 & 2 & 3 & 4 & 5 & 6 \\
\hline 2.1.- Ante una instrucción por escrito, realiza la tarea... & & & & & & \\
\hline $\begin{array}{l}\text { 2.2.- Al leer un texto simple, y ante el requerimiento de extraer la idea } \\
\text { principal, lo hace... }\end{array}$ & & & & & & \\
\hline 2.3.- La capacidad de lectura es... & & & & & & \\
\hline 2.4.- Al narrar un párrafo manuscrito la ortografía observada es... & & & & & & \\
\hline 2.5.- Se desempeña oralmente ante sus pares o superiores... & & & & & & \\
\hline 2.6.- Posee conocimientos sobre historia de Argentina... & & & & & & \\
\hline 2.7.- El nivel respecto de información sobre la actualidad es... & & & & & & \\
\hline 2.8.- Conoce como se compone la división de poderes en Argentina... & & & & & & \\
\hline $\begin{array}{l}\text { 2.9.- El grado de responsabilidad cívica (interés por participar, opinar, } \\
\text { etc.) es... }\end{array}$ & & & & & & \\
\hline 2.10.- Capacidad para comprender catálogos técnicos y manuales... & & & & & & \\
\hline
\end{tabular}

\section{3.- Área Ciencias}

\begin{tabular}{|c|c|c|c|c|c|c|}
\hline El individuo... & 1 & 2 & 3 & 4 & 5 & 6 \\
\hline 3.1.- El conocimiento de los estados de la materia es... & & & & & & \\
\hline 3.2.- El conocimiento sobre primeros auxilios es... & & & & & & \\
\hline 3.3.- El conocimiento sobre seguridad e higiene en el trabajo es... & & & & & & \\
\hline 3.4.- El conocimiento sobre las principales enfermedades de Argentina... & & & & & & \\
\hline 3.5.- El conocimiento sobre los elementos de medición es... & & & & & & \\
\hline 3.6.- Conoce al menos cinco tipos de energía... & & & & & & \\
\hline 3.7.- El nivel de conocimiento sobre el sistema solar es... & & & & & & \\
\hline $\begin{array}{l}\text { 3.8.- El conocimiento sobre el uso de Internet para búsquedas de } \\
\text { información relevante es... }\end{array}$ & & & & & & \\
\hline 3.9.- El uso de los programas básicos de computación es... & & & & & & \\
\hline $\begin{array}{l}\text { 3.9.- El conocimiento sobre las consecuencias que conlleva el consumo } \\
\text { del agua no potabilizada es... }\end{array}$ & & & & & & \\
\hline $\begin{array}{l}\text { 3.10.- El conocimiento sobre las principales vías de contagio del SIDA } \\
\text { es... }\end{array}$ & & & & & & \\
\hline El Individuo... & 1 & 2 & 3 & 4 & 5 & 6 \\
\hline $\begin{array}{l}\text { 3.11.- El conocimiento acerca de los principales elementos de la } \\
\text { economía (inflación, tasas de interés, sistema cambiario, canasta básica) } \\
\text { es... }\end{array}$ & & & & & & \\
\hline $\begin{array}{l}\text { 3.12.- El conocimiento acerca de la tasa de mortalidad (edad promedio } \\
\text { en argentina) es... }\end{array}$ & & & & & & \\
\hline
\end{tabular}




\section{4.- Aptitudes Personales}

\begin{tabular}{|c|c|c|c|c|c|c|}
\hline (n) & 1 & 2 & 3 & 4 & 5 & 6 \\
\hline 4.1.- Responsabilidad en la tarea & & & & & & \\
\hline 4.2.- Creatividad & & & & & & \\
\hline 4.3.- Flexibilidad & & & & & & \\
\hline 4.4.- Puntualidad en el trabajo & & & & & & \\
\hline 4.5.- Respeto por su trabajo y las personas & & & & & & \\
\hline 4.6.- Compañerismo & & & & & & \\
\hline 4.7.- Conocimiento sobre sus propios valores & & & & & & \\
\hline 4.8.- Demuestra Interés y motivación por su trabajo & & & & & & \\
\hline 4.9.- Buena presencia & & & & & & \\
\hline 4.10.- Le interesa trabajar en equipo & & & & & & \\
\hline 4.11.- Grado de adaptación a la tarea & & & & & & \\
\hline 4.12.- Grado de aprendizaje & & & & & & \\
\hline 4.13.- Capacidad para comunicarse y transmitir sus conocimientos & & & & & & \\
\hline 4.14.- Desempeño en el cumplimiento de su tarea & & & & & & \\
\hline 4.15.- Orden y prolijidad en la tarea & & & & & & \\
\hline 4.16.- Capacidad de resolución de problemas y comunicación del mismo & & & & & & \\
\hline 4.17.-Poder de negociación & & & & & & \\
\hline 4.18.- Uso de herramientas apropiadas & & & & & & \\
\hline
\end{tabular}




\subsubsection{Empresarios}
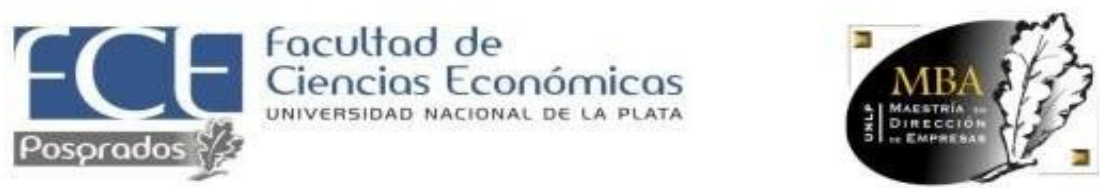

MAESTRIA EN

DIRECCIÓN DE EMPRESAS

Cuestionario para opiniones calificadas (empresarios)

Atributos existentes del graduado de escuela media de (Ensenada)

Las siguientes afirmaciones están destinadas a intentar identificar los atributos existentes del graduado objeto de esta encuesta. Por favor marque con una cruz el número de la respuesta que usted crea que representa sus creencias acerca de la afirmación.

\begin{tabular}{|c|c|c|c|c|c|}
\hline $\begin{array}{c}1=\text { Mal } \\
\text { (calificación } 0 \\
\text { a 2) }\end{array}$ & $\begin{array}{c}2 \text { = Regular } \\
\text { (calificación } \\
\text { más de } 2 \\
\text { hasta 4) }\end{array}$ & $\begin{array}{c}3=\text { Bien } \\
\text { (calificación } \\
\text { más de } 4 \\
\text { hasta 6) }\end{array}$ & $\begin{array}{c}4 \text { = Muy Bien } \\
\text { (calificación } \\
\text { más de } 6 \\
\text { hasta 8) }\end{array}$ & $\begin{array}{c}5= \\
\text { Excelente } \\
\text { (calificación } \\
\text { más de } 8 \\
\text { hasta 10) }\end{array}$ & $\begin{array}{c}\mathbf{6}=\text { NS/NC } \\
\text { (No sabe/ } \\
\text { No contesta) }\end{array}$ \\
\hline
\end{tabular}

\section{1.- Área Matemáticas}

\begin{tabular}{|c|c|c|c|c|c|c|}
\hline El individuo... & 1 & 2 & 3 & 4 & 5 & 6 \\
\hline 1.1.- Realización de cuentas básicas sin uso de tecnología... & & & & & & \\
\hline 1.2.- Ante un cálculo de porcentajes simples, responde... & & & & & & \\
\hline 1.3.- Realiza conversiones con unidades de medidas. & & & & & & \\
\hline 1.4.- Distingue los distintos tipos de figuras geométricas... & & & & & & \\
\hline 1.5.- En caso de fracciones, realiza las operaciones básicas... & & & & & & \\
\hline $\begin{array}{l}\text { 1.6.- Conocimiento acerca de los sistemas monetarios utiliza } \\
\text { Argentina (tipos de cambio más utilizados y conversión)... }\end{array}$ & & & & & & \\
\hline 1.7.- Tiene noción sobre patrones de medida.. & & & & & & \\
\hline 1.8.- Conoce y comprende los distintos tipos de gráficos... & & & & & & \\
\hline 1.9.- Comprende datos estadísticos... & & & & & & \\
\hline 1.10.- Capacidad para realizar un cálculo financiero elemental... & & & & & & \\
\hline
\end{tabular}

\section{2.- Área Lengua}

\begin{tabular}{|l|l|l|l|l|l|l|}
\hline \multicolumn{1}{|c|}{ El individuo... } & 1 & 2 & 3 & 4 & 5 & 6 \\
\hline 2.1.- La comprensión de textos es... & & & & & & \\
\hline 2.2.- La redacción de textos es... & & & & & & \\
\hline 2.3.- La capacidad de lectura es... & & & & & & \\
\hline 2.4.- La caligrafía es... & & & & & & \\
\hline 2.5.- La ortografía es... & & & & & & \\
\hline 2.6.- El desempeño oral es... & & & & & & \\
\hline 2.7.- El nivel de información sobre la actualidad es... & & & & & & \\
\hline 2.8.- Capacidad para comprender catálogos técnicos y manuales... & & & \\
\hline
\end{tabular}




\section{3.- Área Ciencias}

\begin{tabular}{|l|l|l|l|l|l|l|}
\hline \multicolumn{1}{|c|}{ El individuo... } & 1 & 2 & 3 & 4 & 5 & 6 \\
\hline 3.1.- Conocimiento sobre primeros auxilios... & & & & & & \\
\hline 3.2.- Conocimiento sobre seguridad e higiene en el trabajo... & & & & & & \\
\hline 3.3.- Conocimiento sobre los elementos de medición... & & & & & & \\
\hline $\begin{array}{l}\text { 3.4.- Conocimiento sobre el uso de Internet para búsquedas de } \\
\text { información relevante es... }\end{array}$ & & & & & \\
\hline 3.5.- El uso de los programas básicos de computación es... & & & & & \\
\hline $\begin{array}{l}\text { 3.6.- Conocimiento acerca de los principales elementos de la economía } \\
\text { (inflación, tasas de interés, sistema cambiario, canasta básica)... }\end{array}$ & & & & & \\
\hline
\end{tabular}

\section{4.- Aptitudes Personales}

\begin{tabular}{|c|c|c|c|c|c|c|}
\hline El individuo... & 1 & 2 & 3 & 4 & 5 & 6 \\
\hline 4.1.- Responsabilidad & & & & & & \\
\hline 4.2.- Creatividad & & & & & & \\
\hline 4.3.- Flexibilidad & & & & & & \\
\hline 4.4.- Puntualidad & & & & & & \\
\hline 4.5.- Respeto & & & & & & \\
\hline 4.6.- Compañerismo & & & & & & \\
\hline 4.7.- Valores & & & & & & \\
\hline 4.8.- Interés y motivación & & & & & & \\
\hline 4.9.- Presencia & & & & & & \\
\hline 4.10.- Le interesa trabajar en equipo & & & & & & \\
\hline 4.11.- Grado de adaptación al trabajo & & & & & & \\
\hline 4.12.- Grado de aprendizaje & & & & & & \\
\hline 4.13.- Capacidad para comunicarse y transmitir sus conocimientos & & & & & & \\
\hline 4.14.- Desempeño en el cumplimiento de sus tareas & & & & & & \\
\hline 4.15.- Orden y prolijidad & & & & & & \\
\hline 4.16.- Capacidad de resolución de problemas y comunicación del mismo & & & & & & \\
\hline 4.17.- Capacidad de negociación & & & & & & \\
\hline 4.18.- Uso de herramientas apropiadas & & & & & & \\
\hline
\end{tabular}




\subsection{Tablas de resultados de encuestas}

\subsubsection{Docentes}

\begin{tabular}{|c|c|c|c|c|c|c|c|c|}
\hline \multicolumn{9}{|c|}{ 1) Área Matemáticas } \\
\hline & Mal & Regular & Bien & Muy Bien & Excelente & NS/NC & & \\
\hline El individuo... & 1 & 2 & 3 & 4 & 5 & 6 & Total & Saldo Resp \\
\hline 1.1.- Realiza cuentas básicas sin uso de tecnología... & 0 & 2 & 4 & 2 & 1 & 1 & 10 & 3,22 \\
\hline 1.2.- Ante un cálculo de porcentajes simples, responde... & 0 & 2 & 4 & 1 & 2 & 1 & 10 & 3,33 \\
\hline 1.3.- Realiza conversiones con unidades de medidas... & 0 & 5 & 2 & 1 & 1 & 1 & 10 & 2,78 \\
\hline 1.4.- Su conocimiento de los tipos de triángulos existentes es... & 0 & 3 & 5 & 1 & 0 & 1 & 10 & 2,78 \\
\hline 1.5.- Distingue los distintos tipos de figuras geométricas.. & 0 & 1 & 4 & 4 & 0 & 1 & 10 & 3,33 \\
\hline 1.6.- En caso de fracciones, realiza las operaciones básicas... & 0 & 4 & 5 & 0 & 0 & 1 & 10 & 2,56 \\
\hline 1.7.- Es capaz de calcular la superficie de un objeto ... & 0 & 4 & 4 & 1 & 0 & 1 & 10 & 2,67 \\
\hline 1.8.- Es capaz de calcular el volumen de un cuerpo... & 0 & 5 & 3 & 1 & 0 & 1 & 10 & 2,56 \\
\hline $\begin{array}{l}\text { 1.9.- Tiene conocimiento acerca de los sistemas monetarios utilizados en } \\
\text { Argentina (tipos de cambio más utilizados y conversión)... }\end{array}$ & 0 & 2 & 2 & 4 & 1 & 1 & 10 & 3,44 \\
\hline 1.10.- Tiene noción sobre patrones de medida... & 0 & 2 & 6 & 1 & 1 & 0 & 10 & 3,10 \\
\hline 1.11.- Conoce y comprende los distintos tipos de gráficos... & 0 & 4 & 4 & 1 & 1 & 0 & 10 & 2,90 \\
\hline 1.12.- Comprende datos estadísticos.. & 0 & 4 & 5 & 0 & 1 & 0 & 10 & 2,80 \\
\hline 1.13.- Tiene capacidad para realizar un cálculo financiero elemental... & 1 & 4 & 1 & 1 & 1 & 2 & 10 & 2,63 \\
\hline Total & 1 & 42 & 49 & 18 & 9 & 11 & 130 & 2,93 \\
\hline Porcentaje & $1 \%$ & $35 \%$ & $41 \%$ & $15 \%$ & $8 \%$ & & $100 \%$ & \\
\hline
\end{tabular}

\begin{tabular}{|c|c|c|c|c|c|c|c|c|}
\hline \multicolumn{9}{|c|}{ 2) Área Lengua } \\
\hline El individuo... & 1 & 2 & 3 & 4 & 5 & 6 & Total & Saldo Resp \\
\hline 2.1.- Es capaz de comprender un texto... & 0 & 1 & 6 & 2 & 1 & 0 & 10 & 3,30 \\
\hline 2.2.- Es capaz de redactar un texto... & 0 & 6 & 3 & 1 & 0 & 0 & 10 & 2,50 \\
\hline 2.3.- Presenta una habilidad de lectura que es... & 0 & 4 & 6 & 0 & 0 & 0 & 10 & 2,60 \\
\hline 2.4.- Presenta una caligrafía que es... & 0 & 6 & 4 & 0 & 0 & 0 & 10 & 2,40 \\
\hline 2.5.- Presenta una ortografia que es... & 2 & 7 & 1 & 0 & 0 & 0 & 10 & 1,90 \\
\hline 2.6.- Presenta un desempeño oral que es. & 0 & 3 & 7 & 0 & 0 & 0 & 10 & 2,70 \\
\hline 2.7.- Es capaz de exponer una idea en forma oral / escrita.. & 0 & 1 & 9 & 0 & 0 & 0 & 10 & 2,90 \\
\hline 2.8.- Es capaz de reconocer las ideas principales en un texto.. & 0 & 6 & 3 & 1 & 0 & 0 & 10 & 2,50 \\
\hline 2.9.- Tiene capacidad de organizar y jerarquizar conceptos... & 0 & 6 & 1 & 2 & 0 & 1 & 10 & 2,56 \\
\hline 2.10.- Tiene capacidad de resumir un texto... & 0 & 3 & 5 & 2 & 0 & 0 & 10 & 2,90 \\
\hline Total & 2 & 43 & 45 & 8 & 1 & 1 & 100 & 2,63 \\
\hline Porcentaje & $2 \%$ & $43 \%$ & $45 \%$ & $8 \%$ & $1 \%$ & & $100 \%$ & \\
\hline
\end{tabular}

\begin{tabular}{|c|c|c|c|c|c|c|c|c|}
\hline \multicolumn{9}{|c|}{ 3) Área Ciencias } \\
\hline El individuo... & 1 & 2 & 3 & 4 & 5 & 6 & Total & Saldo Resp \\
\hline 3.1.- Tiene conocimiento acerca de los estados de la materia. & 0 & 2 & 5 & 1 & 0 & 2 & 10 & 2,88 \\
\hline 3.2.- Tiene conocimiento sobre primeros auxilios. & 2 & 4 & 0 & 1 & 0 & 3 & 10 & 2,00 \\
\hline 3.3.- Tiene conocimiento sobre seguridad e higiene.. & 0 & 5 & 1 & 1 & 0 & 3 & 10 & 2,43 \\
\hline 3.4.- Tiene conocimiento sobre las principales enfermedades de Argentina. & 1 & 3 & 1 & 1 & 0 & 4 & 10 & 2,33 \\
\hline 3.5.- Tiene conocimiento sobre los elementos de medición.. & 1 & 2 & 4 & 1 & 0 & 2 & 10 & 2,63 \\
\hline 3.6.- Tiene conocimiento de los tipos de energía existentes. & 2 & 2 & 4 & 0 & 0 & 2 & 10 & 2,25 \\
\hline 3.7.- Tiene conocimiento sobre el sistema solar.. & 0 & 2 & 6 & 0 & 0 & 2 & 10 & 2,75 \\
\hline $\begin{array}{l}\text { 3.8.- Tiene conocimiento sobre el uso de Internet para búsquedas de } \\
\text { información relevante es... }\end{array}$ & 0 & 0 & 5 & 3 & 1 & 1 & 10 & 3,56 \\
\hline 3.9.- Usa los programas básicos de computación... & 0 & 0 & 6 & 2 & 1 & 1 & 10 & 3,44 \\
\hline 3.10.- Tiene conocimiento sobre las principales vias de contagio del SIDA... & 1 & 3 & 2 & 1 & 1 & 2 & 10 & 2,75 \\
\hline $\begin{array}{l}\text { 3.11.- Tiene conocimiento acerca de los principales elementos de la } \\
\text { economía (inflación, tasas de interés, sistema cambiario, canasta básica)... }\end{array}$ & 0 & 7 & 1 & 1 & 0 & 1 & 10 & 2,33 \\
\hline $\begin{array}{l}\text { 3.12.- Tiene conocimiento de la tasa de mortalidad (edad promedio en } \\
\text { argentina)... }\end{array}$ & 1 & 5 & 2 & 0 & 0 & 2 & 10 & 2,13 \\
\hline Total & 8 & 35 & 37 & 12 & 3 & 25 & 120 & 2,65 \\
\hline Porcentaje & $8 \%$ & $37 \%$ & $39 \%$ & $13 \%$ & $3 \%$ & & $100 \%$ & \\
\hline
\end{tabular}


Calidad Educativa del Nivel Secundario de Ensenada

\begin{tabular}{|c|c|c|c|c|c|c|c|c|}
\hline \multicolumn{9}{|c|}{ 4) Aptitudes personales } \\
\hline Califique al individuo en las siguientes aptitudes & 1 & 2 & 3 & 4 & 5 & 6 & Total & Saldo Resp \\
\hline 4.1.- Responsabilidad & 0 & 2 & 5 & 2 & 1 & 0 & 10 & 3,20 \\
\hline 4.2.- Creatividad & 0 & 3 & 4 & 3 & 0 & 0 & 10 & 3,00 \\
\hline 4.3.- Flexibilidad & 0 & 1 & 6 & 3 & 0 & 0 & 10 & 3,20 \\
\hline 4.4.- Puntualidad & 3 & 3 & 1 & 3 & 0 & 0 & 10 & 2,40 \\
\hline 4.5.- Respeto & 1 & 1 & 2 & 3 & 3 & 0 & 10 & 3,60 \\
\hline 4.6.- Compañerismo & 0 & 1 & 3 & 5 & 1 & 0 & 10 & 3,60 \\
\hline 4.7.- Valores & 0 & 1 & 4 & 2 & 2 & 1 & 10 & 3,56 \\
\hline 4.8.- Interés y motivación & 0 & 1 & 6 & 3 & 0 & 0 & 10 & 3,20 \\
\hline 4.9.- Presencia & 0 & 0 & 7 & 2 & 0 & 1 & 10 & 3,22 \\
\hline 4.10.- Interés para trabajar en equipo & 0 & 0 & 4 & 4 & 2 & 0 & 10 & 3,80 \\
\hline 4.11.- Grado de adaptación al trabajo & 0 & 0 & 7 & 2 & 1 & 0 & 10 & 3,40 \\
\hline 4.12.- Grado de aprendizaje & 0 & 2 & 4 & 3 & 1 & 0 & 10 & 3,30 \\
\hline 4.13.- Capacidad para comunicarse y transmitir sus conocimientos & 0 & 2 & 7 & 1 & 0 & 0 & 10 & 2,90 \\
\hline 4.14.- Desempeño en el cumplimiento de sus tareas & 0 & 0 & 8 & 1 & 1 & 0 & 10 & 3,30 \\
\hline 4.15.- Orden y prolijidad & 0 & 4 & 2 & 3 & 1 & 0 & 10 & 3,10 \\
\hline 4.16.- Capacidad de resolución de problemas y su comunicación & 0 & 3 & 6 & 1 & 0 & 0 & 10 & 2,80 \\
\hline 4.17.- Capacidad de negociación & 0 & 2 & 6 & 2 & 0 & 0 & 10 & 3,00 \\
\hline 4.18.- Uso de herramientas apropiadas & 0 & 0 & 7 & 2 & 1 & 0 & 10 & 3,40 \\
\hline Total & 4 & 26 & 89 & 45 & 14 & 2 & 180 & 3,22 \\
\hline Porcentaje & $2 \%$ & $14 \%$ & $49 \%$ & $25 \%$ & $8 \%$ & & $99 \%$ & \\
\hline \multicolumn{9}{|c|}{ 5) Global Docentes } \\
\hline & Mal & Regular & Bien & Muy Bien & Excelente & NS/NC & Total & Saldo Resp \\
\hline Área Matemáticas & 1 & 42 & 49 & 18 & 9 & 11 & 130 & 2,93 \\
\hline \begin{tabular}{|l|} 
Área Lengua \\
\end{tabular} & 2 & 43 & 45 & 8 & 1 & 1 & 100 & 2,63 \\
\hline Área Ciencias & 8 & 35 & 37 & 12 & 3 & 25 & 120 & 2,65 \\
\hline Aptitudes Personales & 4 & 26 & 89 & 45 & 14 & 2 & 180 & 3,22 \\
\hline Total & 15 & 146 & 220 & 83 & 27 & 39 & 530 & 2,92 \\
\hline Porcentaje & $3 \%$ & $30 \%$ & $45 \%$ & $17 \%$ & $5 \%$ & & $100 \%$ & \\
\hline
\end{tabular}




\subsubsection{Empresarios}

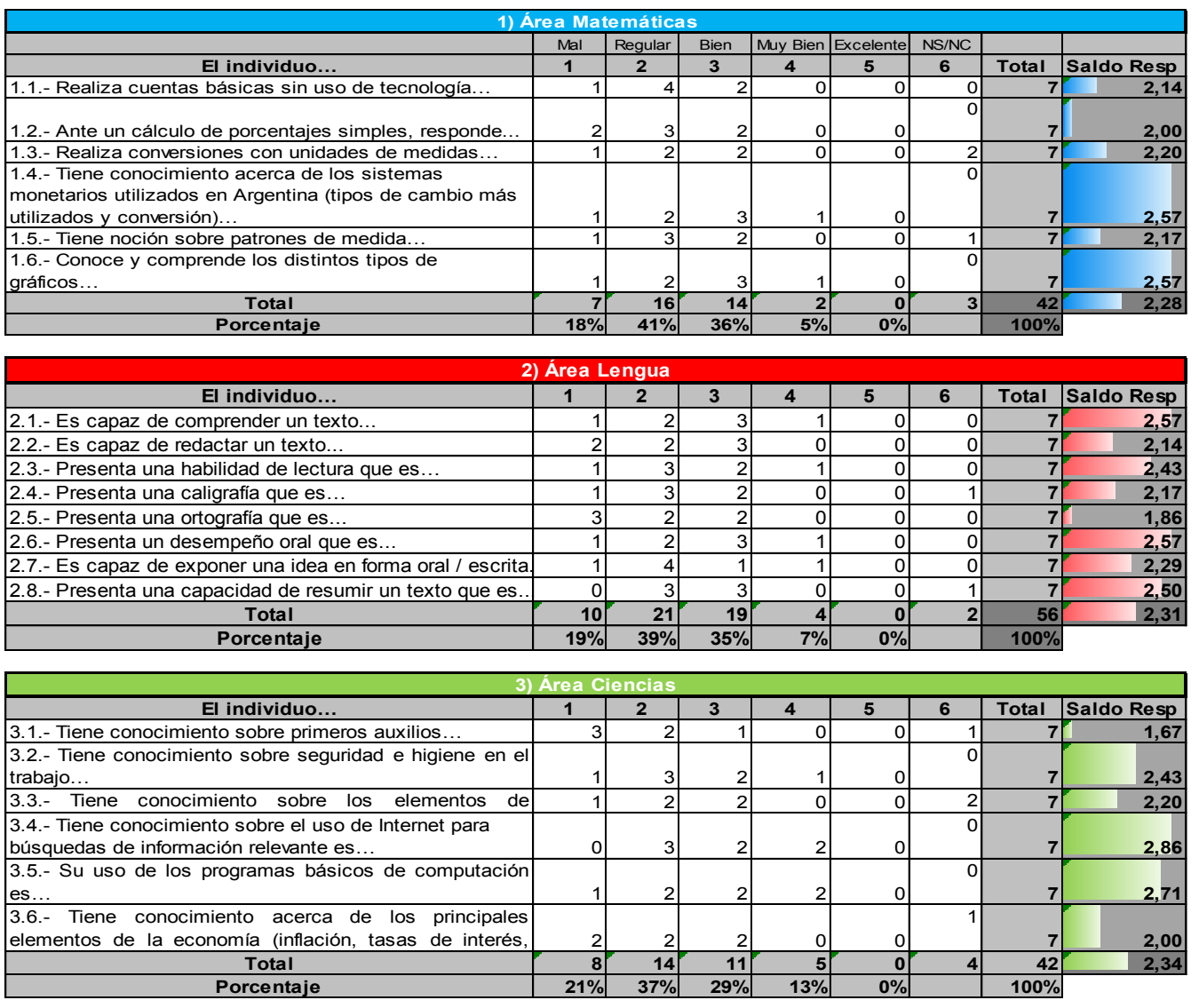

\begin{tabular}{|c|c|c|c|c|c|c|c|c|}
\hline \multicolumn{9}{|c|}{ 4) Aptitudes personales } \\
\hline Califique al individuo en las siguientes aptitudes & 1 & 2 & 3 & 4 & 5 & 6 & Total & Saldo Resp \\
\hline 4.1.- Responsabilidad & 1 & 2 & 3 & 1 & 0 & 0 & 7 & 2,57 \\
\hline 4.2.- Creatividad & 0 & 1 & 2 & 2 & 1 & 1 & 7 & 3,50 \\
\hline 4.3.- Flexibilidad & 1 & 2 & 2 & 1 & 1 & 0 & 7 & 2,86 \\
\hline 4.4.- Puntualidad & 2 & 2 & 2 & 1 & 0 & 0 & 7 & 2,29 \\
\hline 4.5.- Respeto & 2 & 2 & 2 & 1 & 0 & 0 & 7 & 2,29 \\
\hline 4.6.- Compañerismo & 0 & 1 & 3 & 2 & 0 & 1 & 7 & 3,17 \\
\hline 4.7.- Valores & 1 & 1 & 2 & 2 & 1 & 0 & 7 & 3,14 \\
\hline 4.8.- Interés y motivación & 1 & 2 & 2 & 2 & 0 & 0 & 7 & 2,71 \\
\hline 4.9.- Presencia & 1 & 2 & 3 & 1 & 0 & 0 & 7 & 2,57 \\
\hline 4.10.- Interés para trabajar en equipo & 0 & 2 & 3 & 1 & 0 & 1 & 7 & 2,83 \\
\hline 4.11.- Grado de adaptación al trabajo & 1 & 2 & 2 & 1 & 0 & 1 & 7 & 2,50 \\
\hline 4.12.- Grado de aprendizaje & 0 & 2 & 3 & 2 & 0 & 0 & 7 & 3,00 \\
\hline 4.13.- Capacidad para comunicarse y transmitir sus conoc & 1 & 2 & 2 & 2 & 0 & 0 & 7 & 2,71 \\
\hline 4.14.- Desempeño en el cumplimiento de sus tareas & 1 & 2 & 2 & 1 & 1 & 0 & 7 & 2,86 \\
\hline 4.15.- Orden y prolijidad & 1 & 2 & 2 & 1 & 1 & 0 & 7 & 2,86 \\
\hline 4.16.- Capacidad de resolución de problemas y su comuni & 1 & 2 & 2 & 1 & 0 & 1 & 7 & 2,50 \\
\hline 4.17.- Capacidad de negociación & 0 & 2 & 4 & 0 & 0 & 1 & 7 & 2,67 \\
\hline 4.18.- Uso de herramientas apropiadas & 0 & 1 & 3 & 1 & 0 & 2 & 7 & 3,00 \\
\hline Total & 14 & 32 & 44 & 23 & 5 & 8 & 126 & 2,77 \\
\hline Porcentaje & $12 \%$ & $27 \%$ & $37 \%$ & $19 \%$ & $4 \%$ & & $100 \%$ & \\
\hline
\end{tabular}

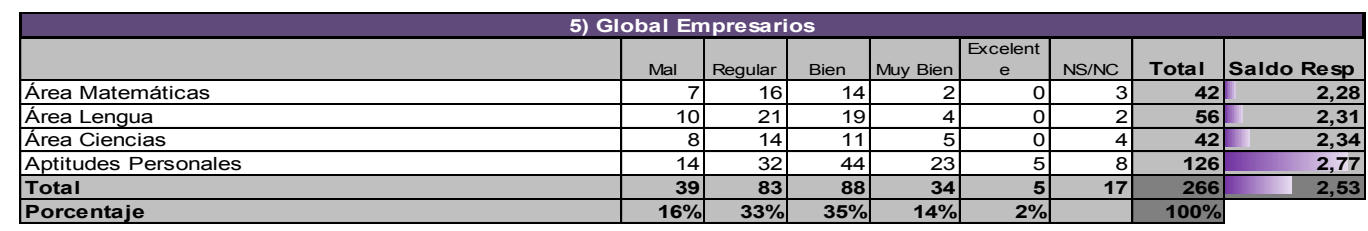


Calidad Educativa del Nivel Secundario de Ensenada

\subsubsection{Total Global}

\begin{tabular}{|c|c|c|c|c|c|c|c|c|}
\hline \multicolumn{9}{|c|}{ 6) Total Global } \\
\hline & Mal & Regular & Bien & Muy Bien & Excelente & NS/NC & & \\
\hline & 1 & 2 & 3 & 4 & 5 & 6 & Total & \begin{tabular}{|l|} 
Saldo Resp \\
\end{tabular} \\
\hline \multirow[t]{2}{*}{ Global Docente } & 15 & 146 & 220 & 83 & 27 & 39 & 530 & 2,92 \\
\hline & $3 \%$ & $30 \%$ & $45 \%$ & $17 \%$ & $5 \%$ & & $100 \%$ & \\
\hline \multirow[t]{2}{*}{ Global Empresario } & 39 & 83 & 88 & 34 & 5 & 17 & 266 & 2,53 \\
\hline & $16 \%$ & $33 \%$ & $35 \%$ & $14 \%$ & $2 \%$ & & $100 \%$ & \\
\hline \multirow[t]{2}{*}{\begin{tabular}{|l} 
Total Global \\
\end{tabular}} & 54 & 229 & 308 & 117 & 32 & 56 & 796 & \\
\hline & $7 \%$ & $31 \%$ & $42 \%$ & $16 \%$ & $4 \%$ & & $100 \%$ & \\
\hline
\end{tabular}




\subsubsection{Comparación Docentes y Empresarios}

\begin{tabular}{|l|r|r|}
\hline \multicolumn{2}{|c|}{ 1) Área Matemáticas } \\
\hline \multicolumn{1}{|c|}{ Saldo Respuesta } \\
\hline \multicolumn{1}{|c|}{ El individuo... } & Docentes & Empresarios \\
\hline 1.1.- Realiza cuentas básicas sin uso de tecnología... & $\mathbf{3 , 2 2}$ & $\mathbf{2 , 1 4}$ \\
\hline 1.2.- Ante un cálculo de porcentajes simples, responde... & $\mathbf{3 , 3 3}$ & $\mathbf{2 , 0 0}$ \\
\hline 1.3.- Realiza conversiones con unidades de medidas ... & $\mathbf{2 , 7 8}$ & $\mathbf{2 , 2 0}$ \\
\hline 1.4.- Tiene conocimiento acerca de los sistemas monetarios utilizados en Argen & $\mathbf{3 , 4 4}$ & $\mathbf{2 , 5 7}$ \\
\hline 1.5.- Tiene noción sobre patrones de medida... & $\mathbf{3 , 1 0}$ & $\mathbf{2 , 1 7}$ \\
\hline 1.6.- Conoce y comprende los distintos tipos de gráficos... & $\mathbf{2 , 9 0}$ & $\mathbf{2 , 5 7}$ \\
\hline Total & $\mathbf{2 , 9 3}$ & $\mathbf{2 , 2 8}$ \\
\hline
\end{tabular}

\begin{tabular}{|c|c|c|}
\hline \multicolumn{3}{|c|}{ 2) Área Lengua } \\
\hline \multicolumn{3}{|c|}{ Saldo Respuesta } \\
\hline El individuo... & Docentes & Empresarios \\
\hline 2.1.- Es capaz de comprender un texto... & $3, \mathbf{3 0}$ & 2,57 \\
\hline 2.2.- Es capaz de redactar un texto... & 2,50 & 2,14 \\
\hline 2.3.- Presenta una habilidad de lectura que es... & 2,60 & 2,43 \\
\hline 2.4.- Presenta una caligrafía que es... & 2,40 & 2,17 \\
\hline 2.5.- Presenta una ortografía que es... & 1,90 & 1,86 \\
\hline 2.6.- Presenta un desempeño oral que es... & 2,70 & 2,57 \\
\hline 2.7.- Es capaz de exponer una idea en forma oral / escrita... & 2,90 & 2,29 \\
\hline 2.8.- Presenta una capacidad de resumir un texto que es... & 2,90 & 2,50 \\
\hline Total & 2,63 & 2,31 \\
\hline
\end{tabular}

\begin{tabular}{|c|c|c|}
\hline \multicolumn{3}{|l|}{ 3) Arrea Lengua } \\
\hline \multicolumn{3}{|l|}{ Saldo Respuesta } \\
\hline El individuo... & Docentes & Empresarios \\
\hline 3.1.- Tiene conocimiento sobre primeros auxilios... & 2,00 & 1,67 \\
\hline 3.2.- Tiene conocimiento sobre seguridad e higiene en el trabajo... & 2,43 & 2,43 \\
\hline 3.3.- Tiene conocimiento sobre los elementos de medición... & 2,63 & 2,20 \\
\hline 3.4.- Tiene conocimiento sobre el uso de Internet para búsquedas de informaciór & 3,56 & 2,86 \\
\hline 3.5.- Su uso de los programas básicos de computación es... & 3,44 & 2,71 \\
\hline 3.6.- Tiene conocimiento acerca de los principales elementos de la economía... & 2,33 & 2,00 \\
\hline Total & 2,65 & 2,34 \\
\hline
\end{tabular}

\begin{tabular}{|c|c|c|}
\hline \multicolumn{3}{|l|}{ 4) Aptitudes Personales } \\
\hline \multicolumn{3}{|l|}{ Saldo Respuesta } \\
\hline Califique al individuo en las siguientes aptitudes & Docentes & Empresarios \\
\hline 4.1.- Responsabilidad & 3,20 & 2,57 \\
\hline 4.2.- Creatividad & 3,00 & 3,50 \\
\hline 4.3.- Flexibilidad & 3,20 & 2,86 \\
\hline 4.4.- Puntualidad & 2,40 & 2,29 \\
\hline 4.5.- Respeto & 3,60 & 2,29 \\
\hline 4.6.- Compañerismo & 3,60 & 3,17 \\
\hline 4.7.- Valores & 3,56 & 3,14 \\
\hline 4.8.- Interés y motivación & 3,20 & 2,71 \\
\hline 4.9.- Presencia & 3,22 & 2,57 \\
\hline 4.10.- Interés para trabajar en equipo & 3,80 & 2,83 \\
\hline 4.11.- Grado de adaptación al trabajo & $3, \mathbf{4 0}$ & 2,50 \\
\hline 4.12.- Grado de aprendizaje & 3,30 & 3,00 \\
\hline 4.13.- Capacidad para comunicarse y transmitir sus conocimientos & 2,90 & 2,71 \\
\hline 4.14.- Desempeño en el cumplimiento de sus tareas & 3,30 & 2,86 \\
\hline 4.15.- Orden y prolijidad & 3,10 & 2,86 \\
\hline 4.16.- Capacidad de resolución de problemas y su comunicación & 2,80 & 2,50 \\
\hline 4.17.- Capacidad de negociación & 3,00 & 2,67 \\
\hline 4.18.- Uso de herramientas apropiadas & 3,40 & 3,00 \\
\hline Total & 3,22 & 2,77 \\
\hline
\end{tabular}




\subsubsection{Resultado Regional - Docentes}

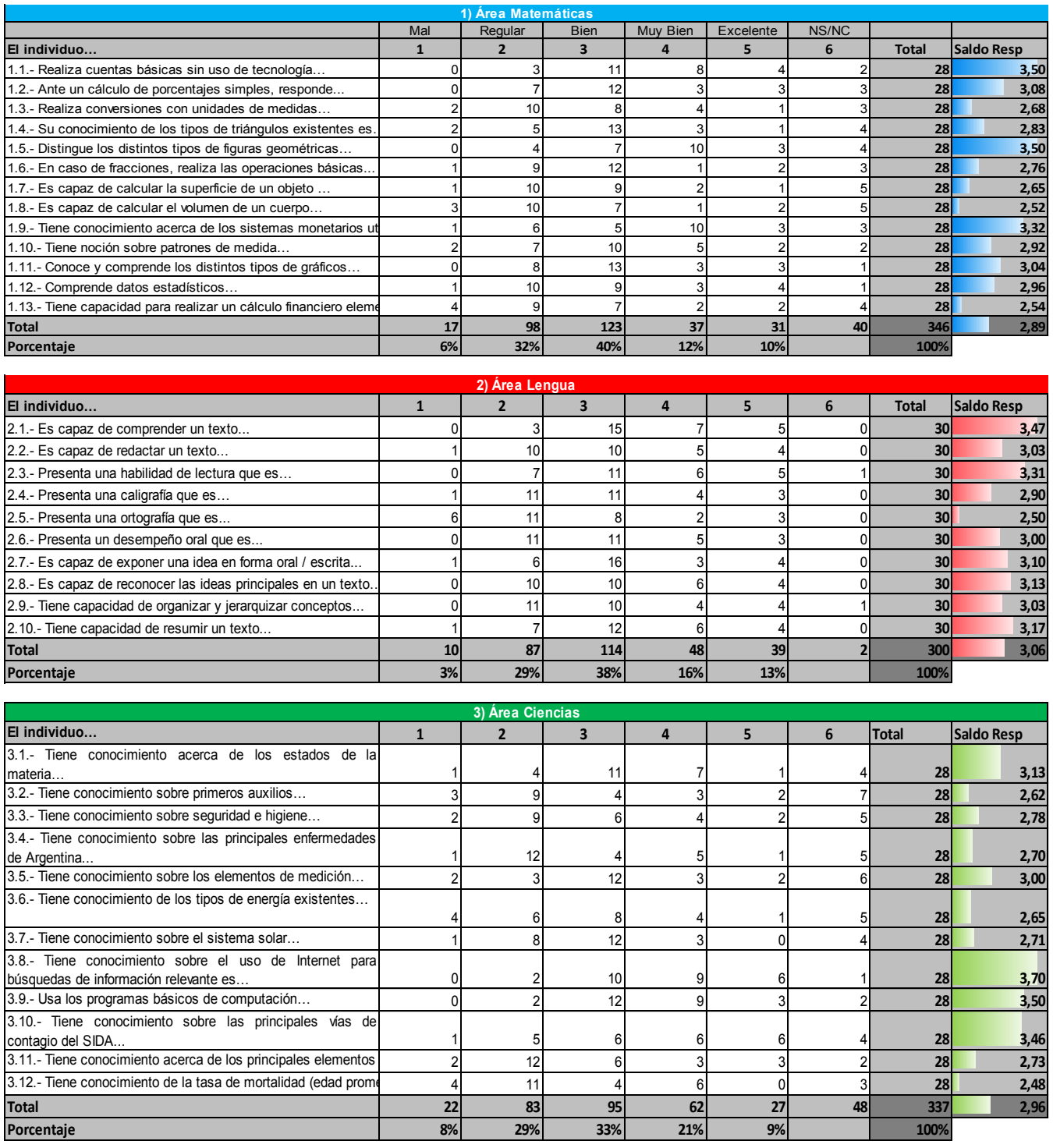

\begin{tabular}{|c|c|c|c|c|c|c|c|c|}
\hline \multicolumn{9}{|c|}{ 4) Aptitudes personales } \\
\hline Califique al individuo en las siguientes aptitudes & 1 & 2 & 3 & 4 & 5 & 6 & Total & Saldo Resp \\
\hline 4.1.- Responsabilidad & 0 & 5 & 13 & 5 & 6 & 0 & 29 & 3,41 \\
\hline 4.2.- Creatividad & 0 & 7 & 10 & 6 & 6 & 0 & 29 & 3,38 \\
\hline 4.3.- Flexibilidad & 0 & 5 & 12 & 8 & 4 & 0 & 29 & 3,38 \\
\hline 4.4.- Puntualidad & 5 & 7 & 7 & 6 & 4 & 0 & 29 & 2,90 \\
\hline 4.5.- Respeto & 1 & 3 & 9 & 7 & 9 & 0 & 29 & 3,69 \\
\hline 4.6.- Compañerismo & 0 & 3 & 9 & 11 & 6 & 0 & 29 & 3,69 \\
\hline 4.7.- Valores & 0 & 4 & 10 & 4 & 8 & 3 & 29 & 3,62 \\
\hline 4.8.- Interés y motivación & 1 & 5 & 10 & 8 & 5 & 0 & 29 & 3,38 \\
\hline 4.9.- Presencia & 0 & 2 & 14 & 6 & 5 & 2 & 29 & 3,52 \\
\hline 4.10.- Interés para trabajar en equipo & 1 & 1 & 9 & 10 & 7 & 1 & 29 & 3,75 \\
\hline 4.11.- Grado de adaptación al trabajo & 0 & 4 & 12 & 6 & 6 & 1 & 29 & 3,50 \\
\hline 4.12.- Grado de aprendizaje & 0 & 7 & 9 & 8 & 4 & 1 & 29 & 3,32 \\
\hline 4.13.- Capacidad para comunicarse y transmitir sus conocimie & 1 & 6 & 13 & 5 & 4 & 0 & 29 & 3,17 \\
\hline 4.14.- Desempeño en el cumplimiento de sus tareas & 1 & 2 & 16 & 6 & 5 & 0 & 30 & 3,40 \\
\hline 4.15.- Orden y prolijidad & 0 & 9 & 8 & 7 & 5 & 0 & 29 & 3,28 \\
\hline 4.16.- Capacidad de resolución de problemas y su comunicacic & 0 & 8 & 12 & 5 & 4 & 0 & 29 & 3,17 \\
\hline 4.17.- Capacidad de negociación & 1 & 5 & 10 & 9 & 2 & 2 & 29 & 3,22 \\
\hline 4.18.- Uso de herramientas apropiadas & 0 & 2 & 14 & 7 & 6 & 0 & 29 & 3,59 \\
\hline Total & 11 & 85 & 197 & 124 & 96 & 10 & 523 & 3,41 \\
\hline Porcentaje & $2 \%$ & $17 \%$ & $38 \%$ & $24 \%$ & $19 \%$ & & $100 \%$ & \\
\hline
\end{tabular}


Calidad Educativa del Nivel Secundario de Ensenada

\begin{tabular}{|c|c|c|c|c|c|c|c|c|}
\hline \multicolumn{9}{|c|}{ 5) Global Docentes } \\
\hline & Mal & Regular & Bien & Muy Bien & Excelente & $\mathrm{NS} / \mathrm{NC}$ & Total & Saldo Resp \\
\hline 1) Área Matemáticas & 17 & 98 & 123 & 37 & 31 & 40 & 346 & 2,89 \\
\hline 2) Área Lengua & 10 & 87 & 114 & 48 & 39 & 2 & 300 & 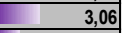 \\
\hline 3) Área Ciencias & 22 & 83 & 95 & 62 & 27 & 48 & 337 & 2,96 \\
\hline 4) Aptitudes Personales & 11 & 85 & 197 & 124 & 96 & 10 & 523 & 3,41 \\
\hline Total & 60 & 353 & 529 & 271 & 193 & 100 & 1506 & 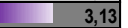 \\
\hline Porcentaje & $4 \%$ & $25 \%$ & $38 \%$ & $19 \%$ & $14 \%$ & & $100 \%$ & \\
\hline
\end{tabular}




\subsubsection{Resultado regional - Empresarios}

\begin{tabular}{|c|c|c|c|c|c|c|c|c|}
\hline \multicolumn{9}{|c|}{ 1) Área Matemáticas } \\
\hline & Mal & Regular & Bien & Muy Bien & Excelente & $\mathrm{NS} / \mathrm{NC}$ & & \\
\hline El individuo... & 1 & 2 & 3 & 4 & 5 & 6 & Total & Saldo Resp \\
\hline 1.1.- Realiza cuentas básicas sin uso de tecnología... & 2 & 12 & 7 & 6 & 2 & 0 & 29 & 2,79 \\
\hline 1.2.- Ante un cálculo de porcentajes simples, responde... & 6 & 9 & 8 & 2 & 4 & 0 & 29 & 2,62 \\
\hline 1.3.- Realiza conversiones con unidades de medidas... & 4 & 10 & 7 & 4 & 1 & 3 & 29 & 2,54 \\
\hline 1.4.- Tiene conocimiento acerca de los sistemas monetarios utili & 3 & 3 & 12 & 7 & 2 & 2 & 29 & 3,07 \\
\hline 1.5.- Tiene noción sobre patrones de medida... & 3 & 7 & 10 & 6 & 1 & 2 & 29 & 2,81 \\
\hline 1.6.- Conoce y comprende los distintos tipos de gráficos... & 2 & 7 & 11 & 7 & 2 & 0 & 29 & 3,00 \\
\hline Total & 20 & 48 & 55 & 32 & 12 & 7 & 174 & 2,81 \\
\hline Porcentaje & $12 \%$ & $29 \%$ & $33 \%$ & $19 \%$ & $7 \%$ & & $100 \%$ & \\
\hline \multicolumn{9}{|c|}{ 2) Área Lengua } \\
\hline El individuo... & 1 & 2 & 3 & 4 & 5 & 6 & Total & Saldo Resp \\
\hline 2.1.- Es capaz de comprender un texto... & 1 & 5 & 13 & 6 & 4 & 0 & 29 & 3,24 \\
\hline 2.2.- Es capaz de redactar un texto... & 3 & 10 & 11 & 2 & 3 & 0 & 29 & 2,72 \\
\hline 2.3.- Presenta una habilidad de lectura que es... & 1 & 7 & 12 & 5 & 4 & 0 & 29 & 3,14 \\
\hline 2.4.- Presenta una caligrafia que es... & 1 & 15 & 8 & 2 & 1 & 2 & 29 & 2,52 \\
\hline 2.5.- Presenta una ortografía que es... & 4 & 14 & 8 & 0 & 2 & 1 & 29 & 2,36 \\
\hline 2.6.- Presenta un desempeño oral que es... & 1 & 3 & 15 & 5 & 5 & 0 & 29 & 3,34 \\
\hline 2.7.- Es capaz de exponer una idea en forma oral / escrita... & 2 & 11 & 8 & 6 & 2 & 0 & 29 & 2,83 \\
\hline 2.8.- Presenta una capacidad de resumir un texto que es... & 1 & 10 & 9 & 2 & 3 & 4 & 29 & 2,84 \\
\hline Total & 14 & 75 & 84 & 28 & 24 & 13 & 238 & 2,88 \\
\hline Porcentaje & $6 \%$ & $33 \%$ & $37 \%$ & $12 \%$ & $11 \%$ & & $100 \%$ & \\
\hline \multicolumn{9}{|c|}{ 3) Area Ciencias } \\
\hline El individuo... & 1 & 2 & 3 & 4 & 5 & 6 & Total & Saldo Resp \\
\hline 3.1.- Tiene conocimiento sobre primeros auxilios... & 9 & 9 & 7 & 2 & 1 & 1 & 29 & 2,18 \\
\hline 3.2.- Tiene conocimiento sobre seguridad e higiene en el trabajo. & 6 & 10 & 4 & 7 & 2 & 0 & 29 & 2,62 \\
\hline 3.3.- Tiene conocimiento sobre los elementos de medición... & 7 & 7 & 9 & 2 & 2 & 2 & 29 & 2,44 \\
\hline 3.4.- Tiene conocimiento sobre el uso de Internet para búsquedas & 0 & 6 & 7 & 11 & 4 & 1 & 29 & 3,46 \\
\hline 3.5.- Su uso de los programas básicos de computación es... & 1 & 6 & 11 & 7 & 3 & 1 & 29 & 3,18 \\
\hline 3.6. - Tiene conocimiento acerca de los principales elementos de la economía... & 6 & 11 & 5 & 4 & 2 & 1 & 29 & 2,46 \\
\hline Total & 29 & 49 & 43 & 33 & 14 & 6 & 174 & 2,73 \\
\hline Porcentaje & $17 \%$ & $29 \%$ & $26 \%$ & $20 \%$ & $8 \%$ & & $100 \%$ & \\
\hline
\end{tabular}

\begin{tabular}{|c|c|c|c|c|c|c|c|c|}
\hline \multicolumn{9}{|c|}{ 4) Aptitudes personales } \\
\hline Califique al individuo en las siguientes aptitudes & 1 & 2 & 3 & 4 & 5 & 6 & Total & Saldo Resp \\
\hline 4.1.- Responsabilidad & 3 & 6 & 8 & 7 & 5 & 0 & 29 & 3,17 \\
\hline 4.2.- Creatividad & 5 & 4 & 6 & 9 & 4 & 1 & 29 & 3,11 \\
\hline 4.3.- Flexibilidad & 2 & 5 & 9 & 8 & 5 & 0 & 29 & 3,31 \\
\hline 4.4.- Puntualidad & 5 & 7 & 9 & 2 & 6 & 0 & 29 & 2,90 \\
\hline 4.5.- Respeto & 2 & 5 & 6 & 6 & 9 & 1 & 29 & 3,54 \\
\hline 4.6.- Compañerismo & 0 & 1 & 12 & 7 & 8 & 1 & 29 & 3,79 \\
\hline 4.7.- Valores & 1 & 4 & 9 & 4 & 8 & 3 & 29 & 3,54 \\
\hline 4.8.- Interés y motivación & 1 & 12 & 4 & 7 & 5 & 0 & 29 & 3,10 \\
\hline 4.9.- Presencia & 1 & 9 & 6 & 4 & 9 & 0 & 29 & 3,38 \\
\hline 4.10.- Interés para trabajar en equipo & 0 & 7 & 7 & 6 & 8 & 1 & 29 & 3,54 \\
\hline 4.11.- Grado de adaptación al trabajo & 1 & 5 & 8 & 8 & 6 & 1 & 29 & 3,46 \\
\hline 4.12.- Grado de aprendizaje & 0 & 7 & 8 & 6 & 8 & 0 & 29 & 3,52 \\
\hline 4.13.- Capacidad para comunicarse $y$ transmitir sus conocimient & 1 & 6 & 10 & 6 & 6 & 0 & 29 & 3,34 \\
\hline 4.14.- Desempeño en el cumplimiento de sus tareas & 1 & 6 & 7 & 6 & 9 & 0 & 29 & 3,55 \\
\hline 4.15.- Orden y prolijidad & 2 & 7 & 7 & 4 & 9 & 0 & 29 & 3,38 \\
\hline 4.16.- Capacidad de resolución de problemas y su comunicación & 3 & 8 & 6 & 4 & 7 & 1 & 29 & 3,14 \\
\hline 4.17.- Capacidad de negociación & 2 & 7 & 9 & 4 & 6 & 1 & 29 & 3,18 \\
\hline 4.18.- Uso de herramientas apropiadas & 2 & 3 & 12 & 4 & 6 & 2 & 29 & 3,33 \\
\hline Total & 32 & 109 & 143 & 102 & 124 & 12 & 522. & 3,35 \\
\hline Porcentaje & $6 \%$ & $21 \%$ & $28 \%$ & $20 \%$ & $24 \%$ & & $100 \%$ & \\
\hline \multicolumn{9}{|c|}{ 5) Global Empresarios } \\
\hline & $\mathrm{Mal}$ & Regular & Bien & Muy Bien & Excelente & NSINC & Total & Saldo Resp \\
\hline 1) Área Matemáticas & 20 & 48 & 55 & 32 & 12 & 7 & 174 & 2,81 \\
\hline 2) Área Lengua & 14 & 75 & 84 & 28 & 24 & 13 & 238 & 2,88 \\
\hline 3) Área Ciencias & 29 & 49 & 43 & 33 & 14 & 6 & 174 & 2,73 \\
\hline 4) Aptitudes Personales & 32 & 109 & 143 & 102 & 124 & 12 & 522. & 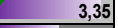 \\
\hline Total & 95 & 281 & 325 & 195 & 174 & 38 & 1108 & 3,07 \\
\hline Porcentaje & $9 \%$ & $26 \%$ & $30 \%$ & $18 \%$ & $16 \%$ & & $100 \%$ & \\
\hline
\end{tabular}




\subsubsection{Resultado total regional}

\begin{tabular}{|c|c|c|c|c|c|c|c|c|}
\hline \multicolumn{9}{|c|}{ 6) Total Global } \\
\hline & Mal & Regular & Bien & Muy Bien & Excelente & NS/NC & & \\
\hline & 1 & 2 & 3 & 4 & 5 & 6 & Total & Saldo Resp \\
\hline \multirow[t]{2}{*}{ Global Docente } & 60 & 353 & 529 & 271 & 193 & 100 & 1506 & 3,13 \\
\hline & $4 \%$ & $25 \%$ & $38 \%$ & $19 \%$ & $14 \%$ & & $100 \%$ & \\
\hline \multirow[t]{2}{*}{ Global Empresarios } & 95 & 281 & 325 & 195 & 174 & 38 & 1108 & 3,07 \\
\hline & $9 \%$ & $26 \%$ & $30 \%$ & $18 \%$ & $16 \%$ & & $100 \%$ & \\
\hline \begin{tabular}{|l} 
Total Global \\
\end{tabular} & 155 & 634 & 854 & 466 & 367 & 138 & 2614 & 3,10 \\
\hline Porcentaje & $6 \%$ & $26 \%$ & $34 \%$ & $19 \%$ & $15 \%$ & & $100 \%$ & \\
\hline
\end{tabular}




\subsection{Datos de Fuente Secundaria}

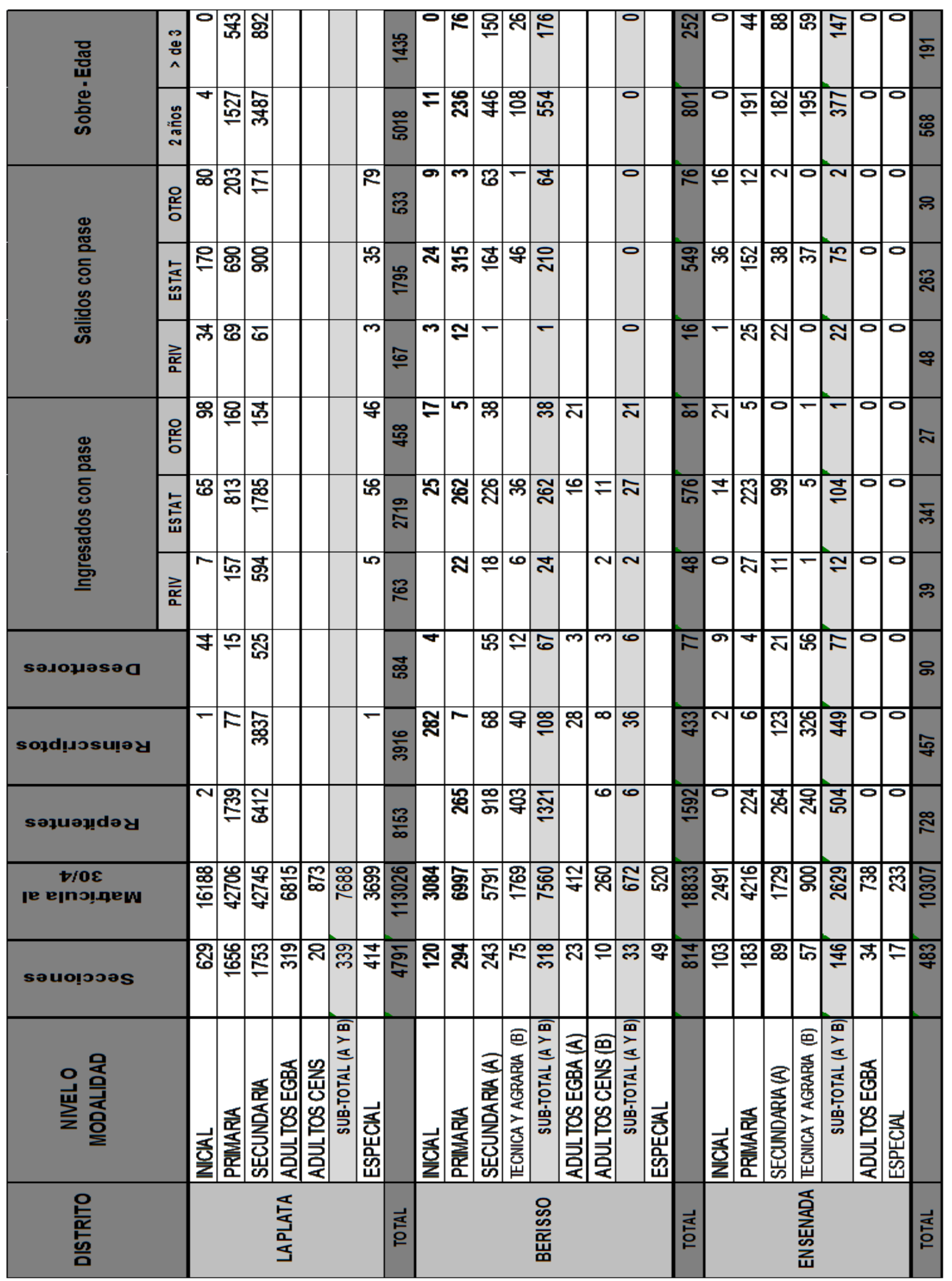




\section{Población}

\begin{tabular}{|l|l|l|l|}
\hline LA PLATA & Chicos entre 12 y 18 años & 67930 & Año 2010 \\
\cline { 2 - 4 } & Chicos entre 11 y 17 años & 66092 & Año 2011 \\
\hline
\end{tabular}

\begin{tabular}{|l|l|l|l|}
\hline BERISSO & Chicos entre 12 y 18 años & 10366 & Año 2010 \\
\cline { 2 - 4 } & Chicos entre 11 y 17 años & 10313 & Año 2011 \\
\hline
\end{tabular}

\begin{tabular}{|l|l|l|l|}
\hline ENSENADA & Chicos entre 12 y 18 años & 6590 & Año 2010 \\
\cline { 2 - 4 } & Chicos entre 11 y 17 años & 6517 & Año 2011 \\
\hline
\end{tabular}

Nota: la población total incluye a las personas viviendo en situación de calle.

El índice de masculinidad indica la cantidad de varones por cada 100 mujeres.

Fuente: INDEC. Censo Nacional de Población, Hogares y Viviendas 2010.

\section{Cantidad de personas que reportan leer y escribir}

\begin{tabular}{|c|c|c|}
\hline \multicolumn{3}{|c|}{2011} \\
\hline LA PLATA & BERISSO & ENSENADA \\
\hline 65302 & 10186 & 6435 \\
\hline
\end{tabular}

Datos suministrados por la Dirección de Información y Estadística de la Dirección Provincial de Planeamiento de la DGCyE 


\subsection{Artículos periodísticos}

\section{La educación argentina marcó uno de los mayores retrocesos a nivel mundial $^{10}$}

Así lo reveló el conocido informe PISA que mide la calidad educativa en el mundo. En 10 años, la Argentina cayó de 418 a 398 puntos, mientras que el resto de los países de la región subieron entre 16 y hasta 40 puntos. Chile es el que está mejor ubicado. (8/12/2010)

Argentina y España se encuentran entre los países que más retrocedieron en materia de educación en la última década, al tiempo que Perú, Chile y Brasil figuran entre los que más progresaron, según el informe PISA de la OCDE publicado hoy.

La clasificación del Programa para la Evaluación Internacional de Alumnos (PISA, por sus siglas en inglés) revela que las naciones latinoamericanas se encuentran, pese al progreso de muchas de ellas, en la segunda parte de la tabla, integrada por 65 países.

El mejor posicionado es actualmente Chile $\left(44^{\circ}\right)$, seguido por Uruguay $\left(47^{\circ}\right)$, México $\left(48^{\circ}\right)$, Colombia $\left(52^{\circ}\right)$, Brasil $\left(53^{\circ}\right)$, Argentina $\left(58^{\circ}\right)$ y Perú $\left(63^{\circ}\right)$. España esté en la mitad de la tabla, en el puesto $33^{\circ}$.

El informe, trienal, analiza la situación tanto de los países de la OCDE (Organización para la Cooperación y el Desarrollo Económicos) un club de una treintena de economías ricas cuyos únicos miembros latinoamericanos son México y Chile como de países asociados.

El promedio de nivel educativo de la OCDE se sitúa en 496 puntos, agrega el informe, que esta vez se focalizó principalmente en la capacidad de lectura de alumnos de 15 años, a punto de concluir su ciclo de escolaridad obligatoria. Los informes de 2003 y 2006 se habían centrado en las competencias matemáticas y en formación científica, respectivamente.

\footnotetext{
10 http://www.infobae.com/2010/12/08/550786-la-educacion-argentina-marco-uno-los-mayores-retrocesosnivel-mundial
} 
La Argentina, que durante el siglo $X X$ fue un país a la punta de la educación en el continente, tuvo un fuerte retroceso entre 2000 y 2009, cayendo de 418 a 398 puntos (-20 puntos).

El nivel de la Argentina se vio superado en ese período por el de Brasil, que pasó de 396 a 412 puntos (+16 puntos), así como por el de Chile, que subió de 410 a 449 puntos (+40 puntos).

Brasil fue uno de los escasos países que aumentó sus competencias en las tres materias estudiadas (comprensión de lectura, matemáticas y ciencias). Colombia también experimentó alzas en los tres ámbitos, pero sólo con referencia al informe de 2006, ya que no participó en ningún estudio anterior.

España cayó 12 puntos con respecto al año 2000, y se situó en 481 puntos, lejos de los 496 puntos de media de la OCDE y de los 497 de Alemania y detrás también de Portugal, que tiene 489 puntos.

Pese a los avances, la directora general de la Organización de las Naciones Unidas para la Educación, la Ciencia y la Cultura (Unesco), Irina Bokova, consideró recientemente que la calidad de la educación sigue siendo deficiente en América Latina y admitió que muchos países recortaron sus presupuestos en esta materia por la crisis.

"Invertir para mejorar la calidad de la educación, al igual que en ciencia, tecnología e innovación, es un camino de salida de la crisis económica, esto ya lo reconocen casi todos", dijo Bokova, que participó el pasado fin de semana en la XX Cumbre Iberoamericana celebrada en Argentina.

Los participantes en esa cumbre se comprometieron a erradicar el analfabetismo en 2015 en América Latina y establecieron un plan educativo hasta 2021 con una inversión de más de 100.000 millones de dólares.

Según la Unesco, en América Latina hay 39 millones de analfabetos y 110 millones de adolescentes no terminaron la escuela primaria. 


\section{$\underline{\text { América Latina: alumnos más felices pero con malos resultados }}^{11}$}

Así lo determinó el informe PISA sobre Evaluación Internacional de Alumnos. Colombia y México lideran el ranking de felicidad. Argentina está en último lugar $(3 / 12 / 13)$

El informe del Programa para la Evaluación Internacional de Alumnos (PISA, por sus siglas en inglés), realizado por la Organización para la Cooperación y el Desarrollo Económicos (OCDE), mide los conocimientos en matemáticas, ciencias y lectura de más de medio millón de alumnos en 64 países o territorios.

Los estudiantes tienen entre 15 años y tres meses y 16 años y dos meses cuando realizan la evaluación, que es complementada con un cuestionario sobre ellos.

En el informe, basándose en las pruebas de 2012, los estudiantes latinoamericanos muestran un alto grado de felicidad con su escuela.

Perú aparece en tercer lugar en esa estadística, seguido de Colombia (5), México (7), Costa Rica (8), Uruguay (13), Chile (25) y Brasil (27), todos ellos por encima de la media de la OCDE y por encima de Shanghai (28), el lugar con mejores resultados académicos. La Argentina

Cinco países/territorios asiáticos copan la parte alta del ranking estrictamente académico: Shanghai (613 puntos), Singapur, Hong Kong, Taiwán y Corea del Sur.

El primero de los países latinoamericanos evaluados es Chile $\left(51^{\circ}\right.$, con 423 puntos), seguido de México $\left(53^{\circ}, 413\right)$, Uruguay $\left(54^{\circ}, 409\right)$, Costa Rica $\left(55^{\circ}, 407\right)$, Brasil $\left(56^{\circ}, 391\right)$, la Argentina $\left(57^{\circ}, 388\right.$ puntos $)$, Colombia $\left(58^{\circ}, 376\right)$ y Perú $\left(59^{\circ}\right.$, 368). Todos ellos están por debajo de la media académica de la OCDE, que es de 494 puntos.

Todos los países latinoamericanos progresaron en alguno de los tres capítulos examinados por PISA, salvo Uruguay y Costa Rica, cuyos alumnos ofrecieron peores resultados tanto en matemáticas como en ciencia y lectura.

${ }^{11}$ www.infobae.com/2013/12/03/1528057-america-latina-alumnos-mas-felices-pero-malos-resultados 
El informe revela una correlación entre los resultados académicos y la puntualidad de los alumnos (quienes admitieron llegar tarde logran 10 puntos menos en las pruebas de matemáticas).

Uruguay, Costa Rica, Chile y Perú están en la franja más alta de impuntualidad, con el $50-60 \%$ de los estudiantes que llegan tarde al menos una vez en las dos semanas anteriores a las evaluaciones PISA. Una cifra que en el caso de los de Hong Kong, Shanghai, Vietnam y Liechtenstein iba del $15 \%$ al 19\%, y en Japón, de 9 por ciento. 
Conclusiones de la semana de la Educación: "Argentina hoy está en emergencia educativa" $^{12}$

Por: Daniela Blanco

(12/09/2013)

Es una opinión que logró consenso entre los principales protagonistas de la educación del país. La calidad educativa de mal en peor: el $52 \%$ de los adolescentes argentinos no comprenden lo que leen y sólo el $44 \%$ termina el secundario en tiempo y forma. Argentina ocupa el puesto número 7 respecto de su calidad educativa en la región y más del 15\% de los jóvenes integran el grupo "ni, ni": ni estudian, ni trabajan. ¿Por qué la sociedad y la política aún no despiertan?

Si repasamos las últimas "calificaciones" que obtuvo la Argentina en el grupo de exámenes internacionales que luego permiten construir los índices e indicadores de calidad educativa de todos los países del mundo, los números nos atraviesan como dagas a toda la sociedad.

Porque las cifras demuestran que la cuestión acerca de la calidad educativa es un desafío urgente e involucra a todos los argentinos y aleja la imagen de la Argentina calificada, que supo ser el país modelo y con la mejor educación de América Latina.

Hoy Argentina, a 125 años de la muerte de Domingo Faustino Sarmiento, ocupa el séptimo lugar en el ranking de países según su calidad educativa, detrás de Brasil, Chile, Colombia, México y Uruguay.

"La calidad educativa está en situación de emergencia", fue una de las conclusiones consensuadas entre los principales referentes del sector entre autoridades nacionales, de la ciudad y del mundo que participaron del V Foro de Calidad Educativa que organiza anualmente la asociación civil Proyecto Educar 2050, en el marco de la Semana de la Educación.

12 www.infobae.com/2013/09/12/1508404-conclusiones-la-semana-la-educacion-argentina-hoy-esta-emergenciaeducativa 
Según el último Informe del Programa Internacional para la Evaluación de Estudiantes o Informe PISA (por su sigla en inglés: Program for International Student Assessment), el $52 \%$ de los adolescentes argentinos de 15 años no comprenden lo que leen, y este es un dato que se sostiene en el caso argentino desde al año 2000. EI PISA se realiza cada tres años en varios países con el fin de determinar la valoración internacional de los alumnos y es llevado a cabo por la Organización para la Cooperación y el Desarrollo Económico (OCDE).

"El primer gran déficit que tiene nuestro país en materia de calidad educativa es la gran desigualdad, que establece diferencias importantes entre regiones y ciudades. En las zonas de mayor pobreza estamos dando la peor educación, cuando la Ley de Educación Nacional exige lo contrario. Las mejores escuelas deberían estar en las zonas más necesitadas", explica Manuel Álvarez Trongé, presidente de la ONG Proyecto Educar 2050.

Según Álvarez Trongé, otro de los grandes desafíos pendientes en la Argentina para lograr calidad educativa es el colegio secundario: "Según las últimas cifras del Ministerio de Educación de la Nación, el 56\% de los chicos no lo terminan y sólo lo completan en tiempo y forma el 44 por ciento".

Bajo el lema "Educar mejor es urgente", los principales referentes del sector se sentaron a debatir durante el Foro y las conclusiones fueron unánimes al señalar el resquebrajamiento de la calidad de la educación hoy en la Argentina y hasta hicieron un mea culpa.

La apertura fue del ministro de Educación de la Ciudad de Buenos Aires, Esteban Bullrich, quien comenzó con un panorama preocupante: "El 25\% de los alumnos que cursan la enseñanza obligatoria en el país (primario y secundario) alcanza buen nivel educativo y el restante $75 \%$ no tiene los niveles mínimos necesarios y suficientes para considerar que el menor esté educado". El ministro hizo un fuerte llamado a terminar con el "fraude educativo" y convocó a los políticos a encarar el tema con visión estratégica de país.

La última mesa de Política Educativa comenzó con un video de una entrevista al ex ministro de Educación de la Nación, Juan Carlos Tedesco, quien señaló que debería declararse de manera urgente la "Emergencia Educativa" en 
determinadas jurisdicciones del país. También hizo referencia a la necesidad de fijar metas a 10 años y que se apruebe su financiamiento por ley.

La jefa de Educación del BID, Emiliana Vegas, expuso un análisis profundo de la realidad en la región con datos y cuadros estadísticos muy detallados, y remarcó la situación argentina como una de las más graves en la región, especialmente en lectura. También señaló la necesidad de que los países que están entre los de menor desempeño (como la Argentina) tengan el objetivo de alcanzar los niveles de calidad mínimos fijados para todas las escuelas del país.

\section{La ley que no alcanzó}

¿Cuáles son las causas principales de esta situación de emergencia educativa? "Tenemos que despabilarnos como sociedad $y$ entender en profundidad el concepto y el desafío de educar. No es sólo una responsabilidad del Estado; el desafío es de la sociedad argentina en su conjunto. La política tiene que tomar a la educación como desafío electoral, y la sociedad se lo tiene que pedir. Está faltando liderazgo educativo en nuestro país", refuerza Álvarez Trongé".

En el año 2006, en la Argentina se sancionó la nueva Ley de Educación Nacional, que reemplazó el marco jurídico que regía en nuestro país desde 1993, logrando consenso mayoritario de la comunidad educativa y política. Si bien la letra de la ley basó sus principios básicos sobre la equidad, la justicia, la solidaridad y el bien común, no alcanzó para revertir la profunda desigualdad y la situación de escolarización degradada en la que se encuentran muchísimos argentinos.

"La Ley de Educación Nacional es muy buena, y eso también hay que decirlo; el gran problema es que no se aplica, no se cumple", advierte Álvarez Trongé. La ley tiene una serie de artículos muy precisos sobre cómo deben destinarse los recursos educativos para evitar la desigualdad; establece que el secundario es obligatorio y esto debe exigirse". 


\section{La generación "ni, ni"}

Tristemente, ya tienen nombre de pila: son los chicos "ni, ni" (ni estudian, ni trabajan) y representan en la Argentina entre el $10 \%$ y el $15 \%$ de la población juvenil, según los últimos informes realizados en base a datos del INDEC. Es la franja joven que aún no ha podido vencer el cerco de la ignorancia.

Alieto Guadagni, en una de las mesas del Foro, se refirió al fenómeno objetando la falta de cifras para encararlo: "Es muy importante contar con datos fidedignos, como ocurre en países vecinos que están mejorando su nivel educativo como Brasil, Uruguay y Chile". Y resaltó como contraste la prohibición del Art. 97 de nuestra Ley Nacional de Educación, que no permite la utilización de esta información por estigmatización, lo cual no ayuda al desarrollo de la calidad.

\section{Las conclusiones}

Pasados 125 años de la muerte de Domingo Faustino Sarmiento y en la semana donde se celebró el Día del Maestro en su honor, fueron más de 40 organizaciones las que se reunieron para convertir a la educación en una pasión argentina, entre el domingo 8 y el sábado 14 de septiembre.

Para Guillermina Tiramonti, de FLACSO, las falencias educativas afectan a todas las clases sociales en un sistema absolutamente fragmentado. Las escuelas públicas se enfocaron en las clases medias bajas y bajas; en cambio, el sector privado puso su ojo en los sectores con recursos medios y altos.

Por su parte, el senador nacional Ernesto Sanz hizo una recorrida histórica por la educación en nuestro país desde la Ley 1420 y explicó la importancia del compromiso político en la cuestión con un enfoque detallado en "tener información sobre cómo se piensa manejar el dinero invertido en educación". Y aseguró que en el país se desperdició dinero y tiempo, y que se perdieron los objetivos planteados. "Hoy la escuela tiene dinero, pero carece de rumbo y estrategias". Su propuesta es lograr un nuevo pacto educativo entre escuelas, docentes, alumnos, Estado, sindicato, familias y sociedad que permita un cambio de enfoque para mirar a la educación como prioridad y mejorar la calidad", expresó Sanz. 
INVESTIGACIÓN EN URUGUAY

$\underline{\text { Quienes desaprobaron en PISA no consiguieron buenos empleos }{ }^{13}}$

¿Para qué sirve el sistema educativo de un país? Para formar su fuerza laboral. El sistema educativo es la cantera de recursos humanos. No hay otra definición posible en el siglo 21. En ese contexto, es muy interesante las conclusiones que se difundieron en Uruguay acerca de resultados del ranking de evaluación educativa llamado PISA.

(04/12/2013)

Es muy equivocado el enfoque de la Administración Cristina sobre la mala calificación PISA de la Argentina. En Uruguay, en cambio, han realizado una interpretación mucho más útil para el futuro de la sociedad uruguaya, si la ubica en acción.

Los estudiantes uruguayos participaron en las pruebas PISA por 1ra. vez en 2003. Hoy esos jóvenes tienen 25 años y se han insertado en el mercado laboral o en los estudios terciarios. Un estudio que realizó un seguimiento de esos alumnos demostró que los que obtuvieron los peores resultados en 2003, diez años después, tienen los trabajos menos calificados mientras que los que tuvieron los mejores resultados, están en mejores puestos y cobran mejores salarios.

En Montevideo, Uruguay, el presidente del Codicen (Consejo de Educación Inicial y Primaria), Wilson Netto, admitió que las pruebas PISA tienen un carácter "predictivo".

A diferencia de los docentes y funcionarios argentinos, Netto consideró que los datos de esas pruebas internacionales que se realizan cada 3 años, sirven para conocer en cierta medida cómo les irá en el futuro a los jóvenes y los resultados variarán según sus conocimientos, tal como lo ha sostenido Urgente24.

El estudio realizado por el sociólogo Tabaré Fernández, y que difundió el diario El Observador, de la capital uruguaya, realizó un seguimiento al $50 \%$ de los estudiantes de 15 años que en 2003 hicieron la prueba, es decir a 2.400 adolescentes.

${ }^{13}$ www.urgente24.com/221540-quienes-desaprobaron-en-pisa-no-consiguieron-buenos-empleos 
Esa investigación reveló que el $30 \%$ de los adolescentes que obtuvo los menores puntajes en 2003 tienen hoy un trabajo manual, no calificado, explicó Netto al presentar el estudio.

En cambio, entre quienes obtuvieron los mejores niveles de desempeño el $90 \%$ tiene empleo y además tiene multiempleo y tiene los mejores ingresos.

En cuánto al nivel de desempleo, a los 20 años, en 2007 , el $60 \%$ de aquellos que habían tenido el menor desempeño estaba trabajando, mientras que de los que habían obtenido un desempeño medio lo hacía el $48 \%$ y de los que habían obtenido mejores resultados lo hacía el $40 \%$.

El estudio demostró también que los mejores resultados llevaron a los jóvenes a seguir estudiando. El $86 \%$ de los estudiantes que en 2003 obtuvo las mejores calificaciones (quedó en los niveles 4,5 y 6) siguió estudiando y hoy está en educación superior.

Esa cifra baja al $60 \%$ entre los jóvenes de los niveles de desempeño medio y a $25 \%$ entre los que habían quedado en el nivel inferior y no mostraron un desempeño adecuado.

Netto explicó al respecto que "lo que mide Pisa es la capacidad de poner en juego aquellos aprendizajes generados a nuevas situaciones". "Está demostado que no se resuelve mágicamente, se resuelve con trabajo", agregó.

"Hay claramente algo predictivo. Aquellos que tuvieron mayor desempeño en 2003 hoy tienen están disfrutando de las mejores oportunidades en nuestra sociedad", concluyó Netto.

En la presentación de resultados de las Pruebas PISA 2012, las autoridades de la enseñanza de Uruguay destacaron que ese país cayó del nivel 2 en el que estaba, que significa "capacidades mínimas para insertarse en la sociedad" al nivel 1.

El director de la Administración Nacional de Educación Pública (ANEP), Wilson Netto, matizó el resultado diciendo que era muy poco lo que se había descendido. Además, en la presentación se intentó contrastar el resultado de Uruguay con el contexto mundial, mostrando que otros países también habían retrocedido. 
De todos modos, reconoció que donde sí empeoró Uruguay fue en la enseñanza media del sector público, aunque adjudicó ese resultado al importante nivel de repetidores que hay entre los jóvenes de 15 años -la edad en la que PISA realizó su evaluación-, ya que el $40 \%$ de ellos son estudiantes rezagados.

En promedio, los resultados del $60 \%$ de alumnos que están en el grado modal, estuvieron 150 puntos por encima de aquellos que repitieron.

En este sentido, las pruebas demostraron que Uruguay está entre los 5 países con mayor porcentaje de repetición, tanto en primaria como en secundaria. 


\section{Aulas sin clima para aprender ${ }^{14}$}

Por Gustavo Laies

Para LA NACION

(21/06/2008)

Los resultados de la evaluación de la Unesco terminaron con la idea de que tenemos la mejor educación de América latina. En esta materia, nos gastamos "las joyas de la abuela".

Los países que muestran resultados superiores a los nuestros tienen tanto modelos centralizados como descentralizados, financiamiento por oferta como por demanda, dispositivos de evaluación de los docentes como ausencia de los mismos, alto porcentaje de matrícula en la educación privada como nula. En ese sentido, no parece que funcione nuestro razonamiento habitual de ideologizar los problemas para evitar responsabilizarnos. Nuestros problemas principales están en la cotidianidad de las escuelas.

Los países que nos superan comunican los resultados de las evaluaciones en tiempo y forma a las escuelas, estos datos resultan creíbles y están a disposición de la comunidad de un modo transparente. En nuestro país, los resultados de las evaluaciones no son devueltos a las escuelas en tiempo y forma, son comunicados con gran discontinuidad, de modos poco claros y todo eso deteriora su credibilidad y pertinencia. El reporte comparativo nos muestra como el país en el que mayor cantidad de alumnos llegó tarde a la prueba, adultos que interrumpieron la situación de evaluación, chicos que transgredieron la norma de quedarse en el aula hasta que todos terminaran.

Parece haber llegado el momento de abordar el problema. Chicos que lleguen en hora, con hábitos de orden y trabajo, docentes que vayan a la escuela todos los días y lleguen temprano, menor interferencia y desorden en las aulas, edificios en condiciones de limpieza y orden, bibliotecas, padres que apoyen a los docentes y exijan a sus hijos, responsabilidad que cada uno debe asumir por los resultados de su tarea.

\footnotetext{
${ }^{14}$ http://www.lanacion.com.ar/1023359-aulas-sin-clima-para-aprender
} 
A nuestra escuela le pasa lo mismo que al país: carece de orden, normas claras y un clima apropiado para producir. Pero esa no puede ser una excusa. Alguna vez fuimos capaces de construir un proyecto educativo que transformó la sociedad y le dio un proyecto a la Nación. 


\section{Cómo mejorar la calidad de la educación ${ }^{15}$}

Que los padres se involucren, que no sólo se mida lengua y matemática, que el colegio sea más abierto son algunas de las claves que proponen docentes y especialistas.

Por Alfredo Dillon

(13/06/2013)

Es la palabra vedette de los debates actuales sobre educación: todos quieren mejorar la calidad educativa. Pero ¿de qué hablamos cuando hablamos de calidad?

Para la Organización para la Cooperación y el Desarrollo Económicos (OCDE), por ejemplo, la calidad de un sistema educativo se mide a través de los aprendizajes de los estudiantes. El instrumento por excelencia es la prueba PISA, que mide el desempeño de los alumnos en matemática, ciencias y lectura. En el último informe PISA disponible, de 2009, Argentina ocupaba el puesto 58 entre las 65 naciones que participaron. La cifra contrasta con el aumento del presupuesto educativo en la última década, que llegó al 6\% del PBI.

La cuestión de la evaluación suele asociarse con los debates sobre calidad. Para Manuel Álvarez Trongé, presidente de la ONG Educar 2050, "la calidad educativa requiere de medición continua. Se necesitan parámetros ciertos y constantes para poder hacer un seguimiento en el corto, mediano y largo plazo. En este sentido, los mejores indicadores para evaluar cómo estamos en calidad son las evaluaciones a los alumnos".

En este punto, Cecilia Veleda, codirectora del programa de Educación de CIPPEC, advierte que no todo es medible en educación, pero a la vez resalta que "hay que generar más y mejores mediciones. Por ejemplo, mejorar los indicadores que ya existen -como los Operativos Nacionales de Evaluación, que deberían ser censales- para avanzar hacia un Sistema Integral de Información Educativa que incluya indicadores sobre infraestructura, equipamiento, diversidad social de los alumnos, etc.". Para ella no alcanza con medir los resultados en Lengua y

\footnotetext{
${ }^{15} \mathrm{http}: / /$ www.clarin.com/sociedad/mejorar-calidad-educacion_0_937106387.html
} 
Matemática: hay que observar "la integralidad del sistema, con miras a instalar en el país una cultura de la evaluación".

Los entrevistados coinciden: la calidad educativa abarca mucho más que la medición de los resultados de los alumnos. Nancy Montes, investigadora de FLACSO, puntualiza que el concepto "engloba también la condición salarial de los docentes, su perfil profesional, los niveles de inversión de una sociedad en su sector educativo, las condiciones de infraestructura y equipamiento, los logros de aprendizaje en otras habilidades (artísticas, deportivas, científicas, culturales en sentido amplio)".

Veleda propone mirar no solo los saberes que la escuela enseña, sino las capacidades que brinda a los chicos: "Una de las finalidades del sistema educativo es dar habilidades para la vida, ayudar a los chicos a construir un proyecto de vida. Esto implica transmitirles capacidades para la acción comunitaria, la inserción en el mercado laboral, el trabajo en equipo". En esta línea, toda evaluación de la calidad debería tener en cuenta la capacidad de acción que el sistema brinda a los jóvenes, y no limitarse a los resultados de un multiple choice.

Alicia Cancilieri, directora de la Escuela Primaria $N^{\circ} 8$ Bernardo de Monteagudo, de Vicente López, coincide: "La escuela de calidad es la que prepara a los chicos para que puedan transformar la realidad".

Desde el Colegio Manuel Belgrano, de Belgrano, el rector Eutimio Rubio Sáez sintetiza: "Un colegio de calidad es un colegio abierto, donde se concibe al alumno como un líder capaz de transformar el barrio. Donde importa no solo lo académico, sino también lo deportivo, lo solidario, lo artístico, lo espiritual. En esos terrenos se van creando lazos entre los chicos, y se genera una pertenencia del estudiante, alineada con los valores institucionales". Una escuela abierta es también aquella en la que "se trabaja con la diversidad", "hay un diálogo fluido entre el profesor y el alumno" y "se incorporan las innovaciones tecnológicas al servicio del aprendizaje", dice Eutimio.

Los directores consultados coinciden en que el trabajo en red es clave. Eduardo Toscano, de la Escuela Media N 6 Padre Carlos Mugica, de Retiro, subraya la necesidad de redes internas (el trabajo en equipo entre 
docentes, junto con los tutores y un equipo de apoyo externo al aula) y externas (el vínculo con otras escuelas de la zona, con los centros de salud del barrio, los terciarios y universidades, y empresas y fundaciones). Desde la Escuela $\mathrm{N}^{\circ} 8$, Alicia Cancilieri hace hincapié en el trabajo interinstitucional. Su escuela trabaja a la par del Jardín $\mathrm{N}^{\circ}$ 901, que está en la misma cuadra, para articular los dos niveles. "Queremos crear un polo educativo en el barrio, para que nuestros alumnos se queden en la escuela pública", cuenta Graciela Muñoz, directora del jardín.

De los diversos testimonios se desprende que la calidad no es tanto un resultado, sino un camino de búsqueda: "La calidad es un proceso de mejora continua, no tiene techo", asegura Eutimio. Y remata con una definición que pone en el centro los vínculos que se tejen en la escuela: "No hay calidad sin calidez, sin la ternura del buen trato, la escucha, el diálogo y el estar disponible para el otro". 


\section{Nuevo bochazo en el examen para ingresar en Medicina en La Plata ${ }^{16}$}

Sólo 318 estudiantes de los 1149 inscriptos superaron la prueba final que les permite acceder a esa disciplina; hicieron un curso de un año y también tuvieron parciales Por Sebastián Lalaurette $\mid$ LA NACION (27/12/2012)

LA PLATA.- Sólo un quinto de los aspirantes a iniciar el año próximo la carrera de medicina en la Universidad Nacional de La Plata (UNLP) aprobó el examen de ingreso. Un nuevo bochazo volvió a poner de relieve la controversia por el sistema de admisión obligatorio en esa disciplina, una de las pocas en esa casa de estudios que restringen el ingreso mediante una prueba.

El resultado no fue sorprendente: año tras año, los porcentajes de ingreso en la carrera de medicina son similares. Sólo que, desde hace tres años, los aspirantes deben completar un curso anual con ocho materias y aprobar exámenes parciales antes de la prueba final que determina si pueden cursar la especialidad. Antes, se requería dar el examen de ingreso, y muchos jóvenes recurrían a cursos particulares durante el verano.

De los 1449 jóvenes que se inscribieron este año en el curso de admisión, sólo 543 llegaron a la instancia final y apenas 318 (un 21,9\% de los aspirantes originales) lograron superarla. En agosto pasado, un parcial de historia de la medicina había "filtrado" a la mayoría: dos tercios de los inscriptos quedaron afuera.

Las autoridades de la Facultad consideran que el sistema es "exitoso" y argumentan que la menor cantidad de ingresantes es beneficiosa para la calidad de la cursada. Aunque la proporción de quienes entran en la carrera es casi la misma que en los años previos, el decano de la casa de estudios cree que el curso anual logra que los ingresantes estén "más maduros" y reduce la deserción.

Así lo explicó Jorge Martínez, titular de la Facultad, a LA NACION, como ocurre cada año. "Una vez que los alumnos ingresaron, la deserción es muy poquita. Los profesores nos dicen que ya en primer año, con este sistema, los estudiantes están más maduros. Y en un plazo de siete años se recibe de médico el 92\%", argumentó Martínez.

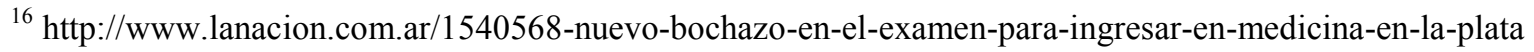


Si bien muchas facultades de la UNLP cuentan con cursos introductorios a las carreras, sólo Ciencias Médicas y Lenguas Modernas (para los traductorados de inglés y francés) tienen exámenes de ingreso obligatorio. En el de admisión a medicina, los aspirantes que no llegan al mínimo exigido de 40 respuestas correctas (sobre 60) pueden aspirar a "premios consuelo": con 30 o más respuestas optan por obstetricia o nutrición, y con menos de 30, a tecnicaturas.

"Por la infraestructura y las posibilidades que tenemos, no podemos aceptar a todos", dijo Martínez. "En los primeros años de la cursada necesitamos suficientes cadáveres para las prácticas de los estudiantes, y después, trabajar con pacientes vivos. Tenemos un límite para poder garantizar una cursada de calidad", explicó.

Victoria Morelli (19 años) pasó el duro examen de ingreso y ya está "adentro". No fue fácil: además del curso de ingreso, estudió un año y medio en un instituto privado para reforzar sus conocimientos. "Si no lo hubiera hecho, habría sido más difícil aprobar", contó Victoria a LA NACION. "De la secundaria salí con una base de conocimientos, pero con lo que vi en el instituto me sentí más segura", añadió.

Victoria aprobó los parciales y 41 de las 60 preguntas de la prueba decisiva. Muchos de sus compañeros no tuvieron la misma suerte. "Creo que hay algunos exámenes que tendrían que aflojar un poco, porque hay mucha gente que tiene toda la vocación y la capacidad para hacer la carrera y termina fallando en exámenes que no son fundamentales. La mayoría cayó en historia de la medicina", afirmó la joven. Aclaró que no está en contra de que haya un examen de admisión, pero consideró que el nivel de exigencia "no debería ser tan estricto".

Ahora, Victoria espera poder recibirse a los 25 y convertirse en médica nutricionista. Su proyecto es tener su consultorio en esta ciudad, donde vive. "Muchos chicos del interior que no pasaron, para no perder un año, decidieron entrar a obstetricia u otra carrera. Pero muchos otros no lo hicieron y van a volver a intentarlo el año que viene", concluyó.

UN FENOMENO QUE CRECE 


\section{Polémica por bochazos en la UNLP ${ }^{17}$}

Los cursos de ingreso desnudan serios problemas entre los estudiantes que llegan del secundario

(14/02/2010)

Año tras año, con el inicio de los cursos de ingreso a la Universidad llegan las desaprobaciones masivas en las evaluaciones diagnósticas. El 2010 no fue la excepción: un promedio de 2 de cada 10 ingresantes aprobaron los exámenes en Informática, Agronomía y el Observatorio. El tema suscitó una honda preocupación y un debate no exento de posiciones disímiles y hasta antagónicas.

En el Observatorio se dicta un curso de nivelación de Matemática. En las tres primeras evaluaciones, el nivel de aprobación osciló entre el 5 y el $25 \%$. "Es un tema difícil de abordar, porque tendría que criticar fuertemente a la escuela secundaria", dice Daniel Carpintero, quien dicta el cursillo en la facultad del Bosque.

"Pareciera que la Universidad siempre busca los culpables afuera. Pero es necesario hacer una crítica constructiva", afirma, y explica: "hace 19 años que damos este curso, que consta de un repaso de temas de la secundaria, y nos encontramos con que el $30 \%$ nunca vio logaritmos, o que el $50 \%$ no pone los paréntesis en las fórmulas; es como si en Lengua no pusieran los acentos".

El astrónomo señala que "a la pobreza en la enseñanza en la escuela media hay que sumarle dos cuestiones: la modalidad de corrección y la poca expectativa que existe sobre la belleza de la Matemática". En el primer caso, asegura que "la Universidad se convierte en la mala porque corrige cosas que antes no se corregían, pero alguien tiene que parar la bola de nieve", enfatiza. En cuanto al segundo aspecto, comenta que "en el Polimodal se presentaban problemas de Matemática relacionándolos con temas de la vida cotidiana para hacerla más llevadera. No está mal, pero también existe una Matemática pura, y la belleza radica en razonarla, pensarla, resolverla. Cuando lo entienden, el

\footnotetext{
${ }^{17}$ http://www.eldia.com/edis/20100214/educacion0.htm
} 
cambio de actitud es notable, y al final del curso el $90 \%$ ya está en otro nivel", asegura.

Los problemas también se detectan en la lectura y comprensión de textos. De hecho, en Bellas Artes se introdujo una materia con ese nombre para todas las carreras. Egresada de la UNLP y docente en escuelas medias, Leticia Cazorla coincide en un punto con el astrónomo: "en la escuela de los últimos años todo lo que suponía esforzarse se desechaba. Se le exigía al profesor que hiciera propuestas divertidas, que incorporara textos de fácil comprensión, breves, desconociendo que el trabajo intelectual exige esfuerzo, dedicación y concentración. Las consecuencias están a la vista", remarca.

\section{CONTRAPUNTO}

Para el decano de Medicina, Jorge Martínez, los denominados "bochazos" representan "la experiencia que hemos recogido en los últimos 17 años. El déficit de la secundaria es tan grande que en un curso corto se hace imposible nivelar. Además, nivelar sin evaluar no sirve y si la evaluación se desaprueba y el alumno ingresa igual, estamos en problemas. El Estado debe ocuparse de la secundaria y a la Universidad deben entrar quienes lo merecen", opina.

Tras aclarar que en su unidad académica han quitado las evaluaciones diagnósticas y han tomado "el camino de reforzar Matemática y de acompañar al alumno en todo su trayecto académico", el decano de Ciencias Exactas, Carlos Della Védova, opina que "si un chico llegó hasta la facultad es porque es apto para cursar cualquiera de las carreras. La experiencia nos dice que muchos que desaprueban al principio, en 5 o $\quad 6$ años son investigadores".

\section{HETEROGENEO}

En Agronomía se toman dos exámenes diagnósticos antes del curso. Uno a finales de diciembre y otro a principios de febrero. Los resultados fueron decididamente malos. "Tenemos una política claramente inclusiva", dice el secretario académico Pablo Yapura, para explicar que "en marzo se toman otras 3 
pruebas, y quienes aún deban contenidos, en abril y mayo pueden hacer una nivelación intensiva".

Luciana Garatte, profesora y coordinadora del ingreso, afirma que "no es que no nos preocupe la escuela media, pero la estrategia apunta a atender la diversidad de experiencias, necesidades y perfiles". "(A los alumnos) se les facilita una instancia efectiva, nadie les regala nada, y al final del curso aprueba cerca del $80 \% "$.

\section{“TEMAS QUE NUNCA VI"}

La alumna platense Florencia López Blanco se inscribió en Agronomía y rindió Matemática y Física en diciembre. "Me preparé sola y salí mal -cuenta-, pero en febrero aprobé. Me presenté a esas materias porque tuve un paso previo por Exactas. En cuanto a Química, preferí hacer el curso porque sólo vi algo en $1^{\circ}$ del Polimodal. En La Plata no hay buen nivel; tengo compañeros en otras facultades y todos coinciden en que el salto (a la Universidad) es muy grande".

Distinto es el caso de Matías Jeanneret, oriundo de Roque Pérez y egresado de la Escuela Agrotécnica Salesiana del Valle, en 25 de Mayo. "Todos los contenidos de las tres materias los tuve en el penúltimo año del colegio. Llegué a La Plata poco antes de que comience el curso. Rendí bien Matemática, y a Química y Física no me presenté porque no tenía las carpetas para repasar", asevera.

\section{EL FACTOR SOCIAL}

"El sentido común me hace ver que hace 20 o 30 años llevarse materias a marzo era la excepción; hoy es la regla", dice el secretario académico de Ingeniería, José Scaramutti, para quien "la responsabilidad no sólo es de la escuela. Llevarse materias antes provocaba un impacto en el hogar. Hoy los padres no le prestan la misma atención y no tienen la misma rigidez. Entonces, cuando se le quieren poner pautas al chico fuera de la casa, se produce un choque".

Leticia Cazorla coincide: "para el docente es sumamente difícil enseñar cuando está tan cuestionado, tan desprestigiado. Algunos padres objetan 
calificaciones, medidas disciplinarias, contenidos. Sin su colaboración, sin su respeto, nuestra tarea se hace cada vez más difícil".

¿Un posible camino? "Nosotros no estamos para juzgar a la escuela media, pero podemos marcar falencias para que se corrijan. Son dos mundos muy distintos que hay que empalmar, y para eso hace falta profundizar en políticas de articulación entre los dos niveles", sugiere el decano de Informática, Armando de Giusti.

\section{DISPARIDADES}

"Las disparidades crecieron de una manera alarmante. Hay una distancia enorme entre lo que los alumnos deberían saber para iniciar con éxito una carrera universitaria y los conocimientos con los que realmente cuentan", asegura Leticia Cazorla, profesora de Lengua de escuelas medias y egresada de la UNLP. 


\section{Ingreso a la UNLP: Agronomía es noticia por los desaprobados ${ }^{18}$}

Los inscriptos en esa carrera realizaron evaluaciones para evitar el curso de ingreso, pero ninguno logró aprobar todas las asignaturas. Ayer arrancaron en Exactas, Observatorio y Periodismo. En la nota, los resultados.

(04/02/2013)

Un minúsculo grupo de ingresantes a la facultad de Agronomía de la Universidad Nacional de La Plata (UNLP) logró evitar el curso de ingreso a esa casa de altos estudios, pero no en su totalidad, sino sólo en alguna de las materias. La razón es que fue masivo el número de desaprobados en los exámenes que les fueron tomados a finales de enero para eludir esa instancia.

Las pruebas de nivelación se llevaron a cabo el 29 y 30 de enero y consistieron en un examen de Química en la primera jornada, y evaluaciones de Matemática y Física al día siguiente.

En Química resultaron aprobados sólo 4 de los 39 aspirantes que se presentaron a rendir. En Matemática aprobaron 2 de los 40 alumnos que realizaron la prueba, en tanto en Física salieron airosos 11 entre 36 examinados.

Curiosamente, ninguno de los aspirantes logró aprobar las tres materias, por lo que de igual modo deberán asistir a cursar alguna de las asignaturas.

\section{Otras carreras.}

Este lunes también se pusieron en marcha los cursos de ingreso en las facultades de Ciencias Exactas, Observatorio y Periodismo.

Respecto del ingreso al Observatorio, este se realiza mediante un curso no obligatorio que finaliza el 9 de marzo y consta de clases teórico-prácticas de Matemática y charlas-taller de participación en la vida universitaria.

Cabe destacar que en esta sede universitaria continúa abierta la inscripción hasta el $1^{\circ}$ de marzo, y el número de interesados ya supera ampliamente los guarismos históricos, con 219 ingresantes. Según fuentes de la facultad, este interés se debe a la importante aceptación que tiene la nueva carrera de Meteorología.

\footnotetext{
${ }^{18}$ http://diagonales.infonews.com/Content.aspx?Id=193612
} 


\section{Mala nota}

Los países latinoamericanos siguen rezagados en ciertos aspectos en comparación a otros

Inversión en educación como \% del PIB

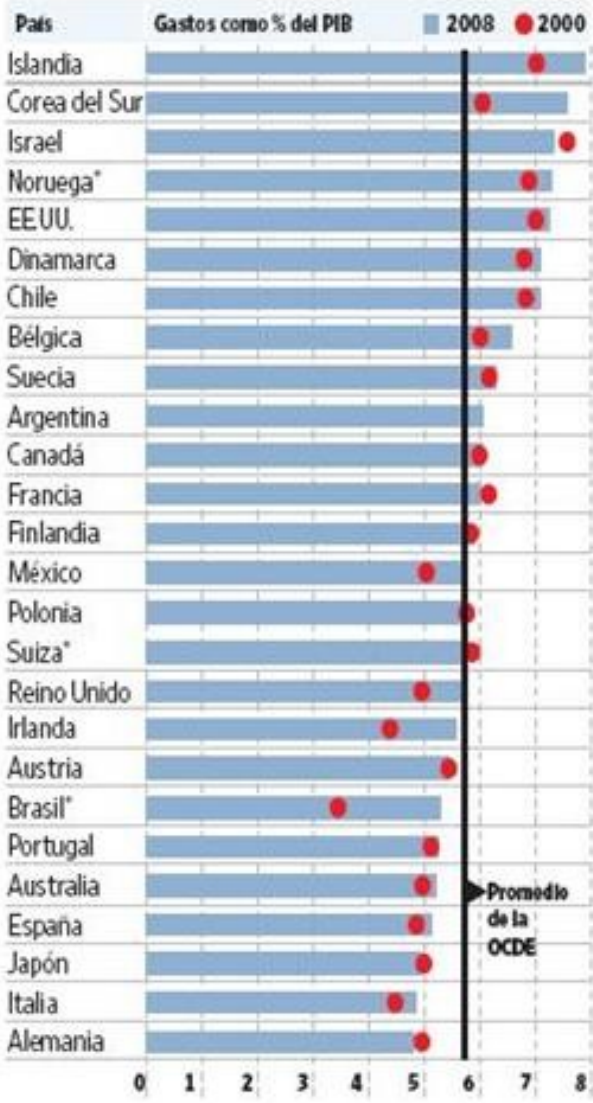

Nota: Para todos los niveles educativos $(2000$ y 2008) y camble porcentual entre 2000 y 2008 (20001 100 , en predos constamesi.

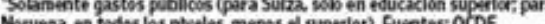
Argentha hdonesix irstrato Unesco para Estadisticas (W orld Edacation Indcaters Progranime).

Inversión en educación en Brasil,

2000-09 en miles de mill. de reales

Prueba Pisa, matematica

Maricipal Estatal Federal

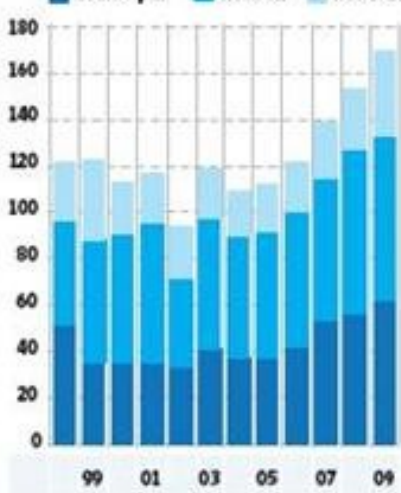

Fuentes: Tesoso Naxionat, OCDE (PAsa), via el Banco Muneal

Años de escolaridad en Brasil por renta familiar

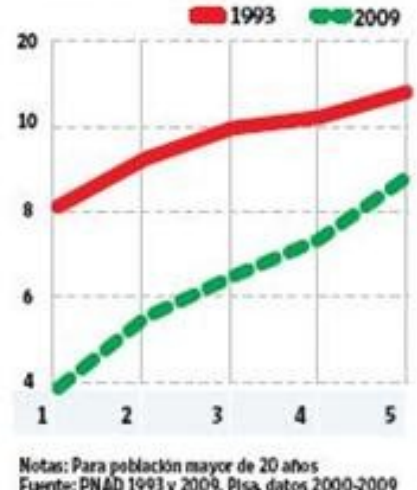

Algunos palses, 2000-2009

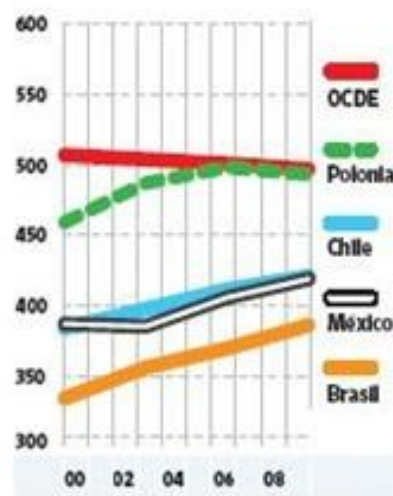

Prueba Pisa, matematica

Por quintil de renta en Brasill

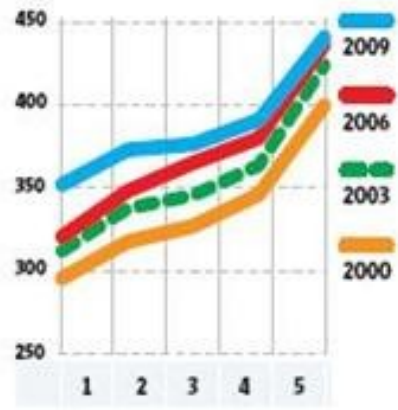

The Wall Street boursal 